\title{
Molecular genetic and biochemical analysis of anti-cell death mechanisms in Arabidopsis thaliana
}

\author{
By Kristina Sabou
}

\begin{abstract}
A thesis submitted to the Faculty of Graduate Studies and Research of Carleton University in partial fulfillment of the requirements of the degree of Master of Science in Biology
\end{abstract}

\author{
Carleton University \\ Ottawa, Ontario \\ (C) 2011, Kristina Sabou
}


Library and Archives Canada

Published Heritage Branch

395 Wellington Street Ottawa ON K1A ON4 Canada
Bibliotheque et

Archives Canada

Direction du

Patrimoine de l'édition

395, rue Wellington

Ottawa ON K1A 0N4

Canada
Your file Votre référence

ISBN: 978-0-494-83154-0

Our file Notre référence

ISBN: 978-0-494-83154-0

\section{NOTICE:}

The author has granted a nonexclusive license allowing Library and Archives Canada to reproduce, publish, archive, preserve, conserve, communicate to the public by telecommunication or on the Internet, loan, distribute and sell theses worldwide, for commercial or noncommercial purposes, in microform, paper, electronic and/or any other formats.

The author retains copyright ownership and moral rights in this thesis. Neither the thesis nor substantial extracts from it may be printed or otherwise reproduced without the author's permission.
AVIS:

L'auteur a accordé une licence non exclusive permettant à la Bibliothèque et Archives Canada de reproduire, publier, archiver, sauvegarder, conserver, transmettre au public par télécommunication ou par l'Internet, prêter, distribuer et vendre des thèses partout dans le monde, à des fins commerciales ou autres, sur support microforme, papier, électronique et/ou autres formats.

L'auteur conserve la propriété du droit d'auteur et des droits moraux qui protège cette thèse. $\mathrm{Ni}$ la thèse ni des extraits substantiels de celle-ci ne doivent être imprimés ou autrement reproduits sans son autorisation.
In compliance with the Canadian Privacy Act some supporting forms may have been removed from this thesis.

While these forms may be included in the document page count, their removal does not represent any loss of content from the thesis.
Conformément à la loi canadienne sur la protection de la vie privée, quelques formulaires secondaires ont été enlevés de cette thèse.

Bien que ces formulaires aient inclus dans la pagination, il n'y aura aucun contenu manquant.

\section{Canadä}




\section{Acknowledgements}

It would be difficult to overstate my gratitude to my supervisor, Dr. Tim Xing, whose patience, enthusiasm, and expertise have been invaluable to me throughout this process. Thank you Dr. X for always encouraging, never negatively criticizing and for keeping me optimistic.

I would also like to thank the members of my committee, Dr. Steve Gleddie and Dr. Doug Johnson for their suggestions and invaluable advice.

I am truly grateful for the financial support provided by the Natural Sciences and Engineering Research Council of Canada, and the Canadian Triticale Biorefinery Initiative Project under the Agricultural Bioproducts Innovation Program (ABIP).

Members of the Xing Lab who have been helpful, especially Kelly, and Sarah. I would like to express my heartfelt thanks to you for the hours of discussions, and for always being patient with me. Also to Mingli Xu for sacrificing many of her lunch breaks to provide me with technical assistance.

Last but not least, I owe my parents the greatest gratitude for being my guiding lights. I thank my mom for always reminding me that "If there's a will, there's a way", and my dad for making me understand that "Life is not about finding yourself. Life is about creating yourself." 


\section{Table of Contents}

List of Tables.

List of Figures.

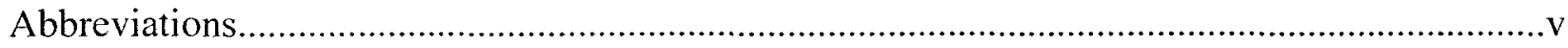

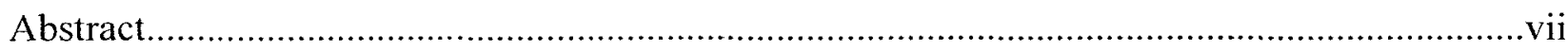

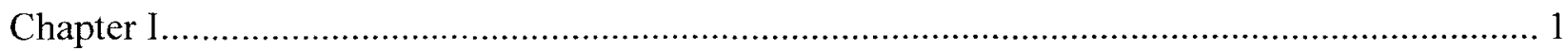

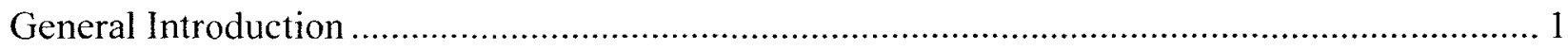

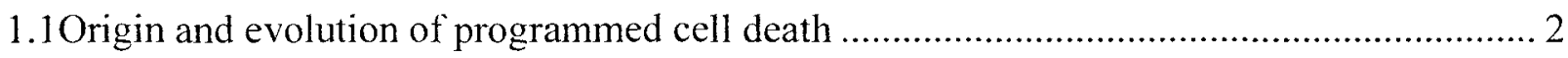

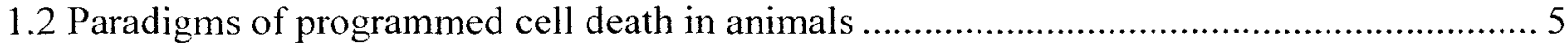

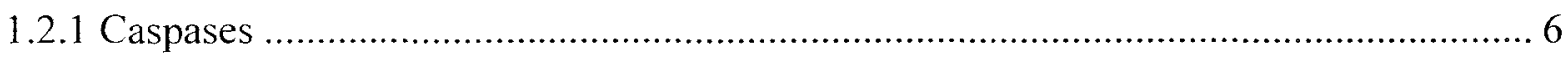

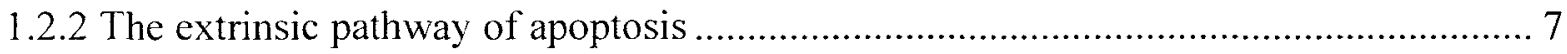

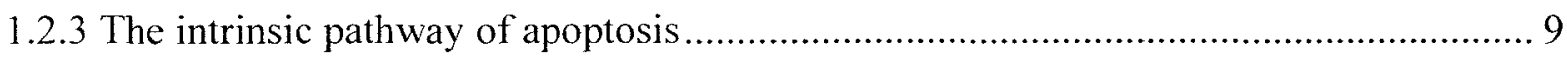

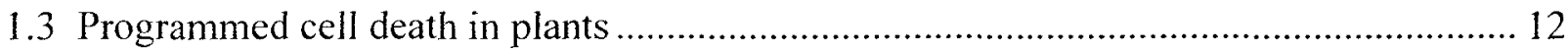

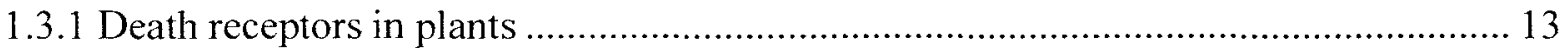

1.3.2 Role of mitochondria and caspase-like proteases in plants ...................................... 14

1.4 Will Die Slowly (WDS) family of genes in Arabidopsis thatiana and my project ............. 16

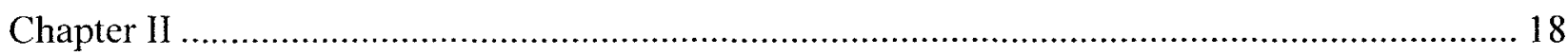

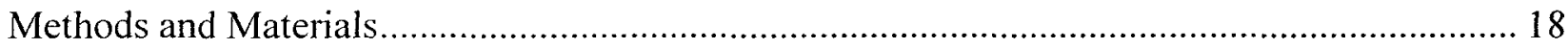

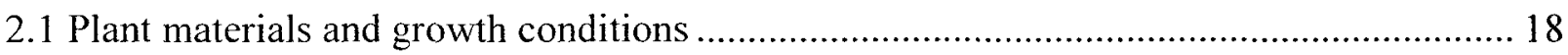

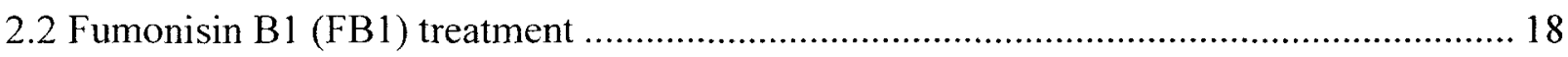

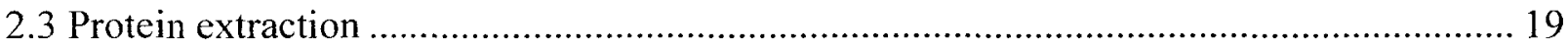

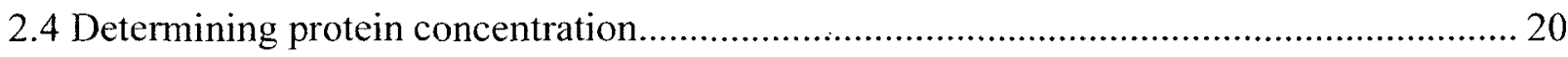

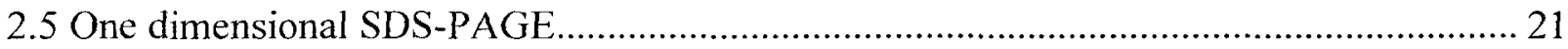

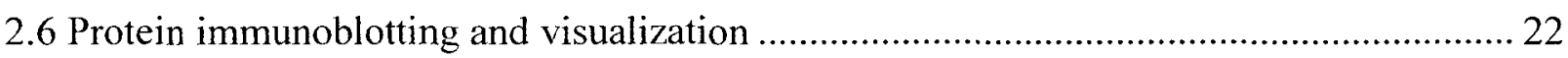

2.7 RNA extraction and reverse transcription polymerase chain reaction (RT-PCR) ….......... 23

2.8 Amplification, mutation and cloning of WDS2 (At5g08560) and WDS3 (AtIg73720) ...... 24

2.8.1 Amplification of WDS2 (At5g08560) and WDS3 (At1g73720)................................. 25

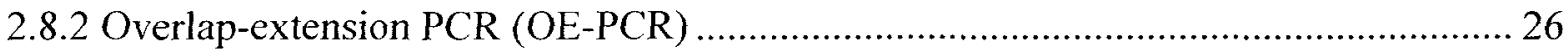

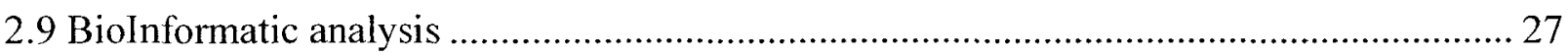

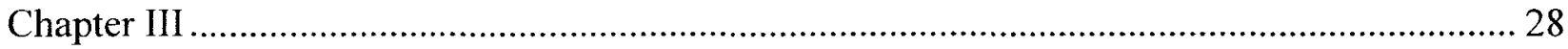

Bioinformatic analysis of WDS gene family members in Arabidopsis thaliana .......................... 28

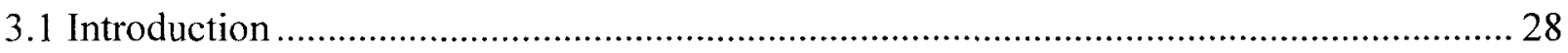

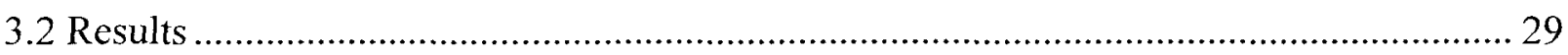

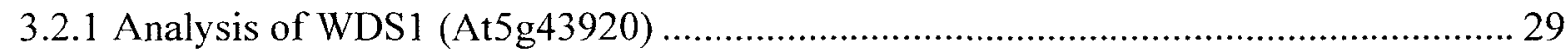

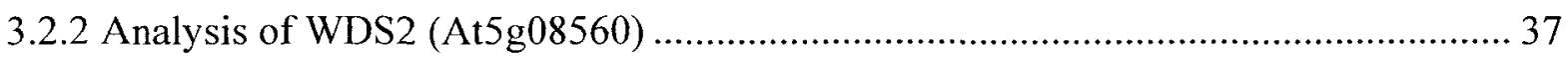

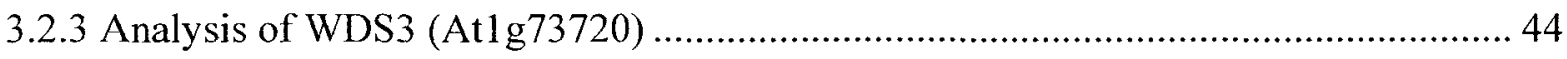

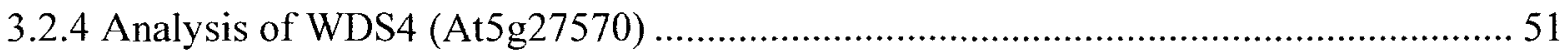

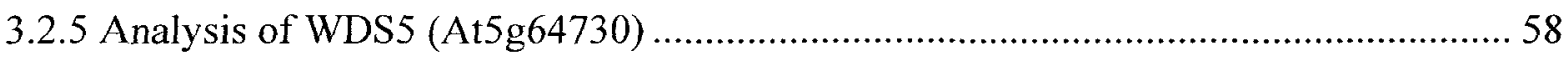

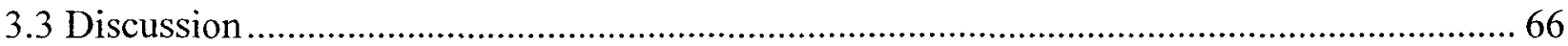




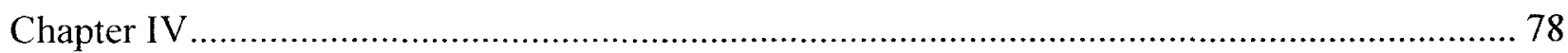

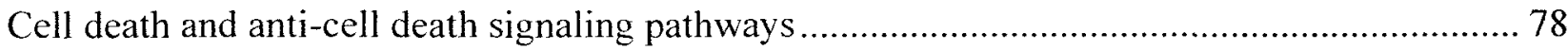

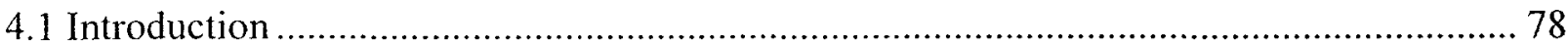

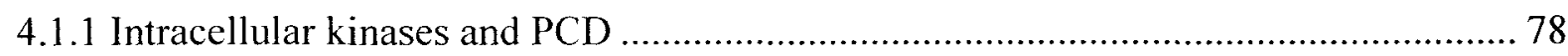

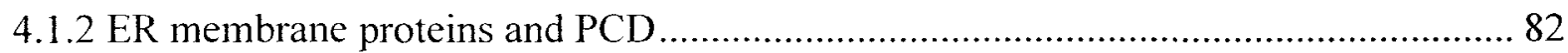

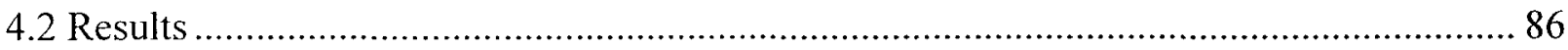

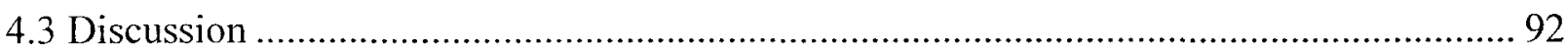

4.3.1 Effects of FB1 treatment and wds1/wds2 mutation on the expression of AtBI-1 and

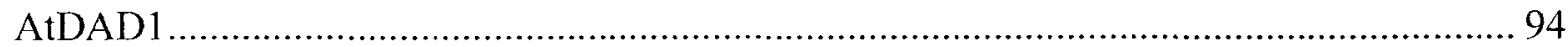

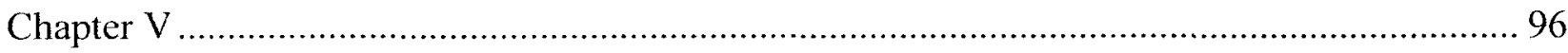

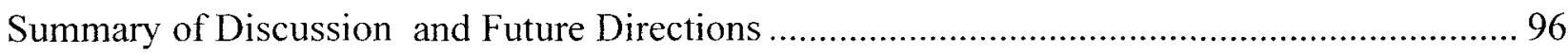

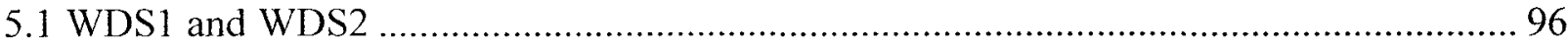

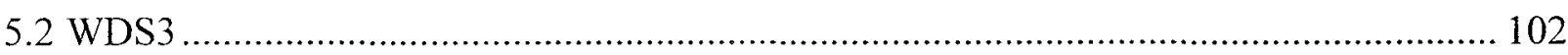

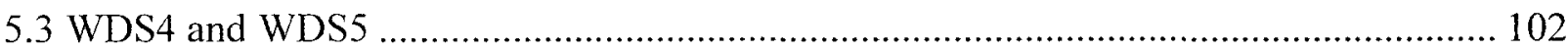

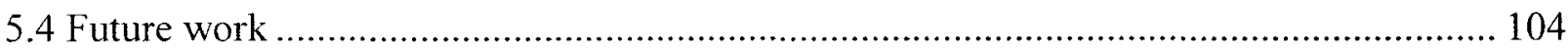

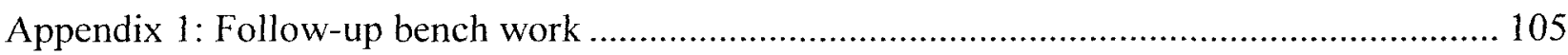

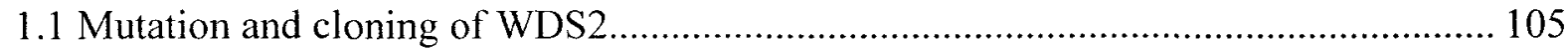

1.2 Preparation of pLRCWHEAT2-gevAgdv-WDS2 construct ........................................... 111

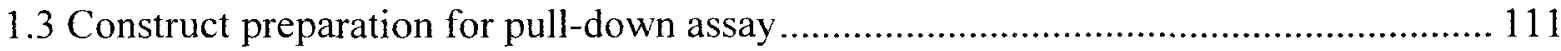

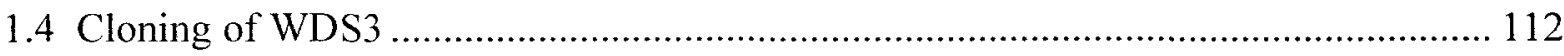

Appendix 2: ScanSite Database Analysis of Arabidopsis WDS proteins..................................113

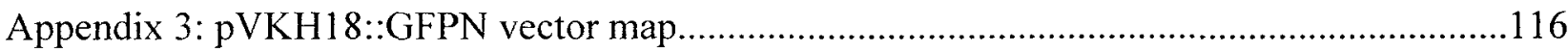

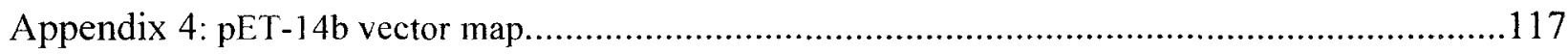

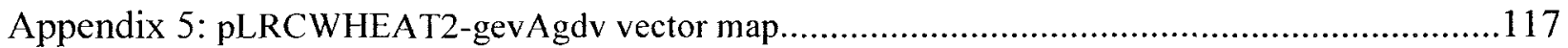

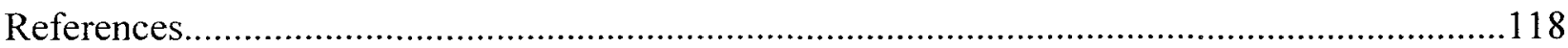




\section{List of Tables}

\section{Chapter 1}

Table 1-1: Unicellular organisms in which active programmed cell death processes have been observed.

\section{Chapter 2}

Table 2-1: Dilutions of BSA solution used for standard curve preparation. .20

Table 2-2: List of primary antibodies used. .23

Table 2-3: Primers used for RT-PCR. .24

Table 2-4: Primers used for PCR .25

Table 2-5: List of primers used to introduce point mutations into WDS2. .26

\section{List of Figures}

\section{Chapter 1}

Figure1.1: General model of the caspase cascade. .7

Figure 1.2: Elements of the extrinsic apoptotic pathway. .8

Figure 1.3: The Bcl-2 protein family

Figure 1.4: a).The intrinsic pathways of apoptosis b). Formation of the apoptosome. 11

\section{Chapter 3}

Figure 3.1 : a). Phylogenic tree of WDS family members b). Domain structure of WDS family members.

Figure 3.2: High stringency ScanSite Motif Scan output for WDS1....

Figure 3.3: Electronic fluorescence pictographic representation of WDS1's subcellular localisation

Figure 3.4: Overall expression of WDS1 across different stages of development. .32

Figure 3.5: Electronic fluorescent pictograph of WDSI's expression pattern 
Figure 3.6: Expression levels of WDSI in rosette leaves of Arabidopsis thaliana at different stages of their development.

Figure 3.7: WDSl expression levels in Arabidopsis thaliana leaves exposed to a variety of pathogenic organisms

Figure 3.8: Effect of elicitors on WDS1 expression in leaves of Arabidopsis thaliana. .35

Figure 3.9: Effect of cold temperature on WDS1 expression in leaves. 35

Figure 3.10: Possible functional partners of WDS1 36

Figure 3.11: Medium stringency ScanSite Motif Scan output for WDS2 .38

Figure 3.12: Electronic fluorescence pictographic representation of WDS2's subcellular localisation. 39

Figure 3.13: Overall expression of WDS2 across different stages of development. 39

Figure 3.14: Electronic fluorescent pictograph of WDS2's expression pattern .40

Figure 3.15: Expression levels of WDS2 in rosette leaves of Arabidopsis thaliana at different stages of their development.

Figure 3.16: WDS2 expression levels in Arabidopsis thaliana leaves exposed to a variety of pathogenic organisms.

Figure 3.17: Effect of elicitors on WDS2 expression levels in Arabidopsis leaves..... 42

Figure 3.18: Effect of cold temperature on $W D S 2$ expression in leaves.

Figure 3.19: Possible functional partners of WDS2

Figure 3.20: High stringency ScanSite Motif Scan output for WDS3

Figure 3.21.: Electronic fluorescence pictographic representation of WDS3's subcellular localisation. 46

Figure 3.22.: Overall expression of WDS3 across different stages of development 46

Figure 3.23.: Electronic fluorescent pictograph of $W D S 3$ 's expression pattern 47

Figure 3.24.: Expression levels of WDS3 in rosette leaves of Arabidopsis thaliana at different stages of their development. 48

Figure 3.25.: WDS3 expression levels in Arabidopsis thaliana leaves exposed to a 
variety of pathogenic organisms 48

Figure 3.26: Effect of elicitors on WDS3 expression levels in leaves of Arabidopsis ................49

Figure 3.27: Effect of cold temperature on WDS3 expression in leaves of Arabidopsis..............49

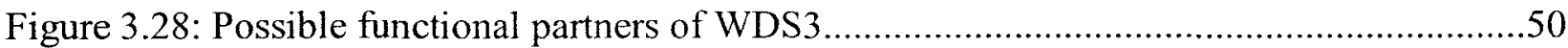

Figure 3.29: Medium stringency ScanSite Motif Scan output for WDS4 .................................52

Figure 3.30: Electronic fluorescence pictographic representation of WDS4's subcellular localisation .53

Figure 3.31: Overall expression of WDS4 across different stages of development....................53

Figure 3.32: Electronic fluorescent pictograph of WDS4 's expression pattern..........................54

Figure 3.33.: Expression levels of WDS4 in Arabidopsis thaliana's rosette leaves at different

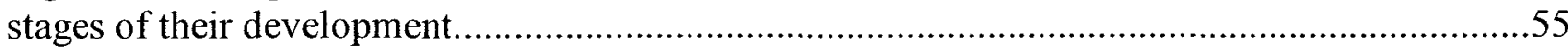

Figure 3.34: WDS4 expression levels in Arabidopsis thaliana leaves exposed to a variety of

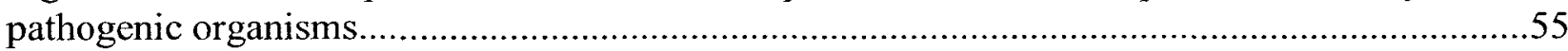

Figure 3.35.: Effect of elicitors on WDS4 expression levels in leaves of Arabidopsis................56

Figure 3.36: Effect of cold temperatures on WDS4 expression in leaves of Arabidopsis............56

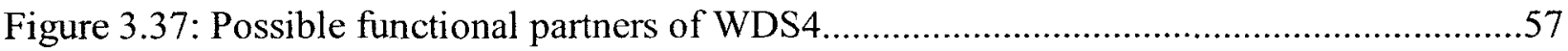

Figure 3.38: Medium stringency ScanSite Motif Scan output for WDS5 ..............................59

Figure 3.39: Electronic fluorescence pictographic representation of WDS5's subcellular localisation

Figure 3.40: Overall expression of WDS5 across different stages of development .60

Figure 3.41: Electronic fluorescent pictograph of WDS5's expression pattern .61

Figure 3.42: Expression levels of WDS5 in Arabidopsis thaliana rosette leaves at different stages of their development.

Figure 3.43: WDS5 expression levels in Arabidopsis thaliana leaves exposed to a variety of pathogenic organisms

Figure 3.44: Effect of elicitors on WDS5 expression levels in leaves of Arabidopsis................63

Figure 3.45: Effect of cold temperatures on WDS5 expression in leaves of Arabidopsis............63 
Figure 3.46: Possible functional partners of WDS5

Figure 3.47: Relative expression levels of WDS family members in drought stressed leaves.

Figure 3.48: Relative expression levels of $W D S$ family members in salt stressed leaves. 65

\section{Chapter 4}

Figure 4.2.: Immunoblots using antibodies specific to the apoptotic proteins PARP, cleaved PARP, caspases 3, 7,9 and cleaved caspases 3, 7, 9.

Figure 4.3: Immunoblots using antibodies specific to substrates of the intracellular kinases

PKA, PKB/Akt, PKC, CDK, ATM/ATR .90

Figure 4.4: RT-PCR analysis with $A t B I-1$ and $A t D A D l$ specific primers.

\section{Chapter 5}

Figure 5.1: Figure 5.1: Predicted model of pathway WDS1 and WDS2 may belong to. 100

\section{Appendix 1}

Figure 3.49: pVKH18::GFPN -WDS2 construct.

Figure 3.50: Site-directed mutagenesis of WDS2.

Figure 3.51: Site-directed mutagenesis of WDS2. 108

Figure 3.52: Site-directed mutagenesis of WDS2 .................................................... 108

Figure 3.53: Site-directed mutagenesis of WDS2.

Figure 3.54: Restriction enzyme digestion of pVKH18::GFPN-WDS2 construct with SalI and BamHI..

Figure 3.55: Colony PCR.....

Figure 3.56: a).Restriction endonuclease digestion of WDS2 and pLRCWHEAT2-gevAgdv with XbaI and PstI b). Colony PCR for confirmation of successful transformation of competent cells.

Figure 3.57: pET-14b-WDS2 construct extracted from NovaBlue cells

Figure 3.58: Ligation of $W D S 3$ into pVKH18::GFPN.. 


\section{Abbreviations}

APAF-1: Apoptotic Protease Activating Factor-1

ATM: Ataxia Telangiectasia Mutated

ATR: ATM and Rad3-related

BH: Bcl2-Homology Domain

BI-1: Bax-Inhibitor 1

CARD: Caspase Recruitment Domain

CDK: Cyclin Dependent Kinase

DAD1: Defender Against Apoptosis 1

DD: Death Domain

DIABLO: Direct IAP binding protein with low $\mathrm{pI}$

IAP: Inhibitors of Apoptosis Proteins

ICAD: Inhibitor of Caspase Activated DNase

ER: Endoplasmic Reticulum

ERK: Extracellular Signal-regulated Kinase

FB1:Fumonisin B1

HR: Hypersensitive Response

MAPK: Mitogen Activated Protein Kinase

PARP: Poly ADP-ribose Polymerase

PR: Pathogenesis Related

PCD: Programmed Cell Death

PKA: Protein Kinase A

PKB: Protein Kinase B 
PKC: Protein Kinase C

PT: Permeability Transition Pore

ROS: Reactive Oxygen Species

SA: Salicylic Acid

SAG: Senescence Associated Gene

SAR: Systemic Acquired Resitance

SMAC: Second Mitochondria Derived Activator of Caspases

WDS: Will Die Slowly 


\begin{abstract}
Programmed cell death is a complex process that involves the selective elimination of unwanted cells and is controlled by multiple developmental and environmental signals. Will Die Slowly $(W D S)$ gene family was initially identified in this laboratory and phenotypic analysis of single and double mutants suggested some of its members to have anti-cell death and anti-senescence functions. In my project, these genes were further studied by genetic analysis of $w d s 1 / w d s 2$ double mutant in response to cell death inducers, followed by biochemical analysis of cell death and anti-cell death pathways. Our bioinformatic analysis including motif search, data mining, and prediction of protein-protein interactions has helped us predict the possible functions of Arabidopsis thaliana's WDS proteins. They seem to be involved in plant development and in plant response to biotic and abiotic stresses. Comparative analysis of wild type and $w d s 1 / w d s 2$ double mutant Arabidopsis plants by using antibodies against cell death and anti-cell death proteins suggests that the double mutation of WDS1 and WDS2 has altered cell death and anticell death pathways in the plant. Generation of WDS2 overexpression lines for further functional analysis is in progress.
\end{abstract}




\section{Chapter I}

\section{General Introduction}

Until recently, senescence and death have been perceived to be unfair aberrations that are results of the accumulation of egregious errors. They were believed to be passive, degenerative and futile processes that are exclusive to old cells, tissues and organisms.

The notion that dead cells/tissues may have a well-defined function was first recorded in writing by Robert Hooke in 1665, in his historic book titled Micrographia, in which he documented his observations of various specimens viewed through his primitive microscopes. One of his observed specimens was the bark tissues of Cork oak tree, about which he wrote that he believed that its cells once contained the "noble juices" of the living cork tree (Gray, 2004; Hooke, 1996). We now know that his observations were accurate because bark tissue is indeed composed of dead phloem cells and its function is to protect the stem and root of woody plants. While many similar observations were made and recorded throughout history, the scientific community was a little slow in recognizing and accepting that death and senescence are not simply futile and passive processes restricted to old cells and tissues, but are internally programmed and, more often than not, are indispensable for the normal development and functioning of organisms (Gray, 2004; Nooden, 2004; Taiz and Zeiger, 2006; Voet and Voet, 2004).

Today it is hypothesized that all cells are programmed to commit suicide unless they are prevented from doing so; programmed cell death (PCD) seems to be the default pathway for every single newly formed cell, and unless external signals prevent these cells from initiating self annihilation, they will do so (Ameisen, 2002, 2004; Gray, 2004; Raff, 1992; Voet and Voet, 2004). 


\subsection{Origin and evolution of programmed cell death}

Programmed cell death processes have been observed in all multicellular organisms that have ever been studied. In animals, the evolutionary conservation of programmed cell death does not only extend to its existence and role but also to the genetic components and mechanisms regulating the dying processes (Campbell and Reece, 2002). This is especially true for apoptosis, the most widely studied form of programmed cell death. Key apoptosis genes were first identified in the nematode Caenorhabditis elegans, in which exactly 131 of the somatic cells undergo apoptosis at precisely the same time during the development of every healthy worm (Campbell and Reece, 2002; Voet and Voet, 2004). Apoptosis pathways in humans and other mammals are more sophisticated than those found in nematodes, but the similarities between apoptosis regulating genes in these organisms suggest that the basic apoptotic mechanisms evolved early in animal evolution. The completion of animal and plant genomes revealed that the known animal apoptotic pathways are not highly conserved in plants but studies done with heterologous systems, in which animal apoptosis regulating genes were engineered into plants, indicated the presence of a machinery that, while being genetically different, is functionally very similar to the machinery that exists in animals (Ameisen, 2004). This finding suggests that the machinery required for self-destruction and the prevention of self-destruction may be as old as the first multicellular organism. It can be assumed that these mechanisms were always present but, throughout evolution, they have been perfected to suit the lifestyle of the organisms in question (Ameisen, 2002, 2004).

It is a fact that PCD is indispensable for the development, maintenance and defense mechanisms of virtually every multicellular organism, but what about its presence in unicellular life forms? 
The existence of PCD in unicellular organisms appears paradoxical because it seems unlikely that such a process would be evolutionarily selected for, but during the past 15 years several papers have been published that provide evidence to the contrary. While most of these papers deal with PCD in unicellular eukaryotes, there are several that characterize PCD processes in prokaryotes (Nedelcu et.al., 2011).

Unicellular prokaryotes have always been regarded as autonomous individuals that mind their "own business", but during the past decade it has become increasingly evident that most, if not all of them, engage in intercellular communications. These intercellular communications may happen between members of the same or different species and, in some cases, even with the cells of a host if the prokaryote happens to be lurking around in a multicellular eukaryote (Bassler and Losick, 2006; Søgaard-Andersen and Yang, 2008). Intercellular communication allows prokaryotes to exhibit primitive mullticellular behaviours, which can benefit the population and the species as a whole. This "one for all and all for one" approach could provide an explanation to why PCD might have been evolutionarily selected for in unicellular organisms.

The following table (Table 1-1) shows a lists of unicellular organisms in which active PCD processes have been observed. 
Table 1-1: Unicellular organisms in which active programmed cell death processes have been observed

\begin{tabular}{|c|c|c|}
\hline \multirow[t]{3}{*}{$\begin{array}{l}\text { Unicellular } \\
\text { Prokaryotes }\end{array}$} & Gram-positive & $\begin{array}{l}\text { Myxococcus, Streptococcus, Staphylococcus (Engelberg-Kulka et.al., 2006; Nariya } \\
\text { \& Inouye, 2008; Regev-Yochay et.al., 2007; Rice et.al., 2007; Søgaard-Andersen } \\
\text { \& Yang, 2008) }\end{array}$ \\
\hline & Gram-negative & $\begin{array}{l}\text { Pseudomonas, Escherichia ( Hazan et.al., 2004; Kolodkin-Gal \& Engelberg-Kulka, } \\
\text { 2008) }\end{array}$ \\
\hline & Cyanobacteria & Trichodesmium, Microcystis (Berman-Frank et.al., 2004; Ross et. al., 2006) \\
\hline $\begin{array}{l}\text { Unicellular } \\
\text { Eukaryotes }\end{array}$ & $\begin{array}{l}\text { Plasmodium, } \\
\text { Terahymena, B } \\
\text { Thalassiosira, } \\
\text { Peridinium, Sy } \\
\text { Emiliania, Gia } \\
\text { Leishmania, Tr } \\
\text { 2004) } \\
\text { Trichomonas, } \\
\text { Chlamydomon, } \\
\text { et.al., 2007; Da }\end{array}$ & $\begin{array}{l}\text { 2002; Meslin et.al. 2007; Nasirudeen et.al., 2001) } \\
\text { ensen et.al., 1998; Cervia et.al., 2009; Takada \& Matsuoka, 2009; Gray 2004) } \\
\text { Atsant et.al., 2007; Chung et.al., 2008) } \\
\text { rococentrum ( Franklin \& Berges, 2004; Zhang et.al., 2006) } \\
\text { e et.al., 2003) } \\
\text { Lee et.al., 2002; Bera et.al., 2003; Welburn ct al. 1996; Ridgley et al. 1999; Gray, } \\
\text { 2003; Gray 2004; Mariante et.al., 2006) } \\
\text { crasterias (Segovia et.al., 2003; Moharikar et.al., 2006; Nedelcu, 2006; Zuppini } \\
\text { zeller ct.al., 2009b; Jimenez et.al., 2009; Murik \& Kaplan, 2009) } \\
\text { 1994; Arnoult et.al., 2001;Tatischeff et.al.. 2001; Mendoza et.al,. 2003; Ramos } \\
\text { 7; Gourlay et.al., 2006; Gray, 2004; Ramsdale, 2008) }\end{array}$ \\
\hline
\end{tabular}


The mechanisms these organisms use to self-destruct is drastically different from the ones used by plants and/or animals, nevertheless their presence in these unicellular life forms suggests that the program to self-destruct and prevention of self-destruction may be as old as the very first cell (Gray, 2004).

\subsection{Paradigms of programmed cell death in animals}

Cell death can be classified according to its morphological appearance, enzymological criteria, functional aspects and immunological characteristics (Kroemer et.al., 2009). Since apoptosis is the most common route of programmed cell death in multicellular animals, the term apoptosis has been incorrectly used interchangeably with PCD (Gray, 2004; Kroemer et.al., 2009). While a detailed description and discussion of the different PCD morphotypes is provided by Kroemer et.al., 2009, my work will limit its focus on apoptosis, the most widely studied and therefore best understood form of animal PCD.

Apoptosis in animals is characterised by cytoplasmic shrinkage, vacuolization, nuclear fragmentation, chromatin condensation, formation of multiple nicks in the DNA, plasma membrane blebbing and formation of apoptotic bodies (Gray, 2004; Nooden, 2004; Kroemer et.al., 2009; Taylor et.al., 2008). This morphology is attained through the action of a special family of proteases known as caspases, which are activated in response to perception of apoptotic signals by the cell. DNA laddering is not always present during apoptosis and while activation of caspase cascades seems to be necessary for the acquisition of apoptotic morphology, some of these caspases may also be activated in cells that are not undergoing apoptosis (Garrido et.al., 2004; Galluzi et.al., 2009; Kroemer et.al., 2009). Due to this, the presence of these biochemical factors alone is not enough to categorize the dying process as 
apoptosis, but they can be used to confirm the type of cell death, given that the morphological characteristics of apoptosis are met (Kroemer et.al., 2009).

In animal cells, activation of caspase cascades can be attained via two general pathways. One, which does not involve the mitochondria, is commonly referred to as the extrinsic pathway of apoptosis, while the other that involves mitochondria is referred to as the intrinsic pathway of apoptosis (Murphy et.al., 2008; Voet and Voet, 2004). Both pathways lead to the same final events, but are initiated by different signals. The extrinsic pathways, as its name suggests, begins outside the cell and is triggered by extra cellular ligands, while the intrinsic pathway is initiated from within the cells in response to signals resulting from events such as DNA damage, defective cell cycle and other kind of severe cell stresses (Ashkenazi, 2002; Moll et al., 2005). While the origin of the signals triggering these pathways is different, it is important to note that the intrinsic and extrinsic pathways of apoptosis are not isolated from one another. It is evident that in some cases the apoptotic signal initiated by the extrinsic pathway needs mitochondrial amplification (Barnhart et.al., 2003).

\subsubsection{Caspases}

Caspases are a family of proteins that belong to a group of enzymes known as cysteinyl aspartate-specific proteases, which cleave proteins after aspartate residues (Murphy et.al., 2008; Taylor et.al., 2008; Voet and Voet, 2004). They are $\alpha 2 \beta 2$ heterotetramers, which, in healthy cells, exists as inactive precursor enzymes known as zymogens or pro-caspases. In response to apoptosis inducing signals, these zymogens are cleaved and acquire proteolytic activity (Murphy et.al., 2008; Taylor et.al., 2008; Voet and Voet, 2004).

The caspases that act during apoptosis can be classified as either initiator caspases or effector caspases. Initiator caspases (Caspase 2, 8,9 and 10) promote apoptosis by cleaving and 
therefore activating other caspases, and the effector caspases (Caspase 3,6,7), which are cleaved and activated by initiator caspases, execute the cellular changes seen in cells undergoing apoptosis. (Murphy et.al., 2008; Taylor et.al., 2008; Voet and Voet, 2004). Caspase cascades (Figure 1.1) play a vital role in the induction, transduction, amplification, and execution of apoptotic signals.

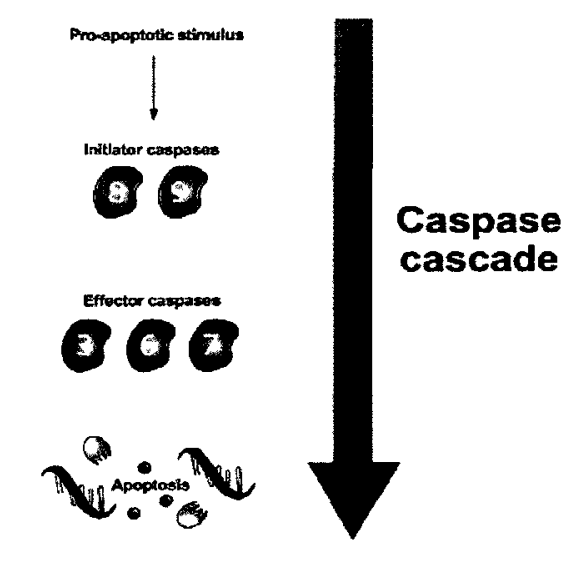

Figure1.1: General model of the caspase cascade (GenentechUSA Inc., 2011)

\subsubsection{The extrinsic pathway of apoptosis}

This pathway is mediated by the activation of so-called death receptors whose cytoplasmic tail contains conserved sequences called death domains (DD). DD containing receptors are located on the surface of cells and transmit apoptotic signals initiated by specific extracellular ligands (Dash et.al., 2007; Murphy et.al. 2008; Taylor et.al. 2008; Voet and Voet, 2004). Binding of extracellular ligands causes trimerization of the receptors and ceramide formation in the plasma membrane. Ceramide is produced by acid sphingomyelinase and its release is believed to promote lipid raft fusion, a phenomenon that causes large scale clustering of death receptors. This large scale clustering is important because it leads to the amplification of the apoptotic signal, an event that is necessary for full scale activation of the apoptotic response (Dash et.al., 2008; Mullen et.al., 2011). 
Receptor trimerization upon ligand binding also triggers a conformational change in the cytoplasmic portion of the receptors that results in the DDs being exposed. The exposed DDs then recruit several adaptor proteins that form a complex called Death Inducing Signaling Complex or DISC. The composition of DISC varies from one type of receptor to the other (eg. TNF or Fas receptor) but its function is always to recruit initiator pro-caspases. The clustering of receptors also causes the clustering of the recruited initiator caspases that, once in close proximity to each other, cleave and activate one another (Dash et.al., 2008; Salvesen and Riedl, 2009). The following image (Figure 1.2) illustrates the elements of the extrinsic apoptotic pathway.

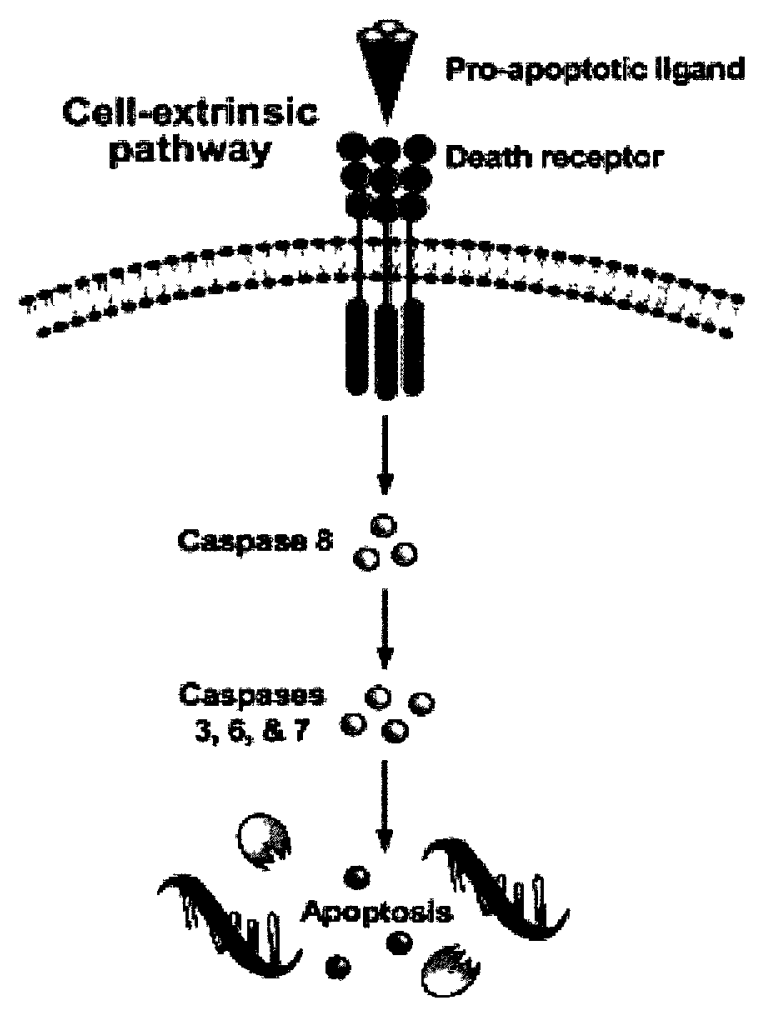

Figure 1.2: Elements of the extrinsic apoptotic pathway (Ashkenazi, 2002; GenentechUSA Inc., 2011) 


\subsubsection{The intrinsic pathway of apoptosis}

This pathway is controlled by the action of Bcl-2 (B-cell lymphoma 2) family of proteins and is triggered when the cell is exposed to stress or when it stops receiving signals that are required for survival. The $\mathrm{Bcl}-2$ family of proteins contain so-called $\mathrm{Bcl}-2$ homology domains (BH 1, 2, 3 or 4) and can be categorized into three groups depending on which of the four $\mathrm{BHs}$ they contain (Figure1.3).

Group 1 members all contain all four regions of homology (i.e. that is $\mathrm{BH} 1$ to $\mathrm{BH} 4$ ) as well as, a short hydrophobic region close to their C-terminal end. The hydrophobic segment is a transmembrane domains that inserts into mitochondrial and, in some cases, the ER membrane. All the proteins that belong to this group are anti- apoptotic (Taylor et.al., 2008; Voet and Voet, 2004). Group II members contain $\mathrm{BH} 1, \mathrm{BH} 2, \mathrm{BH} 3$, and a TM domain, but lack BH4. The members of this group are all exclusively pro-apoptotic. The members of the last group, Group III, are also all pro-apoptotic and contain only BH3 and, in some cases, a TM domain. (Martin, 2010; Taylor et.al., 2008; Voet and Voet, 2004). 


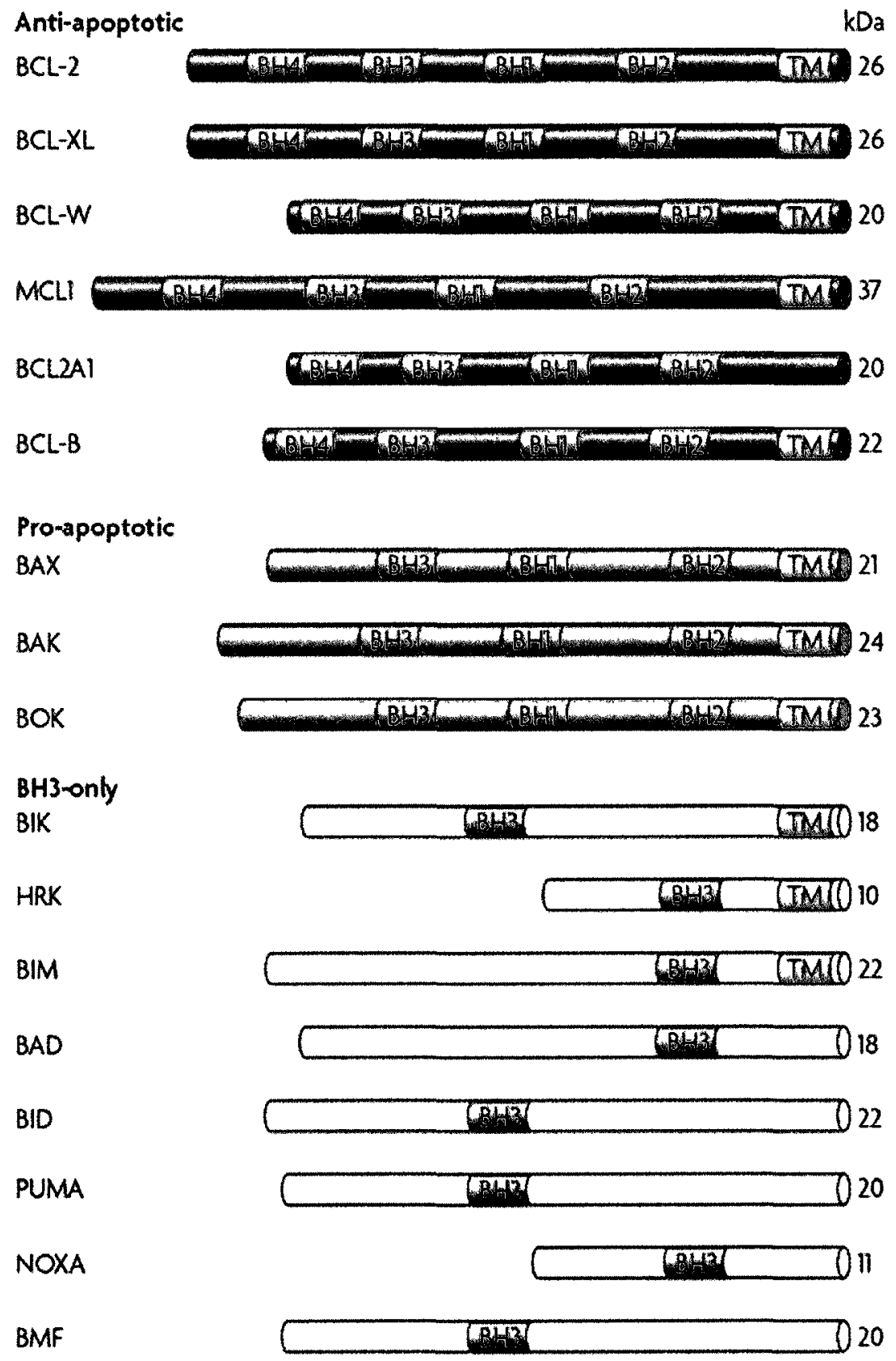

Figure 1.3: The Bcl-2 protein family (Taylor et.al., 2008) 
The sensitivity of cells to apoptotic stimuli may depend on the balance of pro- and antiapoptotic Bcl-2 proteins. The pro-apoptotic members of this family are often found in the cytosol and after the cell is damaged or is exposed to stress they relocate to the surface of the mitochondria, where the anti-apoptotic members reside. The accumulation of pro-apoptotic members of Bcl-2 protein family on the mitochondrial surface and their interactions with the resident anti-apoptotic members cause the formation of so-called permeability transition (PT) pores through which cytochrome $c$ and other pro-apoptotic proteins, including SMAC/DIABLO (second mitochondria derived activator of caspases/direct IAP binding protein with low $\mathrm{pI}$ ), can escape into the cytosol (Figure 1.4 a) (Dash, 2011;Martin, 2010; Ren et.al., 2010;). Once in the cytosol, cytochrome $c$ binds to WD40 repeat portion of apoptotic protease activating factor-1 (Apaf-1), which then recruits initiator pro-caspase 9 to its caspase recruitment domain (CARD) (Figure $1.4 \mathrm{~b}$ ). These individual complexes oligomerize in a way that pro-caspases end up in close proximity to each other, which allows them to proteolytically activate one another (Bratton and Salvesen, 2010; Dash, 2011; Gray, 2004; Kroemer, 1999; Murphy et.al., 2008; Taylor et.al., 2008; Voet and Voet, 2004) (Figure $1.4 \mathrm{a}$ and b).

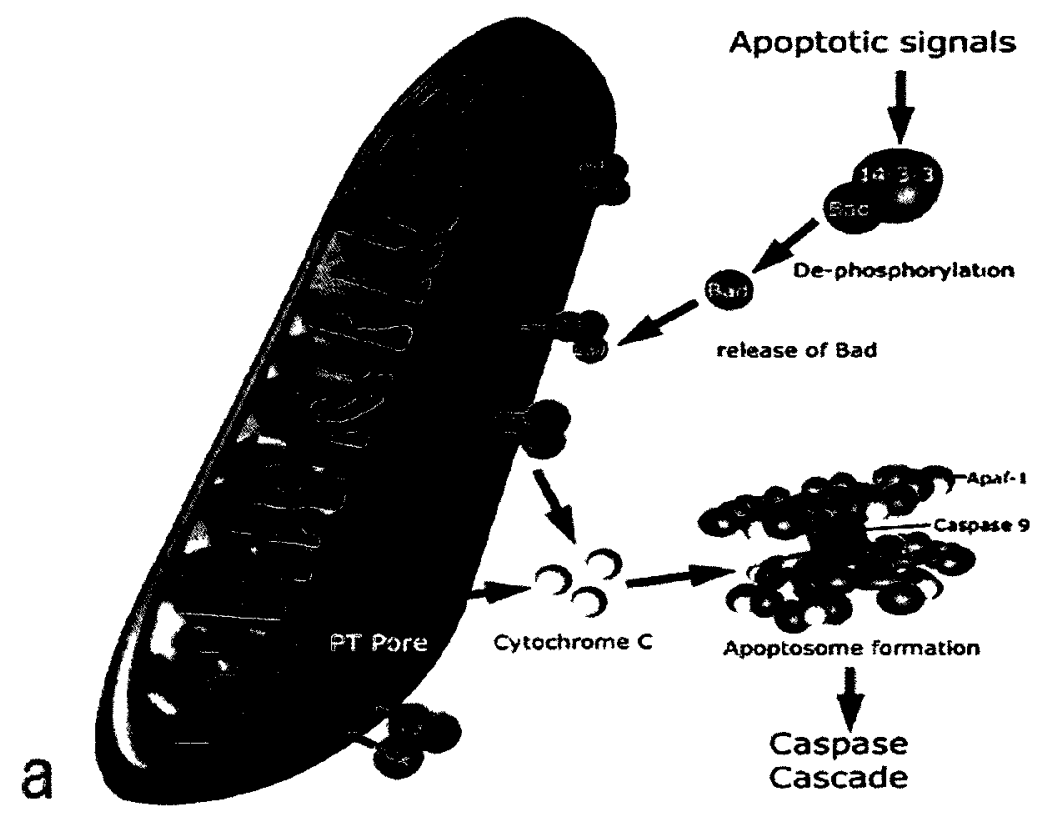




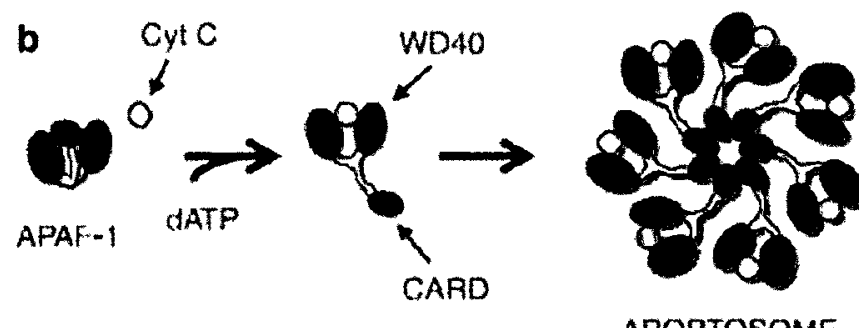

APOPTOSOME

Figure 1.4: a). The intrinsic pathways of apoptosis (Dash, 2011)

b). Formation of the apoptosome (Fadeel et.al., 2008)

The effector caspases activated by the initiator caspases, which are activated via the intrinsic or extrinsic pathway, go on to cleave a wide variety of proteins and initiate the breakdown of chromatin, a task that caspases accomplish by activating DNases, inactivating enzymes involved in DNA repair and breaking down intra-nuclear proteins that maintain the shape of the nucleus. For example caspase 3 , which can be activated by caspase 8 or 9 , cleaves a protein called inhibitor of caspase activated DNase (ICAD). Once ICAD is cleaved, CAD is released, enters the nucleus and causes rapid fragmentation of the DNA. Caspase 3 also cleaves an important DNA repair enzyme called poly ADP-ribose polymerase (PARP), which was one of the first proteins identified as a substrate of caspases (Dash, 2011, Murphy et.al., 2008; Taylor et.al., 2008; Voet and Voet, 2004).

The pro-apoptotic SMAC/DIABLO protein released from the mitochondria promotes apoptosis by physically interacting and blocking the function of inhibitors of apoptosis proteins (IAPs) whose role is to bind and inactivate caspases (Duckett, 2005).

\subsection{Programmed cell death in plants}

PCD plays important physiological roles in a variety of plant processes including deletion of cells that only have temporary functions (eg. aleuron cells in seeds, suspensory cells in embryos, etc), deletion of cells during sculpting of the plant body, removal of cells during plant specialization (e.g. death of tracheary element cells), defense responses against biotic/abiotic 
stresses and senescence (Fukuda, 2004; Nooden, 2004; Filonova et.al., 2002). While, through the combination of genetic, biochemical and molecular approaches, our knowledge of animal PCD mechanisms has grown steadily during the past few decades, our knowledge of the mechanisms controlling plant PCDs are yet to be elucidated (Yin and Dong, 2009).

While there are several type of death processes taking place in plants, the morphology of one of the cell death pathways observed exhibits striking similarity to the morphology seen in animal cells undergoing apoptosis (Cacas, 2010; Reape and McCabe, 2008, 2011). Events such as cell shrinkage, nuclear condensation, and DNA fragmentation have been observed in senescing plant cells, in cells being eliminated after exposure to abiotic stress and also during biotic stress induced hypersensitive response (Reape and McCabe, 2008). While we are familiar with the sequence of events that result in the destruction of animal cells via apoptosis, we know very little of the events that lead to the destruction of plant cells undergoing apoptosis- like PCD. Thus an emerging question is how similar is apoptosis-like PCD in plants to apoptosis in animals.

\subsubsection{Death receptors in plants}

To our knowledge there have been no plant cell surface receptors identified that are structurally identical or even remotely similar to the death receptors of the extrinsic pathway of animal apoptosis. Plants, however, possess so-called resistance genes or $R$ genes, whose protein products are receptors that recognize and bind specific avirulence or avr gene products, which are molecules originating from pathogens (Avijit Das et.al., 2010; Pareek, 2010). The $R$ proteins are also equipped to initiate signaling cascades that activate various plant defense mechanisms, including hypersensitive response (HR), upon avr binding. Researchers have identified more than $20 R$ genes, many of which encode several classes of proteins possessing nucleotide binding 
sites (NBS), leucine-rich repeats (LRR), transmembrane domains (TM), serine/threonine protein kinase (PK) domains and/or N-terminal Toll/Interleukin-1 receptor (TIR) domains (Avijit Das et.al., 2010; Pareek, 2010; Taiz and Zeiger, 2006). The Apaf-1 encoding gene has certain regions that show homology to the NBS domain encoding region of $R$ genes, and its protein structure is similarly organised to that of $R$ proteins. In both Apaf-1 and $R$ proteins, the common NBS domain links an N-terminal effector domain (i.e. caspase recruitment domain of Apaf-1 and TIR of $R$ proteins) to a C-terminal domain (i.e. WD domains in Apaf-1 and LRR domain in $R$ proteins) that is likely to be involved in protein-protein interactions that initiate events that lead to cell death. (Avijit Das et.al., 2010; Pareek, 2010)

\subsubsection{Role of mitochondria and caspase-like proteases in plants}

Regardless of the initiating death signal, animal cells die a stereotypical death executed by caspases. Genomic sequencing efforts have failed to identify canonical caspase homologues in plants, but morphological changes seen in plant cells during apoptosis-like PCD indicate the existence of caspase-like activity (Reape and McCabe, 2008; Watanabe and Lam, 2009; Woltering, 2004). The presence of caspase-like proteases in plant cells was also indirectly confirmed by pharmacological studies in which administration of caspase specific inhibitors into various plants/plant organs prevented the progression of cell death (Bonneau et.al., 2008; Reape and McCabe, 2008; Sanmartin et.al., 2005; Thomas and Franklin-Tong, 2004; Watanabe and Lam, 2009; Woltering, 2004). These studies showed that administration of caspase-1 and caspase-3 specific inhibitors blocks PCD induced by UV radiation, inhibitor of caspase-6 prevents normal plant embryogenesis and administration of caspase 1, 3, 7 suppresses the formation of tracheary elements (Danon et.al., 2004; Bohzkov et.al., 2004; Twumasi et.al., 2010). Furthermore, several experiments have demonstrated that extracts taken from plant tissues 
undergoing PCD contain molecules that are able to cleave caspase substrates in vitro. (Woltering, 2010).

Up until recently metacaspases, a small group of caspase related cystein proteases were believed to account for the caspase-like activity observed in plants. While metacaspases are involved in some plant PCD processes they cannot be the executioners of apoptosis-like PCD because studies show that the metacaspases identified in Arabidopsis thaliana are unable to cleave caspase substrates and caspase inhibitors do not block their activities (Bonneau et.al., 2008; Reape and McCabe, 2010 Woltering, 2010).

While cytochrome $c$ leakage has been reported in many plant species undergoing apoptosis-like PCD, to date there is no evidence for the existence of a well-conserved mitochondria mediated cell death pathway in plant cells. Studies involving cell free systems show that some additional elements are released from the mitochondria that work together with cytochrome $c$ in initiating the dying process. Beyond a doubt the release of cytochrome $c$ is an important part of apoptosis-like PCD in plants but, unlike in animals cells, it does not seem to be the direct activator of the cytosolic proteases that demolish these cells (Balk et.al., 2003; Reape and McCabe, 2010; Cacas, 2010; Vacca et.al., 2006; Yu et.al., 2002). Furthermore, while to date no homologues of the members of the Bcl-2 family of proteins have been identified in plants, studies show that transgenic expression of mammalian death promoting or suppressing members of Bcl-2 family can influence PCD regulating pathways of plants. For example transgenic expression of anti-apoptotic $\mathrm{Bcl}-2$ proteins was shown to suppress the progression of $\mathrm{PCD}$ in plants, while the transgenic expression of pro-apoptotic members was shown to promote it (Dickman and Reed, 2004; Nooden, 2004; Watanabe and Lam, 2009), indicating that database approaches may not be sensitive enough to detect distantly related proteins that have limited 
sequence identity but functional equivalency. A perfect example of the limitations of database approaches is their inability to recognize that while having little sequence homology, the 3D structure of human Bcl-2 family proteins strikingly resembles the structure of some of the poreforming bacterial toxins (Dickman and Reed, 2004). Also, cytoprotective genes/proteins of animal viruses show virtually no sequence homology to mammalian anti-apoptotic Bcl-2 genes/proteins, but in various in vitro models they can functionally substitute for them (Han et.al., 1996; Dickman and Reed, 2004). Based on these findings it can be assumed that while databases searches have failed to identify plant genes/proteins that share sequence homology with animal $\mathrm{Bcl}-2$ genes/proteins, plants may possess functional equivalents.

\subsection{Will Die Slowly (WDS) family of genes in Arabidopsis thaliana and my project}

While searching for genes that negatively regulate Mitogen Activated Protein Kinase (MAPK) pathways in Arabidopsis thaliana, previous members of our laboratory have identified a gene family whose members share significant sequence homology with Drosophila melanogaster's Will Die Slowly (WDS) gene. There were five genes identified and, due to their similarity to the fruit fly gene, they were named $W D S 1,2,3,4$ and 5 . Since mutations in Drosophila's WDS gene cause premature death in fruit fly larvae (Shannon et.al.,1972; Hollmann et.al., 2002) members of our laboratory hypothesized that the members of this newly identified Arabidopsis gene family may play a role in PCD regulation (Al-Shammari, 2009; Xiong, 2007).

Studies done by our laboratory's former graduate students indicated that the protein products of WDS1 (to a lesser extent than WDS2) and WDS2 are negative regulators of both senescence associated and stress induced PCD and that they act synergistically to fulfill their role (Al-Shammari, 2009; Xiong, 2007). Their experiments showed that the expression of both, $W D S 1$ and $W D S 2$, was up-regulated in leaves treated with salicylic acid (SA), a phytohormone 
that is believed to be a very important signaling molecule that mediates plant responses to both, biotic and abiotic stress, and also regulates gene expression during leaf senescence. (Morris et.al., 2000). They found that while no difference was seen in the senescing times of $w d s l$ and wild-type (WT) plants, wds $1 / w d s 2$ and $w d s 2$ plants started to senescence sooner than their WT relatives. When exposed to the fungal toxin Fumonisin $\mathrm{B} 1, w d s 1, w d s 2, w d s 1 / w d s 2$ leaves started to show signs of senescence sooner than the leaves of WT plants. Exposure to the fungal toxin also caused $w d s 1$ plants to exhibited accelerated induction of the expression of Senescence Associated Gene 12 (SAG12), a senescence specific marker gene. Their studies also indicated that WDSI and WDS2 play a role in osmotic stress induced PCD and that plants engineered to contain constitutively active WDSI were more tolerant to this abiotic stress (Al-Shammari, 2009; Xiong, 2007).

While these findings suggest that $W \mathrm{DS} 1$ and $W D S 2$ are negative regulators of plant $\mathrm{PCD}$ pathways, they do not give any indication of how and where the protein products of these genes act. During my endeavours as a graduate student in the Xing Lab, I have attempted to further investigate the function of $W D S$ genes, especially that of $W D S 2$, and to confirm that $W D S 1$ and WDS2 are two genes whose protein products act synergistically in negatively regulating apoptosis-like cell death in Arabidopsis. In order to do this, molecular genetic, genomic, proteomic, and bioinformatic approaches have been employed, which the next few chapters of this thesis will elaborate on. 


\section{Chapter II}

\section{Methods and Materials}

\subsection{Plant materials and growth conditions}

Arabidopsis thaliana ecotype Columbia-0 (Col-0) seeds were obtained from Ohio State University's Arabidopsis Biological Resource Center. The seeds were surface sterilized in $70 \%$ ethanol for 2 minutes, then in a solution containing 30\% (v/v) bleach and $0.005 \%(\mathrm{v} / \mathrm{v})$ Triton X100 for 8 minutes. After sterilization the seeds were rinsed thoroughly ten times with autoclaved water, were resuspended in $0.1 \%(\mathrm{w} / \mathrm{v})$ autoclaved agarose solution and allowed to vernalize in complete darkness for 4 days at $4{ }^{\circ} \mathrm{C}$. After vernalization the seeds were germinated for about 10-12 days in Petri dishes containing 1X Murashige and Skoog (MS) basal medium (SigmaAldrich Corp., USA), 3\% (w/v) sucrose (BioShop Canada Inc.) and 0.8\% agar (BioShop Canada Inc.). After germination the seedlings (at 2-rosette leaves stage) were transferred to autoclaved soil and were grown at $22^{\circ} \mathrm{C}$ under 12 hours of light and 12 hours of darkness in a temperature controlled growth chamber (ENCONAIR Technologies Inc., Canada)

$w d s 1 / w d s 2$ mutants were generated by Adel Al-Shammari (2009) by crossing $w d s 1$ and $w d s 2$ plants. Loss of function mutations were generated via T-DNA insertion, a step carried out at the SALK institute. The seeds were grown under the same conditions as the wild type specimen.

\subsection{Fumonisin B1 (FB1) treatment}

Leaves, both rosette and cauline, were collected from 3 weeks old WT and $w d s 1 / w d s 2$ Arabidopsis thaliana Col-0 plants. The collected leaves were vacuum infiltrated with $2 \mu \mathrm{M}$ FB1 fungal toxin and then placed into Petri dishes lined with toxin soaked filter papers. The leaves were incubated in the fungal toxin at $22^{\circ} \mathrm{C}$ under short day conditions. Samples were collected at 
0 and 48 hours, photographed, placed into sterile RNase-free Falcon tubes, snap-frozen in liquid nitrogen and stored at $-80^{\circ} \mathrm{C}$. The same procedure was concurrently carried out with the leaves that served as control and were infiltrated with autoclaved water. The frozen samples were then used for protein and RNA extraction.

\subsection{Protein extraction}

Using a porcelain mortar and pestle approximately $100 \mathrm{mg}$ of frozen leaf tissue was homogenized in $1 \mathrm{ml}$ of TRIzol ${ }^{\circledR}$ Reagent. (Invitrogen, USA) The homogenate was then transferred into a sterile tube and after 5 minutes of incubation at room temperature $0.2 \mathrm{ml}$ of chloroform was added to it. This mixture was shaken vigorously for about 15 seconds and then allowed to incubate for 3 minutes at room temperature. After incubation the sample was centrifuged using a bench-top centrifuge at $12000 \mathrm{x} \mathrm{g}$ for 15 minutes at $4{ }^{\circ} \mathrm{C}$. Following centrifugation the top aqueous layer was disposed of and DNA was precipitated from the remaining solution by the addition of $0.3 \mathrm{ml}$ of $100 \%$ ethanol. To sediment the precipitated DNA the content of the tube was centrifuged at $2000 \mathrm{x} g$ for 5 minutes at $4^{\circ} \mathrm{C}$. Once the tubes were removed from the centrifuge the phenol-ethanol supernatant was carefully removed using a pipette and transferred into clean tubes to which $1.5 \mathrm{ml}$ isopropyl alcohol was added. Samples were then incubated at room temperature for 10 minutes to allow protein precipitation. After precipitation, the proteins were pelletted by centrifugation at $12000 \mathrm{x} \mathrm{g}$ for 10 minutes at $4^{\circ} \mathrm{C}$. The resulting protein pellets were washed 3 times in $2 \mathrm{ml}$ of $0.3 \mathrm{M}$ guanidine hydrochloride in $95 \%$ ethanol. During each wash cycle the protein pellets were soaked in the wash solution for 20 minutes at room temperature and then centrifuged at $7500 \times \mathrm{g}$ for 5 minutes at $4{ }^{\circ} \mathrm{C}$. After the final wash the protein pellets were soaked in $100 \%$ ethanol for 20 minutes and then centrifuged at $7500 \mathrm{x}$ g for 5 minutes at $4{ }^{\circ} \mathrm{C}$. After centrifugation the ethanol was removed from the tubes 
and the protein pellets were dried using a vacuum centrifuge. The dried pellets were broken up mechanically using a pipette tip and then dissolved in $1 \%(\mathrm{w} / \mathrm{v})$ sodium dodecyl sulphate (SDS). To remove insoluble substances the tubes were centrifuged at $10000 \mathrm{x}$ for 10 minutes at $4^{\circ} \mathrm{C}$ and the protein containing supernatants were transferred into clean tubes and stored at $-20^{\circ} \mathrm{C}$.

\subsection{Determining protein concentration}

Protein concentration was determined using Bradford assay. To prepare $200 \mathrm{ml}$ of the Bradford reagent $200 \mathrm{mg}$ of Coomassie Blue G250 was mixed with $10 \mathrm{ml}$ of $95 \%$ ethanol, $20 \mathrm{ml}$ of $85 \%$ phosphoric acid and distilled water. The mixture was stored in a dark container at $4{ }^{\circ} \mathrm{C}$ and filtered few minutes before use.

To prepare a standard curve $10 \mathrm{mg} / \mathrm{ml}$ of bovine serum albumin (BSA) solution was prepared by diluting $30 \mathrm{mg}$ of BSA in $30 \mathrm{ml}$ of $1 \% \mathrm{SDS}$. This solution was then used to prepare a series of solutions of known concentration. (see Table 2-1)

Table 2-1: Dilutions of BSA solution used for standard curve preparation

\begin{tabular}{|c|c|c|}
\hline $\begin{array}{c}\text { Final BSA } \\
\text { concentration } \\
(\mathrm{mg} / \mathrm{ml})\end{array}$ & $\begin{array}{c}10 \mathrm{mg} / \mathrm{ml} \mathrm{BSA} \\
\text { volume }(\mu \mathrm{l})\end{array}$ & $1 \%$ SDS $(\mu \mathrm{l})$ \\
\hline 0.25 & 2.5 & 97.5 \\
\hline 0.50 & 5.0 & 95.0 \\
\hline 0.75 & 7.5 & 92.5 \\
\hline 1.00 & 10.0 & 90.0 \\
\hline 1.25 & 12.5 & 87.5 \\
\hline
\end{tabular}

$1 \mathrm{ml}$ of filtered Bradford reagent was mixed with $20 \mu \mathrm{l}$ of each dilution and added to UV spectrometer cuvettes. The mixtures were allowed to incubate for $\sim 5$ minutes at room temperature and then their absorbencies at $595 \mathrm{~nm}$ was measured, recorded and plotted against their concentration. The same steps were concurrently carried out with the protein extracts obtained from FB1 and water treated leaf tissues. The concentration of these extracts was calculated using the formula of the standard curve generated using Microsoft Office Excel. 


\subsection{One dimensional SDS-PAGE}

Once the protein samples were isolated and their concentration determined they were run on a protein SDS-PAGE mini gel. Before the running step a minigel consisting of two parts (i.e. the separating and the stacking layer) had to be prepared. To prepare the separating gel, $2.5 \mathrm{ml}$ of separating solution (45.5 $\mathrm{g}$ of Tris base, $1 \mathrm{~g}$ of SDS per $250 \mathrm{ml}$ of MilliQ water, $\mathrm{pH} \mathrm{8.8)} \mathrm{was}$ mixed with $3.3 \mathrm{ml}$ of $30 \%$ acrylamide solution (BioRad Laboratories Inc., USA), $4.16 \mathrm{ml}$ of sterile water, $30 \mu \mathrm{l}$ of $10 \%$ ammonium persulfate and $6.6 \mu \mathrm{l}$ of TEMED and poured into a preassembled gel casting apparatus. After the separating gel solidified, the stacking gel was prepared by mixing $1.25 \mathrm{ml}$ of stacking solution (12.1 $\mathrm{g}$ of Tris base, $0.8 \mathrm{~g}$ electrophoresis grade SDS per $200 \mathrm{ml}$ of MilliQ water, $\mathrm{pH} 6.8$ ) with $3.05 \mathrm{ml}$ of MilliQ water, $0.65 \mathrm{ml}$ of $30 \%$ acrylamide , $25 \mu 1$ of $10 \%$ ammonium persulfate and $5 \mu 1$ of TEMED. Once mixed, the solution was poured on top of the solidified separating gel and a comb was inserted into it. The stacking gel was allowed to solidify for about 30 minutes.

Before loading the protein samples into the wells of the gel, their concentration was adjusted to $1 \mu \mathrm{g} / \mu \mathrm{l}$ with $1 \mathrm{X}$ SDS sample buffer $(50 \mathrm{mM}$ Tris-HCl, 2\% (w/v) SDS, 10\% (v/v) glycerol, $0.1 \%$ bromophenol blue and $5 \%(\mathrm{v} / \mathrm{v}) 2$-meracaptoethanol in water, $\mathrm{pH} 7.4)$. The samples were then heated for 10 minutes at $90{ }^{\circ} \mathrm{C}$, mixed by vortexing and loaded (15 $\left.\mu 1\right)$ into the wells of the previously prepared gel. BenchMark ${ }^{\text {TM }}$ Pre-Stained Protein Ladder (Invitrogen, USA) was used as standard. Separation was carried out in $1 \mathrm{X}$ running buffer $(3.03 \mathrm{~g}$ of Tris base, $14.3 \mathrm{~g}$ of glycine and $1 \mathrm{~g}$ of SDS per liter of MilliQ water, $\mathrm{pH} \sim 8.3$ ) at $150 \mathrm{~V}$ for $\sim 50$ minutes at room temperature. After electrophoretic separation, the proteins were either transferred onto polyvinylidene fluoride membranes for western blotting or stained with BioSafe 
Coomasie Stain (BioRad Laboratories Inc, USA) and the desired bands excised to be sent out for mass spectrometric analysis.

Protein transfer onto PVDF was carried out via wet transfer in chilled transfer buffer ( $3 \mathrm{~g}$ of Tris base, $14.4 \mathrm{~g}$ of glycine, $200 \mathrm{ml}$ of methanol per liter of water) at $70 \mathrm{~V}$ for about 2 hours. In order to prevent overheating of the buffer, sealed icepacks were placed into the buffercontaining tank. For protein separation and transfer, a Mini-PROTEAN 3 system (BioRad Laboratories Inc, USA ) was utilised.

\subsection{Protein immunoblotting and visualization}

After protein transfer, the PVDF membranes were blocked in 5\% BSA or non-fat milk in TBST (1.2 $\mathrm{g}$ of Tris base, $9 \mathrm{~g}$ of $\mathrm{NaCl}, 0.5 \mathrm{ml}$ of Tween-20 per liter of water) for $\sim 30$ minutes. After blocking, the membranes were washed three times for 5 minutes in TBST and then incubated in primary antibody $(10 \mathrm{ml}$ of TBST, $0.5 \mathrm{~g}$ of BSA or non-fat milk depending on the antibody used and $10 \mu 1$ of the primary antibody). This incubation step was carried out on a shaking platform overnight at $4{ }^{\circ} \mathrm{C}$. The blots were washed three times for 5 minutes in TBST and incubated in 1:2000 HRP-linked secondary antibody $(10 \mathrm{ml}$ of TBST, $0.5 \mathrm{~g}$ of BSA or nonfat milk and $5 \mu \mathrm{l}$ of HRP-linked secondary antibody). The membranes were then washed three times for 5 minutes in TBST and then incubated in $10 \mathrm{ml}$ of LumiGLO ${ }^{\circledR}(0.5 \mathrm{ml} 20 \mathrm{X}$ LumiGLO $^{\circledR}, 0.5 \mathrm{ml} 20 \mathrm{X}$ Peroxide and $9 \mathrm{ml}$ Milli-Q water). After 1 minute of gentle agitation, the developing solution was drained from the membranes, which were then sandwiched between two plastic sheets and scanned using FluoroChem Q imaging system (Alpha Innotech Corp., USA).

To confirm equal loading of the sample in each lane, the blots were stained with a Coomassie Blue staining solution $(0.25 \%(\mathrm{w} / \mathrm{v})$ coomassie blue R-250, 7.5\% (v/v) acetic acid, 
$40 \%(\mathrm{v} / \mathrm{v})$ methanol) for about 10-15 minutes and then destained for 30 minutes in a solution containing $10 \%(\mathrm{v} / \mathrm{v})$ acetic acid and $25 \%(\mathrm{v} / \mathrm{v})$ methanol.

The following table (Table 2-2) lists the type of antibodies used:

Table 2-2: List of primary antibodies used

\begin{tabular}{|c|c|}
\hline \multicolumn{2}{|c|}{$\begin{array}{c}\text { Phospho-(Ser/Thr) Kinase Substrate Antibody Sampler Kit } \\
\text { manufactured by Cell Signaling Technology } ®\end{array}$} \\
\hline \multicolumn{2}{|c|}{ Phospho-(Thr) MAPK/CDK Substrate Mouse mAb } \\
\hline \multicolumn{2}{|c|}{ Phospho-Akt Substrate (RXXS*/T*) Rabbit mAb } \\
\hline \multicolumn{2}{|c|}{ Phospho-PKA Substrate (RRXS*/T*) Rabbit mAb } \\
\hline \multicolumn{2}{|c|}{ Phospho-(Ser/Thr) ATM/ATR Substrate Antibody } \\
\hline \multicolumn{2}{|c|}{ Phospho-(Ser) PKC Substrate Antibody } \\
\hline \multicolumn{2}{|c|}{ Phospho-(Ser) CDKs Substrate Antibody } \\
\hline \multicolumn{2}{|c|}{ Apoptosis Antibody Sampler Kit } \\
\hline Cleaved Caspase- 3 & Caspase-9 Antibody \\
\hline Caspase- 3 Antibody & Cleaved Caspase-9 \\
\hline PARP Antibody & Caspase-7 Antibody \\
\hline Cleaved PARP & Cleaved Caspase-7 \\
\hline
\end{tabular}

\subsection{RNA extraction and reverse transcription polymerase chain reaction (RT-PCR)}

RNA was extracted from previously frozen FB1 and water treated leaf tissues using RNeasyß Mini Kit (Qiagen, Germany). For cDNA synthesis Cloned AMV First-Strand cDNA Synthesis Kit (Invitrogen, USA) was used. The cDNAs obtained were then used as template for subsequent PCR reactions that were carried out with primers specific to $A t B I I$ and $A t D A D-1$, as well as AtACTIN2 gene (TAIR accession \# At3g18780) which was used as control (Table 2-3). 
Table 2-3: Primers used for RT-PCR

\begin{tabular}{|c|c|}
\hline \multirow{2}{*}{$A t A C T I N 2$} & $\begin{array}{l}\text { Fw } \\
\text { 5'-CCTCATGCCATCCTCCGTCTTG-3. }\end{array}$ \\
\hline & $\begin{array}{l}\text { Rev } \\
\text { 5'-TTCCATCTCCTGCTCGTAGTCAAC-3. }\end{array}$ \\
\hline \multirow{2}{*}{$A t B I-1$} & $\begin{array}{l}\text { Fw } \\
\text { 5'-ACCTGGTAGCAGAAGCTGGA-3', }\end{array}$ \\
\hline & $\begin{array}{l}\text { Rev } \\
\text { 5'-CACCACCATGTATCCCACAA-3 }\end{array}$ \\
\hline \multirow[t]{2}{*}{$A t D A D-1$} & $\begin{array}{l}\text { Fw } \\
\text { 5'-TGGTGAAATCGACGAGTAAGG-3, }\end{array}$ \\
\hline & $\begin{array}{l}\text { Rev } \\
\text { 5'-ATCAAAGGGTCCCATTAGGC-3, }\end{array}$ \\
\hline
\end{tabular}

The reactions were carried out using Taq DNA polymerase (Invitrogen, USA) at the following settings:

$$
\left.\begin{array}{l}
\text { Denaturation } \rightarrow 94{ }^{\circ} \mathrm{C} \text { for } 2 \text { minutes } \\
\text { Denaturation } \rightarrow 94{ }^{\circ} \mathrm{C} \text { for } 15 \text { seconds } \\
\text { Annealing } \rightarrow 55{ }^{\circ} \mathrm{C} \text { for } 30 \text { seconds } \\
\text { Extension } \rightarrow 72{ }^{\circ} \mathrm{C} \text { for } 1 \text { minute } \\
\text { Extension } \rightarrow 72{ }^{\circ} \mathrm{C} \text { for } 10 \text { minute }
\end{array}\right\} 25 \mathrm{X}
$$

\subsection{Amplification and mutation and cloning of WDS2 (At5g08560) and WDS3 (At1g73720)}

pVKH18::GFPN-WDS2, a construct generated by Adel Al-Shammari (2009), was used as template for the PCR reactions. The pVKH18::GFPN plasmid containing the WDS2 gene was inserted into E.coli DH5a cells for long term strorage in glycerol at $-80^{\circ} \mathrm{C}$. The bacterial cells containing the plasmids with our gene of interest were plated onto kanamycin containing LB plates $(10 \mathrm{~g}$ tryptone, $5 \mathrm{~g}$ yeast extract, $10 \mathrm{~g} \mathrm{NaCl}, 15 \mathrm{~g}$ agar and $1 \mathrm{ml}$ of $50 \mu \mathrm{g} / \mathrm{ml}$ kanamycin per liter of water) and incubated overnight at $37^{\circ} \mathrm{C}$. After incubation individual colonies were removed and used to inoculate about $4 \mathrm{ml}$ of liquid $\mathrm{LB}$ media $(10 \mathrm{~g}$, tryptone, $5 \mathrm{~g}$ yeast extract, $10 \mathrm{~g} \mathrm{NaCl}$, and $1 \mathrm{ml}$ of $50 \mu \mathrm{g} / \mathrm{ml}$ kanamycin per liter of water) that was then shaken at $37^{\circ} \mathrm{C}$ overnight at $225 \mathrm{rpm}$ in a shaking incubator. The next day, plasmids were isolated from the amplified cells using Wizard® Plus Minipreps DNA Purification System (Promega Corp., USA) 
The concentration of the isolated plasmids was measured and agarose gel electrophoresis was performed to ensure the purity of the isolated samples.

E.coli cells containing cDNA library of Arabidopis thaliana within kanamycin resistance gene containing pUNI51 plasmids were obtained from the Arabidopsis resource center. The cells were grown on kanamycin containing LB media (see above) and after culturing individual colonies overnight, their plasmids were extracted using Wizard® Plus Minipreps DNA Purification System (Promega Corp., USA)

\subsubsection{Amplification of WDS2 (At5g08560) and WDS3 (AtIg73720)}

Since the product of the PCRs was meant to be used for molecular cloning Platinum ${ }^{\circledR} P f x$ DNA Polymerase (Invitrogen, USA), a proofreading polymerase, was used. The primers used in our experiments were designed to contain restriction endonuclease cleavage sites so that the PCR products can inserted into various plasmids' multiple cloning sites. The following table, Table 2-4, lists the pair of primers used and the endonuclease cleavage sites they contained.

Table 2-4: Primers used for PCRs with restriction endonuclease cleavage sites highlighted

\begin{tabular}{|c|c|}
\hline Fw At5g08560-Sall & 5'-AGAGTCGACATGGGAGTTGTGGAGGATACTG-3' \\
\hline Rev At5g08560-BamHI & 5'AGAGGATCCTCAATTCCCATTGCATCGGT-3' \\
\hline Fw At5g08560- Xbal & 5'GGATCTAGAACCATGGGAAGTAAAGGAGAAGAA-3' \\
\hline Rev At5g08560-PstI & 5'-TCCCTGCAGTCAATTCCCATTGCATCGGTG-3' \\
\hline Fw At5g08560-NdeI & 5'-AGACATATGATGGGAGTTGTGGAGGATACTG-3' \\
\hline Rev At5g08560-XhoI & 5'-AGACTCGAGTCAATTCCCATTGCATCGGT-3' \\
\hline Fw Atlg73720-SalI & 5'-AGAGTCGACATGGCGTCGAAATCGAAGC-3' \\
\hline Rev At1g73720-BamHI & 5'-AGAGGATCCTCAGGGCTTCCATAACTTCATA-3' \\
\hline
\end{tabular}

\subsubsection{Overlap-extension PCR (OE-PCR)}

OE-PCR was also carried out using Platinum $® P f x D N A$ Polymerase. For generating the two halves $p V K H 18: \because G F P N-W D S 2$ was used as template. Primers "a" and " $b$ " were used to generate the first half of the mutated genes while "c" and " $\mathrm{d}$ " were used to generate the second 
half. After the size of the PCR products was tested using agarose gel electrophoresis they were cleaned using Wizard® SV Gel and PCR Clean-Up System (Promega, USA). After obtaining the two halves a second round of PCR was carried out, but this time the templates used were the first and second halves generated during the first round and the primers used were "a" and " $d$ ". In both, the first and second rounds, 25 cycles were run at settings suggested by Platinum $\mathbb{R} P f \mathrm{DNA}$ Polymerase's manufacturer. A list of primer used for mutating WDS2 can be found in Table 2-5. (see below)

Table 2-5: List of primers used to introduce point mutations into WDS2 (also indicates the site of mutation and the resulting amino acid change)

\begin{tabular}{|c|c|}
\hline Site of mutation & Primer's nucleotide sequence \\
\hline $\mathrm{T} 435$ to $\mathrm{A}(\mathrm{c})$ & $\begin{array}{l}5^{\prime} \text {-TCA CTA TTT GAT AGA GAA GCT GCA GTT GAG AGA } \\
\text { TTA ATA GAA GAG-3' }\end{array}$ \\
\hline $\mathrm{T} 435$ to $\mathrm{A}(\mathrm{b})$ & $\begin{array}{l}\text { 5'-CTC TTC TAT TAA TCT CTC AAC TGC AGC TTC TCT } \\
\text { ATC AAA TAG TGA-3' }\end{array}$ \\
\hline T435 to $\mathrm{E}(\mathrm{c})$ & 5'-GAT AGA GAA GCT GAA GTT GAG AG- 3' \\
\hline $\mathrm{T} 435$ to $\mathrm{E}(\mathrm{b})$ & $5^{\prime}$-CT CTC AAC TTC AGC TTC TCT ATC- $3^{\circ}$ \\
\hline S511 to $\mathrm{A}(\mathrm{c})$ & $\begin{array}{l}\text { 5'-GCT AGC GGA AGC GAG GAC GCT CAG GTA TAT ATA } \\
\text { TGG CAC AGA-3' }\end{array}$ \\
\hline S511 to $A(b)$ & $\begin{array}{l}\text { 5'-TCT GTG CCA TAT ATA TAC CTG AGC GTC CTC GCT } \\
\text { TCC GCT AGC-3' }\end{array}$ \\
\hline S511 to D (c) & $\begin{array}{l}5^{\prime} \text {-GCT AGC GGA AGC GAG GAC GAT CAG GTA TAT ATA } \\
\text { TGG CAC AGA - } 3^{\circ}\end{array}$ \\
\hline S511 to $\mathrm{D}(\mathrm{b})$ & $\begin{array}{l}\text { 5'- TCT GTG CCA TAT ATA TAC CTG ATC GTC CTC GCT } \\
\text { TCC GCT AGC-3' }\end{array}$ \\
\hline $\mathrm{H} 284 \rightarrow \mathrm{D}, \mathrm{K} 287 \rightarrow \mathrm{E}(\mathrm{c})$ & 5'-G CAA TTT TCA GAT AAT GGC GAA TAT TTG GC -3' \\
\hline $\mathrm{H} 284 \rightarrow \mathrm{D}, \mathrm{K} 287 \rightarrow \mathrm{E}(\mathrm{b})$ & $\begin{array}{l}\text { 5'-AGC CAA ATA TTC GCC ATT ATC TGA AAA TTG CAA } \\
\text { GAA CCA AAC TTC-3' }\end{array}$ \\
\hline $\mathrm{R} 518 \rightarrow \mathrm{E}, \mathrm{K} 522 \rightarrow \mathrm{E}, \mathrm{H} 530 \rightarrow \mathrm{D}$ (c) & $\begin{array}{l}\text { 5'-TGG CACGAA TCT ACA GGG GAG TTA ATA GTT GAG } \\
\text { CTA CCA GGC GAT GCA GGA-3' }\end{array}$ \\
\hline $\mathrm{R} 518 \rightarrow \mathrm{E}, \mathrm{K} 522 \rightarrow \mathrm{E}, \mathrm{H} 530 \rightarrow \mathrm{D}(\mathrm{b})$ & $\begin{array}{l}\text { 5'-TCC TGC ATC GCC TGG TAG CTC AAC TAT TAA CTC } \\
\text { CCC TGT AGA TTC GTG CCA-3' }\end{array}$ \\
\hline $\mathrm{F}_{\mathrm{W}}$ At5g08560-Sall (a) & 5'-AGAGTCGACATGGGAGTTGTGGAGGATACTG-3' \\
\hline Rev At5g08560-BamHI(d) & 5'-AGAGGATCCTCAATTCCCATTGCATCGGT-3' \\
\hline
\end{tabular}

The size of the PCR products was confirmed using agaros gel electrophoresis, cleaned using Wizard $®$ Plus Minipreps DNA Purification System (Promega Corp., USA) and then 
restriction enzyme digested with the proper restriction enzymes. Concurrently pVKH18::GFPN, which were obtained from cells stored in glycerol stock (see above), pLRCWHEAT2-gevAgdv plasmids that were recovered from a CloneSaver Card (Whatmasn Biosciences, USA) and pET$14 \mathrm{~b}$ (EMD Chemicals Inc., USA) were also digested with the appropriate restriction endonucleases. pLRCWHEAT2-gevAgdv contained a lethal gene, which was entirely removed after digestion with the enzyme. Following digestion the wild type gene products were inserted into pLRCWHEAT2-gevAgdv, as well as pET-14b and the genes containing the point mutations were inserted into pVKH1 8::GFPN using Invitrogen's T4 DNA ligase.

After repeated failure and limited success with cloning, we attempted to clone our genes into TOPO ${ }^{\circledR}$ vector before restriction enzyme digestion. Invitrogen's ZeroBlunt ${ }^{\circledR}$ TOPO ${ }^{\circledR}$ PCR

Cloning Kits and Mach1 ${ }^{\mathrm{TM}} \mathrm{T} 1$ Phage-Resistant $\left(\mathrm{T} 1^{\mathrm{R}}\right)$ E.coli competent cells were used for cloning and amplification of the TOPO-gene constructs. For both cloning and cell transformation the protocol outlined by the manufacturer was used.

\subsection{Biolnformatic analysis}

For microarray data mining Genevestigator was used. The data was manually recorded and then plotted using Microsoft Office Excel 2007. Motif analysis was performed using ScanSite analysis tool (http://scansite.mit.edu/), while Protein-protein interactions were predicted using Atted-II 6.0 (http://atted.jp/) and STRING 9.0 (http://string-db.org/) databases.

University of Toronto's BAR (http://bar.utoronto.ca/welcome.htm) was utilized to predict expression patterns in different tissues and to predict subcellular localization. The latter was also predicted using WoLF PSORT (http://wolfpsort.org/) prediction tool. 


\section{Chapter III}

\section{Bioinformatic analysis of WDS gene family members in Arabidopsis thaliana}

\subsection{Introduction}

It was through bioinformatic approaches that members of our laboratory have identified and briefly characterized the $W D S$ gene family of $A$. thaliana. Their use of bioinformatic tools was limited to predicting the domain structure of the proteins and generating a phylogenic tree to determine similarities between the five members (Xiong 2007; Al-Shammari, 2009) (Figure 3.1).

a.

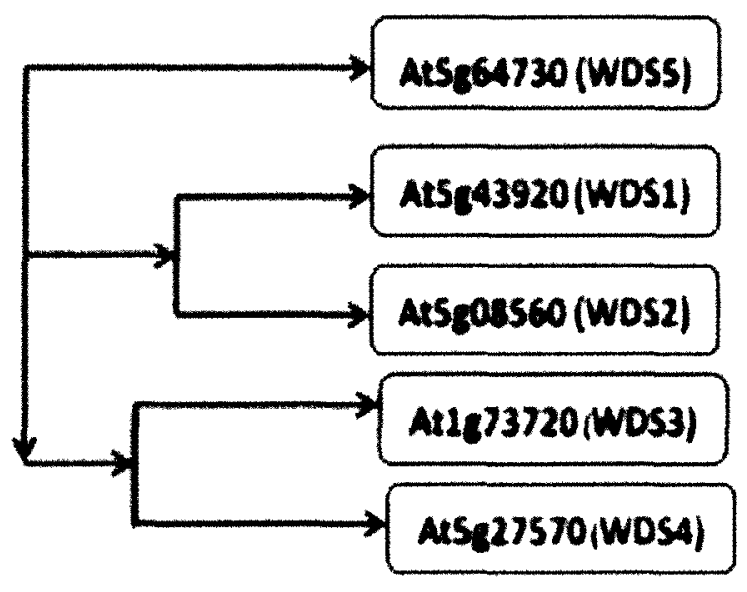

b
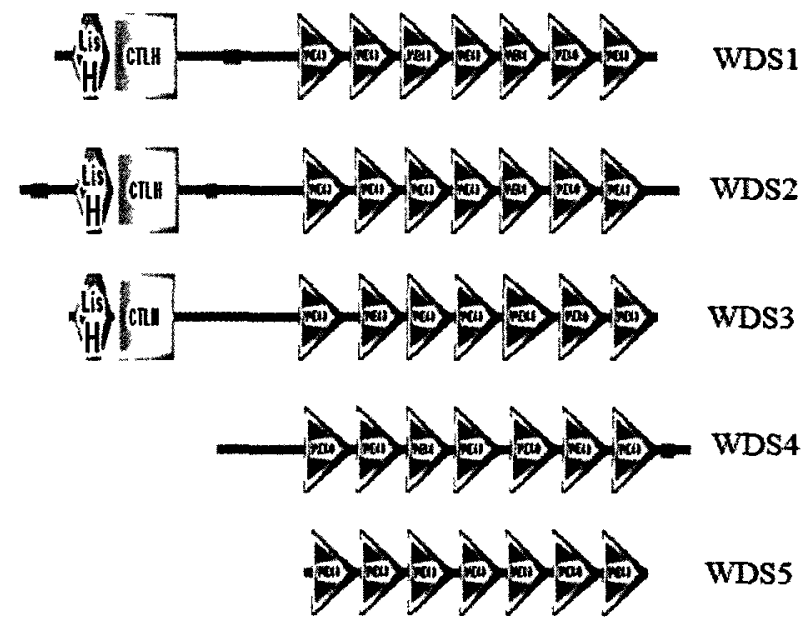

Figure 3.1: a). Phylogenic tree of WDS family members

b). Domain structure of WDS family members; the seven WD40 repeats are conserved among all the members, while only WDS 1,2 and 3 contained a LisH and CTLH domains. (Images adapted with permission from Al-Shammari, 2009)

Bioinformatics, however, also allows us to find out more about genes and their protein products. By utilizing bioinformatics the folding pattern, physical and chemical properties, subcellular localization, and possible post-translational modifications of proteins can be 
predicted. It is even possible to predict what proteins interact with the protein of interest and how its expression pattern changes as the organism in question goes through different developmental stages or is exposed to environmental stresses. Bioinformatics makes it possible for us to access integrated data from thousands of transcriptome experiments done by researchers from all over the world. It is a powerful tool that can help us better plan and design experiments.

In this chapter. bioinformatic analysis of WDS family members will be presented. Using online bioinformatic tools, we will describe the expression patterns, expression levels under different conditions, subcellular localization, and interactome profiles of the five WDS proteins.

\subsection{Results}

\subsubsection{Analysis of WDS1 (At5g43920)}

WDS1 encodes a 523 amino acid long protein with a molecular mass of $59122 \mathrm{Da}$. Motif analysis using ScanProsite tool indicated the presence of three so-called ERK-docking domains (L107, L363, V365), which are sites that proteins use to physically interact with mitogen activated protein kinases belonging to the ERK family (Figure 3.2). Using University of Toronto`s Bar Cell eFP tool (Figure 3.3) and WoLF PSORT analysis tool (output not shown) the protein was predicted, though with low confidence, to be located in the cytosol (Figure 3.3). The gene's overall expression seems to increase slightly as the plant matures (Figure 3.4). While the overall trend shows an increase in expression levels, they tend to fluctuate slightly during different stages of development (Figure 3.4). At the tissue level, it appears that expression levels are highest in dry seeds and lowest in mature pollen while all other tissues exhibit intermediate expression levels (Figure 3.5). When taking a closer look at the leaves of the plant, it was observed that as the leaves matured they exhibited up-regulated WDS1 expression (Figure 3.6). 
Transcriptome analysis was also used to study the effect of pathogen exposure on WDS1's expression in leaves. After analysis of the data collected, no clear trend in the expression pattern of the gene was observed, but more often than not, the expression of the gene was down-regulated following pathogen exposure. Treatment with the fungal pathogens Botrytis cinerea and Blumeria graminis caused the most significant down-regulation of WDSI. The fungal pathogen Erysiphe cichoracerum also caused its down-regulation, however to a much lesser extent than B. cinerea and B. graminis. Exposure to Erysiphe orontii, also a fungal pathogen, caused a slight up-regulation of WDSI, while infections with Cabbage leaf curl virus, Turnip mosaic virus, and the arthropods Bemisia tabaci (type B) and Myzus persicae all resulted in its down-regulation. WDSI's expression was up-regulated after treatment with the bacterial pathogen Pseudomonas syringae, however its expression levels plummeted by the 12 th hour following exposure (Figure 3.7).

Effects of common elicitors on the gene's expression were also tested. Both flagellin (FLG22) and harpin (HrpZ) caused down-regulation of WDS1. In both cases, expression was about twofold lower 4 hours after treatment with the elicitor than 1 hour after. Exposure to lipopolysaccharide (LPS) caused an up-regulation in WDS1's expression within the first hour but expression levels declined about fourfold during the following 3 hours (Figure 3.8).

Data from transcriptome analyses also suggested that expression of WDSI gradually decreases as the environmental temperature decreases. Leaf samples were exposed to decreasing temperatures for 6 and 78 hours. Samples collected at 78 hours exhibited similar expression patterns as the samples collected after 6 hours, however, the level of down-regulation seemed to be lower in them than in the leaves that were tested after 6 hours (Figure 3.9). Down-regulation of WDS1 expression in leaves of 5 week old plants treated with $250 \mathrm{mM} \mathrm{NaCl}$ for 24 hours was 
also observed (Figure 3.48) along with an up-regulation in leaves of 34 days old plants that were completely deprived of water for 10 days (Figure 3.47).

Six proteins were identified that are likely to directly interact with WDS1 (Figure 3.10). Motif analysis suggests that WDS1 may interact with one or more ERK-type kinases (Figure 3.2). Co-expression analysis identified two proteins with unknown function (At4g02210 and At3g07310) and a protein that is a cellular repressor of E1A-stimulated genes (CREGs) (At2g04690) (Figure 3.10a) to possibly interact with WDS1. Co-occurrence analysis identified Atlg78070, which is located in CUL4 RING E3 ubiquitine ligase complex, and At5g50120, an unknown protein with unknown function (Figure 3.10b) to also possibly interact with WDS1.

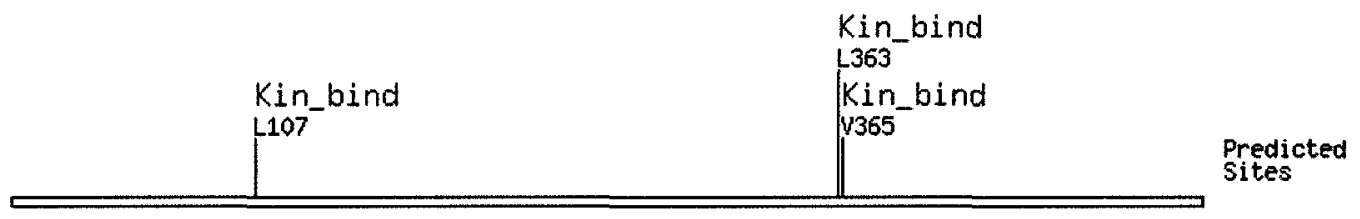

Figure 3.2: High stringency ScanSite Motif Scan output for WDS1 protein sequence indicating possible ERK docking sites. (see Appendix 2 for database analysis) 


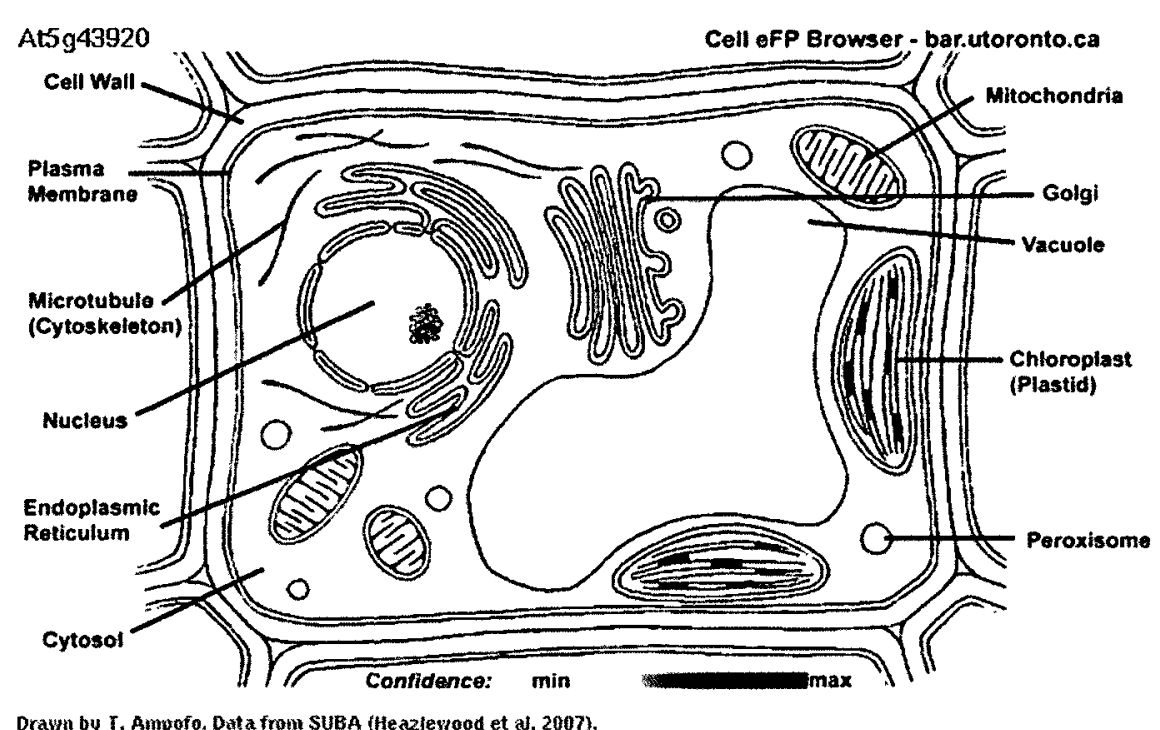

Figure 3.3: Electronic fluorescence pictographic representation of WDS1's subcellular localisation. Shaded area on image indicates site of expression and the yellow colour indicates low confidence. Subcellular localisation was predicted based on documented and predicted localizations in SUBA database (Heazelwood et.al., 2007).

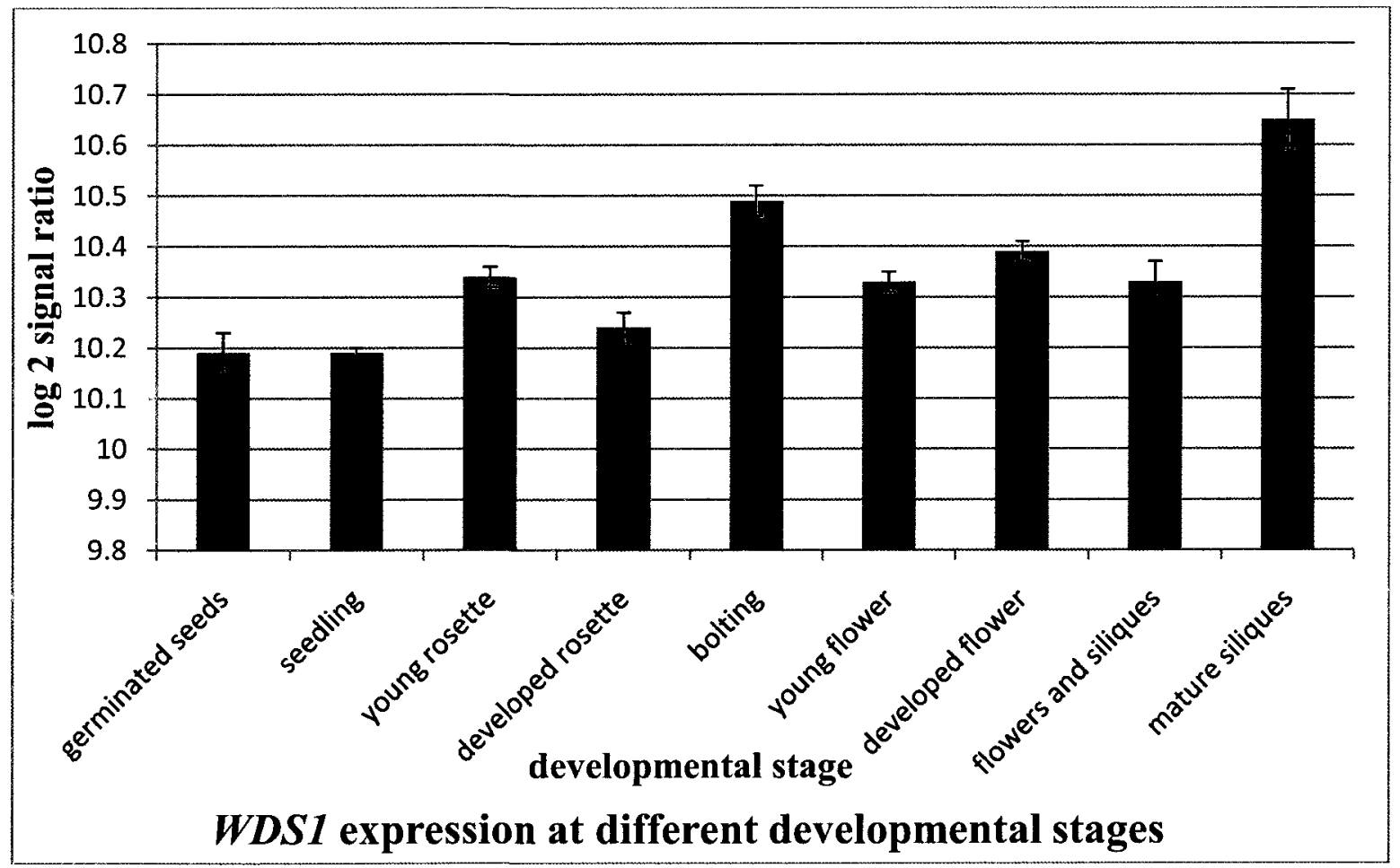

Figure 3.4: Overall expression of WDS1 across different stages of development. Each stage comprised between up to $170322 \mathrm{k}$ arrays from different tissues of Arabidopsis thaliana from which the average expression values were calculated. Chart was generated using pre-existing microarray data obtained from Genevestigator database. 


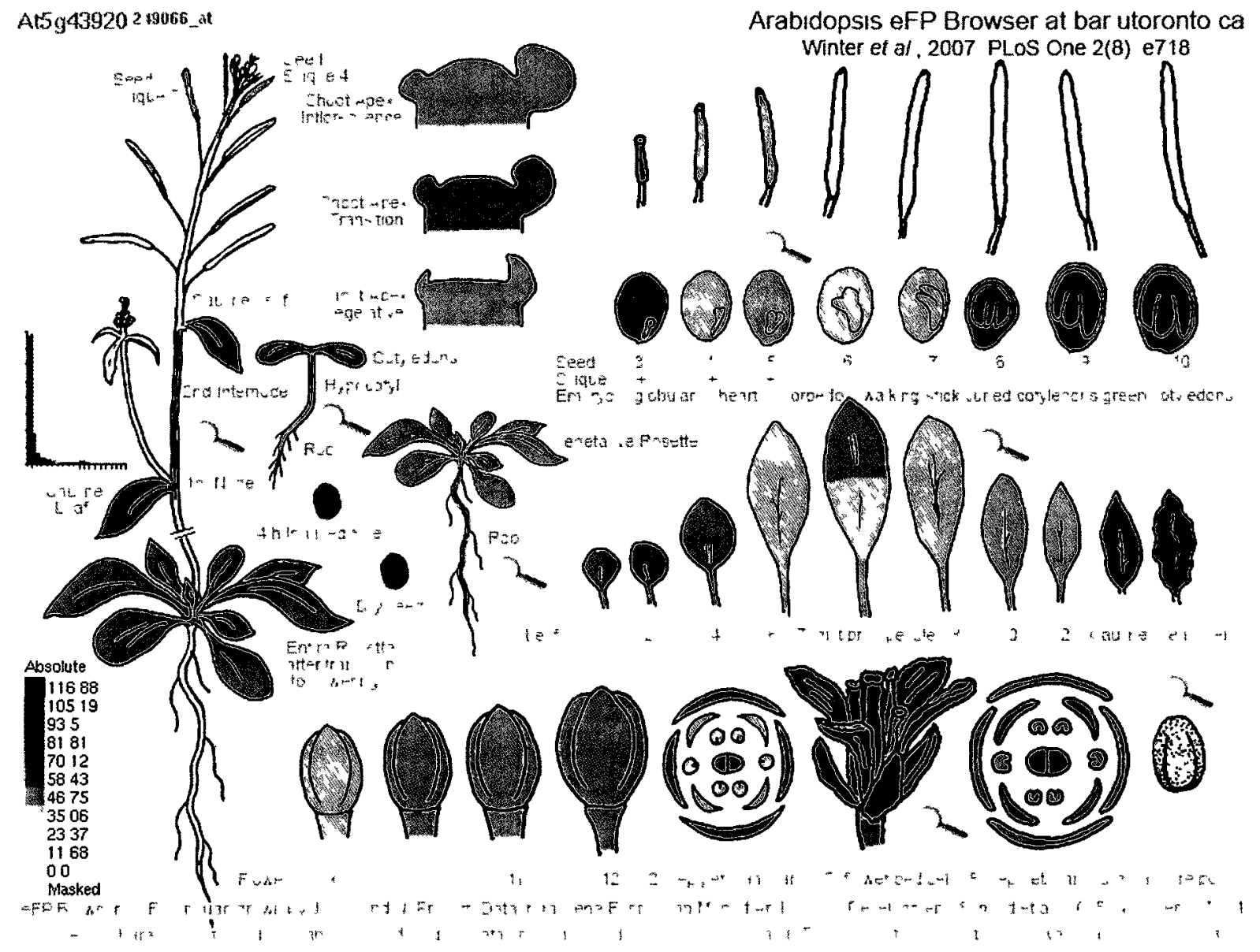

Figure 3.5: Electronic fluorescent pictograph of WDS1's expression pattern. Image illustrates expression levels in different tissues at different developmental stages. High levels of expression are indicated in red, intermediate levels in orange and low levels in yellow. Image was generated using Arabidopsis eFP browser which uses data from AtGenExpress Consortium data (Schmid et.al., 2005). 


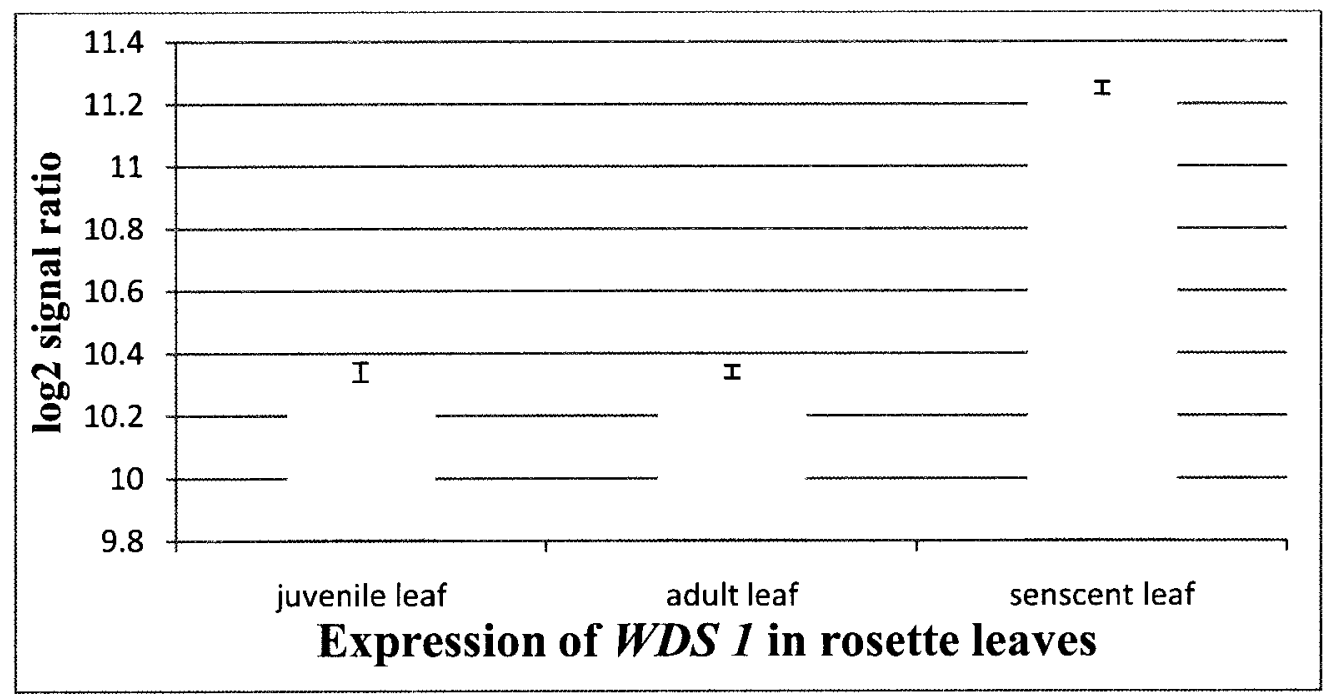

Figure 3.6: Expression levels of WDS1 in rosette leaves of Arabidopsis thaliana at different stages of their development. Senescent leaves exhibit the highest level of expression. Graph was generated using pre-existing microarray data obtained from Genevestigator database.

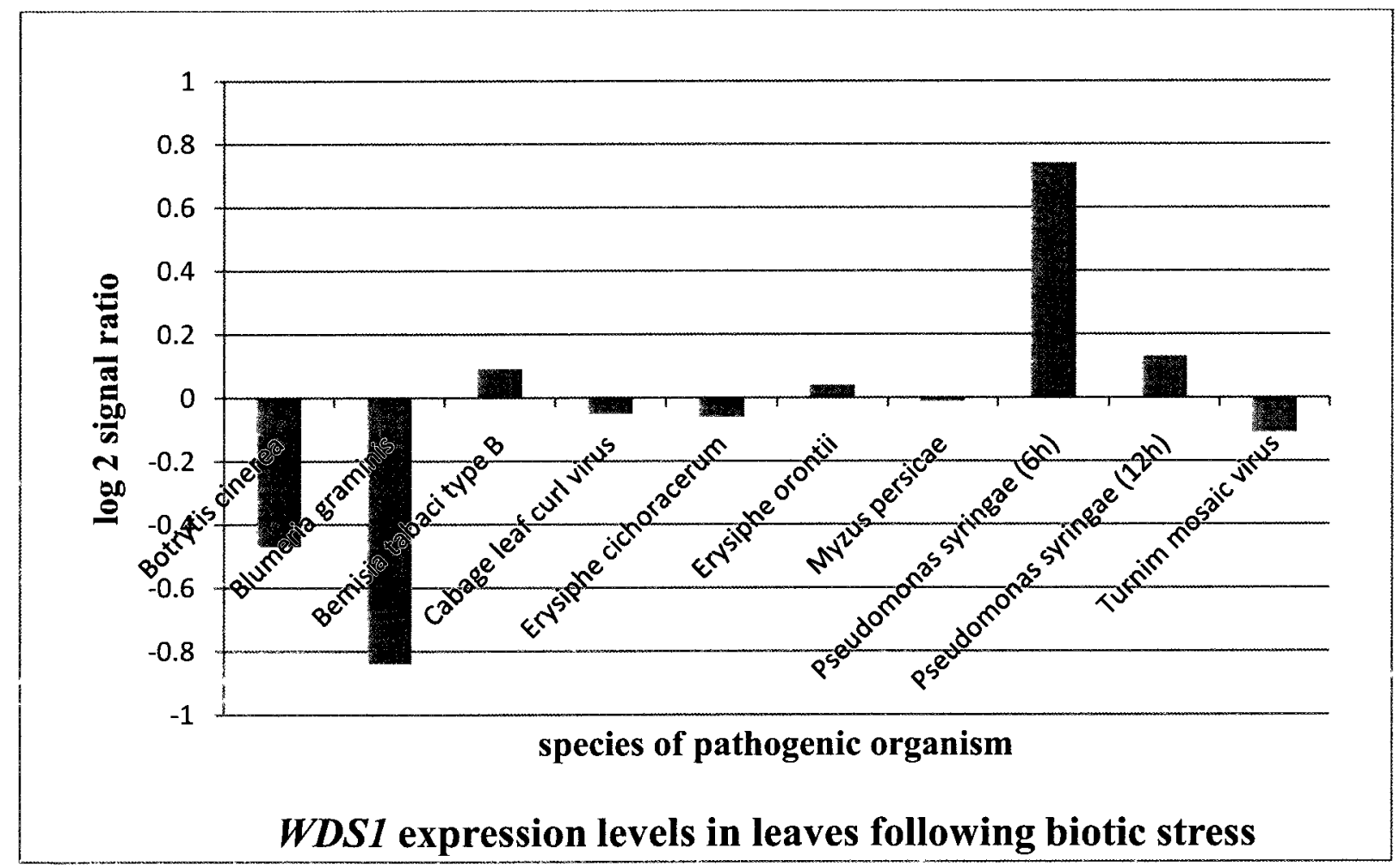

Figure 3.7: WDS1 expression levels in Arabidopsis thaliana leaves exposed to a variety of pathogenic organisms. Chart was generated using pre-existing microarray data obtained from Genevestigator database. Single repeat experiment; no error value provided. 


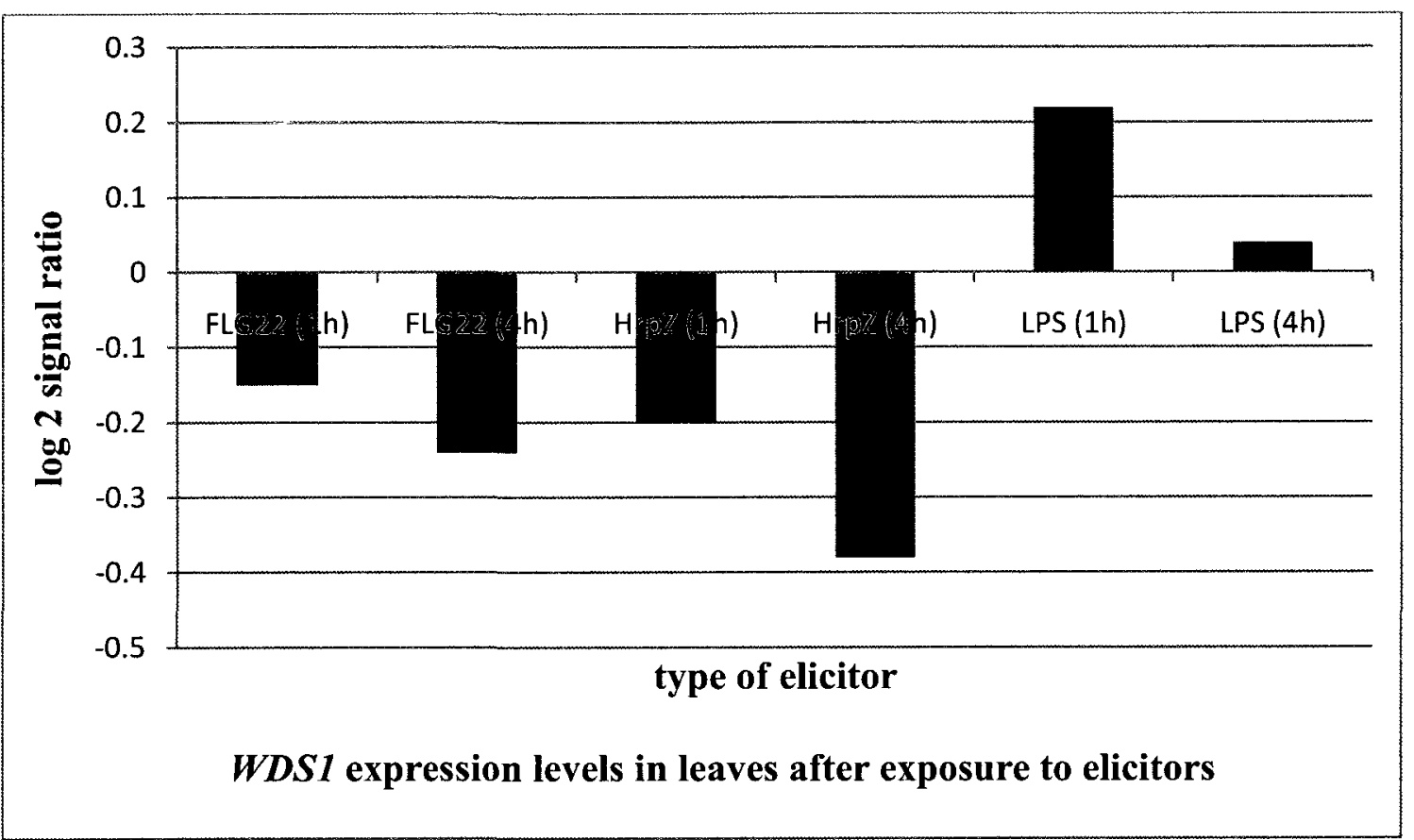

Figure 3.8: Effect of elicitors on WDSl expression in leaves of Arabidopsis thaliana. Chart was generated using pre-existing microarray data obtained from Genevestigator database. Single repeat experiment; no error value provided.

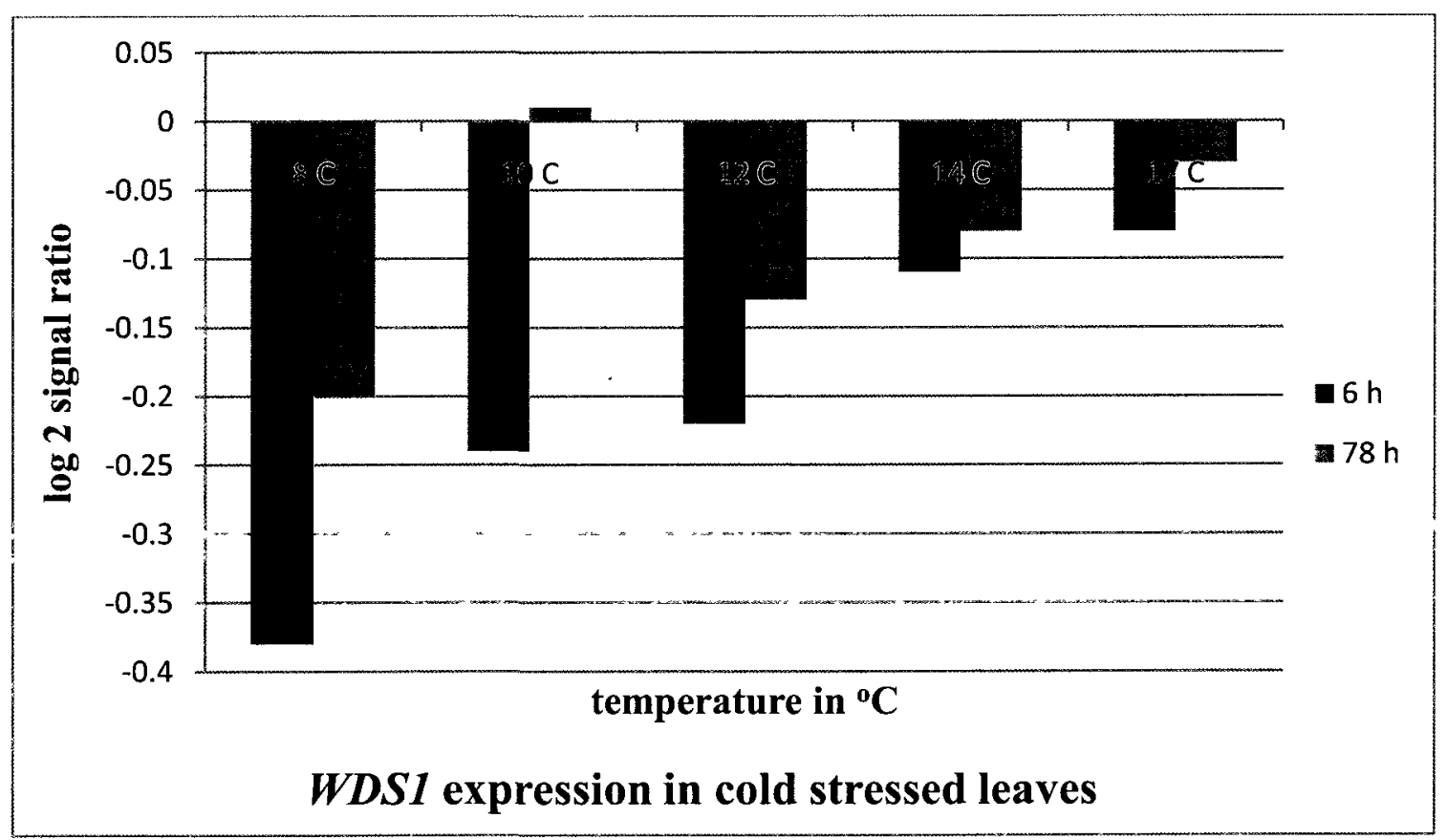

Figure 3.9: Effect of cold temperature on WDS1 expression in leaves of Arabidopsis thaliana. Figure was generated using data obtained from Genevestigator database. Single repeat experiment; no error value provided. 


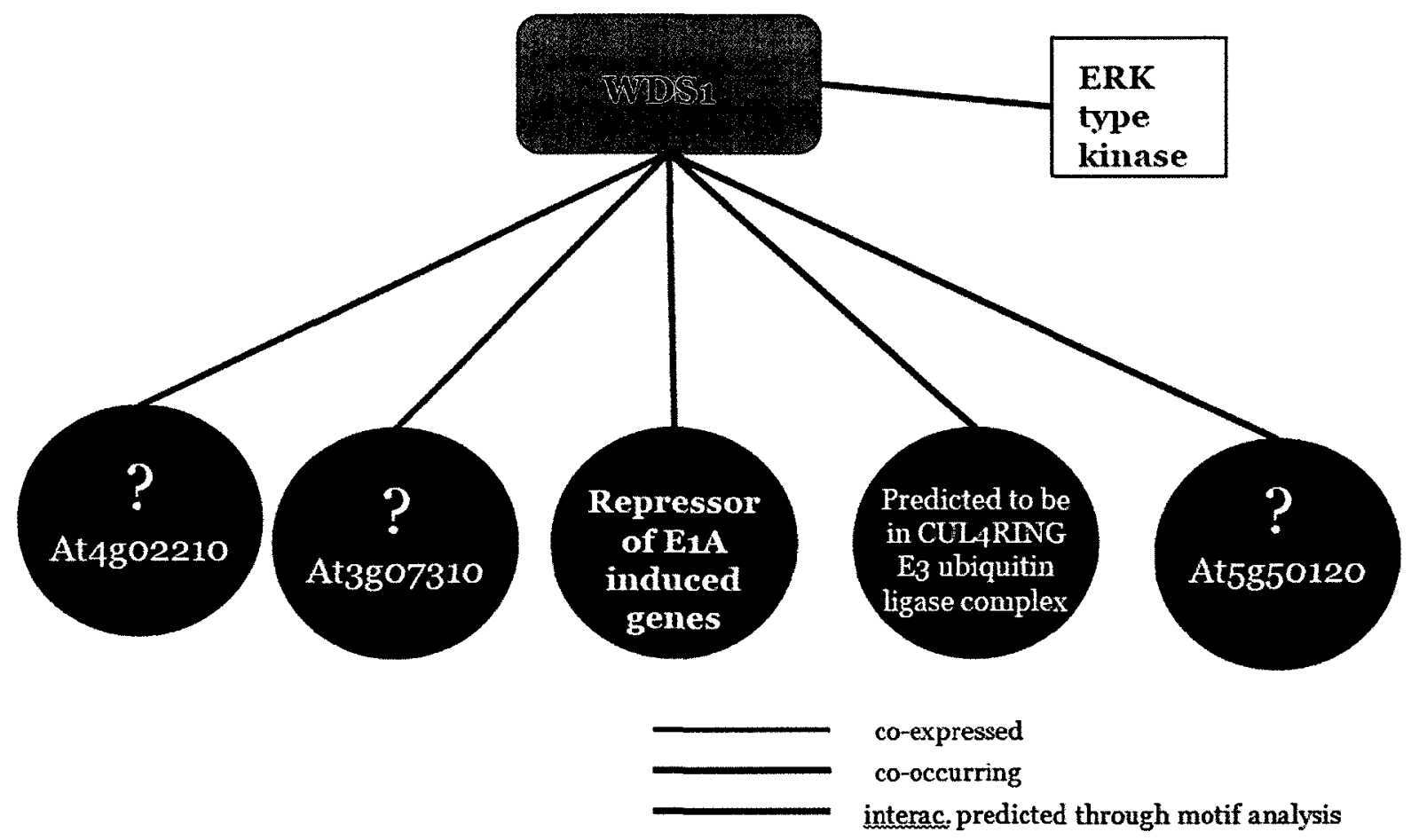

\begin{tabular}{|l|l|l|}
\hline Protein ID/Name & Mode of prediction & Function \\
\hline At4g02210 & co-expression & unknown \\
\hline At3g07310 & co-expression & unknown \\
\hline At2g04690 & co-expression & $\begin{array}{l}\text { cellular repressor of E1A- } \\
\text { stimulated genes (CREG) family }\end{array}$ \\
\hline At1g78070 & co-occurrence & $\begin{array}{l}\text { unknown, but predicted to have } \\
\text { ubiquitin ligase activity }\end{array}$ \\
\hline At5g50120 & co-occurrence & $\begin{array}{l}\text { unknown } \\
\text { WDnaling protein/may regulate }\end{array}$ \\
\hline N/A & motif analysis & \\
\hline
\end{tabular}

Figure 3.10: Proteins predicted to directly interact with WDS1

Atted-II 6.0 database (http://atted.jp/) was used to predict proteins that are co-expressed with WDS1; STRING 9.0 (http://string-db.org/) database was used to predict proteins that co-occur with WDS1; Motif analysis of WDS1 was performed using ScanSite (http://scansite.mit.edu/) database (Figure 3.2). 


\subsubsection{Analysis of WDS2 (At5g08560)}

WDS2 encodes a protein that is 589 amino acids long and has a molecular mass of 65830 Da. This protein is probably expressed in the nucleus (Figure 3.12), and while high stringency motif analysis did not return any results, medium stringency motif analysis predicted that WDS2 has 9 possible phosphoprylation sites (at S95, S182, A185, T193, T435, S494, S511, Y514, T55), two kinase docking sites (at S283 and V525) and a Src homology 2 (SH2) domain binding site at Y457 (Figure 3.11).

Overall expression of $W D S 2$ appears to be the highest right after germination and at mature silique stage, when the seeds are fully formed. During other developmental stages, expression levels seem relatively constant with slight fluctuations (Figure 3.13). At the tissue level, maturing and dry seeds exhibit highest WDS2 expression. In all other tissues, expression levels exhibit a slight increase as the tissue in question matures (Figure 3.14). Figure 3.15 illustrates the change in the expression of WDS2 in leaves at different stages of their maturity. Senescent leaves exhibited the highest level of expression (Figure 3.15).

Expression of WDS2 was up-regulated after exposure to all but two of the pathogens tested. The highest level of expression was induced after exposure to Cabbage leaf curl virus and the bacteria Pseudomonas syringae. The fungi Erysiphe cichoracearum and Erysiphe orontii both caused a slight down-regulation of WDS2 (Figure 3.16).

Exposure to FLG22, HrpZ and LPS all caused similar patterns of WDS2 expression in leaves. Following exposure to the elicitors, the expression of WDS2 was rapidly down-regulated and then rapidly up-regulated within the first four hours. The largest flux in gene expression was observed in leaves treated with FLG22, followed by HrpZ and then LPS (Figure 3.17). 
Unlike the expression of WDS1, the expression of WDS2 in cold stressed leaves did not display a clear pattern. In most samples, exposure to temperatures between 10 and $17{ }^{\circ} \mathrm{C}$ caused up-regulation of WDS2, while exposure to $8^{\circ} \mathrm{C}$ caused its down-regulation (Figure 3.18). WDS2 was also down-regulated in leaves of salt stressed plants, while up-regulated in the leaves of drought stressed ones (Figure 3.47 and 3.48).

WDS2 was predicted to interact with a protein (Atlg02890) that belongs to the AAA-type ATPase family of proteins, ACBP2 (At4g27780), which is an acyl-CoA binding protein, a plant homeo-domain (PHD) finger family protein (At5g16680) and a WD40 repeat containing protein (At1g49450) with unknown function. The latter protein co-occurs with WDS2, while all the others are co-expressed with it (Figure $3.19 \mathrm{a}$ and b). Motif analysis indicated that WDS2 may interact with an ERK-type kinase, variety of kinases involved in DNA damage sensing and repair, and 3-phosphoinositide-dependent protein kinase-1.

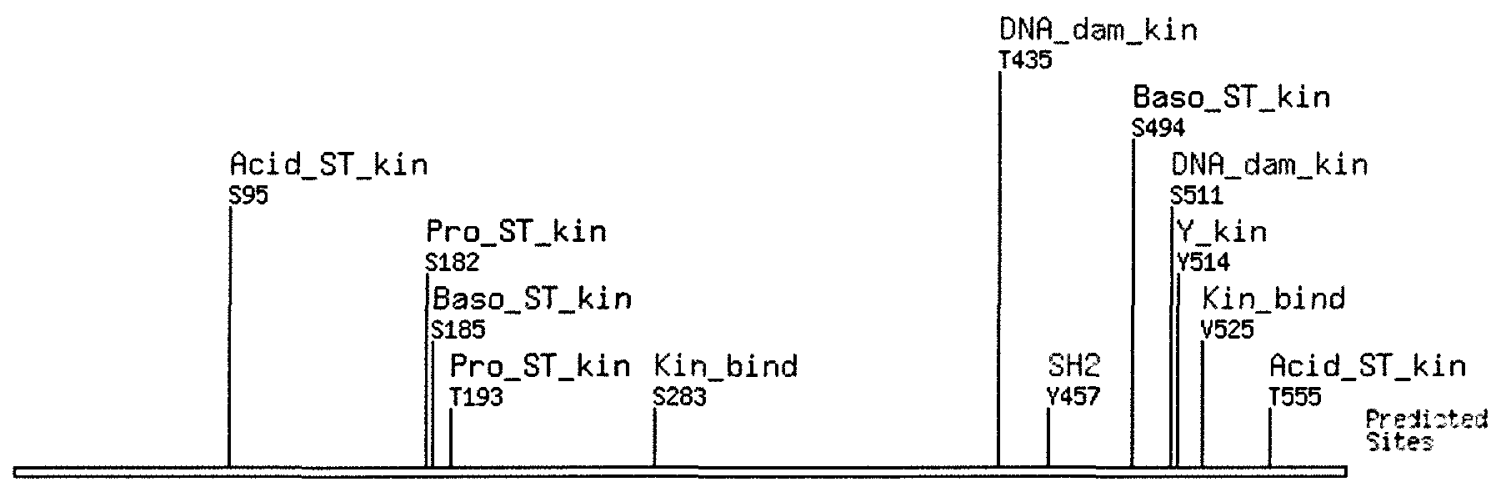

Figure 3.11: Medium stringency ScanSite Motif Scan output for WDS2 protein sequence indicating possible protein phosphorylation sites, kinase and Src homology 2 binding sites. (see Appendix 2 for database analysis). 


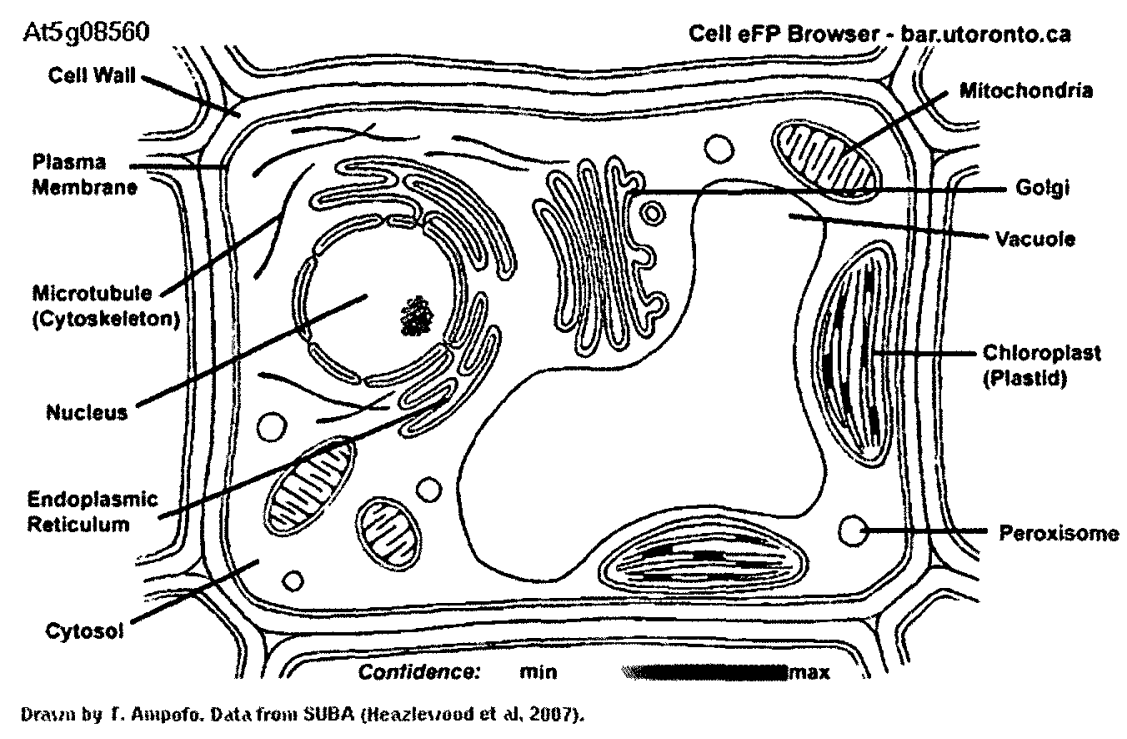

Figure 3.12: Electronic fluorescence pictographic representation of WDS2's subcellular localisation. Shaded area on image indicates site of expression and the yellow colour indicates low confidence. Subcellular localisation was predicted based on documented and predicted localizations in SUBA database (Heazelwood et.al., 2007).

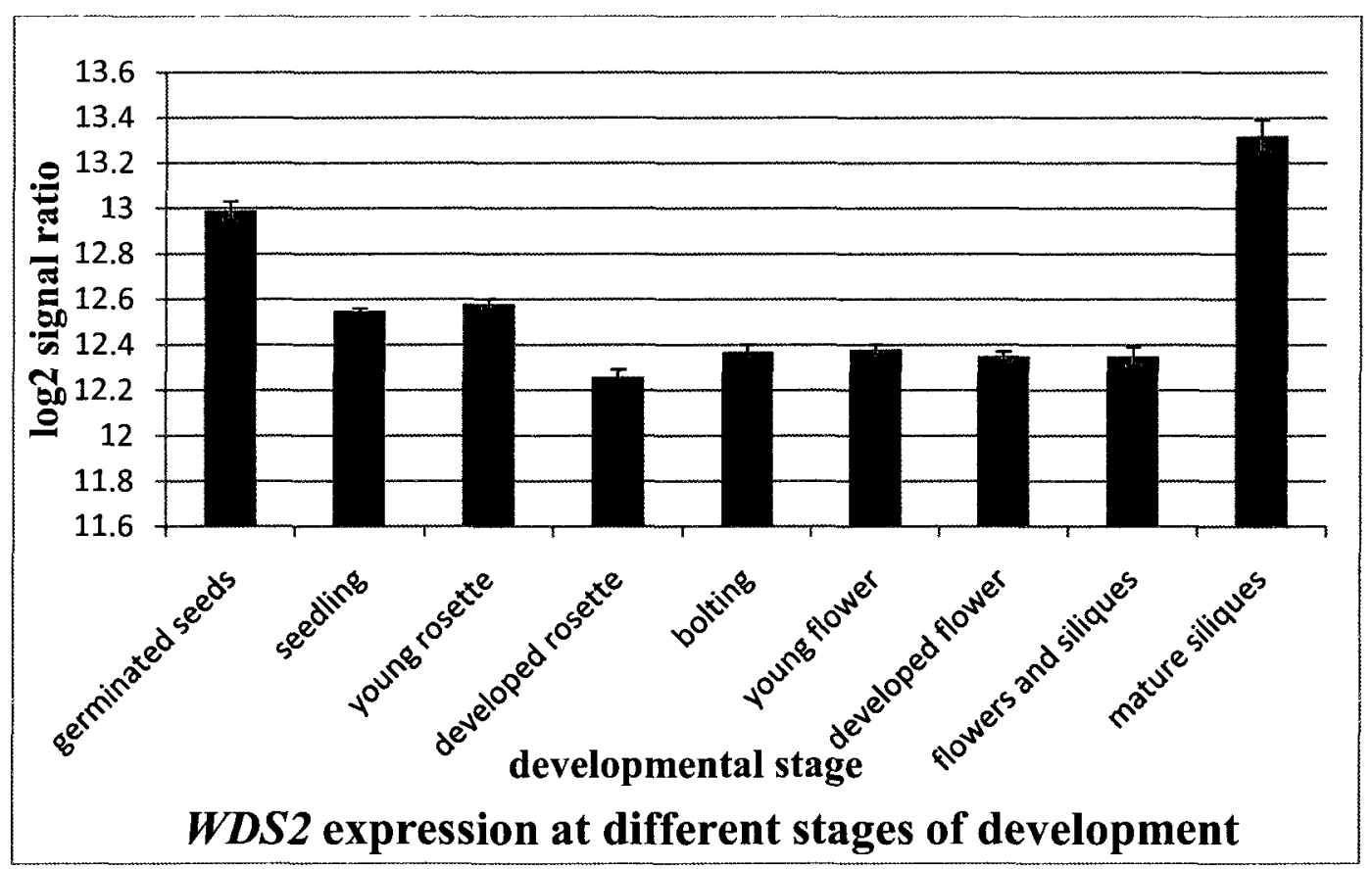

Figure 3.13: Overall expression of WDS2 across different stages of development. Each stage comprised up to $170022 \mathrm{k}$ arrays from different tissues of Arabidopsis thaliana from which the average expression values were calculated. Chart was generated using pre-existing microarray data gathered from Genevestigator database. 


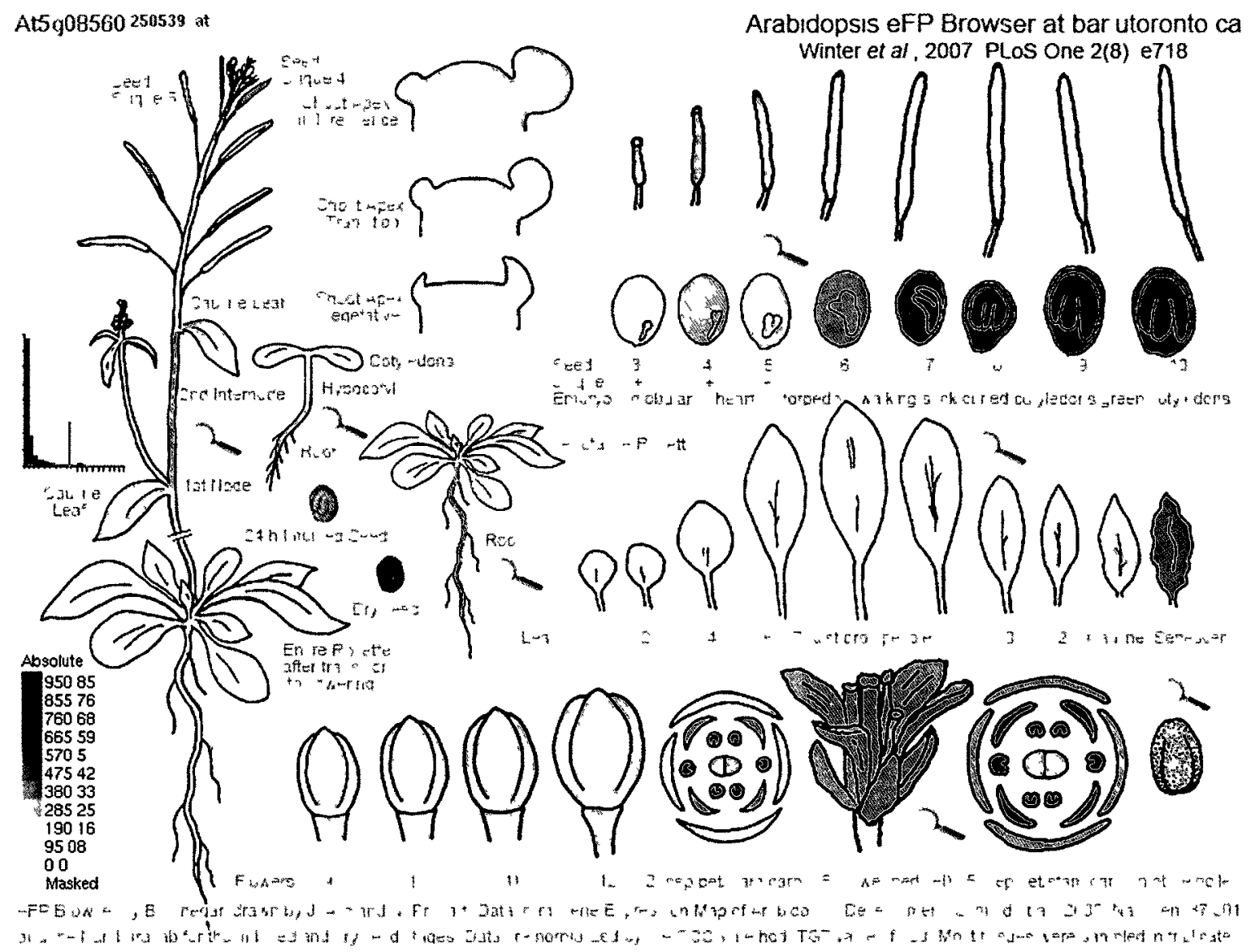

Figure 3.14: Electronic fluorescent pictograph of WDS2's expression pattern. Image illustrates expression levels in different tissues at different developmental stages. High levels of expression are indicated in red, intermediate levels in orange and low levels in yellow. Image was generated using Arabidopsis eFP browser which uses data from AtGenExpress Consortium data (Schmid et.al., 2005). 


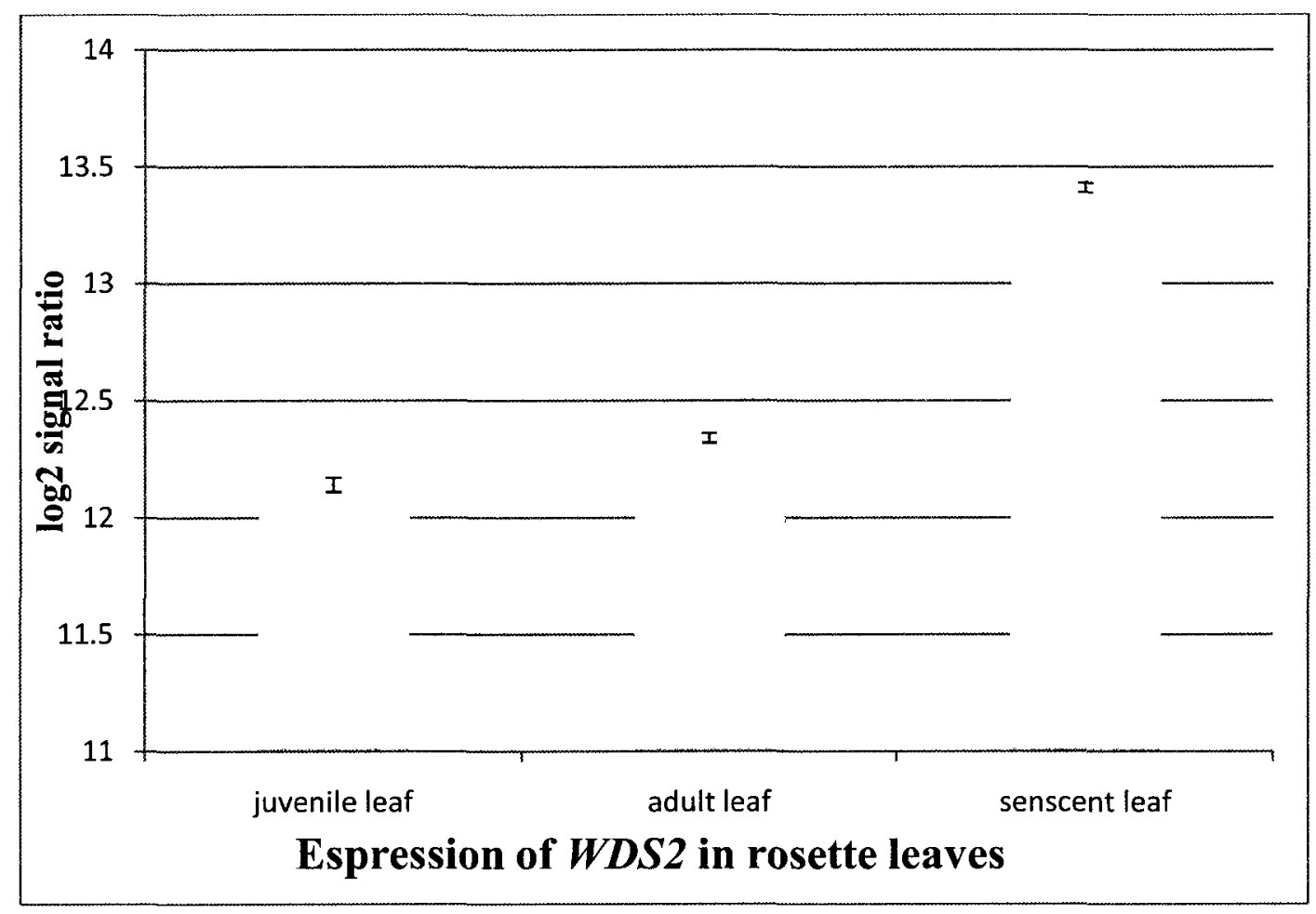

Figure 3.15: Expression levels of WDS2 in rosette leaves of Arabidopsis thaliana at different stages of their development. Graph was generated using pre-existing microarray data obtained from Genevestigator database.

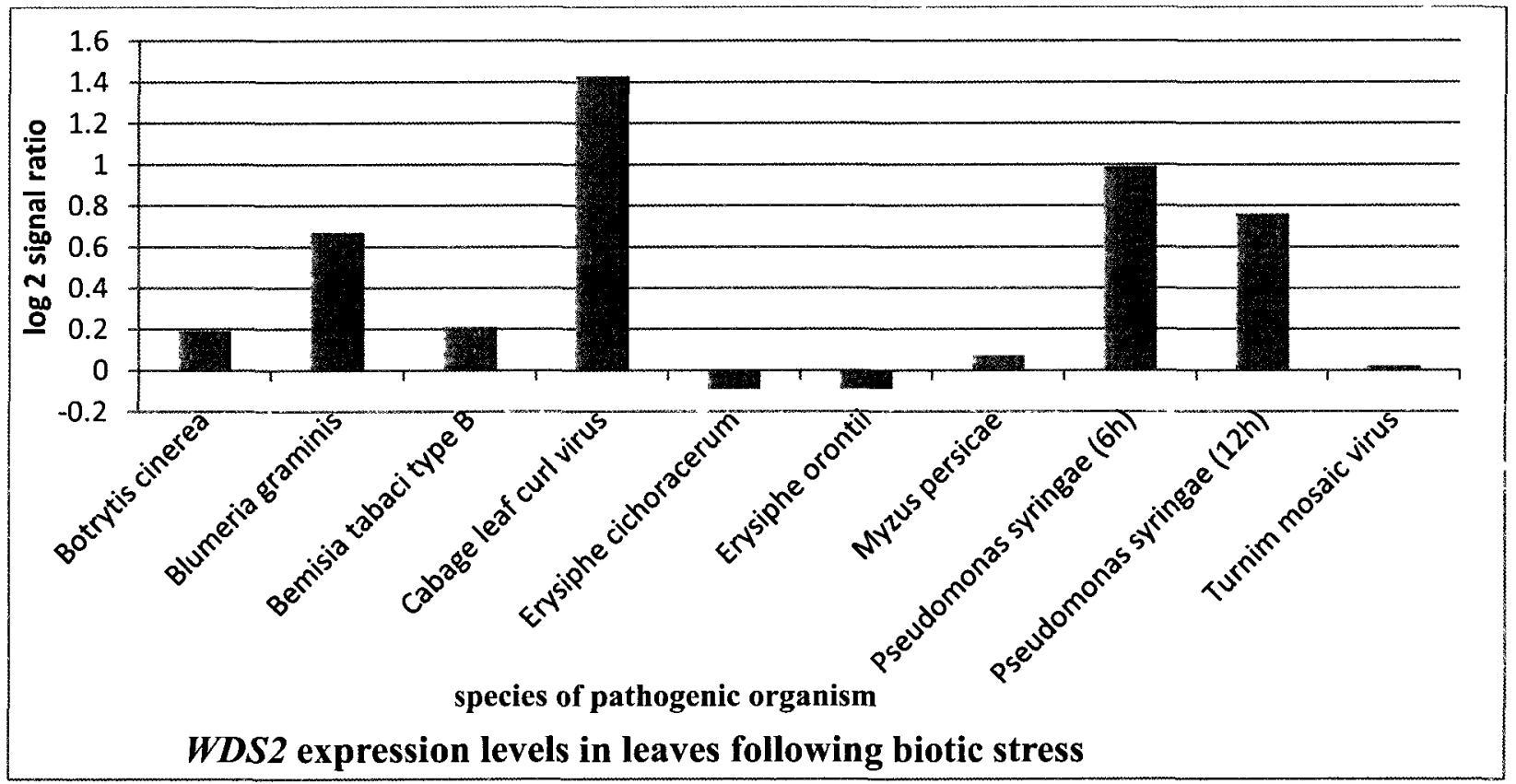

Figure 3.16: WDS2 expression levels in Arabidopsis thaliana leaves exposed to a variety of pathogenic organisms. Chart was generated using pre-existing microarray data obtained from Genevestigator database. Single repeat experiment; no error value provided. 


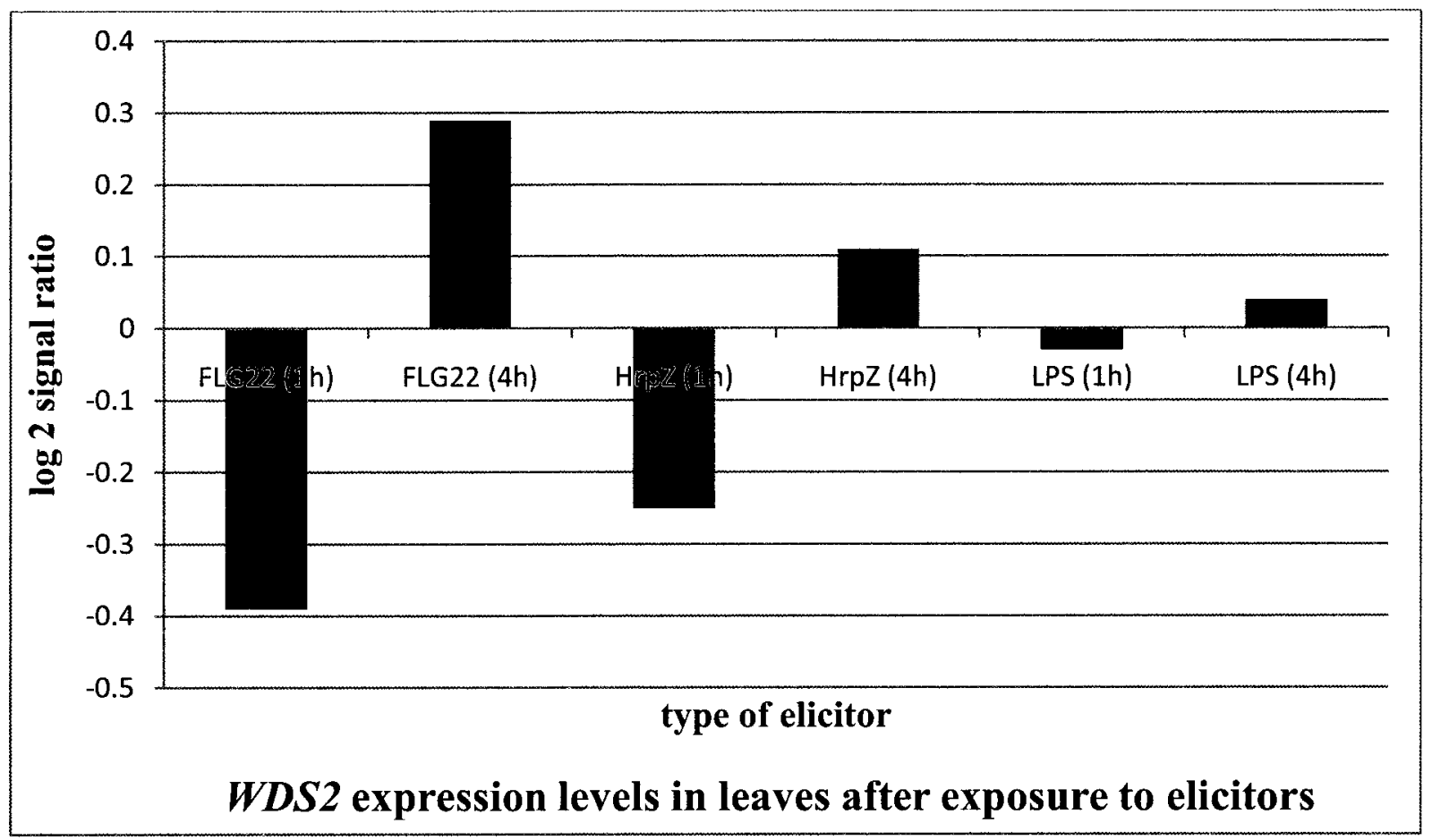

Figure 3.17: Effect of elicitors on WDS2 expression levels in Arabidopsis thaliana leaves. Chart was generated using pre-existing microarray data obtained from Genevestigator. Single repeat experiment; no error value provided.

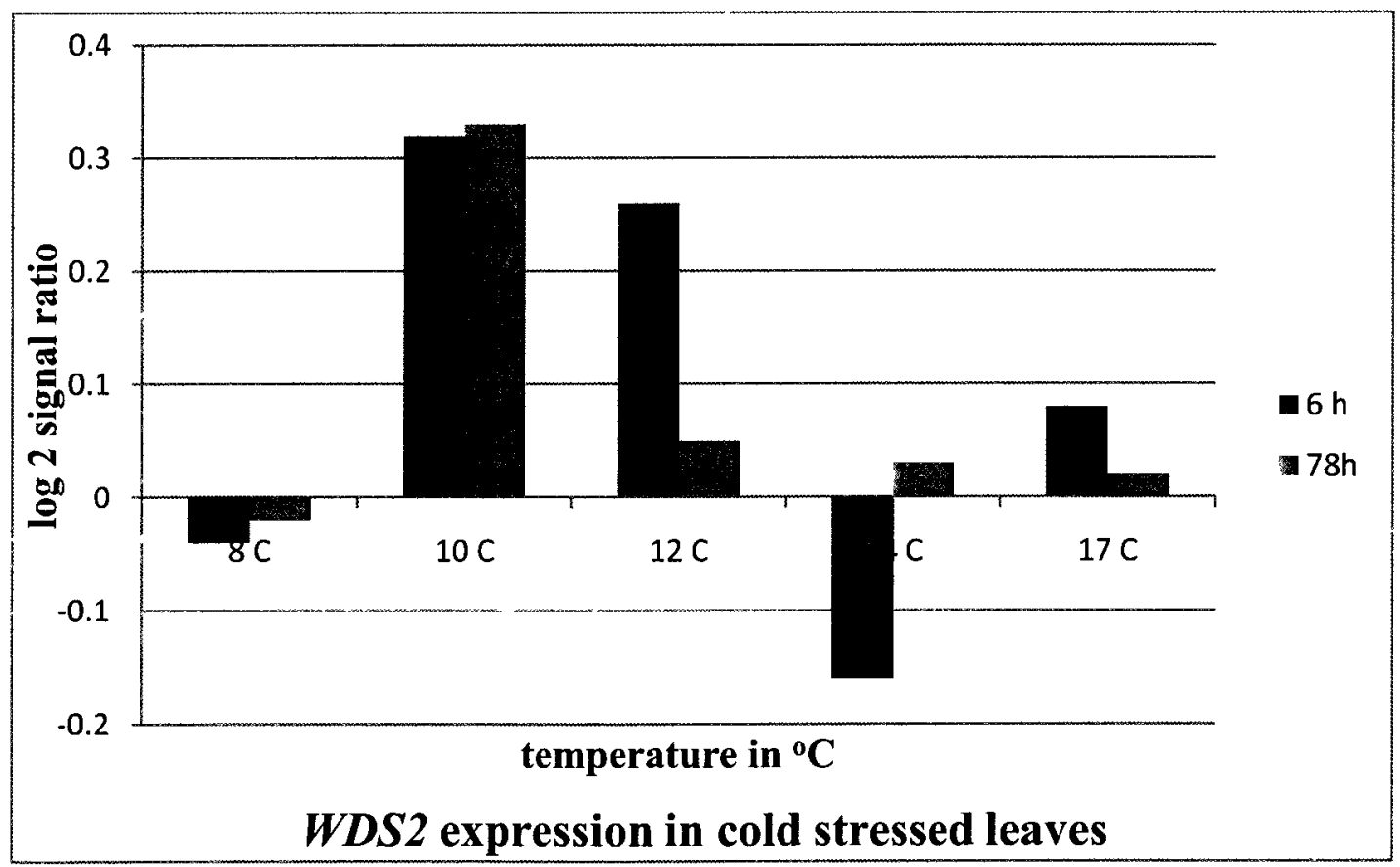

Figure 3.18: Effect of cold temperature on WDS2 expression in leaves of Arabidopsis thaliana. Chart was generated using pre-existing transcriptome data obtained from Genevestigator database. Single repeat experiment; no error value provided. 


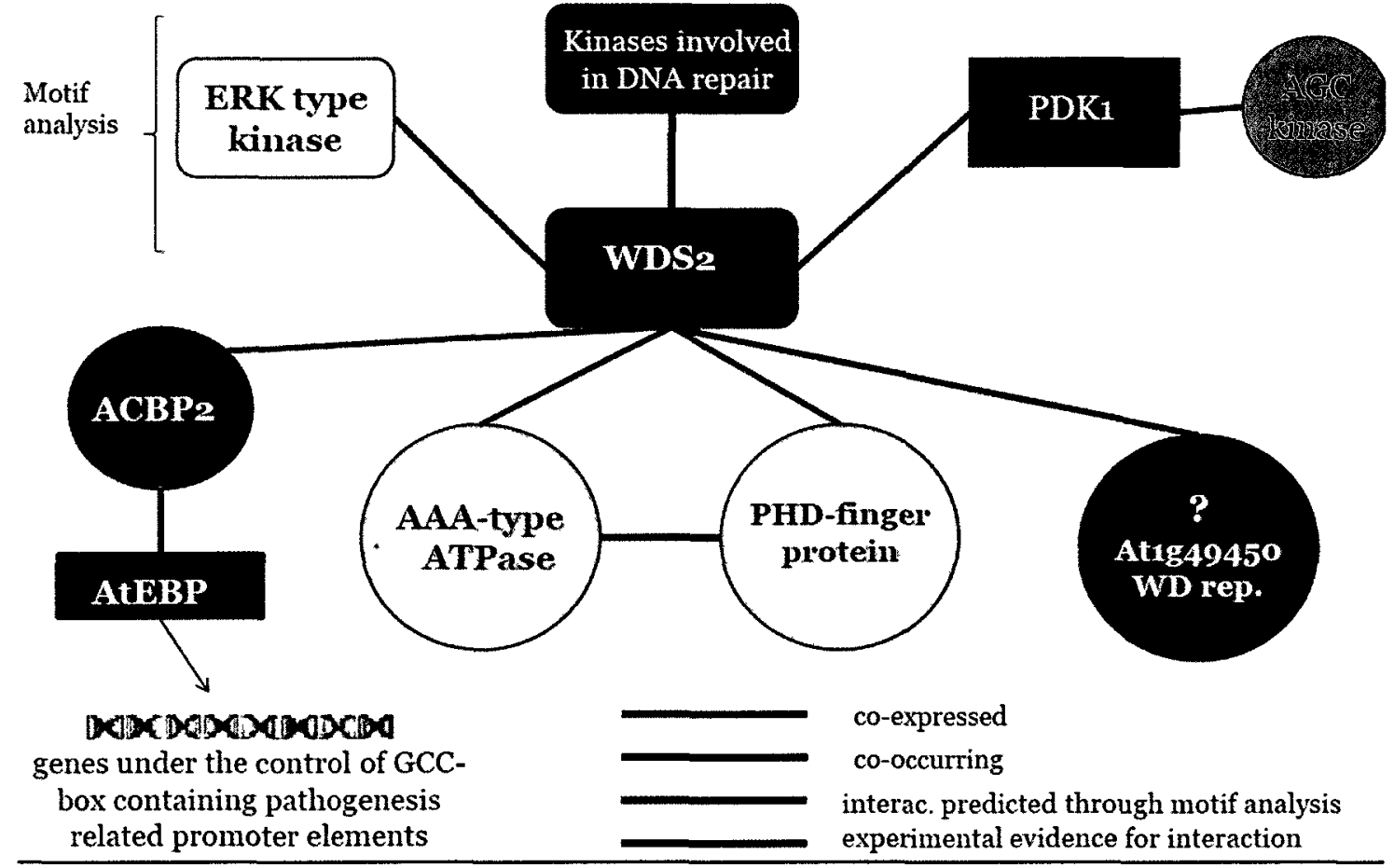

\begin{tabular}{|l|l|l|}
\hline ProteinID/Name & Mode of prediction & Function \\
\hline $\begin{array}{l}\text { At4g27780 } \\
\text { (Acyl CoA Binding Protein 2) }\end{array}$ & co-expression & $\begin{array}{l}\text { interacts with AtEBP } \\
\text { (ethylene responsive element } \\
\text { binding protein); transcription } \\
\text { regulation }\end{array}$ \\
\hline $\begin{array}{l}\text { At5g16680 } \\
\text { (PHD finger protein) }\end{array}$ & co-expression & $\begin{array}{l}\text { chromatin mediated } \\
\text { transcriptional regulation }\end{array}$ \\
\hline $\begin{array}{l}\text { At1g02890 } \\
\text { (AAA-type ATPase) }\end{array}$ & co-expression & $\begin{array}{l}\text { ATPase associated with } \\
\text { diverse cellular activities }\end{array}$ \\
\hline At1g49450 & co-occurance & $\begin{array}{l}\text { WD repeat protein with } \\
\text { unknown function }\end{array}$ \\
\hline $\begin{array}{l}\text { N/A } \\
\text { ERK-type kinase }\end{array}$ & motif analysis & $\begin{array}{l}\text { post translational } \\
\text { modification of WDS2 }\end{array}$ \\
\hline $\begin{array}{l}\text { N/A } \\
\text { DNA damage signaling/repair } \\
\text { kinases }\end{array}$ & motif analysis & $\begin{array}{l}\text { DNA damage signaling and } \\
\text { post translational modification } \\
\text { of WDS2 }\end{array}$ \\
\hline $\begin{array}{l}\text { N/A } \\
\text { (PDK1) }\end{array}$ & motif analysis & $\begin{array}{l}\text { gene silencing experiments } \\
\text { indicate PCD antagonistic } \\
\text { function }\end{array}$ \\
\hline
\end{tabular}

Figure 3.19: Possible functional partners of WDS2

Atted-II 6.0 database (http://atted.jp/) was used to predict proteins that are co-expressed with WDS2; STRING 9.0 (http://string-db.org/) database was used to predict proteins that co-occur with WDS2; Motif analysis of WDS2 was performed using ScanSite (http://scansite.mit.edu/) database (Figure 3.11). Experimental evidence found through literature searches. 


\subsubsection{Analysis of WDS3 (Atlg73720)}

WDS3 encodes a 511 amino acid long protein with a molecular mass of about $57724 \mathrm{Da}$ that is likely to be expressed in the nucleus of the cell (Figure 3.21). High stringency motif scan analysis using ScanSite analysis tool predicted a possible phosphorylation site at $Y 77$ and two possible Src Homology 3 (SH3) domain binding sites at P387 and P390 (Figure 3.20).

Overall expression level of WDS3 at different stages of the plant's development exhibits a double bottom chart pattern. A slight decline in the gene's expression can be observed following the germinated seed stage. This decline continues all the way to the young rosette stage. The expression level then slightly increases during the developed rosette stage and continues to increase into the bolting stage. After bolting, the expression level drops sharply and then gradually increases as the plant continues to mature. Expression appears to be highest at the germinated seed, bolting and mature silique stage (Figure 3.22).

At the tissue level, WDS3 expression seems to be highest in rapidly dividing tissues (i.e. shoot apex) and in imbibed seeds, while lowest in leaves and pollen (see Figure 3.23). By taking a closer look at the leaves it can be observed that juvenile leaves exhibit the highest level of WDS3 expression follwed by senescent leaves (Figure 3.24).

WDS3 expression appeared to be down-regulated after exposure to Pseudomonas syringae. Measurements taken 6 and 12 hours post-infection indicated a gradual decline in the gene's expression. Infection with Cabbage leaf curl virus and Turnip mosaic virus caused an increase in the expression of WDS3. Up-regulation following Cabbage leaf curl exposure was about fourfold higher than after Turnip mosaic infection. Exposure to the fungal pathogen, Erysiphe orontii, and the aphid Myzus persicae caused a slight up-regulation in the gene's 
expression, while exposure to the fungi Botrytis cinerea and Blumeria graminis and the arthropod Bemisia tabaci (type B) caused its down-regulation. (Figure 3.25)

All elicitors tested caused down-regulation of WDS3. One hour after exposure to FLG22 there was no change in WDS3 expression, however, 4 hours following infiltration downregulation was observed. WDS3 down-regulation also happened following HrpZ treatment. Expression levels were twofold lower 4 hours after treatment than they were after $1 \mathrm{~h}$. LPS treatment caused an initial increase in the expression of the gene but 4 hours after exposure, the levels were lower than in the control specimen (Figure 3.26).

While both drought and salt stress caused up-regulation of WDS3 in leaves (Figure 3. 47 and 3.48), no clear trend in the gene's expression pattern was observed after cold treatment (Figure 3.27).

WDS3 was shown to directly interact with 40 S ribosomal protein S14, replication factor C, a WD40 repeat protein (At2g19430) with unknown function and a RED repeat containing protein AtSMU2 (At2g26460) (Figure 3.28 a and b). Motif analysis indicates that WDS3 may also interact with a tyrosine kinase and/or proteins that contain SH3 domains.

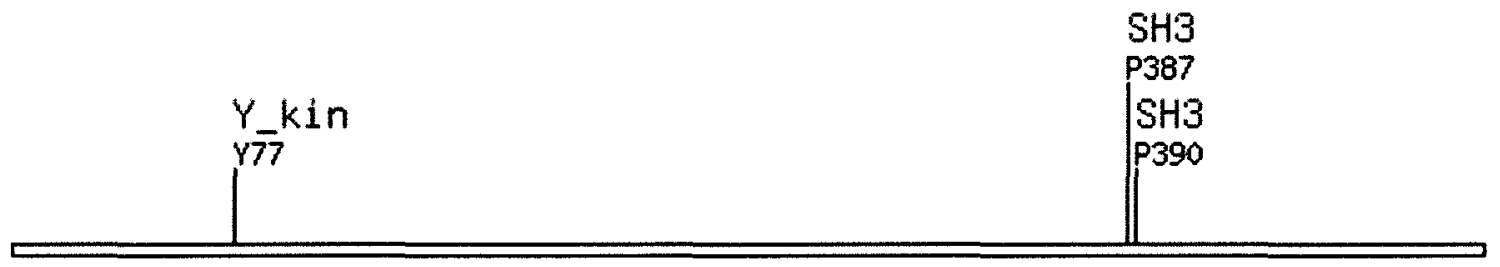

Figure 3.20 : High stringency ScanSite Motif Scan output for WDS3 protein sequence indicating a possible phosphoprylation site at $\mathrm{Y} 77$ and two SH3 binding sites at P387 and P390. (see Appendix 2 for database analysis). 


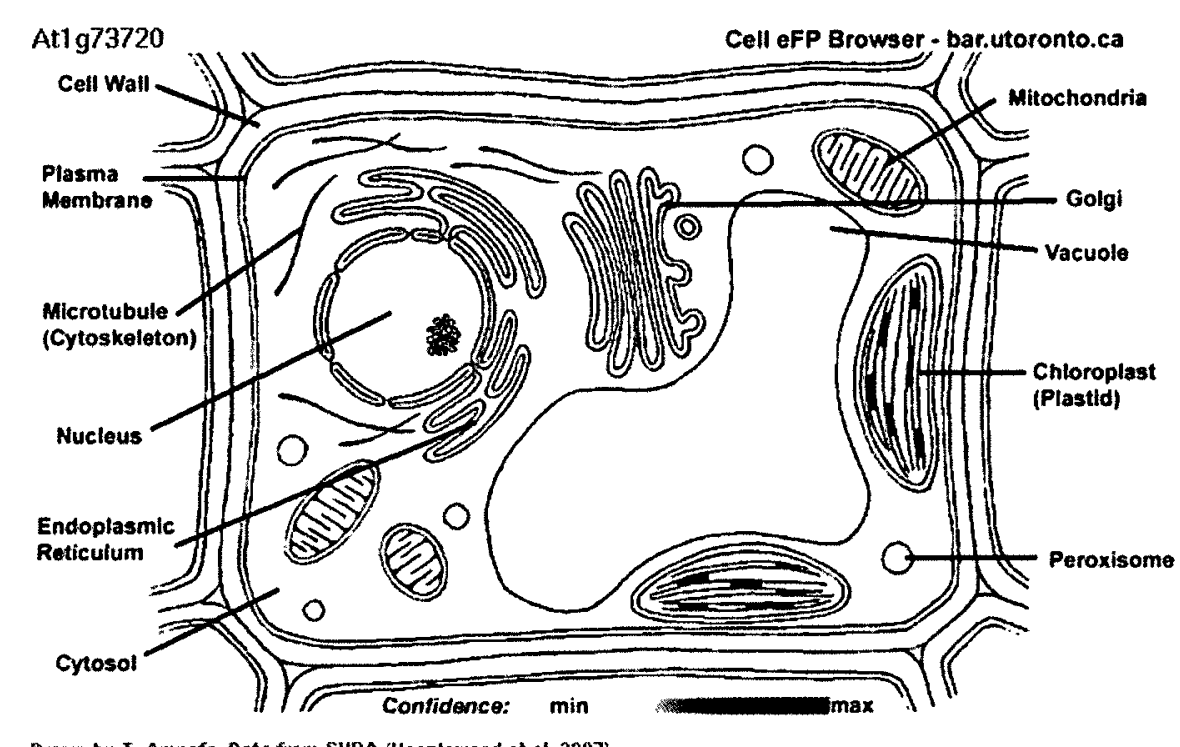

Dravm by $T$. Ampofo. Data from SUBA (Heazlevood et ad, 2007).

Figure 3.21.: Electronic fluorescence pictographic representation of WDS3's subcellular localisation. Shaded area on image indicates site of expression and the yellow colour indicates low confidence. Subcellular localisation was predicted based on documented and predicted localizations in SUBA database (Heazelwood et.al., 2007).

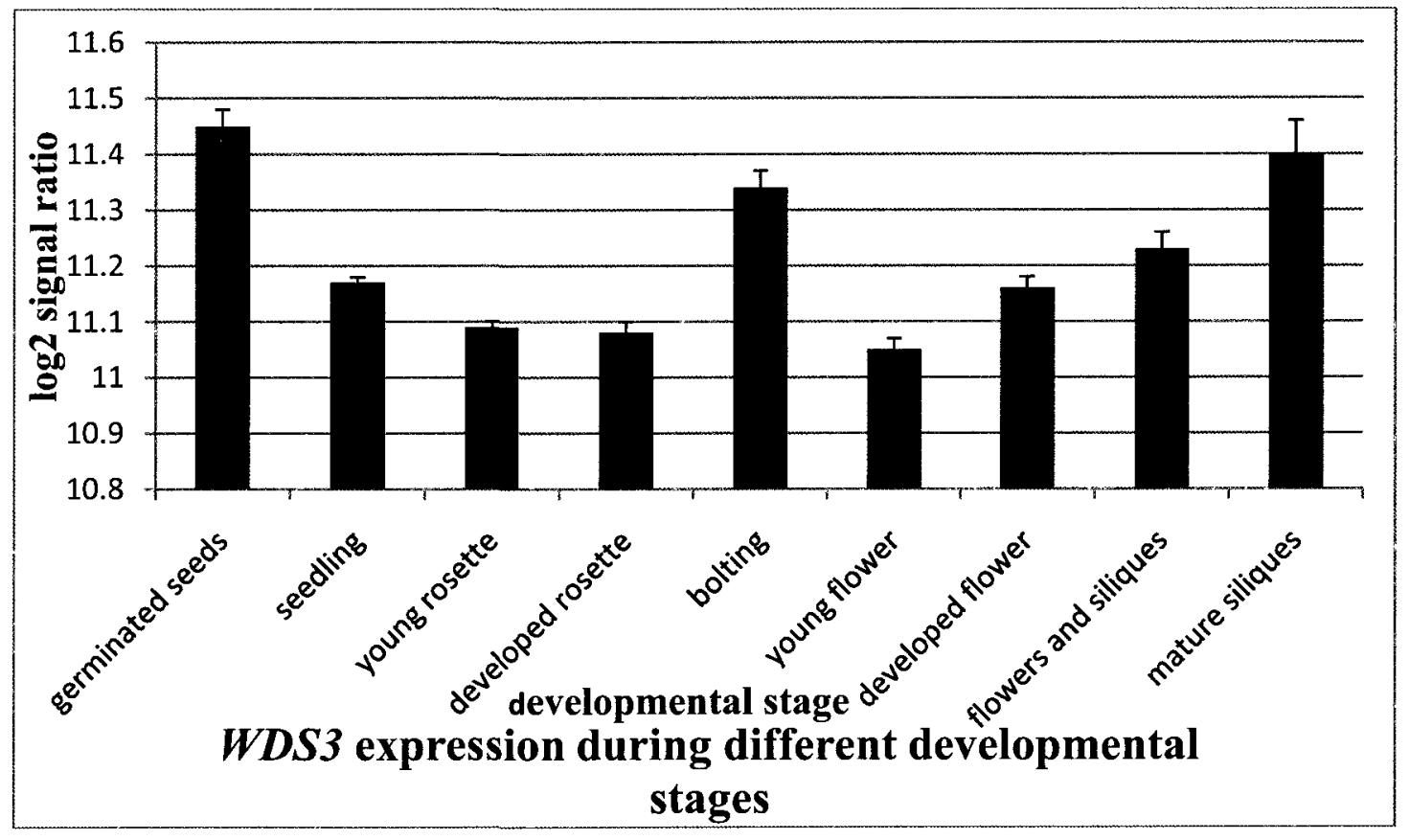

Figure 3.22.: Overall expression of WDS3 across different stages of development.

Each stage comprised up to $170322 \mathrm{k}$ arrays from different tissues of Arabidopsis thaliana from which the average expression values were calculated. Image was generated using pre-existing microarray data obtained from Genevestigator database. 


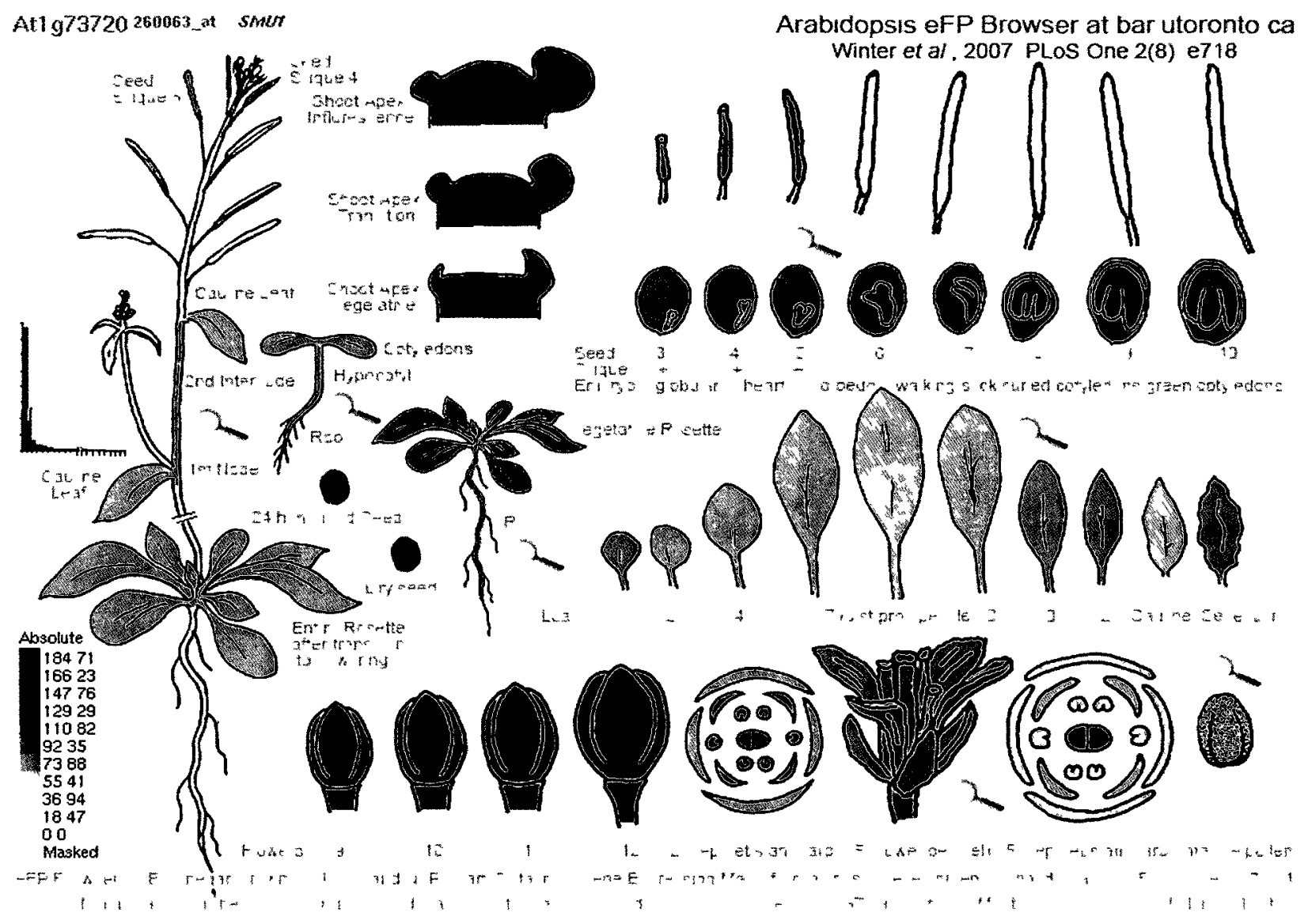

Figure 3.23.: Electronic fluorescent pictograph of WDS3's expression pattern. Image illustrates expression levels in different tissues at different developmental stages. High levels of expression are indicated in red, intermediate levels in orange and low levels in yellow. Image was generated using Arabidopsis eFP browser which uses data from AtGenExpress Consortium data (Schmid et.al., 2005). 


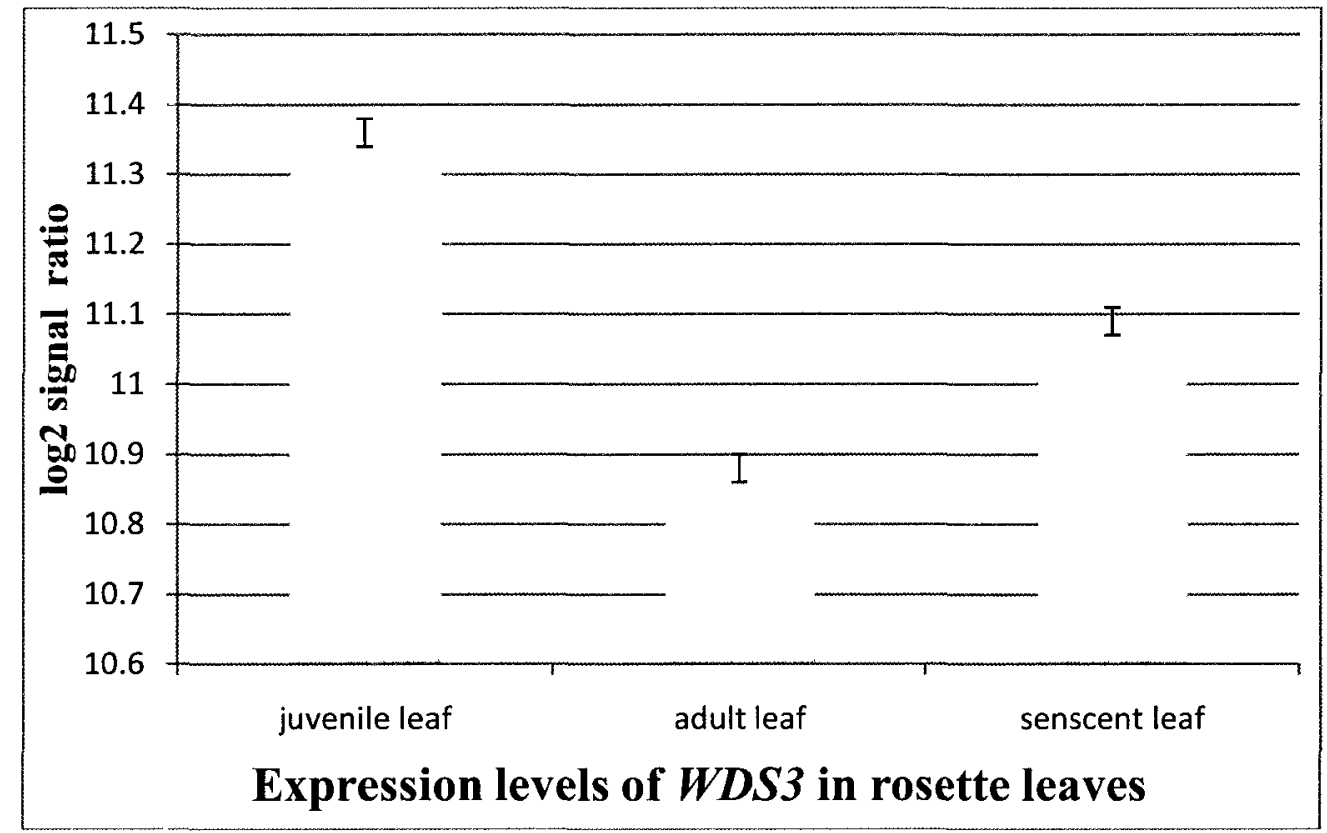

Figure 3.24.: Expression levels of WDS3 in rosette leaves of Arabidopsis thaliana at different stages of their development. Chart was generated using pre-existing microarray data obtained from Genevestigator database.

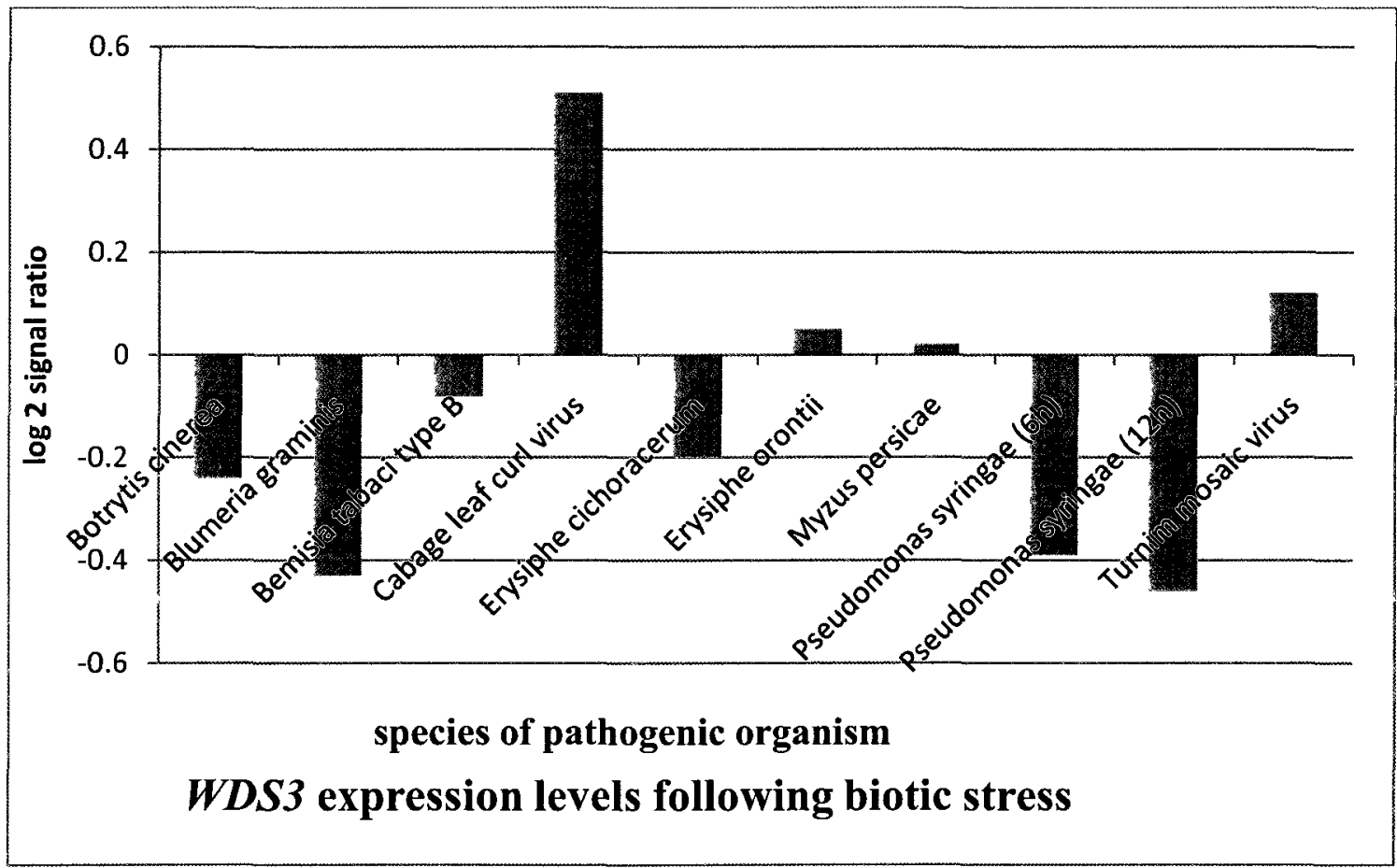

Figure 3.25.: WDS3 expression levels in Arabidopsis thaliana leaves exposed to a variety of pathogenic organisms. Chart was generated using pre-existing microarray data obtained from Genevestigator database. Single repeat experiment; no error value provided. 


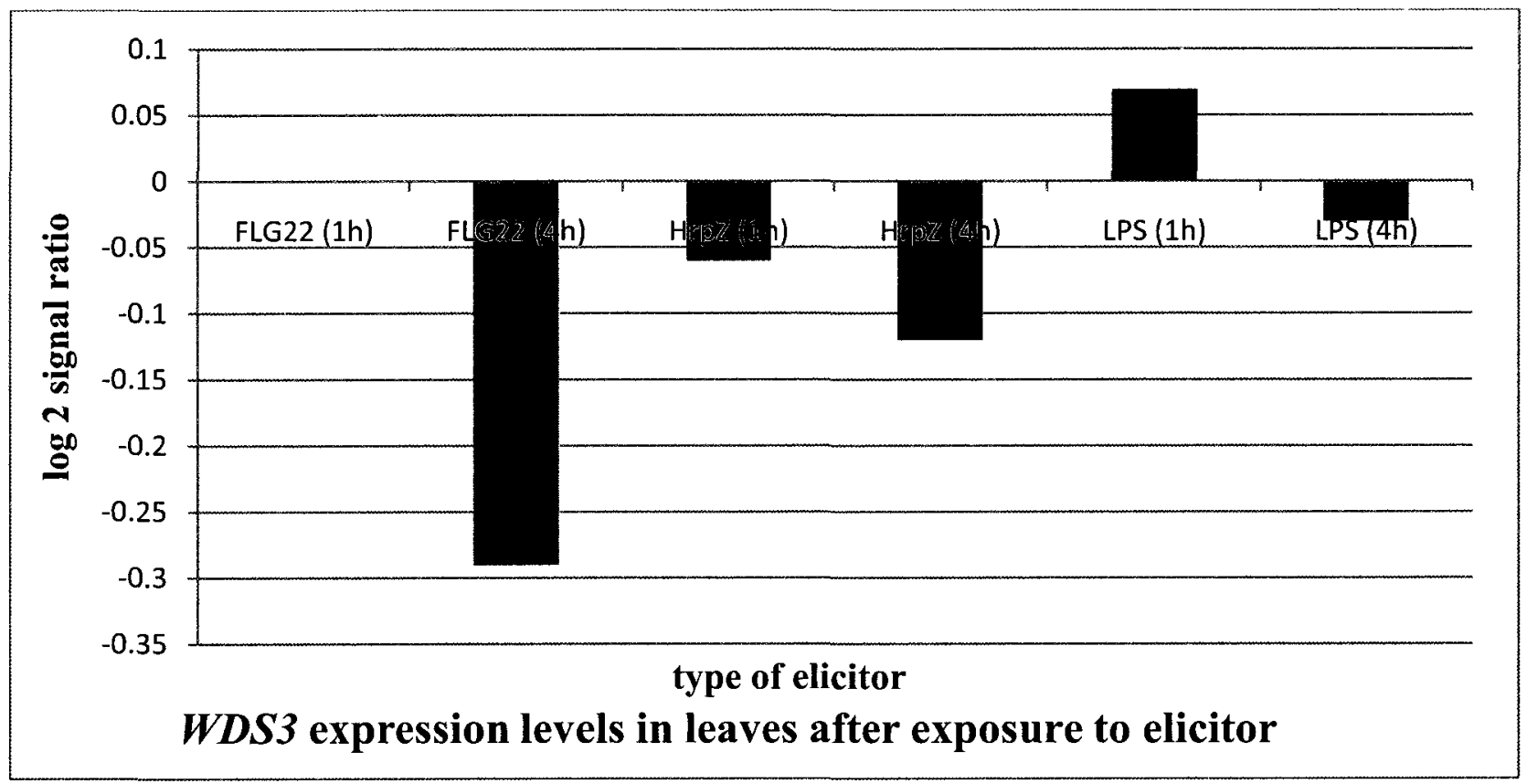

Figure 3.26: Effect of elicitors on WDS3 expression levels in leaves of Arabidopsis thaliana. Chart was generated using pre-existing microarray data obtained from Genevestigator database. Single repeat experiment; no error value provided.

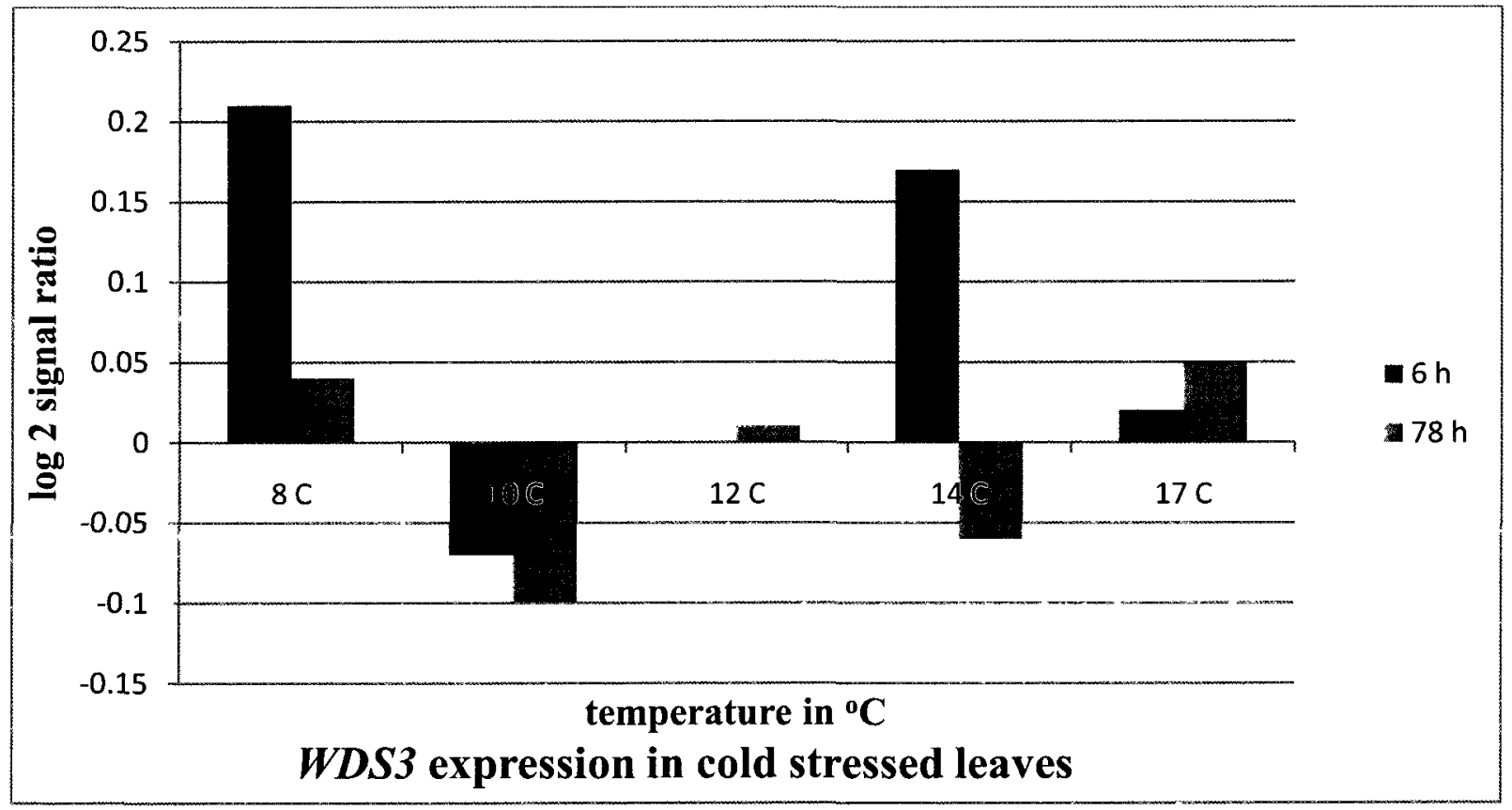

Figure 3.27: Effect of cold temperature on WDS3 expression in leaves of Arabidopsis thaliana. Figure was generated using pre-existing transcriptome data obtained from Genevestigator database. Single repeat experiment; no error value provided. 


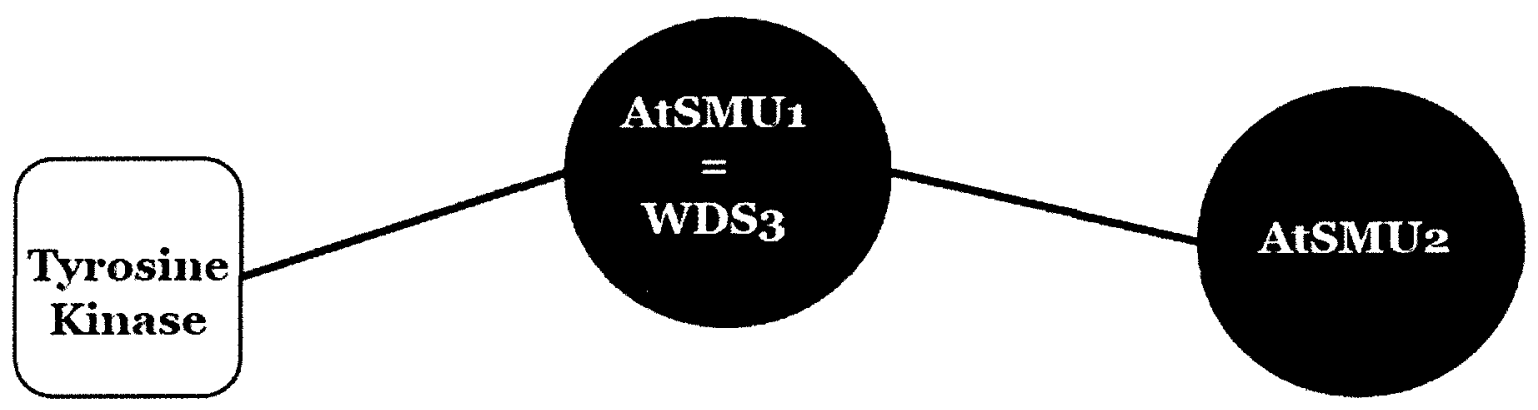

\begin{tabular}{|l|l|l|}
\hline Protein ID/Name & Mode of prediction & Function \\
\hline $\begin{array}{l}\text { At2g26460 } \\
\text { AtSMU2 }\end{array}$ & experimental evidence & $\begin{array}{l}\text { role in pre-mRNA splicing } \\
\text { (Chung } \text { et.al., 2009). }\end{array}$ \\
\hline $\begin{array}{l}\text { N/A } \\
\text { Tyrosine kinase }\end{array}$ & motif analysis & $\begin{array}{l}\text { post-translational modification } \\
\text { of WDS3 }\end{array}$ \\
\hline
\end{tabular}

Figure 3.28: Possible functional partners of WDS3

Motif analysis of WDS3 was performed using ScanSite (http://scansite.mit.edu/) database (Figure 3.20). Experimental evidence found through literature searches. 


\subsubsection{Analysis of WDS4 (At5g27570)}

WDS4 encodes a 411 amino acid long protein with a molecular mass of about $45556 \mathrm{Da}$. The protein was predicted to be expressed in the cell wall and/or the nucleus (Figure 3.30), however transient expression of GFP-WDS2 in tobacco leaves indicated that WDS2 is located in the nucleus (Al-Shammari, 2009). While high stringency motif scans did not return any results, 9 possible phosphorylation sites, a kinase and a SH2 domain binding sites were identified with medium stringency scan (Figure 3.29).

Slight up-and-down fluctuations can be observed in WDS4 expression during different developmental stages, but overall, as the plant matures, a decreasing trend can be observed (Figure 3.31). Mature pollen and the seeds right before they become fully mature exhibit the highest expression levels, while all other tissues express only low levels of the gene (Figure 3.32). WDS4 expression appears highest in adult leaves and slightly lower in juvenile leaves. Senescent leaves express over twofold lower levels than adult or juvenile ones (Figure 3.33).

With the exception of Cabbage leaf curl virus, and the fungi Erysiphe cichoracearum and Erysiphe orontii, exposure to all pathogens resulted in up-regulation of WDS4. The highest gene expression was induced following exposure to the bacteria Pseudomonas syringae (Figure 3.34). Exposure to all the elicitors tested resulted in up-regulation of WDS4. Both FLG22 and HrpZ caused an immediate up-regulation of WDS4, but measurements taken 4 hours after exposure indicated that expression levels started to decline. Exposure to LPS caused an initial down-regulation but measurements taken 4 hours after initial exposure indicated an upregulation that resulted in expression levels that surpassed levels seen in the control samples (Figure 3.35). 
Exposure to cold temperatures mostly caused up-regulation of WDS4, but no clear trend in expression patterns was observed (Figure 3.36). While salt stress caused no change in WDS4 expression, drought stress induced its slight up-regulation (Figure 3.47 and 3.48).

WDS4 was experimentally shown to interact with a protein known as HOBBIT (HBT) (Perez-Perez et.al., 2008). The protein was also shown to co-occur with four other WD40 repeat family of proteins (At5g60940, At4g34380, At1g49450 and At3g50390), the proteins Root Initiation Defective 3 (RID3) and Embryo Defective 2757 (EMB2757) (Figure 3.37). While coexpression data was not available for WDS4, motif analysis indicated that WDS4 may alkso interact with variety of kinases, many of which are involved in DNA damage signalling/repair (Figure 3.29).

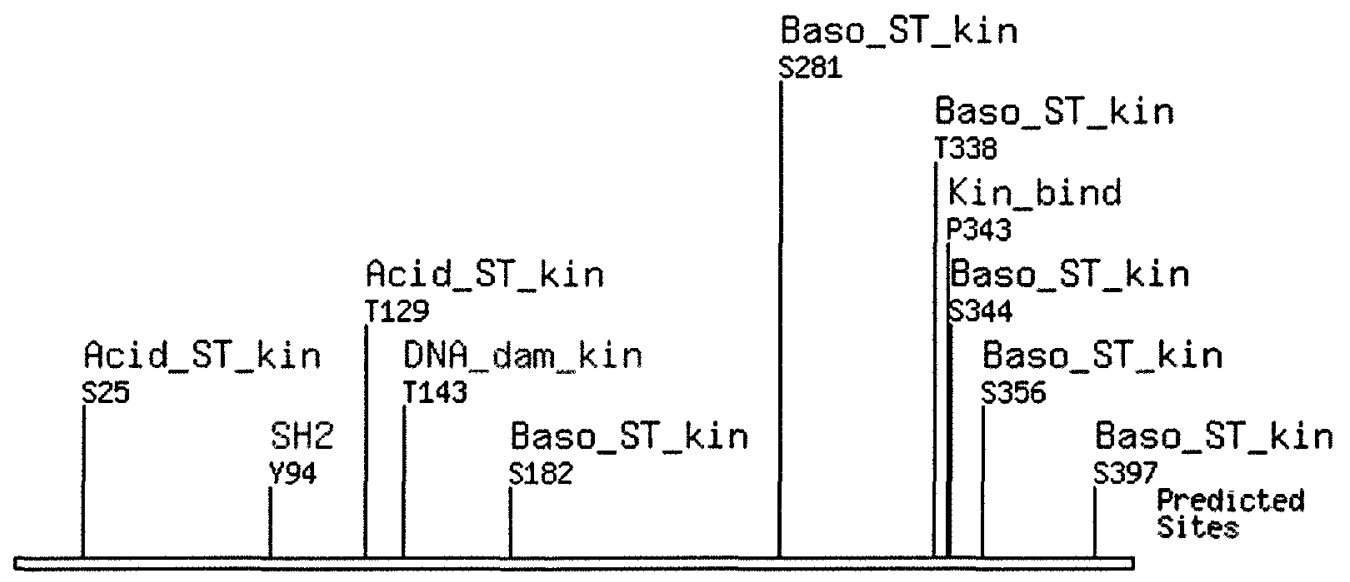

Figure 3.29: Medium stringency ScanSite Motif Scan output for WDS4 protein sequence indicating possible protein phosphorylation, kinase and SH2 binding sites. (see Appendix 2 for database analysis). 


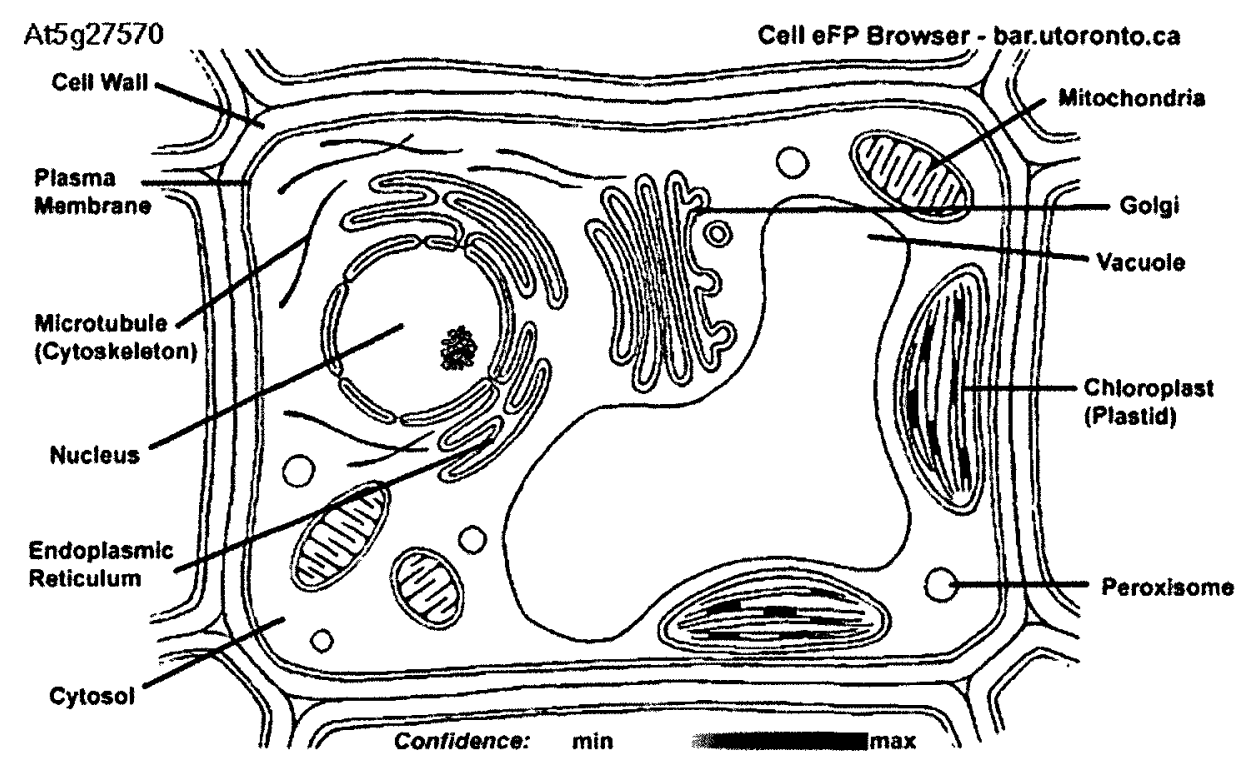

Drawn by T. Ampofo. Data from SUBA (Heazlewood et al, 2007).

Figure 3.30: Electronic fluorescence pictographic representation of WDS4's subcellular localisation. Shaded areas on image indicate predicted site of expression. Yellow colour indicates low confidence. Subcellular localisation was predicted based on documented and predicted localizations in SUBA database (Heazelwood et.al., 2007).

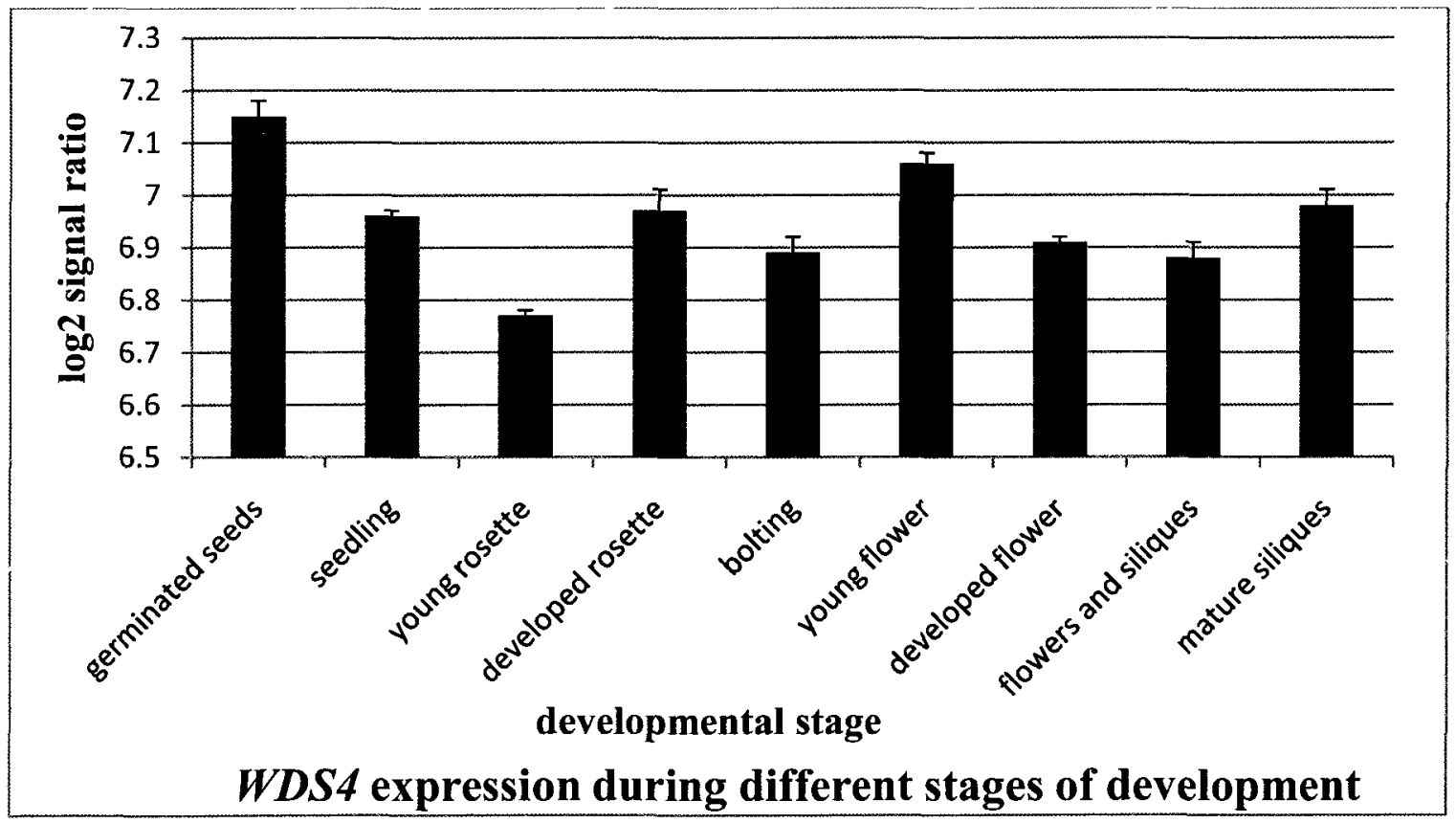

Figure 3.31: Overall expression of WDS4 across different stages of development. Each stage comprised up to $170022 \mathrm{k}$ arrays from different tissues of Arabidopsis thaliana from which the average expression values were calculated. Image was generated using pre-existing microarray data gathered from Genevestigator database. 


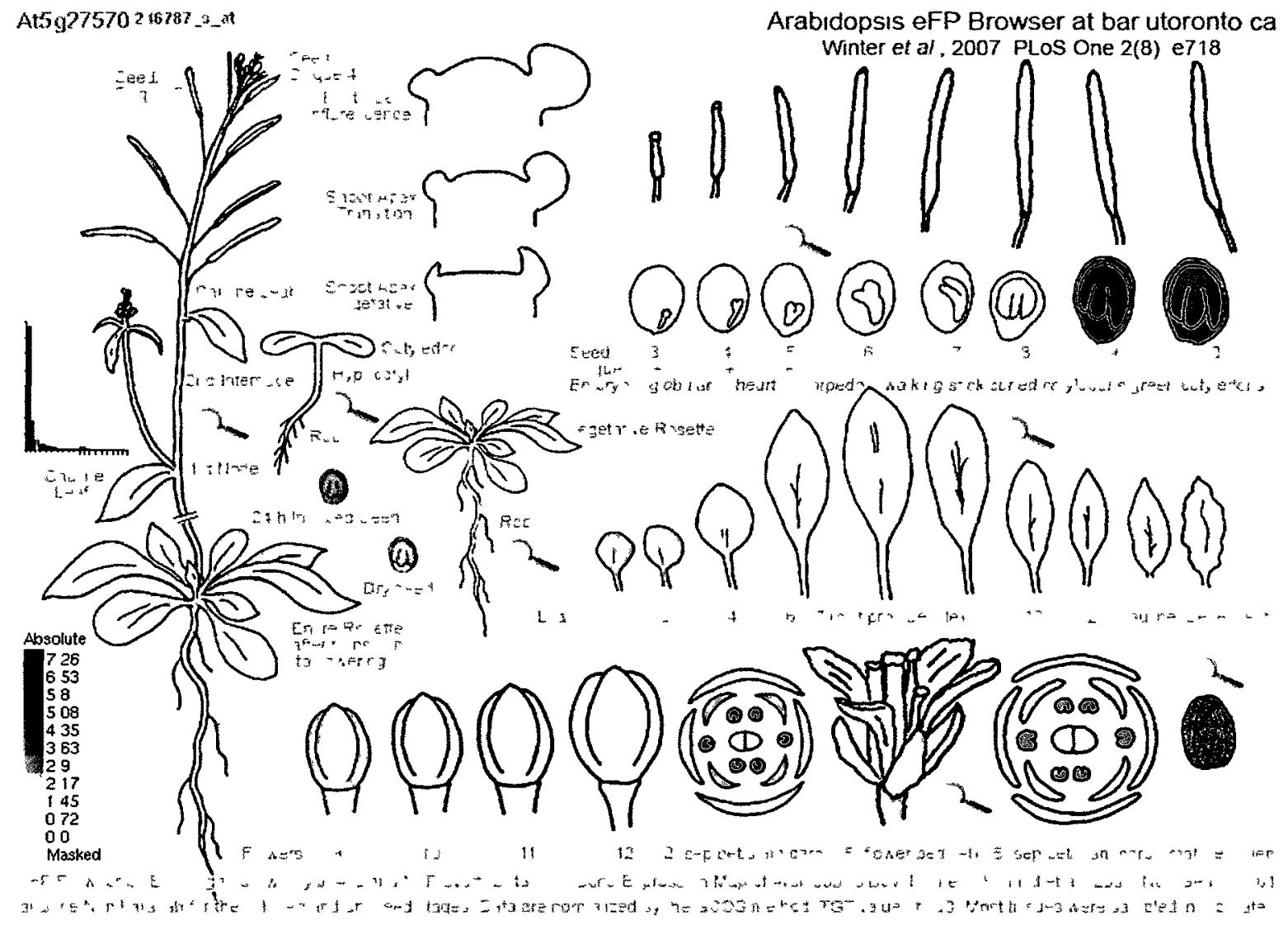

Figure 3.32: Electronic fluorescent pictograph of WDS4's expression pattern. Image illustrates expression levels in different tissues at different developmental stages. High levels of expression are indicated in red, intermediate levels in orange and low levels in yellow. Image was generated using Arabidopsis eFP browser which uses data from AtGenExpress Consortium data (Schmid et.al., 2005). 


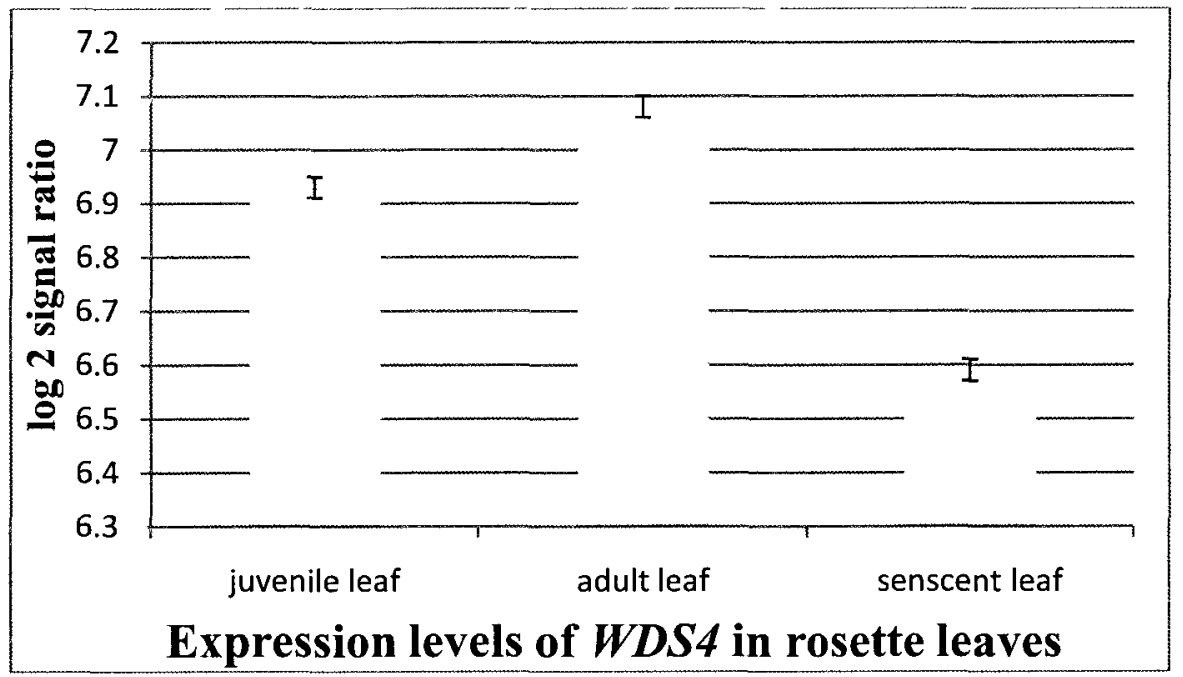

Figure 3.33.: Expression levels of WDS4 in Arabidopsis thaliana's rosette leaves at different stages of their development. Chart was generated using pre-existing microarray data obtained from Genevestigator database.

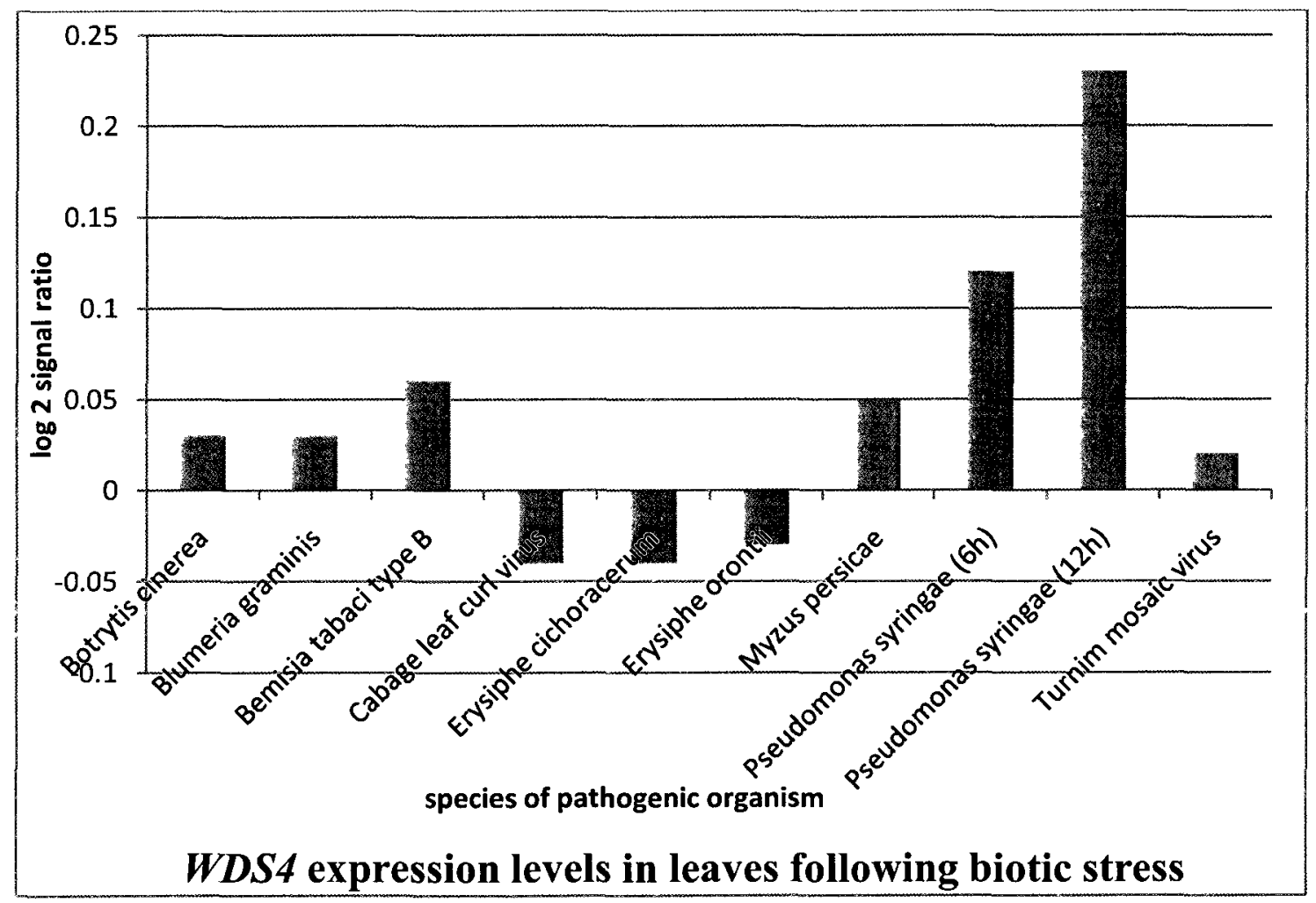

Figure 3.34: WDS4 expression levels in Arabidopsis thaliana leaves exposed to a variety of pathogenic organisms. Chart was generated using pre-existing microarray data obtained from Genevestigator database. Single repeat experiment; no error value provided. 


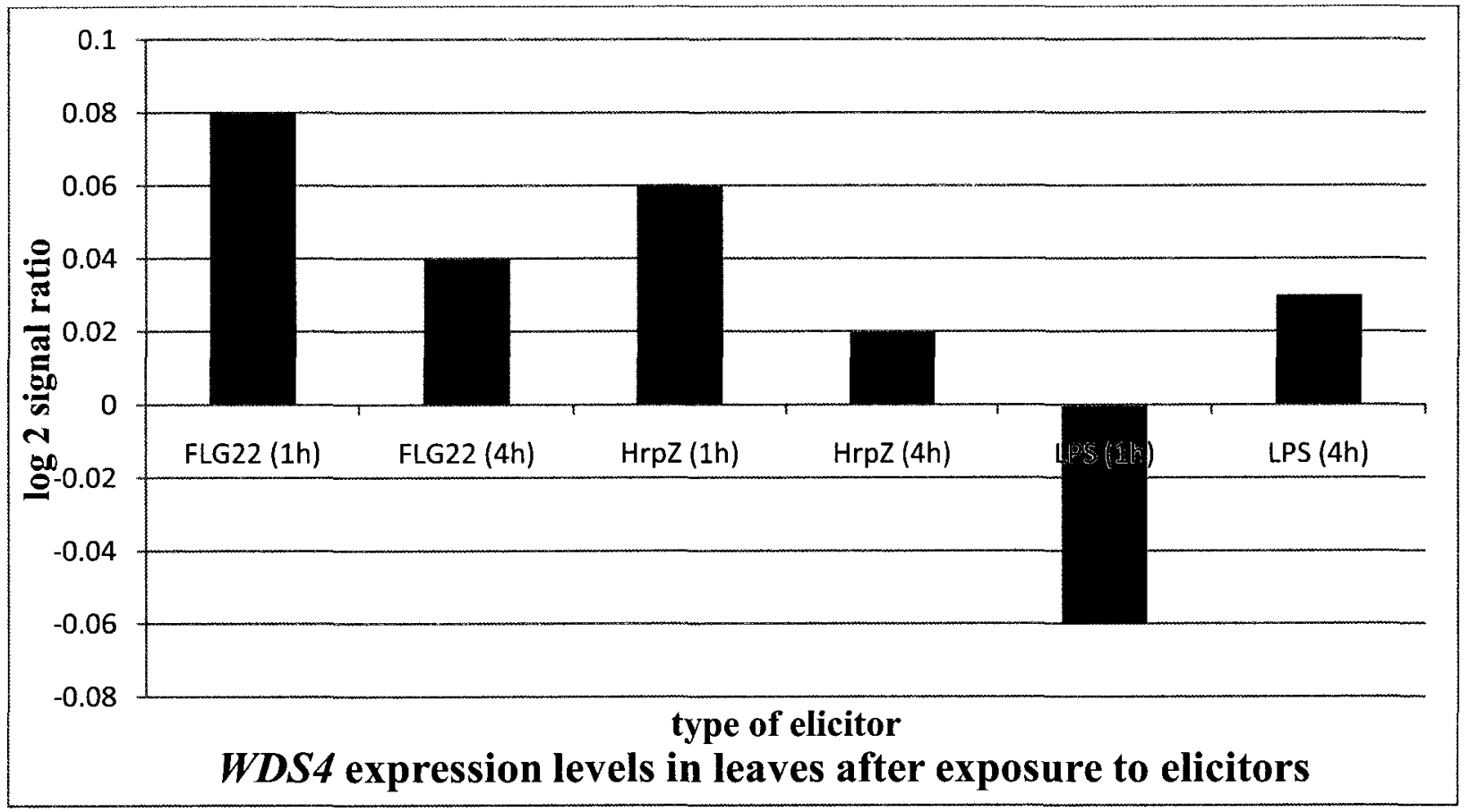

Figure 3.35.: Effect of elicitors on WDS4 expression levels in leaves of Arabidopsis thaliana. Chart was generated using pre-existing microarray data obtained from Genevestigator database. Single repeat experiment; no error value provided.

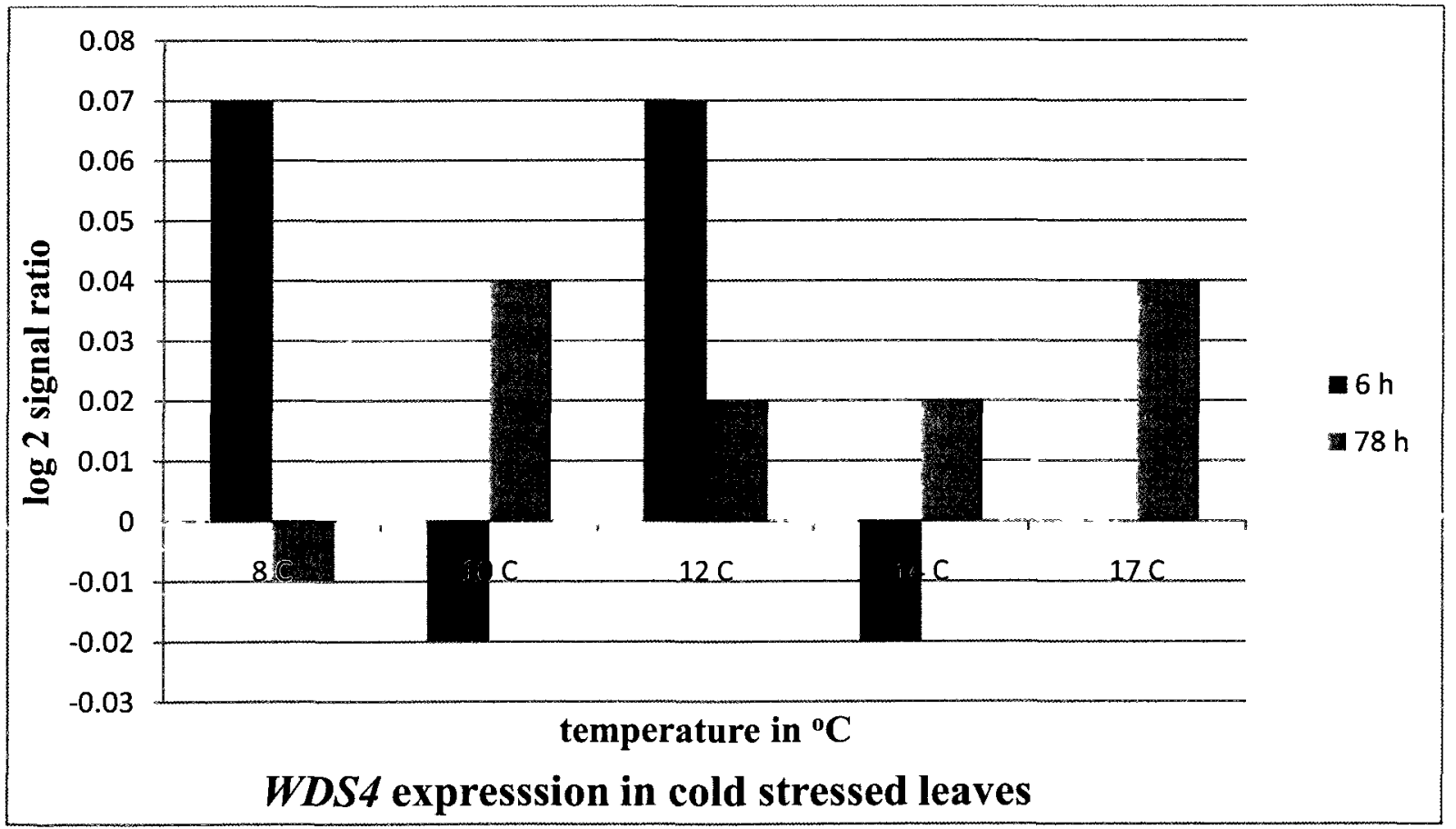

Figure 3.36: Effect of cold temperatures on WDS4 expression in leaves of Arabidopsis thaliana. Chart was generated using pre-existing microarray data obtained from Genevestigator database. Single repeat experiment; no error value provided. 


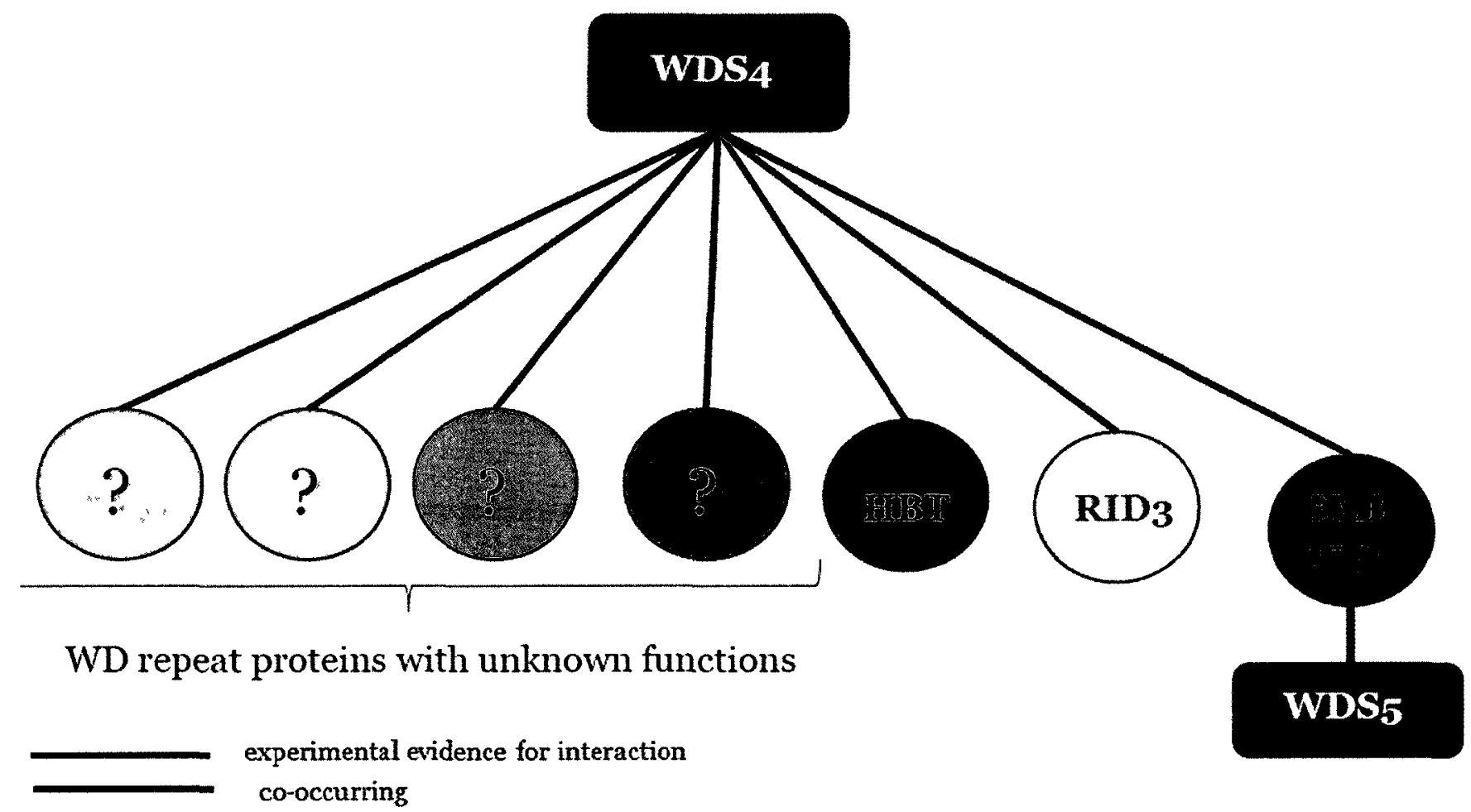

\begin{tabular}{|l|l|l|}
\hline Protein ID/Name & Mode of prediction & Function \\
\hline HOBBIT & experimental evidence & $\begin{array}{l}\text { part of Anaphase promoting } \\
\text { complex; regulation of cell } \\
\text { cycle (Perez-Perez et.al., } \\
\text { 2008) }\end{array}$ \\
\hline Root Initiation Defective 3 & co-occurrance & cell cycle regulation \\
\hline Embryogenesis defective 2757 & co-occurance & cell cycle regulation \\
\hline At3g50390 & co-occurance & unknown \\
\hline At5g60940 & co-occurance & unknown \\
\hline At1g49450 & co-occurance & unknown \\
\hline At4g34380 & co-occurance & unknown \\
\hline Figure $3.37:$ Pas
\end{tabular}

Figure 3.37: Possible functional partners of WDS4 (At5g27570)

STRING 9.0 (http://string-db.org/) database was used to predict proteins that co-occur with

WDS4; experimental evidence found through literature searches 


\subsubsection{Analysis of WDS5 (At5g64730)}

WDS5 encodes a 299 amino acid long protein that is likely to be expressed in the cytoplasm (Figure 3.39). The protein`s molecular mass is about $33066 \mathrm{Da}$ and has two possible lipid binding pleckstrin-homology (PH) domains (at F230 and W297) and also a site that may bind to 14-3-3 domains of other proteins (Figure 3.38). Resembling the overall expression of WDS3 at different stages of development, WDS5 expression also displays a double bottom chart pattern. A slight decline can be observed following the germinated seed stage. This decline continues all the way to the young rosette stage. The expression level slightly increases during the developed rosette stage and continues to increase into the bolting stage. After bolting the expression level drops sharply and then gradually increase as the plant matures. Expression appears to be highest at the mature silique stage followed by germinated seed and then bolting stages (Figure 3.40). WDS5 expression levels seem to increase as the seeds mature with highest values observed in dry seeds (Figure 3.41). A slight increase in WDS5 expression can also be observed in leaves as they age (Figure 3.42).

WDS5 expression was slightly down-regulated in leaves that were infected with Botrytis cinerea, Erysiphe orontii and Erysiphe cichoracerum. Exposure to all the other pathogens caused up-regulation of WDS5 with Blumeria graminis inducing the highest increase in expression (Figure 3.43). Following exposure to FLG22 and HrpZ, WDS5 expression was rapidly downregulated and then up-regulated within the first four hours following exposure. Treatment with LPS also caused an increase in gene expression; $4 \mathrm{~h}$ after exposure, expression levels were twofold higher than expression levels observed $1 \mathrm{~h}$ post-exposure (Figure 3.44)

Cold, drought and salt stress all seemed to cause up-regulation of WDS5 in the leaves of Arabidopsis thaliana (Figure 3.45, 3.47, 3.48). 
WDS5 is co-expressed with the protein At5g51130 that has methyltransferase activity and STE24, a zinc metalloproteinase. WDS5, like WDS4, appears to co-occur with EMB2757 (Figure 3.46).

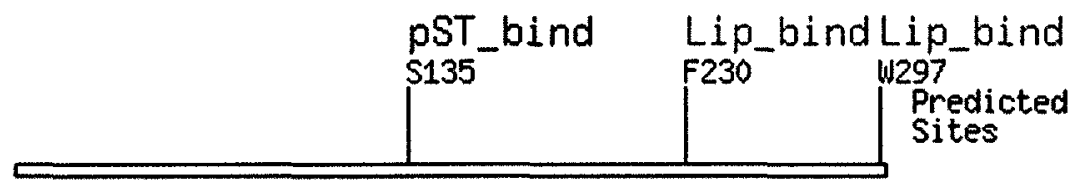

Figure 3.38: Medium stringency ScanSite Motif Scan output for WDS5 protein sequence indicating possible 14-3-3 binding site (pST_bind) at S135 and two possible lipid binding PH domains. (see Appendix 2 for database analysis)

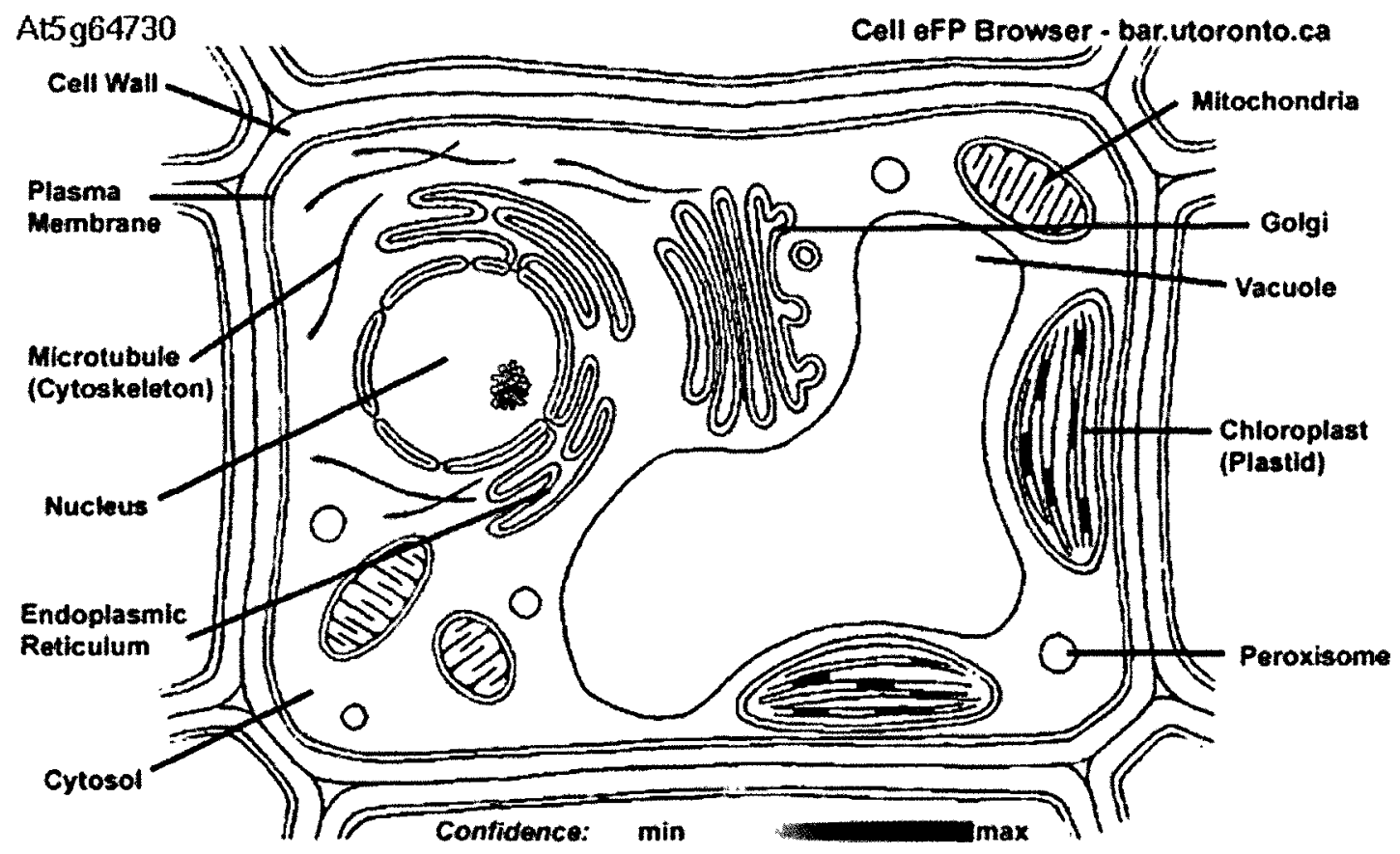

Draba by I. Amparo. Ddta from SUBA (Hedelewood et a. 2007).

Figure 3.39: Electronic fluorescence pictographic representation of WDS5's subcellular localisation. Shaded area on image indicates site of expression and the yellow colour indicates low confidence. Subcellular localisation was predicted based on documented and predicted localizations in SUBA database (Heazelwood et.al., 2007). 


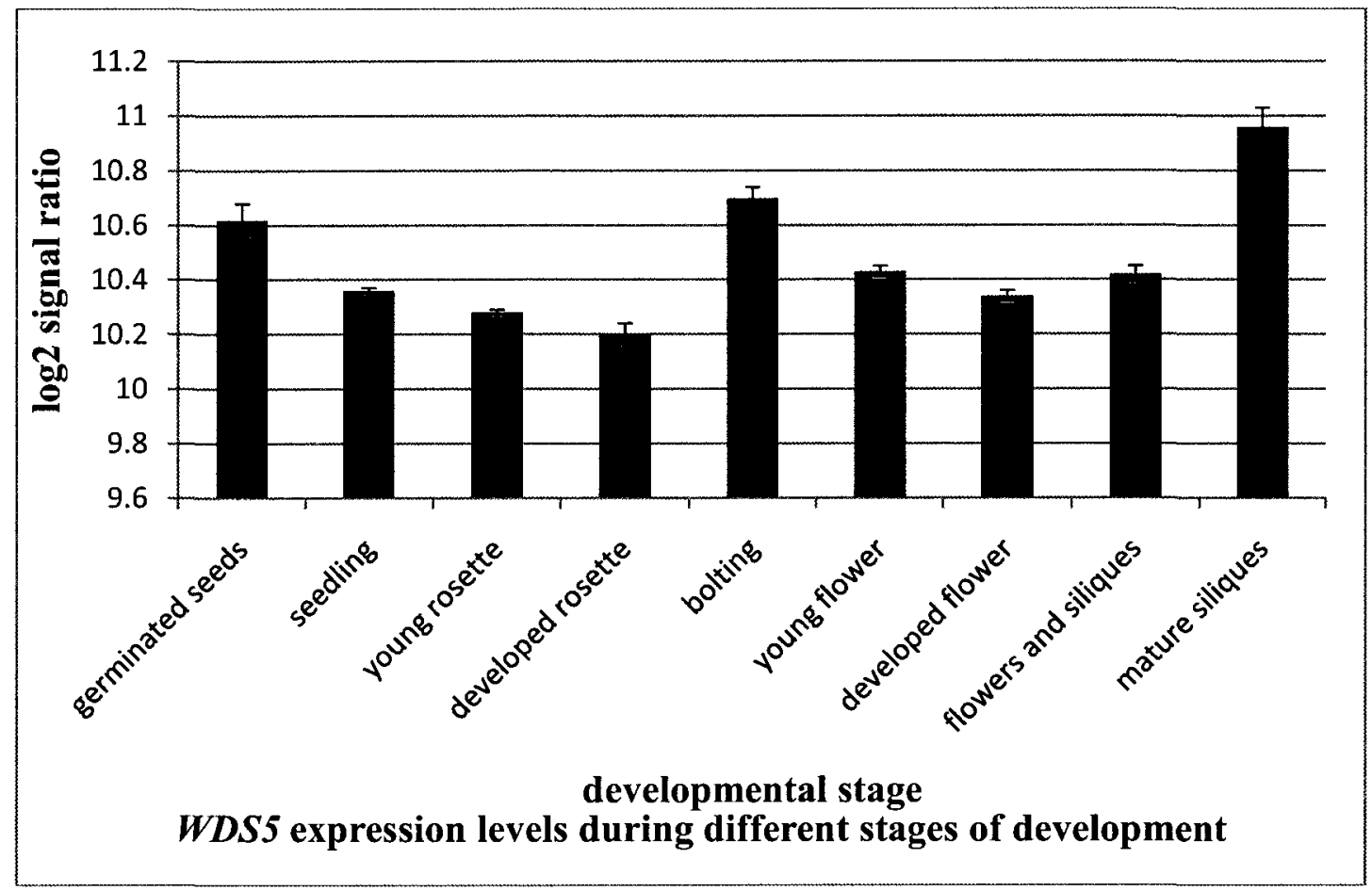

Figure 3.40: Overall expression of WDS5 across different stages of development. Each stage comprised up to $170022 \mathrm{k}$ arrays from different tissues of Arabidopsis from which the average expression values were calculated. Image was generated using pre-existing microarray data gathered from Genevestigator database. 
At $5964730217256 \ldots$ at

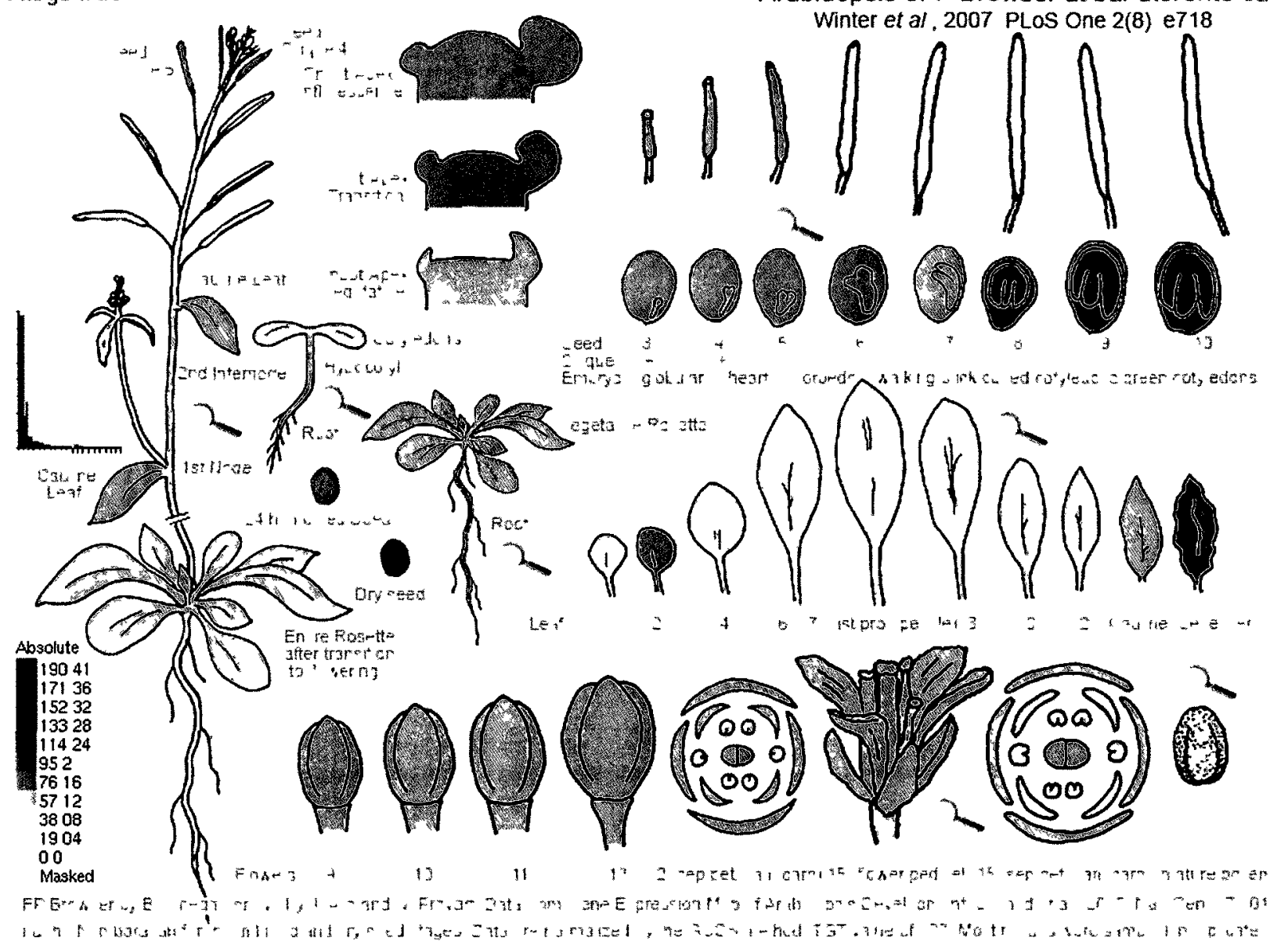

Figure 3.41: Electronic fluorescent pictograph of WDS5's expression pattern. Image illustrates expression levels in different tissues at different developmental stages. High levels of expression are indicated in red, intermediate levels in orange and low levels in yellow. Image was generated using Arabidopsis eFP browser which uses data from AtGenExpress Consortium data (Schmid et.al., 2005). 


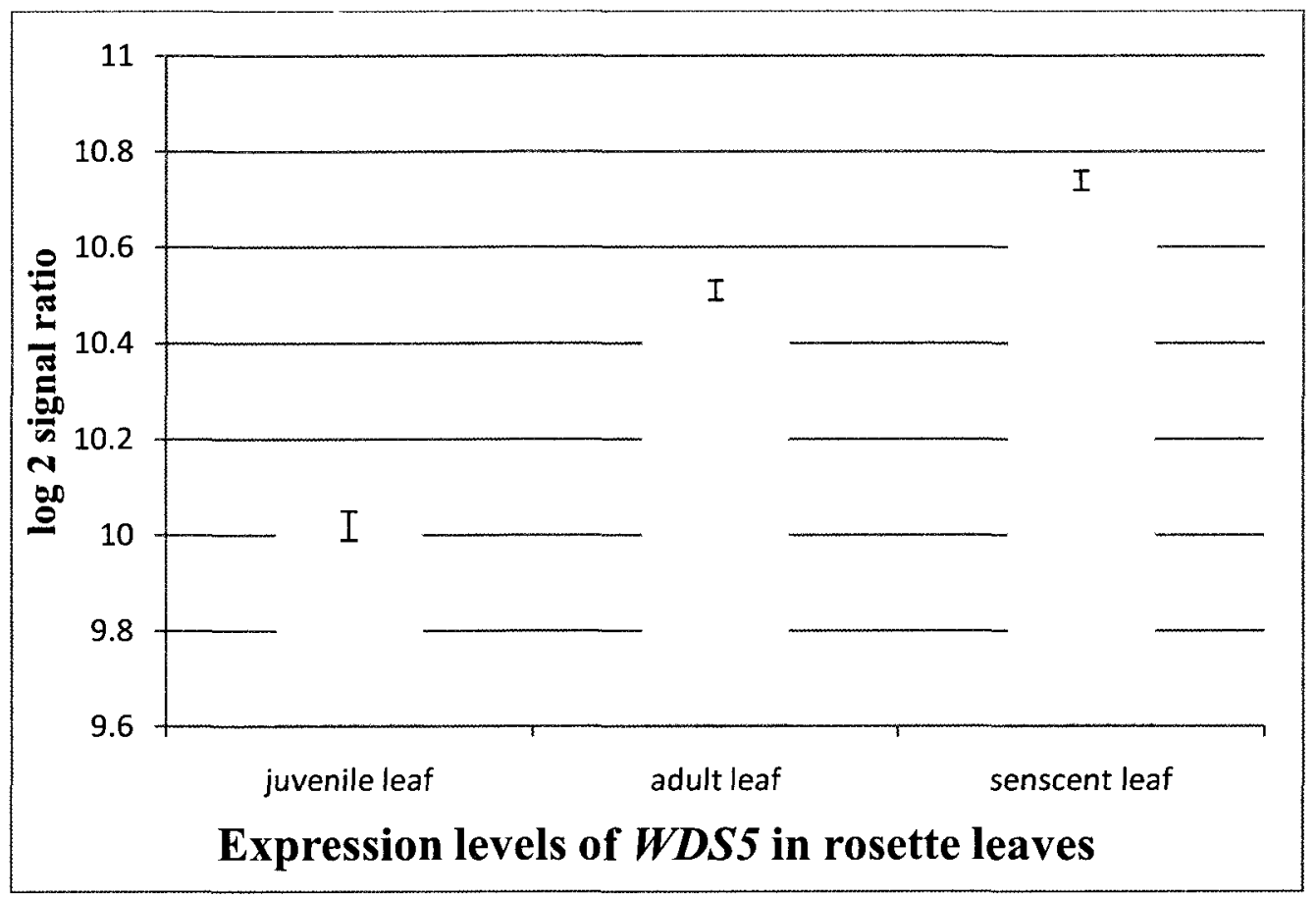

Figure 3.42: Expression levels of WDS5 in Arabidopsis thaliana rosette leaves at different stages of their development. Chart was generated using pre-existing microarray data obtained from Genevestigator database.

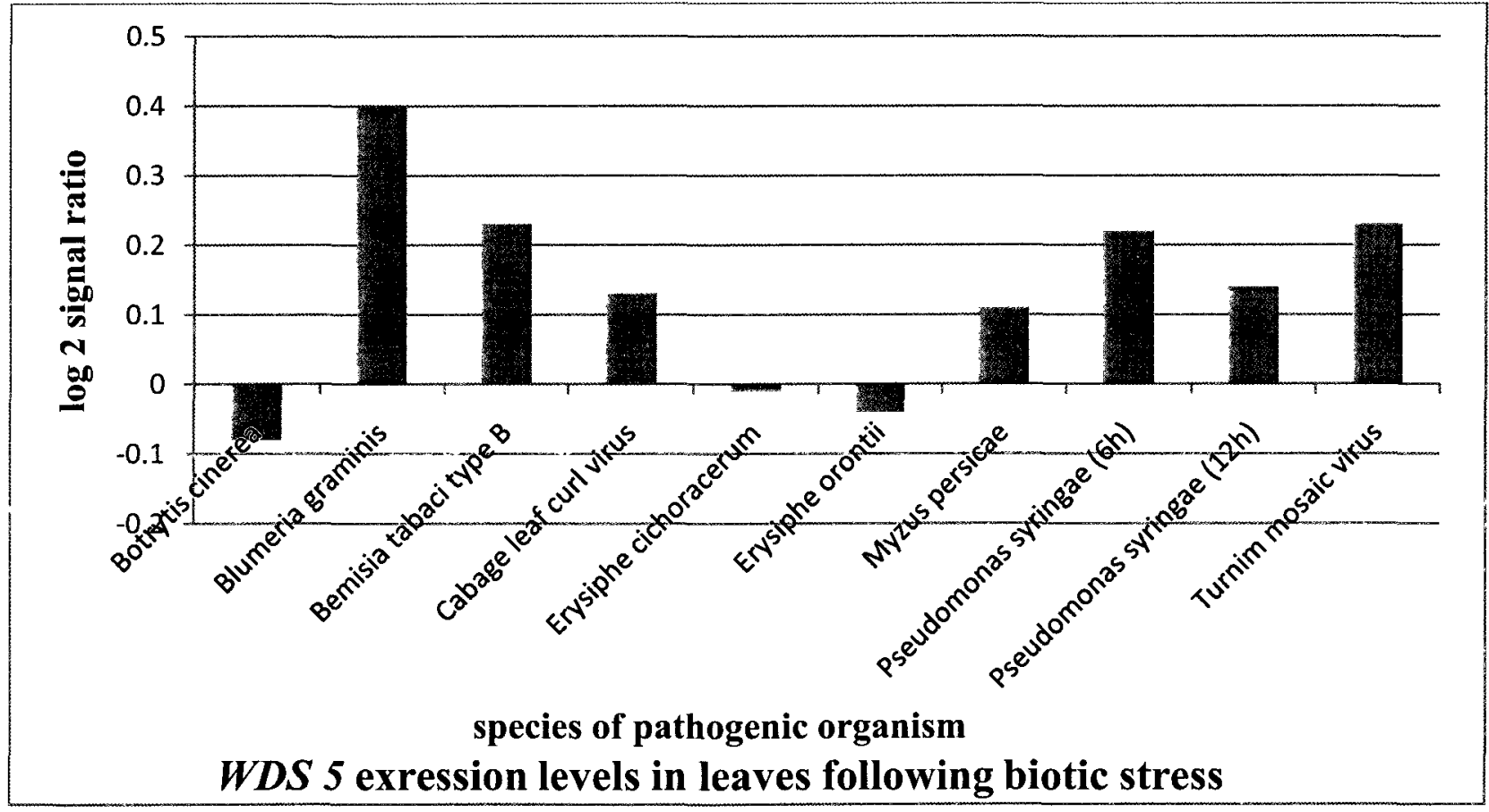

Figure 3.43: WDS5 expression levels in Arabidopsis thaliana leaves exposed to a variety of pathogenic organisms. Chart was generated using pre-existing microarray data obtained from Genevestigator database. Single repeat experiment; no error value provided. 


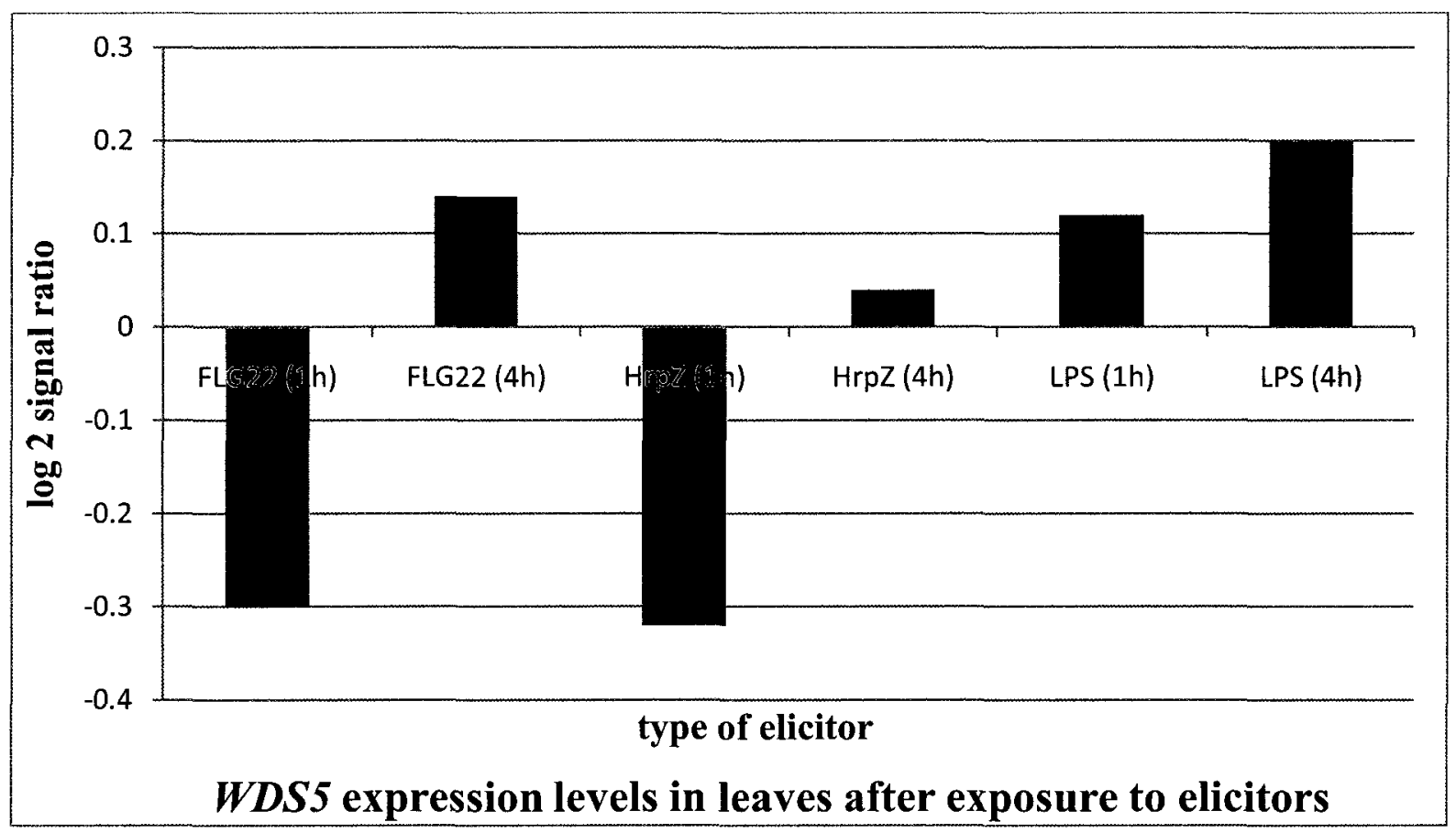

Figure 3.44: Effect of elicitors on WDS5 expression levels in leaves of Arabidopsis thaliana. Chart was generated using pre-existing microarray data obtained from Genevestigator database. Single repeat experiment; no error value provided.

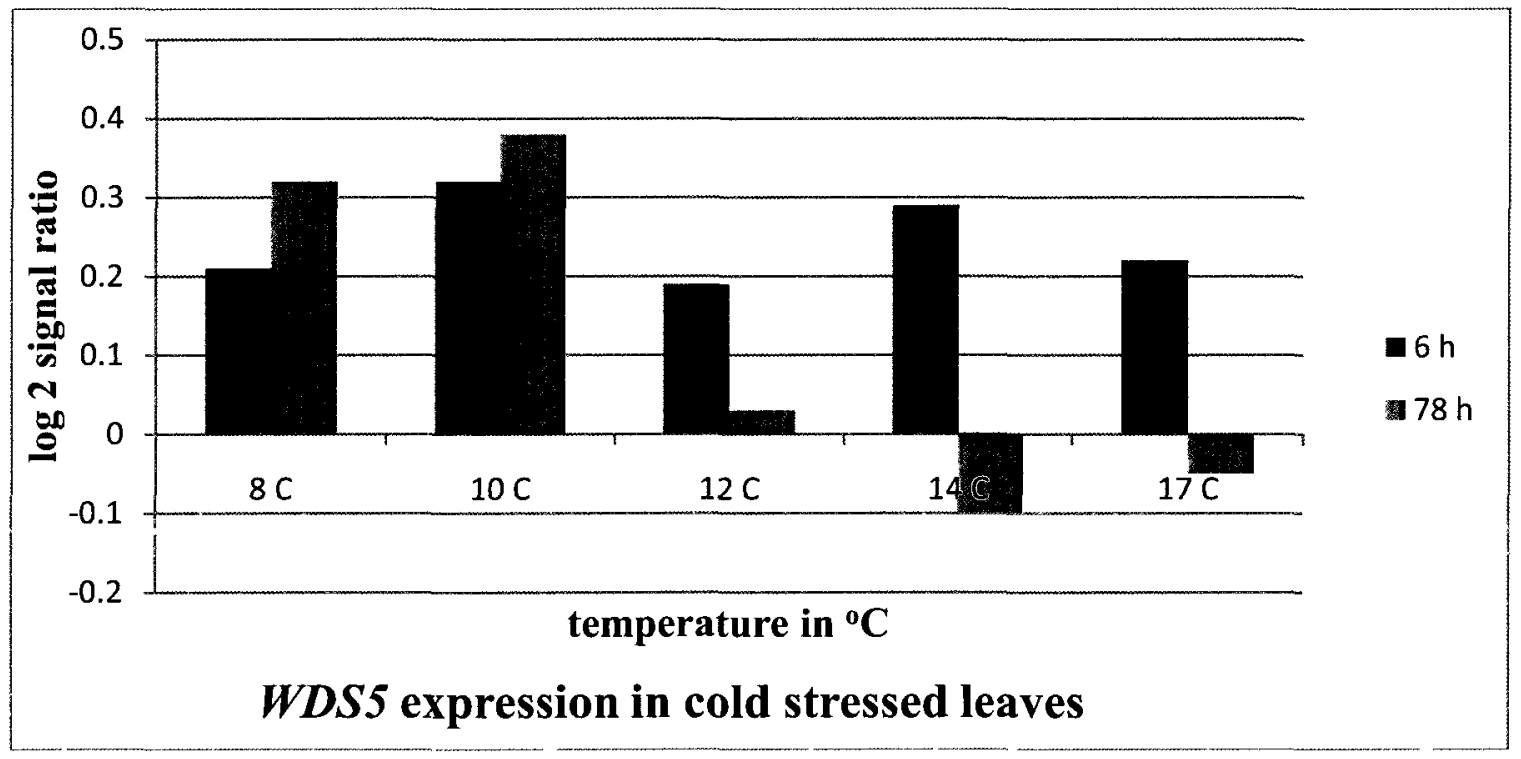

Figure 3.45: Effect of cold temperatures on WDS5 expression in leaves of Arabidopsis thaliana Chart was generated using pre-existing microarray data obtained from Genevestigator database. Single repeat experiment; no error value provided. 


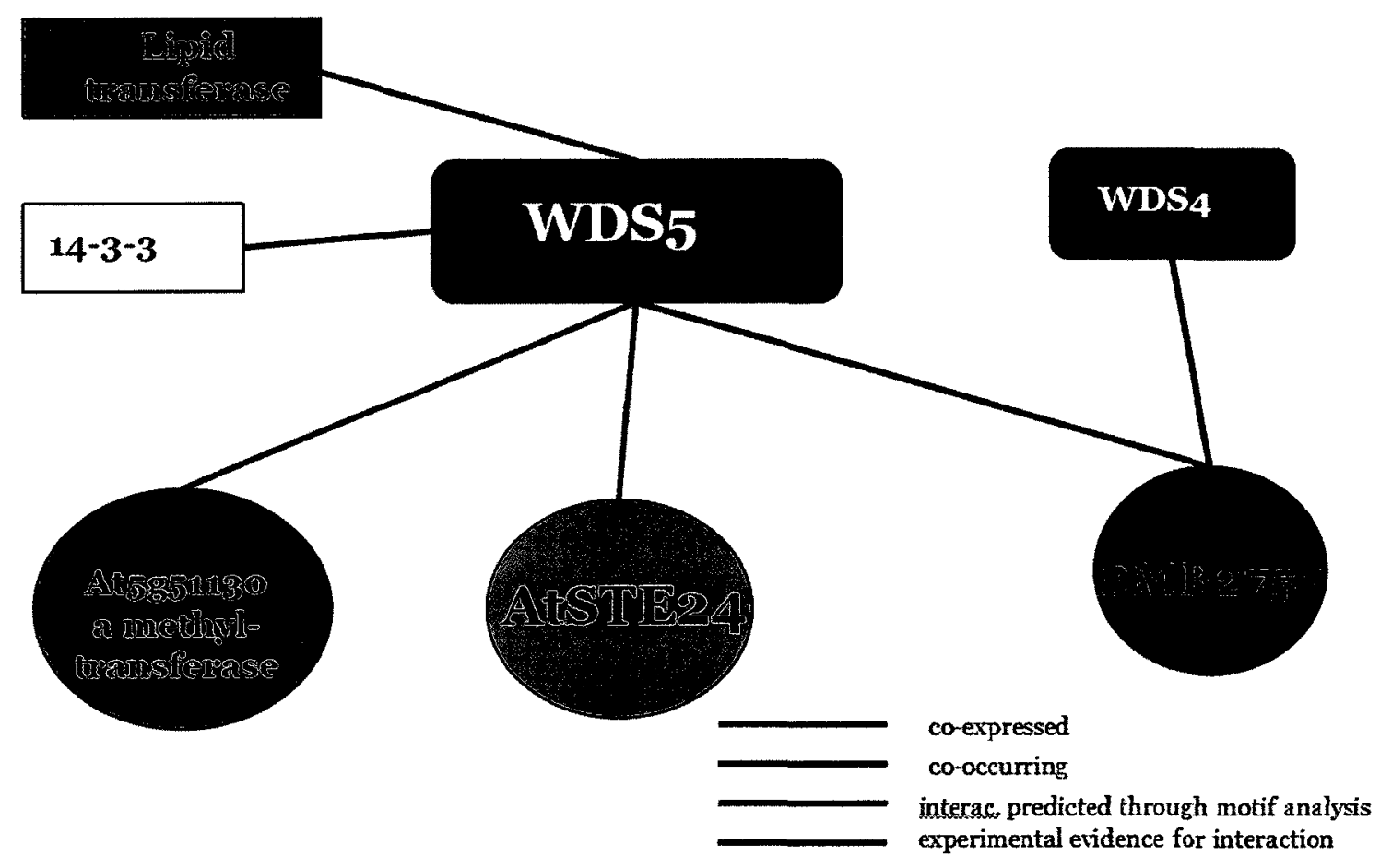

\begin{tabular}{|l|l|l|}
\hline Protein ID/Name & Mode of prediction & Function \\
\hline $\begin{array}{l}\text { At5g51130 } \\
\text { (methyl transferase) }\end{array}$ & co-expression & $\begin{array}{l}\text { methyl transferase; involved in post } \\
\text { translational modification of proteins }\end{array}$ \\
\hline $\begin{array}{l}\text { At4g01320 } \\
\text { AtSTE24) }\end{array}$ & co-expression & $\begin{array}{l}\text { CAAX protease with broad substrate } \\
\text { specificity. Localized exclusively to the } \\
\text { endoplasmic reticulum }\end{array}$ \\
\hline EMB2757 & co-occurance & cell cycle regulation \\
\hline $\begin{array}{l}\text { N/A } \\
\text { (lipid transferase) }\end{array}$ & motif analysis & $\begin{array}{l}\text { lipid transferase; post translational } \\
\text { modification of proteins }\end{array}$ \\
\hline 14-3-3 & motif analysis & unknown function \\
\hline
\end{tabular}

Figure 3.46: Possible functional partners of WDS5

Atted-II 6.0 database (http://atted.jp/) was used to predict proteins that are co-expressed with WDS5; STRING 9.0 (http://string-db.org/) database was used to predict proteins that co-occur with WDS1; Motif analysis of WDS5 was performed using ScanSite (http://scansite.mit.edu/) database (Figure 3.38). 


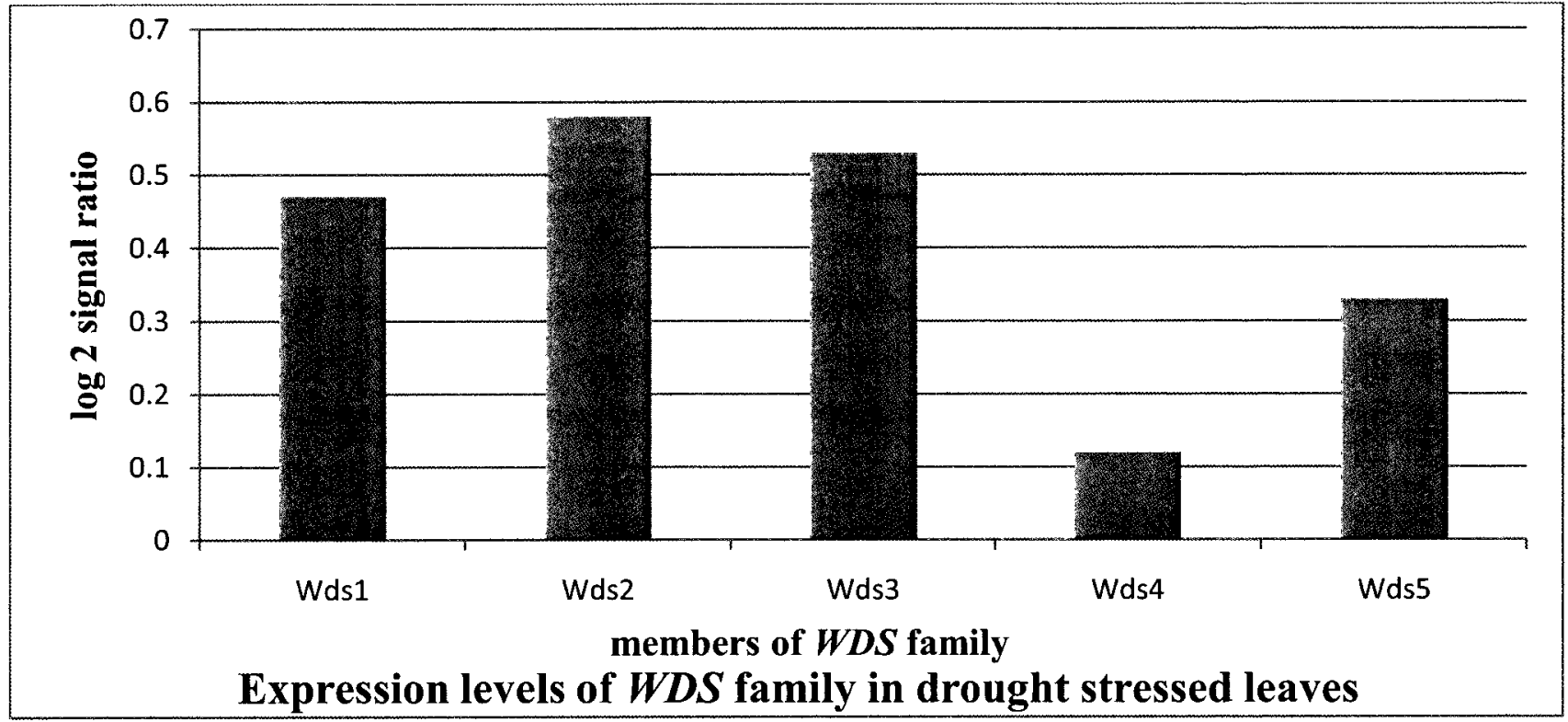

Figure 3.47: Relative expression levels of $W D S$ family members in leaves removed from plants that were grown under normal watering conditions for 24 days and then stressed by completely depriving of irrigation for 10 days. Chart was generated using pre-existing microarray data obtained from Genevestigator database. Single repeat experiment; no error value provided.

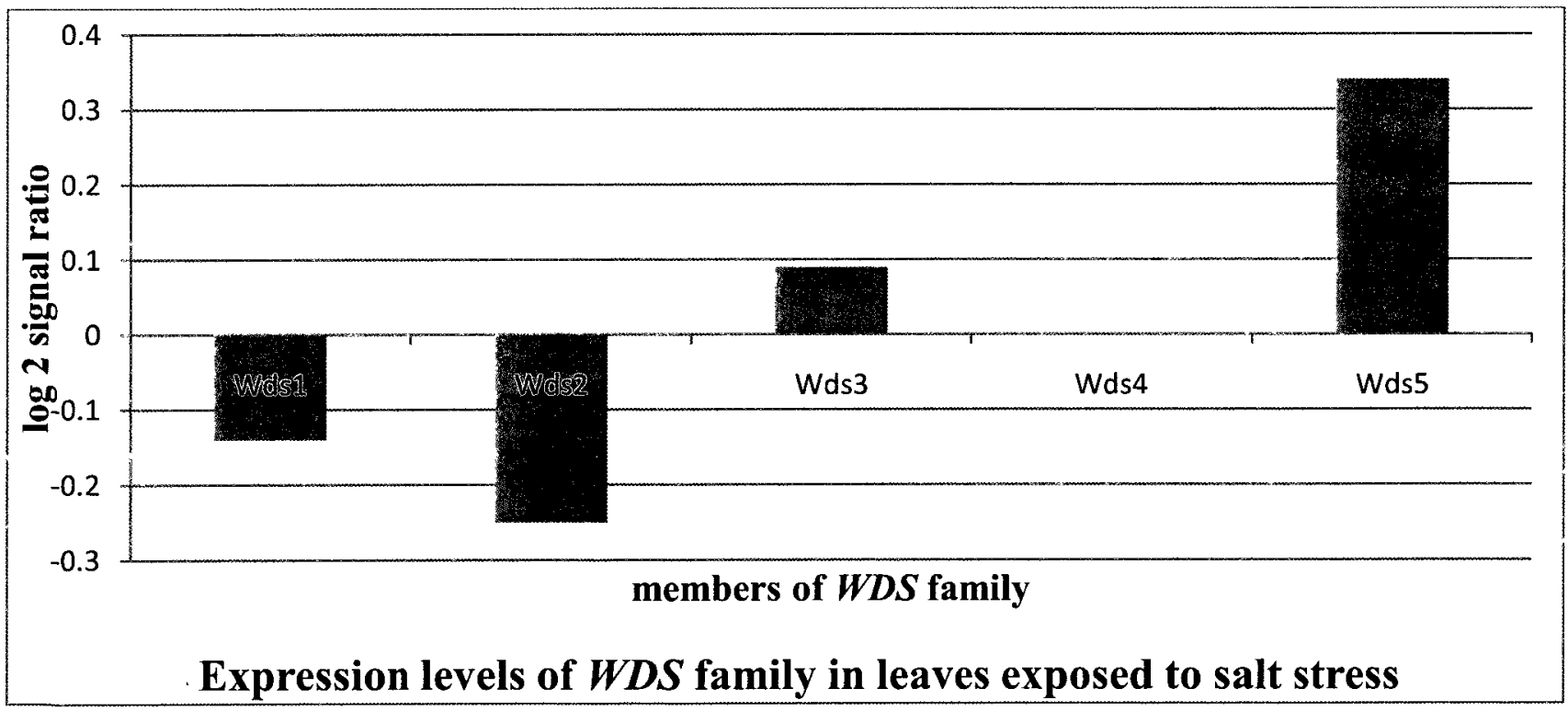

Figure 3.48: Relative expression levels of WDS family members in leaves removed from 5 weeks old plants that were treated with $250 \mathrm{mM} \mathrm{NaCl}$ for 24 hours. Chart was generated using preexisting microarray data obtained from Genevestigator database. Single repeat experiment; no error value provided. 


\subsection{Discussion}

All five members of the WDS family contain seven copies of the protein-protein interaction motif known as WD40 repeat that is, as its name suggests, about 40 amino acid residues long. These motifs occur in 4-10 tandemly repeating units and form a series of fourstranded, anti-parallel $\beta$-sheets that fold into a higher order structure known as a $\beta$-propeller, which can be visualized as a short, open cylinder (Nocker and Ludwig, 2003). The strong and rigid nature of $\beta$-propellers make them ideal to serve as scaffolds for protein interactions. WD repeats are common and are found in many different proteins that regulate diverse cellular processes, including signal transduction, transcription, pre-mRNA splicing, cytoskeletal organization, vesicular fusion, cell cycle control and, among many others, apoptosis (Wei et.al., 2010).

Three of the five WDS proteins, namely WDS1, 2 and 3 contain a N-terminal LisH (Lissencephaly type-1-like homology) domain that has an $\alpha$-helical structure and is believed to play a role in dimerization (Gerlitz et.al., 2005; Kim et.al., 2004; Mateja et.al.,2006). They also contain a CTLH (C-terminal to LisH) domain that is also $\alpha$-helical in structure and is believed to aid LisH dimerization (Mateja et.al.,2006; Umeda et.al., 2003).

When trying to identify proteins that potentially interact with the WDS proteins, different analysis tools gave different results. This variance in the identified proteins can be accounted for the different parameters and characteristics each consider when identifying potential interactions. One of the bioinformatic tools I used considered co-expression exclusively, while the other looked at available experimental data, position of the genes on chromosomes relative to one another, the possibility of fusion events, co-occurrence and co-expression patterns. Analysis of co-expression patterns is useful for protein interaction prediction because large-scale gene 
expression and protein interaction data show that protein pairs encoded by co-expressed genes interact with each other more frequently than with random proteins. Also, genes or genes similar to the query genes that tend to co-occur in different species have a higher probability of coding for proteins that interact with one another (Kerrigen et.al., 2010). The approach that considers the location of genes relative to one another relies on the notion that proximity is a result of selective pressure to associate genes that are co-regulated and code for proteins that are interacting with each other. One of the limitations of this latter approach is that it fails to identify interactions between protein products of distantly located genes. Prediction of fusion events may help overcome this problem by exploiting the fact that certain proteins in a given species consist of fused domains that usually correspond to single, full-length proteins in other species. For example if two portions of a single protein of a certain species exhibit unique similarities to two separate proteins of another species that are not necessarily encoded by neighbouring genes, then these two separate proteins may act as functional partners that interact with one another (Enright et.al., 1999).

Most of the proteins predicted to interact with WDS family members were identified based on co-expression and co-occurrence patterns. There was absolutely no overlap between the predicted co-expressed and co-occurring proteins (Figure 3.10, 3.19, 3.28, 3.37, 3.45). While this makes the prediction unreliable, it may help reinforce whatever we already $\mathrm{know} /$ presume about the proteins of our interest.

Based on co-expression data, WDS1 was predicted to interact with two completely unknown proteins and a protein that represses genes that are activated by E1A (early region 1a), an adenovirus oncogene product. Adenovirus normally infects terminally differentiated mammalian cells and uses the 243 amino acid long E1A protein for transitioning cells from the 
quiescent G1 phase of cell cycle into S phase, thus creating an environment that is favourable for its viral reproduction (Ferreon et.al., 2009; Sha et.al., 2010; Voet and Voet, 2004). To achieve this, E1A physically interacts with members of retinoblastoma associated protein family (eg. $\mathrm{pRb}, \mathrm{p} 130, \mathrm{p} 107)$ whose function is to bind and inactivate the E2F family of transcription factors that play important roles in regulating the expression of genes involved in cell cycle proliferation, as well as apoptosis. Binding of E1A to retinoblastoma associated proteins makes them unable to interact with E2F transcription factors that are now free to bind their target promoters (Ferreon et.al., 2009; Gingsberg, 2002; Sha et.al., 2010; Voet and Voet, 2004). So far eight members of E2F transcription factors have been identified. Form these, the first three, E2F1 to E2F3 are inhibited exclusively by pRP and are activators of E2F responsive genes, while the rest, E2F4 to E2F8, are their repressors (Gingsberg, 2002; Sha et.al., 2010). It has been shown that E2F1 is the only one that has the unique ability to induce apoptosis (Gingsberg, 2002). Induction of apoptosis by E2F1 happens either via a p53 dependent or independent manner. Regardless of the involvement of $\mathrm{p} 53$, cell death is mostly facilitated via the mitochondria dependent apoptotic pathway (Amaral, 2010; Gingsberg, 2002; Lu et.al., 2011).

p53 is one of the most widely studied tumour suppressor proteins in animals and it is commonly described as a sequence-specific transcription factor that is kept at low levels in healthy cells (Amaral, 2010). The level of p53 is normally kept in check by an ubiquitin ligase called Mdm2 E3 (mouse double minute 2), which tags the p53s for degradation in proteasomes. However, when E2F1 is active then it triggers the expression of a gene that codes for a protein that physically interacts and inactivates Mdm2 E3 ubiquitin ligase, resulting in the accumulation of $\mathrm{p} 53$, which, when present in high numbers, initiates myriad arrays of cellular events that lead to apoptosis (Voet and Voet, 2004). Interestingly, the protein At1g78070, which was also 
identified to possibly interact with WDS1, is predicted to be located in the CUL4-RING E3 ubiquitin protein ligase complex (Figure 3.10b), which may serve a function similar to that of Mdm2 E3 ubiquitin ligase and may control the levels of a protein in plants that is similar in function to $\mathrm{p} 53$. While to date no homologues of p53 were identified in plants, many scientists believe that functional equivalents do exist.

Considering that previous experiments performed in our laboratory indicated WDS1 to play a role in suppressing apoptosis-like cell death, and the current finding that one of the proteins that possibly interact with WDS1 is presumed to repress genes that are activated by E1A, while the other to be a part of an ubiquitin ligase complex, make the idea that WDS1 acts as a negative regulator of a cell death pathway, similar to the one present in animals, plausible.

WDS1 was also indicated to have three possible ERK-D domains, that are docking domains that proteins use to attach to ERK-type MAPKs. ERK, which stands for extracellularsignal-regulated kinase, enters the nucleus upon its activation via phosphorylation, and regulates the activity of various transcription factors by phosphorylating them. ERK is part of a sequential phophorylation signaling cascade that has been shown to play a role in many cellular responses, including apoptosis (Cagnol and Chambard, 2009; Murphy et.al., 2008; Voet and Voet, 2004). ERK activity has been linked with classical markers of apoptosis, such as cytochrome $c$ release, PARP cleavage, caspase activation, DNA fragmentation and condensation of chromatin (Cagnol and Chambard, 2009). One of the ways ERK has been implicated to regulate apoptosis was by its ability to promote the stabilization and activation of p53 (Cagnol and Chambard, 2009). Supposedly ERK does this by phosphorylating p53, an action that prevents it from associating with Mbm2 E3 ubiquitin ligase, which would result in its degradation (Cagnol and Chambard, 2009; She et al., 2000). 
Based on the protein sequence and interactome analyses performed so far, as well as the result of experiments performed with loss of function WDS1 mutants, it appears possible that WDS1 fits into a network similar to the ERK-p53 mediated apoptotic pathway of animals, as a negative regulator.

If the above was true, and WDS1 was a negative regulator of cell death, then we would expect to see an increase in its expression in plants being exposed to biotic stresses that normally trigger HR. This however was not the case; with the exception of Pseudomonas syringae (a gram-negative bacterium), Erysiphe orontii (a fungus) and Bemisia tabaci (typeB) (an arthropod), all the pathogens tested caused down-regulation of WDS1. Similar response was induced by exposure to elicitors. With the exception of LPS, all the elicitors tested caused downregulation of WDS1. LPS, which is a compound in which a lipid molecule is covalently bound to a polysaccharide, is found in the cell walls of gram negative bacteria (Raetz and Witfield, 2002). $P$. syringae is a gram-negative bacterium, so up-regulation of WDS1 after exposure to LPS exposure was not surprising. Down-regulation of the gene following exposure to FLG22, a 22 amino acid long sequence of the conserved N-terminal part of flagellin, and HrpZ, a small protein that forms pores in membranes, however was surprising because $P$. syringae is a flagellate that is known to secrete HrpZ (Ichinose, 2009). An explanation for this difference may be that FLG22 and HrpZ are perceived by different surface receptors and induce HR via different signaling cascades than LPS. Also, it is possible that FLG22 and HrpZ pose a stress that can conquer the anti-cell death mechanism of the cell, resulting in the down-regulatoin of anti-cell death genes. The same is true for the pathogens that caused down-regulation of WDS1. The increase in expression of WDS1 after $P$. syringae infection did not continue on forever. After 12 hours, a drop was observed in the gene's expression, which could have indicated that the cell 
death mechanism started taking over, an event that might have happened a lot quicker in the presence of the other pathogens.

Similar trends were seen in WDS1 expression in cold stressed leaves. The colder the temperature was larger the down-regulation became. Cold temperature causes the death of plant cells and the lower the temperature gets the sooner and faster the dying process sets in. It is possible that at the coldest temperatures the death mechanism took over sooner, thus causing a more extensive down-regulation of WDS1 expression during the same time period. The same theory could be applied to explain the trends seen in the expression of the gene in salt and heat stressed leaves.

Down-regulation of the gene in response to these stresses could also indicate that WDS1 is a positive regulator or death whose level is decreased by pro-survival proteins activated/produced during stress response. This is, however, unlikely, because in the past, through the analysis of $w d s 1$ loss of function and WDS1 over-expressing A.thaliana plants, our laboratory has produced strong evidence to support the hypothesis that WDS1 is a negative regulator of cell death (Xiong, 2007). The analysis of the identified motifs and the possible functional partners of WDS1 gave us an idea of where and how this protein might act. While these findings are not definitive, they can help narrow our focus when designing future experiments.

Experiments involving $w d s 2$ loss of function mutations also identified WDS2 as a negative regulator of cell death (Al-Shammari, 2009). Using bioinformatic approaches four proteins have been predicted to directly interact with WDS2. At1g49450, a WD40 repeat protein with unknown function, was indentified based on co-occurrence patterns, while the rest of the proteins identified were co-expressed with our protein of interest. Atlg02890, one of the co- 
expressed proteins, was identified as a AAA-type ATPase protein, which belongs to a family of proteins found in all organisms (Kressler et.al., 2008). AAA stands for "ATPases associated with different activities", and as the name suggests proteins belonging to this family have been identified to take part in many cellular processes (Kressler et.al., 2008). The second protein that appears to be co-expressed with WDS2, was identified as a plant homeodomain (PHD) finger protein. The PHD finger is a short domain that contains a zinc binding motif and the proteins containing them have been frequently associated with chromatin mediated transcriptional regulation (Salma and Geman, 2011). Transcriptional activation and repression of genes are both orchestrated by post-translational modifications of the DNA packing histones (Sanchez and Zhou. 2011; Zeng et.al., 2010). Acetylation and methylation of the lysine residues of histones coordinate the recruitment of multi-protein complexes that change the architecture of chromatin at the target gene loci. These modifications can result in either transcriptional initiation or repression, depending on the state of post-translational modification (Sanchez and Zhou, 2011; Zeng ct.al., 2010). PHD finger proteins are believed to influence transitions between chromatin states and to regulate transcriptional activity by being able to "read" the state of histone methylation and to a smaller extent acetylation (Mellor, 2006: Sanchez and Zhou, 2011).

The third protein identified to be co-expressed with WDS2 was a protein known as acylCoA binding protein 2 (ACBP2). As the name suggest this protein binds to acyl-CoA esters with high affinity. What is interesting about ACBP2 is that it interacts with Arabidopsis' ethyleneresponsive element binding protein (AtEBP), whose activity has been shown to confer resistance to Bax and abiotic stress (heat and hydrogen peroxide) induced cell death (Ogawa et.al., 2005; Pan et.al., 2001). AtEBP is a transcriptional activator that regulates the expression of cell death 
antagonist genes. It has been shown to bind to GCC-box of pathogenesis related promoter element of pathogenesis related genes (Buttner and Singh, 1997; Ogawa et.al., 2005).

Our analyses identified WDS2 to be located in the nucleus of the cell and based on its predicted functional partners it may function in AtEBP regulation. Motif analysis identified several possible phosphorylation sites on WDS2. Among these were two motifs where phophorylation by DNA damage kinases may take place. DNA damage kinases are activated upon DNA damage and signal the induction of DNA repair mechanisms, or, if the damage is unrepairable, then the destruction of the cell. The protein also appears to contain motifs that are used for docking onto other kinases. One of these motifs was identified as an ERK D-domain (role of ERK discussed above), while the other as a domain that binds to phosphoinositidedependent kinase $1(\mathrm{Pdk} 1)$. Pdk1 is believed to regulate the activity of AvrPto-dependent Ptointeracting protein 3 (Adi3), a member of the AGC family of kinases, through phosphorylation. Studies involving gene silencing experiments have indicated that both Pdk1 and Adi3 are negative regulators of plant cell death (Devarenne and Martin, 2005,2006, 2007). The exact way they confer cell death resistance is yet to be elucidated, but nevertheless Pdk1's possible interaction with WDS2 further confirms our findings that WDS2 is a negative regulator of cell death. This notion was further confirmed by the data obtained from transcriptome analyses. The expression of WDS2 was up-regulated in response to all three of the elicitors tested, as well as, in response to exposure to most pathogens and heat stress. Past experiments performed in our laboratory have indicated WDS2 to play a role in salt stress tolerance (Al-Shammari, 2009). However, according to pre-existing transcriptome data, salt stress causes down-regulation of the gene. If WDS2 really does provide resistance to salt stress, then the down-regulation of expression could have happened because the stress was so severe that it conquered the anti-cell 
death mechanism. However, if future experiments will prove our experimental findings to be wrong, then down-regulation of WDS2 could mean that the network that mediates salt stress resistance does not involve WDS2.

WDS3 was recently identified as AtSMU1, a protein with ubiquitin ligase activity (Higa et.al., 2006; Chung et.al., 2009). AtSMU1 directly interacts with AtSMU2, which has been shown to play a role in pre-mRNA splicing (Chung et.al., 2009). atsmu2 mutant plants show altered splicing of target pre-mRNA, occasionally develop abnormal cotyledon numbers and higher than normal seed weights. atsmul mutations result in similar but more dramatic changes in phenotype, which may indicate that they are part of the same complex, for whose proper functioning the presence of AtSMU1 is more important than that of AtSMU2 (Chung et.al., 2009). Due to its ubiquitin ligase activity, AtSMU1 has been proposed to control pre-mRNA splicing by regulating the levels of spliceosomal proteins (Chung et.al., 2009). While this hypothesis is yet to be supported experimentally, it is undeniable that the protein's ubiquitin ligase activity makes it ideal for this role (Chung et.al., 2009).

High stringency motif analysis identified one phosphorylation site (Y77) on AtSMU1 and two possible $\mathrm{SH} 3$ binding sites. SH3 domains are believed to regulate interactions between kinases and regulatory proteins (Voet and Voet, 2004). They occur in many different proteins, including tyrosine kinases (Voet and Voet, 2004), which are probably responsible for phosphorylation of Y77 of AtSMU1. This finding suggests that AtSMU1's activity may be regulated through phopshorylation.

Based on its predicted interactions, WDS4, which is predicted to be part of an ubiquitin ligase complex, appears to play a role in cell cycle regulation. It interacts with four WD40 repeat proteins with unknown functions and also with the proteins HOBBIT (HBT), Root initiation 
defective 2 (RID3) and Embryogenesis defective 2757 (EMB2757). HBT has been shown to be a part of a multisubunit ubiquitin ligase known as anaphase-promoting complex $(\mathrm{APC} / \mathrm{C})$, which regulates cell cycle progression and mitotic exit by inducing the proteolysis of several cell cycle regulators, including mitotic cyclins (Perez-Perez et. al., 2008). The gene that codes for HBT is exclusively expressed in dividing and elongating cells. The HBT protein has been implicated to be required predominantly post-embryonically for cell division and differentiation and has been shown to physically interact with activators of APC/C (Perez-Perez et. al., 2008). RID3, a protein that is important for de novo formation of root apical meristem has also been implicated in cell division control (Tamaki et.al., 2009). rid3 mutation caused ill controlled cells division in the root tip region and shoot apex which resulted in suppressed root elongation and disturbed morphogenesis (Tamaki et.al., 2009). RID3 appears to be a negative regulator of cell division or a positive regulator of cell death because rid3 mutant calluses, which are a mass of undifferentiated plant cells used for research, exhibited massive cell division and produced unusually large cell mounds that failed to develop meristems (Tamaki et.al., 2009).

EMB2757, a WD40 repeat protein, appears to interact not only with WDS4 but also with WDS5. A loss of function mutation in the gene that codes for EMB2757 causes defects in both embryo and seedling development (Baster et.al., 2009; Yamagishi et.al., 2005). The way EMB2757 functions is not yet known, but considering that all the other proteins WDS4 interacts with act in cell cycle regulation, it can be assumed that EMB2757 does, too. WDS4's predicted ubiquitin ligase activity and its interaction with HBT suggests that it may also be part of $\mathrm{APC} / \mathrm{C}$, and like RID 3, it function in negative regulation of cell cycle progression. The idea that WDS4 is a negative regulator of the cell cycle that promotes mitotic exit is further supported by transcriptome data analysis, which indicated that the expression of WDS4 is up-regulated 
following exposure to biotic and abiotic stresses, which are known to negatively affect plant growth through inhibition of the cell cycle machinery (Veylder et.al., 2007). Recently Kevei et.al. (June, 2011) published a paper in which they have identified WDS4 to be a cofactor of the $\mathrm{APC} / \mathrm{C}$, confirming our hypothesis that was based on the above-presented transcriptome data and predicted interactome profile analysis.

Besides its predicted interaction with EMB2757, WDS5 was also predicted to directly interact with a methyltransferase and a protein identified as AtSTE24. The C-terminal end of many proteins undergo post translational modifications that are required for their targeting (Bracha et.al., 2002). AtSTE24 is a CAAX protease that proteolytically cleaves the prenylated (or lipidated) C-terminal end of proteins terminating with a conserved CXXX motif. Proteins that are terminated in a $\mathrm{CXXX}$ motif (where $\mathrm{C}$ is a cystein residue), commonly referred to as a CAAX box, undergo three steps of post-translational modifications (Bracha et.al., 2002). First, they are prenylated (or lipidated) at their CAAX box, then the amino acids downstream of the prenylated site are proteolytically cleaved off by AtSTE24 or other CAAX proteases, and then the truncated C-terminal end of the proteins undergo methylation (Bracha et.al., 2002). Interestingly, motif analysis identified two possible lipid binding PH domains on WDS5, which has also been predicted to directly interact with a methyltransferase. Since in animals and yeasts homologues of AtSTE24 are localized in the ER membrane, proteolytic cleavage of prenylated proteins by AtSTE24 is thought to take place on the cytoplasmic surface of the endoplasmic reticulum (Bracha et.al., 2002). This suggests that WDS5, a CAAX motif containing protein, is prenylated in the cytoplasm and then undergoes further processing in the endomembrane system (Bracha et.al., 2002). Interestingly not unlike WDS5, most of the members of the mammalian Ras family of proteins terminate with a C-terminal CAAX box and undergo prenylation. (Bracha 
et.al., 2002; Wennerberg et.al., 2005). Ras proteins are GTPases that function as GDP/GTPregulated molecular switches that activate cytoplasmic MAPK signaling networks that control gene expression, regulate cell proliferation, differentiation, and survival (Wennerberg et.al., 2005). While there are no homologues of Ras proteins in plants, they may possess functional equivalents, and WDS5 may be one of them. (Alberts et.al., 2006; Voet and Voet, 2004; Wennerberg et.al., 2005). What further supports this notion is that WDS5 was also predicted to contain a 14-3-3 domain-binding motif. 14-3-3 family of proteins are present in all eukaryotes and are known to bind certain phosphorylated motifs in a wide variety of proteins, including Ras family of GTPases. (Morrison, 2008). Since binding of 14-3-3 proteins to Ras proteins can either enhance or suppress their (i.e. Ras GTPases) activity (Cheng and Rubin, 1997; Henriksson et.al., 2000; Light et.al., 2002; Morrison, 2008), whether the binding of a 14-3-3 protein enhances or suppresses the activity of WDS5 is hard to determine.

Since both WDS4 and WDS5 interact with EMB2757, it can be proposed that they are all part of the same cell cycle regulating pathway. Considering the proteins subcellular localization (i.e. WDS4 located in the nucleus, WDS5 located in the cytosol) WDS5 could be an upstream regulator of WDS4. Whether WDS5 negatively or positively regulates WDS4 is hard to determine. 


\section{Chapter IV}

\section{Cell death and anti-cell death signaling pathways}

\subsection{Introduction}

\subsubsection{Intracellular kinases and PCD}

Intracellular signaling pathways regulate the decision of whether a cell lives or dies. While death promoting extracellular ligands bind to death receptors to trigger caspase activation, anti-cell death ligands bind to receptors and activate intracellular kinases that promote the proliferation of cells. Some of the intracellular kinases that promote cell cycle progression are also tightly linked with apoptosis (Demasi, 2007). Such kinases include, among many others, protein kinase $A(P K A)$, protein kinase $B(P K B$ or $A k t)$, protein kinase $\mathrm{C}(\mathrm{PKC})$ and cyclindependent kinases (CDKs). Depending on the cell type and cellular environment these intracellular kinases can activate or inhibit cellular proteins involved in apoptosis, or transcription factors that inhibit the expression of pro-apoptotic proteins, or promote the expression of cell survival proteins.

\section{$P K A$}

PKA is a serine/threonine kinase that is activated by cyclic adenosine monophosphate (cAMP). An increase in cAMP levels can both inhibit and promote apoptosis by mechanisms that are poorly understood (Zhang et.al., 2008; Vermeulen et.al., 2003). Inappropriate activation of cAMP-PKA pathway causes mitochondria dysfunction that leads to membrane potential depolarization, accumulation of ROS, cytochrome $c$ and SMAC release, all apoptosis related events (Leadsham et.al., 2009; Zhang etl.al., 2008). PKA was also shown to phosphorylate Bim and Bad, two pro-apoptotic BH3-only Bcl-2 proteins. Phosphorylation of Bim, causes its 
stabilization, which means that it is protected from proteasomal degradation. Phosphorylated Bim can now promote apoptosis by interacting with and disrupting the function of anti-apoptotic members of the Bcl-2 family of proteins (Moujalled et.al., 2011). PKA can also regulate apoptosis by phosphorylating Bad, an action that causes its inactivation. When Bad is in its dephosphorylated state, it interacts with the mitochondrial membrane and promotes the formation of permeability transition pores through which cytochrome $c$ and other pro-apoptotic proteins escape (Roy et.al., 2009). It appears that the cAMP-PKA pathway regulates mitochondria dependent apoptosis by post-translationally regulating the activity of the proapoptotic BH3-only Bcl-2 family of proteins. Whether PKA acts in negative or positive regulation of the cell death pathway is probably dependent on the cell type and the mechanisms by which apoptosis is induced (Vermeulen et.al., 2003).

\section{$P K B / A k t$}

$\mathrm{PKB}$ is a proto-oncogen product with serine/threonin kinase activity. It is the primary mediator of the downstream effects of activated phosphatidylinositol 3-kinase (PI3K) (Parcellier et.al., 2008). Consecutive activation of PKB results in uncontrolled cell proliferation and suppressed apoptotic pathways (Parcellier et.al., 2008). During the past decade, a lot has been learned about the mechanisms by which PKB suppresses apoptosis. Like PKA, it has been shown to phosphorylate Bad. It also phosphorylates Bax, an action that prevents it Bax from inserting into the mitochondrial membrane and causing the disruption of membrane potential, an event that would lead to the subsequent death of the cell (Duronio, 2008; Parcellier et.al., 2008). PKB also phopsphorylates acinus, a caspase 3 activated nuclear pro-apoptotic protein that is involved in chromatin condensation. Phosphorylation by PKB blocks acinus' pro-apoptotic effects by making it resistant to proteolytic cleavage by caspase 3 (Parcellier et.al., 2008). 
PKB has also been shown to negatively regulate $\mathrm{p} 53$-mediated apoptosis. $\mathrm{p} 53$, which was briefly discussed in the previous chapter, is commonly inhibited under conditions in which PKB is activated. PKB can phosphorylate $\mathrm{Mdm} 2$, a protein with ubiquitin ligase activity, which interacts with and promotes the degradation of p53. Phophorylation of Mdm2 causes its stabilization, which increases its lifetime by delaying its protesomal degradation (Duronio, 2008; Parcellier et.al., 2008).

\section{PKC}

PKC, also a serine/threonine kinase, transduces numerous signals mediated by the release of diacylglycerol (DAG) (Voet and Voet, 2004; Rayland, 2007). Just like PKA and PKB, it can mediate a myriad array of cellular functions including apoptosis. PKCs can regulate apoptosis induced by both the receptor mediated extrinsic pathway and the mitochondria dependent intrinsic pathway (Rayland, 2007). In mammals, PKC has about eleven isozymes, from which some are pro- and some are anti-apoptotic. Most PKC isozymes that are classified as prosurvival/anti-apoptotic can also function to promote apoptosis (Rayland, 2007). This is also true of pro-apoptotic nembers that occasionally function to promote cell survival. It appears that the functional outcome of PKC activation reflects the specific PKC isozyme expression profile of the cell type being observed (Rayland, 2007).

The mechanisms by which the different PKC isozymes carry out their pro- or antiapoptotic functions is not yet fully understood. To date, the experimental data available implies that PKCs interact, in a number of different ways, with virtually all known cell death regulating pathways. Description of the current knowledge of PKC regulated cell death pathways is beyond the scope of this thesis, however the book entitled Apoptosis, Cell Signaling, and Human Diseases: Molecular Mechanisms (Volume 2) dedicates a chapter to the topic. 


\section{$C D K$}

CDK activity mediates most cell-cycle processes. Its role in cell-cycle mediation is accepted based on solid evidence from genetic and biochemical experiments. Surprisingly CDK activity has also been reported in cells undergoing apoptosis. While a lot is known about the role of CDKs in cell division, very little is known of how they operate during apoptosis, but nevertheless experimental approaches, including studies using genetic mutants, protein inhibitors, and chemical inhibitors of protein kinase activity, provide strong evidence for the role of CDK in apoptosis (Borgne et.al., 2006; Golsteyn, 2005). CDK activation is regulated by inhibitory phosphorylation that is mediated by the Wee1 family of protein kinases and by CDC25-mediated dephosphorylation of Wee1-mediated phosphorylation (Branzei and Foiani, 2008). Inactivation of $\mathrm{CDC} 25$ plays an important role in the sensing and repairing of double strand DNA (dsDNA) breaks. Upon dsDNA break a number of sensor proteins belonging to the Rad protein family bind to the damaged site on the DNA strand and form a complex. Upon binding, these sensor proteins recruit and activate two large protein kinases known as ATM and ATR that respectively phosphorylate Chk2 and Chk1 (Checkpoint kinase 1 and 2), which phosphorylate CDC25 (Branzei and Foiani, 2008; Myers et.al.,2009; Tse et.al., 2007; Voet and Voet, 2004). Phosphorylation of CDC25 causes it to associate with members of 14-3-3 family of adaptor proteins, an action that makes it impossible for CDC25 to enter the nucleus and dephosphorylate/activate CDK. Failure to dephosphorylate CDKs results in halting of cell cycle progression (Branzei and Foiani, 2008; Myers et.al.,2009; Tse et.al., 2007; Voet and Voet, 2004). ATM and Chk2 can both phosphorylate p53, thus preventing it from binding to Mdm2, an event that causes the accumulation of $\mathrm{p} 53$ in the nucleus. $\mathrm{p} 53$ can either prolong cell cycle arrest by up-regulating the transcription of genes that code for proteins that inhibit the activation 
of CDKs, or can induce apoptosis if the damage is irreparable and p53 accumulates to high levels (Branzei and Foiani, 2008; Myers et.al.,2009; Tse et.al., 2007; Voet and Voet, 2004).

The equivalents of the above-described intracellular kinases are present in all eukaryotes, including plants. To see how $w d s 1 / w d s 2$ mutation, FB1 treatment and senescence affect the activity of these intracellular kinases in Arabidopsis thaliana, we performed immunoblotting with antibodies specific to phosphorylated substrates of PKA, PKB, PKC, CDK, ATM and ATR.

Immunoblotting was also performed with antibodies that recognize mammalian apoptotic proteins, namely caspase 3 , cleaved caspase 3 , caspase 7 , cleaved caspase 7 , caspase 9 , cleaved caspase 9, PARP and cleaved PARP. To our knowledge no one has ever attempted doing this, and positive recognition of some plant proteins by these antibodies may reinforce the idea that, while there are no known homologues of animal apoptotic proteins in plants, some functional equivalents may exist.

\subsubsection{ER membrane proteins and PCD}

The endoplasmic reticulum (ER) is a highly evolved, dynamic organelle that functions in nascent protein synthesis, folding, and post-translational modifications. The loading of unfolded peptides into the ER lumen is a tightly controlled process that depends on the cell's requirements. Under stressful conditions, the loading of newly synthesized proteins can increase so drastically that the folding capacity of the ER lumen becomes overwhelmed, causing the production and eventual accumulation of unfolded and/or misfolded proteins. The accumulation of the faultily folded proteins in the ER lumen causes disturbances in the homeostasis of the cell. The series of events just described are commonly referred to as ER-stress, and cells have evolved sophisticated mechanisms to cope with it. If the damage is too extensive and the coping mechanisms fail, the cell undergoes PCD (Watanabe and Lam, 2009). Studies utilizing 
pharmacological approaches indicated that compromised ER function in plant cells leads to apoptosis-like PCD, not unlike it does to apoptosis in animal cells (Watanabe and Lam, 2009).

Bax-inhibitor 1 (BI-1) and defender against apoptosis 1 (DAD1) are two PCD regulators that reside in the ER. These proteins are evolutionarily conserved membrane proteins that have cytoprotective functions in both plants and animals. BI-1 was originally isolated from a human cDNA library because its expression in yeast inhibited cell death triggered by ectopic expression of the mouse Bax gene (which, if you recall is, a pro-apoptotic member of Bcl-2 family) in yeast (Xu et.al., 2998; Watanabe and Lam, 2009). Plant BI-1 homologues were indentified in a number of plants, including Arabidopsis thaliana, and their ability to rescue yeast cells from Bax-induced cell death was confirmed through experiments that involved the cloning of plant homologous of the gene (Cacas, 2010; Kawai et.al., 1999; Watanabe and Lam, 2009). The expression level of both the plant and mammalian BI-1 is enhanced during senescence and stressful conditions (Watanabe and Lam, 2009). Overexpressin of Arabidopsis BI-1 (AtBI-1) can suppress mammalian Bax-induced lethality in Arabidopsis thaliana plants, and also the apoptosis-like PCD induced by exposure to various fungal pathogens, fungal elicitors, hydrogen peroxide, heat, and cold (Kawai et.al., 2004; Watanabe and Lam, 2009). The leaves of WT Arabidopsis thaliana were reported to exhibit increased AtBI-1 mRNA levels immediately after exposure to the fungal toxin fumonisin B1 (FB1). This up-regulation is only noticeable immediately prior to the induction of PCD, suggesting that AtBI-1 functions in basal inhibition of cell death activation (Watanabe and Lam, 2009). Leaves of loss of function AtBI-1 mutant plants exhibit accelerated progression of PCD after exposure to the fungal toxin FB1, further confirming the role of AtBI-1 as a cell death suppressor (Watanabe and Lam, 2009). The mutant plants do not display obvious phenotype differences, indicating that AtBI-1 does not 
affect developmental PCD processes, but is exclusive to cell death processes triggered by stress (Watanabe and Lam, 2006, 2009). The exact mechanism though which AtBI-1 executes its cytoprotective function is not yet known, however it is speculated that it interacts with mitochondria dependent cell death pathways because overexpression of AtBI-1 in yeast cells containing a mutated, non-functional version of cytochrome $c$ oxidase, failed to rescues them from Bax-induced cell death (Oshima et. al., 2007; Watanabe and Lam, 2009). AtBI-1 does not seem to regulate death by directly interacting with the mitochondrial membrane, because when the anti-apoptotic $\mathrm{Bcl}-2$, which is known to integrate into the mitochondrial membrane, was expressed in the cytochrome $c$ oxidase defective yeast cells, they were rescued from Bax-induced death. Based on this finding it is speculated that AtBI-1 is involved in the generation of secondary messengers that directly interact with the mitochondria and suppress the cell death promoting signals generated from it (Cacas, 2010; Oshima et. al., 2007; Watanabe and Lam, 2009). The secondary messenger is believed to be calcium, and BI-1 is believed to regulate Bax action through the control of the ER's calcium homeostasis. Under stress conditions, the ER releases calcium that is taken up by the mitochondria. There is a limit to how much calcium can be untaken by the mitochondria, therefore once the threshold if exceeded, irreversible PCD signaling is initiated (Cacas, 2010; Watanabe and Lam, 2009). The role of AtBI-1 in calcium homeostasis of the ER was indicated by experiments in which overexpression of the AtBI-1 gene resulted in decreased calcium release from the ER after pharmacologically induced ER-stress in Arabidopsis plants (Ihara-Ohori et.al., 2007). The notion that AtBI-1 regulates calcium homeostasis exclusively at the ER was indicated by studies in which AtBI-1 expression failed to rescue yeast cells mutated to lack ER membrane embedded calcium pumps from Bax induced 
cell death, but succeeded in rescuing yeast cells that were mutated to lack plasma membrane or vacuole embedded calcium pumps. (Ihara-Ohori et.al., 2007).

The fungal toxin FB1 can alter sphingolipid metabolism in plant cells, causing PCD. Sphingolipids can act as secondary messengers that mediate signaling cascades that have been implicated in cell death, cell proliferation, and various stress responses. In yeast cells AtBI-1 physically interacts with an ER the membrane protein cytochrome $b 5$ that is known to interact with fatty acid hydroxylase (FAH), whose function appears to be indispensable for AtBI-1 dependent protection against PCD (Cacas, 2010; Nagano et.al., 2009; Watanabe and Lam, 2009). Arabidopsis has homologues of cytochrome $b 5$ and FAH, and physical interaction between AtCytochrome $b 5$ and AtBI-1 at the ER membrane was confirmed using fluorescence resonance energy transfer (FRET) analysis. (Nagano et.al., 2009; Watanabe and Lam, 2009).It is likely that the latter three proteins interact with one another and form a large complex, which under stress conditions regulate apoptosis like PCD in plants (Watanabe and Lam, 2009).

Glycosylation of the N-terminal region of proteins is a post-translational modification that takes place in the ER and is required for the proper folding, trafficking and stability of many proteins (Yan and Lennarz, 2004). The enzyme that catalyzes glycosylation of proteins is a multisubunit ER membrane embedded protein complex known as olygosaccharyl transferase (OT) (Yan and Lennarz, 2004; Hauptmann et.al., 2006). DAD1 is a part of this complex and appears to be indispensable for the complex's proper functioning (Hauptmann et.al., 2006). Compromised N-glycosylation causes apoptosis in animal cells, and dadl mutation mimics the effects of pharmacological agents that specifically target $\mathrm{N}$-linked glycosylation (Cacas, 2010). Many plants, including Arabidopsis thaliana, posses homologues of DAD1. Expression of AtDAD1 in animal cells that were mutated in their own DAD1, could rescue them from 
apoptosis (Gallois et.al., 1997; Cacas, 2010). Overexpression of AtDAD1 in Arabidopsis protoplast indicated that, not unlike animal DAD1, AtDAD1 is located in the ER and could rescue protoplast from cell death induced by overexposure to ultraviolet light (Danon et.al., 2004).

In order to verify whether $w d s 1 / w d s 2$ mutation, FB1 treatment and senescence affect the expression of AtBI-1 and AtDAD1, I performed RT-PCR analysis on mRNA extracted from WT and wdsl/wds2 Arabidopsis leaves (both rosette and cauline) that were treated with $\mathrm{H}_{2} \mathrm{O}$ (control) or $2 \mu \mathrm{M} \mathrm{FB1}$ for either 0 or 48 hours.

\subsection{Results}

$w d s 1 / w d s 2$ mutation caused no apparent change in leaf morphology. The appearance of the leaves of WT and $w d s l / w d s 2$ plants was identical pre- and post-treatment with water and FB1, regardless of the incubation periods. In all leaf samples chlorophyll loss was apparent after 48 hours of incubation; FB1 treated plants appeared just as yellow as the $\mathrm{H}_{2} \mathrm{O}$ treated ones (Figure 4.1).

Figure 4.2 illustrates the immunoblots performed using antibodies specific to the animal apoptotic proteins. With the exception of the proteins recognized by cleaved PARP and cleaved caspase 3 antibodies, the expression level of all other proteins recognized by the other antibodies appeared constant regardless of whether they were extracted from WT or mutant leaves and regardless of the treatment the leaves received. Cleaved PARP antibody bound to three Arabidopsis proteins that were $\sim 55, \sim 21$ and $18 \mathrm{kDas}$, respectively (on the figure illustrated below only the $\sim 55 \mathrm{kDa}$ one is shown because the band intensities of the other two remained constant in all samples). The $\sim 55 \mathrm{kDa}$ protein was present in higher levels in leaves after 48 hours of incubation than after 0 hour. The protein recognized by cleaved caspase 3 antibody, was about 
$16 \mathrm{kDa}$, and it was present in lower levels in the $w d s 1 / w d s 2$ leaves than in the WT samples. It was also apparent that the FB1 treated double mutant samples had less than the water treated ones.

Figure 4.3 illustrates the immunoblots performed using antibodies specific to the phosphorylated substrates of the intracellular kinases PKA, PKB/Akt, PKC, CDKs (one that phosphorylates threonine and one that phosphorylates serine within CDK motifs), and ATM/ATR. The $\sim 105 \mathrm{kDa}$ substrate recognized by the PKB/Akt antibody exhibited higher phosphorylation levels in the $0 \mathrm{~h}$ WT samples than in the $0 \mathrm{~h} w d s / / w d s 2$ double mutants. The phosphorylation level of the double mutants appeared to be the same as the phosphorylation level of the $48 \mathrm{~h}$ samples. The $\sim 36 \mathrm{kDa}$ substrate of PKC appeared to be phosphorylated in the $0 \mathrm{~h}$ samples, but not in the $48 \mathrm{~h}$ ones, while the $\sim 27 \mathrm{kDa}$ substrate of the same antibody appeared to be equally phosphorylated in both the 0 and $48 \mathrm{~h}$ samples. The $\sim 110 \mathrm{kDa}$ substrate of the serine specific CDK appeared to be less phosphorylated in the WT samples at $0 \mathrm{~h}$ than in the $w d s 1 / w d s 2$ sample at $0 \mathrm{~h}$, which exhibited the same band intensity as the samples at $48 \mathrm{~h}$. The $\sim 25 \mathrm{kDa}$ substrate of the threonine specific CDK antibody exhibited higher level of phosphorylation in the WT samples at $0 \mathrm{~h}$ than in the double mutants at $0 \mathrm{~h}$. The phosphorylation level exhibited by the double mutants at $0 \mathrm{~h}$ was the same as the phosphorylation exhibited by the $48 \mathrm{~h}$ samples. The $\sim 19 \mathrm{kDa}$ substrate of the same threonine specific CDK antibody was only phosphorylated in $48 \mathrm{~h}$ samples; no apparent phosphorylation of the $0 \mathrm{~h}$ samples took place. The phosphorylation level of the substrate of ATM/ATR was constant in all 8 samples.

Figure 4.4 (see below) illustrates the results of RT-PCR analysis performed using AtBI-1 and AtDAD1 specific primers. The primers were designed to generate 500 bp long DNA 
segments of their respective genes. RT-PCR analysis indicated no remarkable difference in AtBI-1 and AtDAD1 mRNA levels in the samples tested.
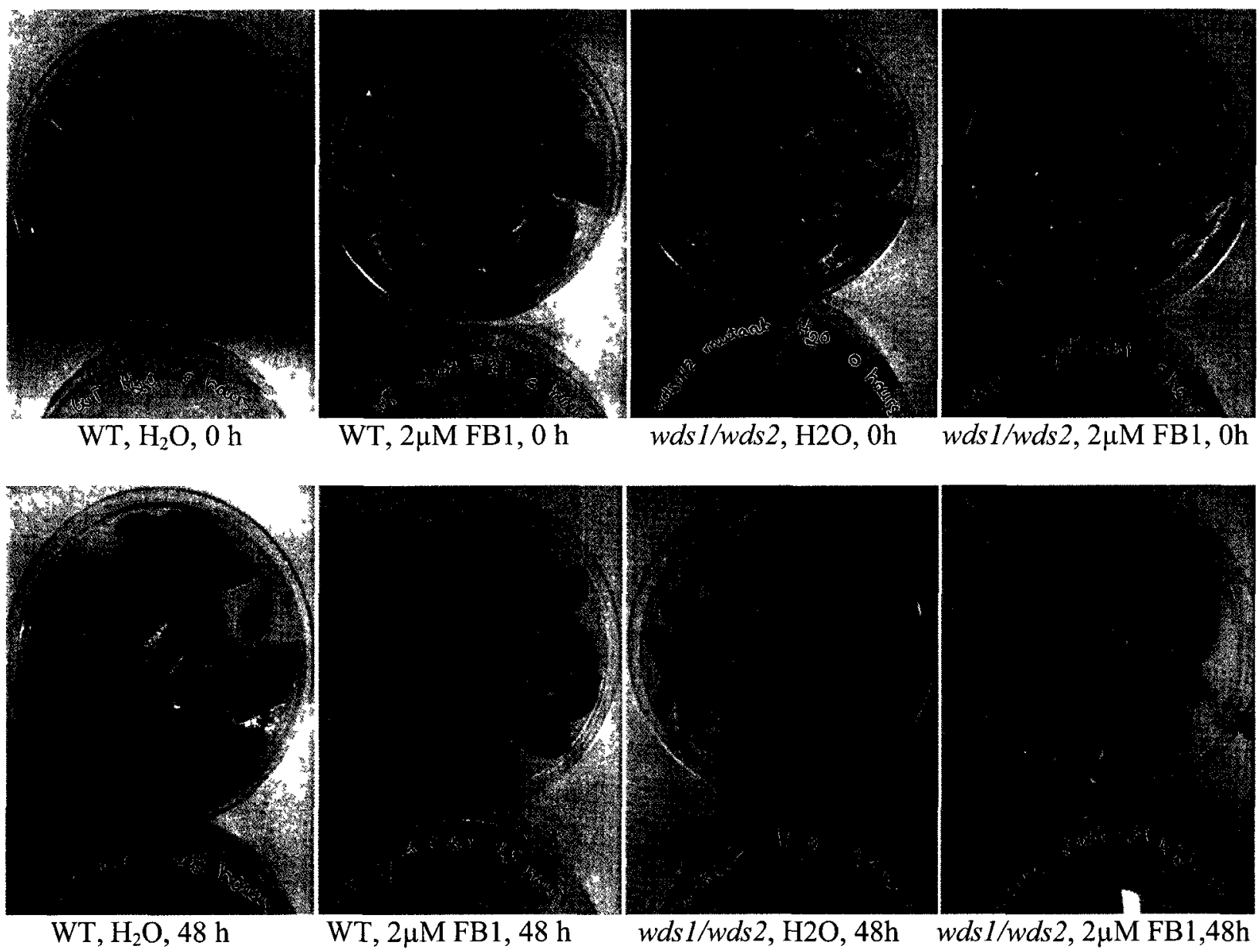

Figure 4.1: Images of $\mathrm{H}_{2} \mathrm{O}$ and $2 \mu \mathrm{M} \mathrm{FB1}$ treated Arabidopsis thaliana leaves after 0 and 48 hours of incubation. All plant materials were grown and incubated under identical conditions. This experiment was repeated twice. 


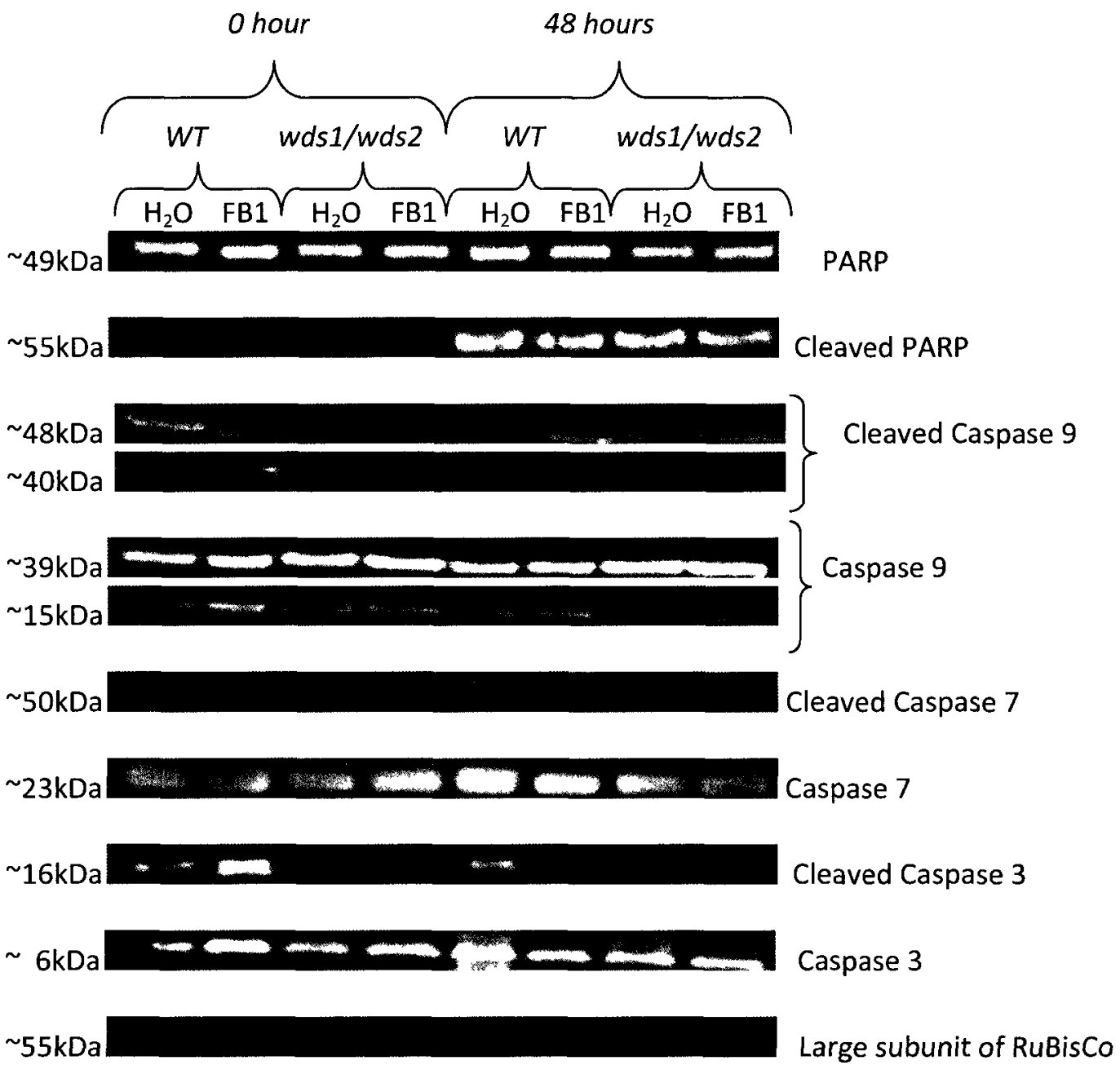

Figure 4.2.: Immunoblots using antibodies specific to the apoptotic proteins PARP, cleaved PARP, caspases 3, 7, 9 and cleaved caspases 3, 7, 9. The proteins blotted were extracted from Arabidopsis thaliana leaves treated with $\mathrm{H}_{2} \mathrm{O}$ and $2 \mu \mathrm{M} \mathrm{FBl}$ for 0 and 48 hours. All plant materials were grown and incubated under identical conditions. The large subunit of RuBisCo stained with Coomassie Blue dye is shown as control. Two repeat experiments were carried out. 


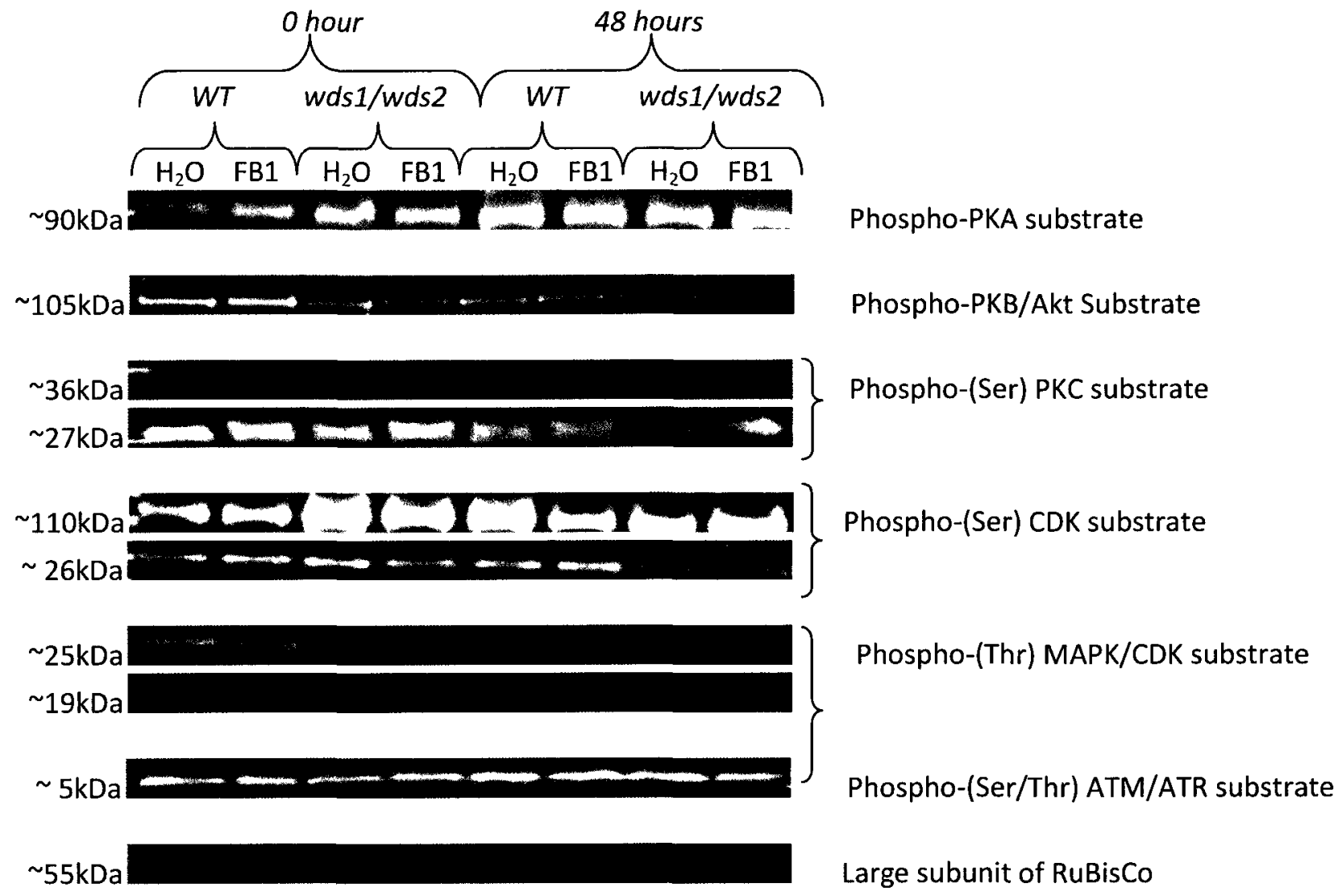

Figure 4.3: Immunoblots using antibodies specific to substrates of the intracellular kinases PKA, PKB/Akt, PKC, CDK, ATM/ATR. The proteins blotted were extracted from Arabidopsis thaliana leaves treated with $\mathrm{H}_{2} \mathrm{O}$ and $2 \mu \mathrm{M}$ FBl for 0 and 48 hours. All plant materials were grown under identical conditions. The large subunit of RuBisCo stained with Coomassie Blue dye is shown as control. Two repeat experiments were performed. 


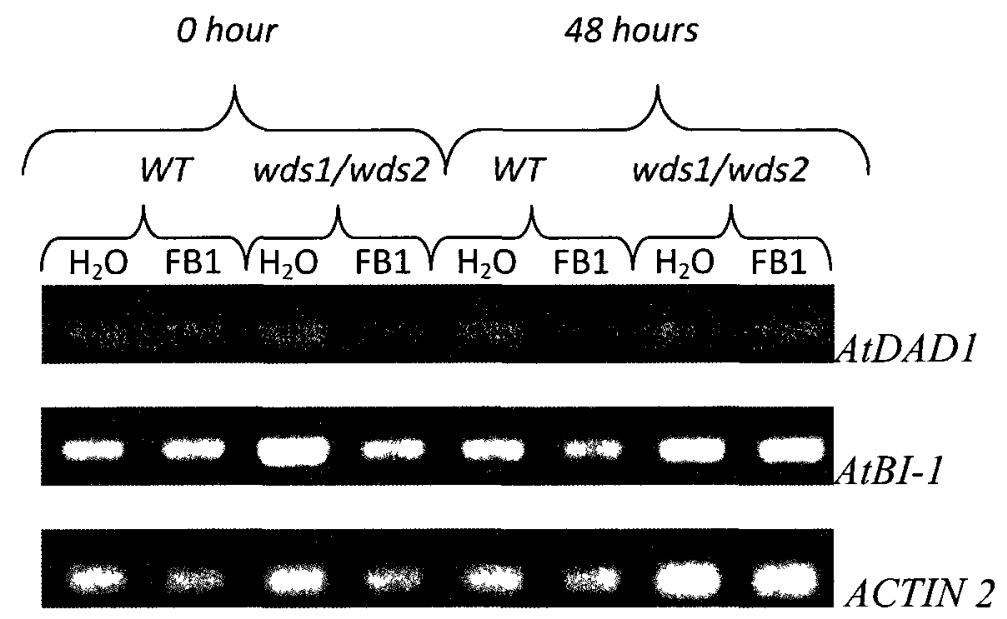

Figure 4.4: RT-PCR analysis with AtBI-1 and AtDAD1 specific primers. Actin 2 (ACTIN 2) was used as the control. cDNA synthesis was performed once, PCR with AtBI-1 and AtDAD1 specific primers was repeated three times. 


\subsection{Discussion}

All the animal apoptotic protein-specific antibodies recognized and bound to proteins extracted from the $W T$ and $w d s 1 / w d s 2$ Arabidopsis thaliana plants. While the molecular mass of the recognized proteins did not match the molecular mass of the mammalian apopototic proteins, the fact that the antibodies (which are claimed to be highly specific to large fragments of their respective proteins) recognized plant proteins may further support the notion that while there are no homologues of animal apoptotic genes in the plant's genome, genes that code for functionally equivalent proteins may exist. There are many examples in nature of proteins that vary in molecular mass but fulfill identical functions in different cells (Garrett and Grisham, 1999), therefore it is possible that some of the plant proteins recognized by the antibodies used in our experiments may be the functional equivalents of the apoptotic proteins of animal cell.

Based on band intensity patterns, it appears that PARP cleavage was a lot more extensive in samples that were incubated in $\mathrm{H}_{2} \mathrm{O}$ and $\mathrm{FB} 1$ for $48 \mathrm{~h}$ than in the other samples. PARP cleavage is a hallmark of apoptosis in animal cells, and the higher extent of PARP cleavage seen in plant cells after $48 \mathrm{~h}$ was consistent with our expectations because the cell death that has taken place by the $48^{\text {th }}$ hour mark is more extensive than at $0 \mathrm{~h}$. PARP is cleaved by activated caspase 3 and caspase 7 in vivo. There were, however, no remarkable difference in the levels of caspase 3, caspase 7, cleaved caspase 3 and cleaved caspase 7 between the samples incubated for 0 and $48 \mathrm{~h}$.

The level of the protein recognized by cleaved caspase 3 antibody was reduced in $w d s 1 / w d s 2$ mutants with the reduction being slightly larger in the FB1 treated samples. This is not what I expected because based on past experimental results ( Al-Shammari 2009; Xion, 
2007) my hypothesis was that WDS1 and WDS2 are PCD antagonistic, therefore less caspase 3 cleavage was expected to take place in the WT samples than in the double mutants. To further investigate the nature of the proteins recognized by the PARP and cleaved caspase 3 antibodies, the protein bands will be cleaved and sent for mass spectrometric analysis.

PKB activity has been indicated to have cell death antagonistic effects (Duronio, 2008; Parcellier et.al., 2008). Since the substrate of PKB was less phosphorylated in the double mutants at $0 \mathrm{~h}$ than in the WTs at $0 \mathrm{~h}, \mathrm{I}$ assume that in the mutants cell death started earlier and that the absence of WDS1 and/or WDS2 affected PKB activity. Where is the pathway that leads to $\mathrm{PKB}$ activation do WDS1 and/or WDS2 may play a role is hard to determine. To further investigate the nature of the protein recognized by PKB substrate specific antibody, the band was cleaved from the gel and sent for mass spectrometric analysis, the result of which will be available soon.

The observation that the $\sim 36 \mathrm{kDa}$ substrate of $\mathrm{PKC}$ was detected in the $0 \mathrm{~h}$ samples but not in the $48 \mathrm{~h}$ ones, could either mean that it was degraded by the $48^{\text {th }}$ hour or that PKC that phosphorylated it was inactive in the senescing leaved. Since the $\sim 27 \mathrm{kDa}$ substrate of PKC was phosphorylated in both the 0 and $48 \mathrm{~h}$ samples, it can be concluded that it was the $\sim 36 \mathrm{kDa}$ substrate that was degraded as the leaves senesced and not the PKC inactivated. To identify the $\sim 36 \mathrm{kDa}$ protein recognized by the PKC substrate specific antibody, the protein band was cleaved and sent for mass spectrometric analysis.

The substrate of serine specific CDK appeared less phosphorylated in the WT samples at Oh than the double mutant samples at $0 \mathrm{~h}$. This finding indicates that the absence of WDS1 and/or WDS2 may affect the activity of serine specific CDK. 
The $\sim 25 \mathrm{kDa}$ substrate of threonine specific CDK was more phosphorylated in the WT at Oh than in the $w d s 1 / w d s 2$ double mutants at 0 hours, while the $\sim 19 \mathrm{kDa}$ substrate of the same kinase was only phosphorylated in the $48 \mathrm{~h}$ samples. This indicates that the activity of threonine specific CDK may be affected by both the absence of WDS1 and/or WDS2 and senescence. The protein bands recognized by the CDK substrate specific antibodies were cleaved and sent for mass spectrometric analysis, the results of which will be available soon.

Phosphorylation of the substrate recognized by ATM/ATR substrate specific antibody appeared constant in all the samples tested. This indicated that if the activity of the CDKs described above are controlled via a DNA damage sensing/repair signaling pathway then WDS1 and/or WDS2 act downstream of ATM/ATR (refer back to the introduction of this chapter for a detailed description of this signaling pathway).

\subsubsection{Effects of FB1 treatment and wds1/wds2 mutation on the expression of AtBI-1 and $A t D A D 1$}

To examine the effect of $w d s 1 / w d s 2$ mutation on the role of AtBI-1 and AtDAD1 in the regulation of $\mathrm{PCD}$ progression, the fungal toxin FBl was selected as a biotic stress inducer. Treatment with this toxin triggers characteristic PCD response in Arabidopsis thaliana leaves. RT-PCR analysis revealed that treatment with $2 \mu \mathrm{M}$ FB 1 and/or $w d s 1 / w d s 2$ mutation did not affect the expression of either AtBI-1 or that of AtDAD1 (Figure 5.1). The observation that the expression of AtBI-1 was not up-regulated by FB1 treatment was not consistent with the results previously published by Watanabe and Lam (2006). Their results indicate a difference between AtBI-1 expression of distilled water and of FB1 treated Arabidopsis leaf samples; FB1 treated leaves exhibiting an increase in the gene's expression after 48 hours of treatment. The age and ecotype of plant materials used by them and us were identical, however while we grew our plants 
under $12 \mathrm{~h}$ of light $/ 12 \mathrm{~h}$ of dark, they grew theirs under long day conditions ( $16 \mathrm{~h}$ light $/ 8 \mathrm{~h}$ dark) and the toxin concentration they used was 5 times higher $(10 \mu \mathrm{M})$ than the concentration used in our experiments. The difference in toxin concentration could account for the different trends in AtBI-1 expression seen in our experiment and that of Watanabe and Lam (2006). The lack of difference between the expression levels seen in 0 and 48 hours samples suggests that the expression of AtBI-1 is not up-regulated as senescence progresses, which is contradictory to previous reports (Watanabe and Lam, 2009).

AtDAD1 has not yet been implicated in biotic stress induced cell death regulation. In our experiments its expression remained constant under all conditions tested, indicating that $w d s 1 / w d s 2$ mutation, and/or FB1 treatment may not affect the pathways in which AtDAD1 is involved.

The absence of WDS1 and WDS2 seem to have no effect on the levels of AtBI-1 and AtDAD1, suggesting that WDS1 and WDS2 may mediate cell death in an AtBI-1 and AtDAD1 independent manner. 


\section{Chapter V \\ Summary of Discussion and Future Directions}

\subsection{WDS1 and WDS2}

Leaf senescence, a developmentally programmed degeneration process, is recognized as a form of PCD (Lim et.al., 2007, Nooden, 2004 ). It has been shown that in senescing Arabidopsis thaliana leaves the expression of 827 genes, from which 43 encode transcription factors, is enhanced. During HR, 326 from the latter 827 senescence associated genes and 28 of the 43 senescence induced transcription factors are up-regulated, indicating that at the molecular level some common steps or crosstalks exist between the senescence-associated and pathogenesisinduced death pathways (Lim et.al., 2007).

In their experiments, Xiong (2007) and Al-Shammari (2009) found that WDSI and WDS2 act as suppressors of cell death pathways induced by both ageing and exposure to environmental stress. The expression of senescence associated gene 12 (SAG12), whose expression is associated exclusively with developmentally induced leaf senescence, begins sooner in leaves of $w d s 1$ mutant plants than in the wild type specimen (Xiong, 2007). RT-PCR analysis performed with genetic material extracted from different plant tissues at different developmental stages indicated that the level of WDS1 mRNA increases and is maintain at high levels in senescing plants (Xiong, 2007). This was confirmed by the analysis of publicly available microarray data, the results of which are presented in an earlier chapter of this thesis. According to transcriptome analysis, WDSI expression exhibits a two-fold increase in senescing leaves, relative to the levels seen in juvenile and adult leaf tissues. A similar pattern is exhibited by the expression of WDS2, however its expression is more significantly induced in senescing leaves relative to the expression levels seen in juvenile and adult specimen. In Al-Shammari (2009) experiment, wds2 
and $w d s 1 / w d s 2$ plants started to show signs of leaf senescence sooner than $w d s I$ and WT specimen did. This observation was, however, not consistent with the observations made during most recent experiments involving these plants, in which the leaves of $w d s 1 / w d s 2$ mutants started to show visible signs of senescence at virtually the same time. The lack of remarkable differences between the development and phenotypes of WT, wds1, wds2 and $w d s 1 / w d s 2$ plants indicate that WDS1 and WDS2 do not mediate PCD pathways that are responsible for shaping the architecture of the Arabidopsis plant. WDS1 and WDS2 are both expressed in high levels in dry seeds. Seeds are dehydrated in order to lower their metabolism, but the cells of the seeds need to be kept alive. The high expression of WDS1 and WDS2 in dry seeds, indicates that these genes may play a role in keeping the seed alive. It would be interesting to see how the levels of WDS genes, change during seed germination at the time at which the aleurone layer is degraded by PCD. Would they be down-regulated or up-regulated and conquered by death signals? Further experimentation may help find answers for these questions.

$\mathrm{SA}$ is a phytohormone that is known to play a role in the regulation of plant defense responses against various pathogens, pests and abiotic stresses (Bari and Jones, 2008). It is also known to influence and affect signaling pathways that lead to changes in the expression of senescence associated genes (Lim et.al., 2007). The expression of both WDS1 and WDS2 was shown to be up-regulated in a time and dose dependent manner by salicylic acid (SA) treatment, indicating the possible role of these genes in SA-dependent stress signaling (Al-Shammari, 2009; Xiong 2007). WDS2 was also shown to be up-regulated during osmotic stress, and while the expression of WDS1 was indicated to be unaffected when the plant is exposed to this stress, its overexpression in transgenic plants did appear to confer increased tolerance to osmotic stress (Al-Shammari, 2009; Xiong, 2007). The finding that osmotic stress causes the up-regulation of 
WDS2 is not consistent with the results of publicly available microarray data that was used in my analysis. Analysis of microarray data, which is presented in an earlier chapter of this thesis, indicates a decline in the expression of both WDS1 and WDS2 following osmotic stress, suggesting that osmotic stress may conquers the anti-cell death pathway WDS1 and/or WDS2 may play a role in.

Analysis of publicly available transcriptome data also indicated that while the expression of WDSI was dowregulated following most biotic stress treatment (i.e. treatment pathogen and elicitor), the expression of WDS2 was almost always up-regulated further confirming the speculation that it may act as a cell death antagonist during biotic stress, and suggesting that if the two proteins (i.e. WDS1 and WDS2), as proposed by Al-Shammari (2009) and Xiong (2007), belong to the same signaling pathway, then WDS1 may be a negative regulator of WDS2 activity. While a similar pattern is displayed by the expression of the two genes during cold stress treatment, drought stress treatment cause the up-regulation of both of their expression, indicating that they may act synergistically in drought induced signaling pathways.

Through the utilization of bioinformatic tools, I predicted WDS1 to be located in the cytoplasm, to contain three possible ERK docking sites, to interact with a protein that appears to function in the repression of genes that may induce apoptosis via a mitochondria mediated pathway and also a protein that seems to be part of an ubiquitin ligase complex. WDS1's interaction with a protein that may have ubiquitin ligase activity, suggests that its (WDS'1) level may be regulated by proteasomal degradation or that it may be a component of this complex. Its possession of ERK docking domains, which are domains that proteins use to interact with ERKtype MAPKs, and its interaction with a protein that possibly suppresses the expression of cell 
death promoting genes, indicate that WDS1 may be a signaling molecule that regulates the activity of gene expression controlling proteins.

WDS2 was experimentally shown to be located in the nucleus. It also has ERK docking sites, indicating its possible interaction with ERK-type MAPKs. WDS2 was predicted to interact with an ATPase belonging to the family of AAA-type ATPases that fulfil many cellular functions, a protein belonging to the PHD finger protein family, the members of which are known to function in chromatin remodelling, and an acyl-CoA binding protein known as ACBP2. This latter protein interacts with AtEBP, a transcription factor that activates cell death antagonist genes that are under the control of GCC-box containing pathogenesis related promoter elements. WDS2 nuclear localization and its interaction with proteins that are actively involved in chromatin remodelling and gene expression of death antagonist genes, suggest that WDS2 functions as a transcription factor, or is part of a protein complex that regulates the expression of genes that suppress cell death.

Both WDS1 and WDS2 were shown to interact with ERK-type MAPKs. It is possible that WDS1 and WDS2 are parts of the same pathway and WDS1 acts as an upstream regulator of WDS2. This has to be further investigated experimentally. Pull down assay or similar protein physical interaction determining experiments could be carried out with WDS1 and WDS2 as bait to test whether any of the proteins that interact with one would also interact with the other, or if they (i.e. WDS1 and WDS2) physically interact with each other.

Past experiments performed in our laboratory indicated that loss of function WDS2 mutation results in similar but more dramatic phenotype changes (i.e. sooner onset of senescence and increased susceptibility to environmental stresses) as WDS1 loss of function mutation (Xiong, 2007; Al-Shammari, 2009). This indicated that the two genes may act in the same cell 
death regulating pathway. The following image, Figure 5.1 illustrated the proposed model of the pathway WDS1 and WDS2 may belong to.

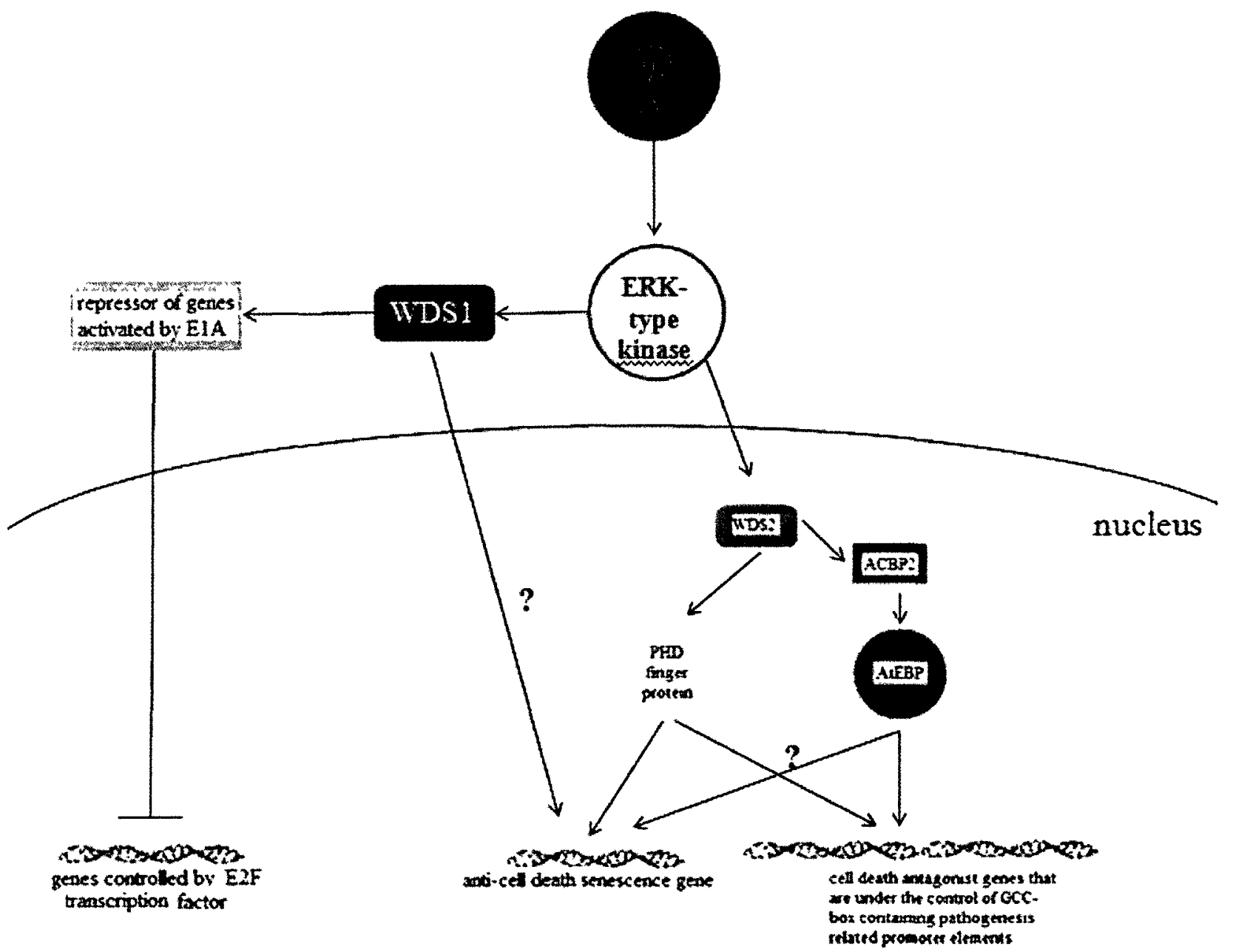

Figure 5.1: Predicted model of pathway WDS1 and WDS2 may belong to.

$A t B I-1$ and $A t D A D I$ code for proteins that both act as the suppressors of ER stress induced PCD. Neither the expression of $A t B I-1$, nor that of $A t D A D I$ was affected by $w d s 1 / w d s 2$ mutation, indicating that WDS1 and WDS2 do not play a role in ER homeostasis. WT and $w d s 1 / w d s 2$ plants did not exhibit differences in neither $A t B I-1$ nor $A t D A D 1$ expression after treatment with the fungal toxin FB1, which was previously indicated to induce ER stress that is 
mediated by, among many other proteins, AtBI-1 and AtDAD1. Furthermore the expression of AtBI-I and AtDADI appeared constant over the $48 \mathrm{~h}$ period tested regardless of the treatment the leaves received. Therefore, our results indicate that neither $2 \mu \mathrm{FB} 1$ treatment nor $w d s I / w d s 2$ mutation interfere with normal ER homeostasis, and that if WDS1 and WDS2 do act as cell death antagonist, they do so in an AtBI-1 and AtDAD1 independent manner.

The results of the western blotting experiments performed indicated that WDS1 and/or WDS2 influence the cleavage of a protein recognized by mammalian cleaved caspase 3 specific antibody. It was observed that the level of the protein recognized by cleaved caspase 3 antibody was lower in $w d s l / w d s 2$ leaves than in the WTs (Figure 4.2). This was not what I expected because past experiments carried out in our lab and the bioinformatic analysis described earlier indicated that WDS1 and WDS2 are possible cell death antagonists that are supposed to suppress PCD and caspase 3 cleavage, which is a hallmark of PCD. This protein was sent for mass spectrometric analysis and more will be found out about the nature of this protein once the mass spectrometric analysis' results will be available. The proteins recognized by the other apoptotic protein specific antibodies exhibited no differences between the WT and the double mutant samples indicating that the absence of WDS1 and/or WDS2 had no effect on their levels in plant cells.

All the intracellular kinases tested have been implicated to regulate apoptosis in animal cells in one or more ways. From the immunoblotting experiments described earlier it appears that the absence of WDS1 and/or WDS2 affects the activity of PKB/Akt, and both the activity of serine and threonine specific CDKs in an ATM/ATR independent manner. 


\subsection{WDS3}

From the five genes belonging to the WDS gene family, only WDS3 is located on chromosome 3, while the rest are located on chromosome 5. WDS3, also known as AtSMU1, has been indicated to have ubiquitin ligase activity and to be located in the nucleus of the cell where it interacts with a protein known as AtSMU2 that was shown to function in pre-mRNA splicing (Higa et.al., 2006; Chung et.al., 2009). The formation of eukaryotic mRNA starts with the transcription of the entire gene, including introns, to form pre-mRNA. The pre-mRNA is then capped, which is followed by excision of the introns and connecting of the ends of the exons. Splicing is carried out by the spliceosome, a multi subunit protein complex composed of several small nuclear ribonucleoproteins (snRNPs), whose levels are tightly regulated. atsmul and atsmu2 loss of function mutations also cause similar changes in phenotype, further confirming that AtSMU1/WDS3, not unlike aAtSMU2, plays a role in pre-mRNA splicing. Due to its predicted ubiquitin ligase activity, the role of AtSMU1/WDS3 in pre-mRNA splicing is proposed to be the regulation of the levels of snRNPs during pre-mRNA splicing (Higa et.al., 2006; Chung et.al., 2009).

The expression of the gene encoding AtSMU1/WDS3 seems to be down-regulated during biotic stress, and up-regulated during osmotic and drought stress indicating that maybe it does not act in the processing of pathogenesis related gene products, but acts in the processing of products of genes active in certain abiotic stress responses.

\subsection{WDS4 and WDS5}

WDS4 was shown to be part of the multi-subunit ubiquitin ligase called anaphasepromoting complex $(\mathrm{APC} / \mathrm{C})$ that regulates cell cycle progression and mitotic exit by targeting cell cycle regulating proteins, including mitotic cyclins, for proteasomal degradation (Kevei 
et.al., 2011; Perez-Perez et. al., 2008). Within this complex WDS4 appears to be in direct contact with HBT, a protein whose absence causes defects in cell division and expansion (Sarrelbo et.al., 2006). WDS4 also interacts with RID 3, a protein that has been implicated in negative regulation of cell division (Tamaki et.al., 2009) and EMB2757, which also controls cell division (Baster et.al., 2009; Yamagishi et.al., 2005) and has been predicted to interact with WDS5. Transcriptome data analaysis indicated that WDS4 levels increase in Arabidopsis leaves exposed to a variety of biotic and abiotic stress that are known to negatively affect plant growth through inhibition of the cell cycle machinery (Veylder et.al., 2007). Up-regulation of WDS4 would allow quicker degradation of cylins and therefore quicker mitotic exit.

Our motif analysis presented in Chapter III of this thesis indicated that WDS5 is a cytosolic protein that belongs to the CAAX box family of proteins. Proteins belonging to this family have C-terminal ends that terminate in a conserved CXXX motif that undergoes prenylation in the cytoplasm and then methylation and further processing in the ER (Bracha et.al., 2002; Wennerberg et.al., 2005). The mammalian Ras family of proteins also terminate in a CAAX box that is prenylated and subsequently methylated (Bracha et.al., 2002; Wennerberg et.al., 2005). Ras proteins are GTPases that function as molecular switches that activate cytoplasmic MAPK signaling networks that control gene expression, regulate cell proliferation, differentiation, and survival (Wennerberg et.al., 2005). Ras protein homolougs have not been identified in plants, but many scientists believe that plants do possess their functional equivalents. Assuming that this is true, WDS5 could possibly be one such molecular switch that fits into a signaling pathway that involves EMB2757 and WDS4. WDS5 could be either a negative or positive regulator of WDS4, which promotes cyclin degradation and mitotic exit. Upregulation of WDS5 following biotic and abiotic stresses suggests that WDS5 is either a positive 
regulator of WDS4 and function is promotion of mitotic exit and cell cycle arrest, or that WDS5 is a negative regulator of WDS4 and is triggered when the plant is stressed as part of an antistress pathway that tries to maintain normal cellular processes.

\subsection{Future work}

By studying the control of degenerative processes that take place during stress and senescence induced PCD it will be possible to identify genes that encode proteins that delay or accelerate PCD. Research indicates that there are many different signaling pathways involved in these cell death processes. Many of pathways are initiated by different signals but they may crosstalk with one another. This crosstalk could be the explanation of why some of the genes whose expression is up-regulated during senescence is also up-regulated during pathogenesis induced HR. By gaining an understanding of how these pathways work and the components that positively and negatively regulate them, we would be able to engineer crops that have increased life spans and/or are more resistant to environmental stress. This would help farmers reduce crop yield losses caused by environmental stresses, and in some cases could even increase the shelf life of produce, which in the modern globalized world have to travel thousands of miles before reaching grocery stores.

Our laboratory's past experiments and the bioinformatic and transcriptome data analysis performed during my time in the Xing Lab indicate that WDS1 and WDS2 may negatively regulate senescence and stress induced cell death pathways in plants. WDS4 and WDS5 were also predicted to be stress responsive proteins. In order to further support our prediction, other gene expression and protein-protein interaction databases will be consulted and if our future experiments will prove that these proteins provide increased resistance against stresses, then their 
over-expression in agriculturally important plants could help increase crop yields compromised by environmental stresses.

\section{Appendix 1: Follow-up bench work}

\subsection{Mutation and cloning of WDS2}

Since previous work carried out in our laboratory indicated that WDS2 has a more significant role in suppressing PCD than WDS1, I have decided to introduce mutations into WDS2's key motifs, which were identified by the in silico motif analysis described above. To confirm which motifs may play a significant role in WDS2's functioning, I chose to mutate two potential phosphorylation sites (black rectangles), as well as two potential kinase docking sites (red rectangles).

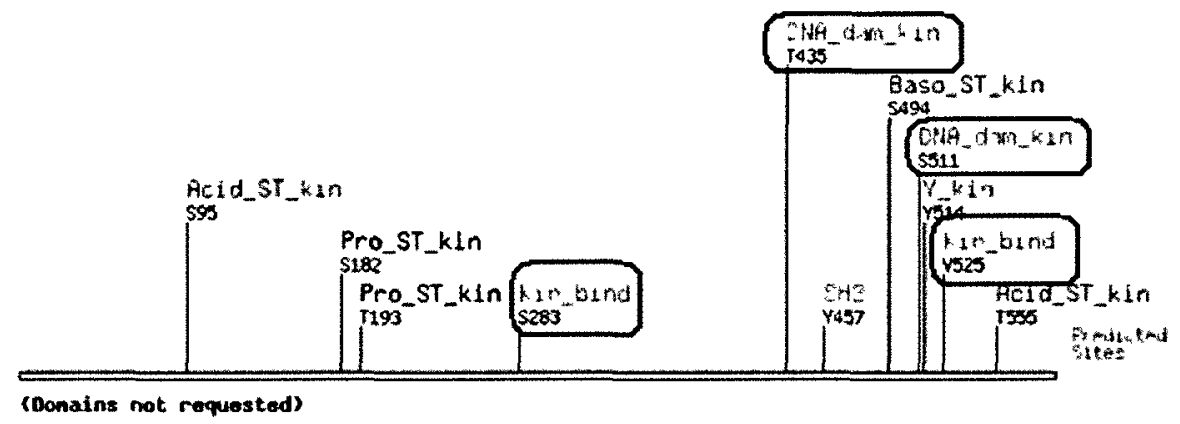

The threonine residue at position 435 (T435), as well as the serine residue at position 511 (S511) are possibly phosphorylated, an event that may alter the activation state of WDS2. Since phosphorylation introduces a negative charge to the protein, I have decided to introduce negatively charged residues (i.e. glutamic acid $\mathrm{E}$ and aspartic acid D, respectively) in place of T435 and S511, hoping that this action would resemble the phosphorylation carried out by upstream kinases, and therefore permanently lock the protein in a conformation that mimics the conformation induced by the addition of a phosphate group (Figure 3.50 and 3.51). If these sites were important for this protein's activity, then the plants harbouring these mutant forms of 
WDS2 would exhibit altered life spans and/or stress tolerance compared to their wild type relatives.

Mutations to change T435 and S511 to alanine (A, a nonpolar, neutral amino acid) were also carried out (Figure 3.50 and 3.51). The presence of alanine would make it impossible for kinases to act on their target motifs, causing the protein to stay permanently in its unphosphorylated form. Again, if these sites were important for this protein's activity then a difference would be observed in their life span and stress resistance.

As an initial test, all of the above-described mutations were carried out separately, meaning that no more than one mutation was introduced at one time.

The potential kinase docking sites identified by the motif analysis tool had positively charged amino acids grouped at one end of the motif and negatively charged amino acids grouped at the opposite end. To cause a conformational change in these sites I chose to introduce negatively charged residues in place of the positive ones. WDS2 was targeted for an arginine (R) to glutamic acid (E), lysine $(\mathrm{K})$ to glutamic acid $(\mathrm{E})$, and histidine $(\mathrm{H})$ to aspartic acid (D) mutation at positions 518, 522 and 530, respectively (Figure 3.52). WDS2 was also targeted for a histidine (H) to aspartic acid (D) and lysine (K) to glutamic acid (E) mutation at position 284 and 287, respectively (Figure 3.53). By introducing these mutations I hoped to change the conformation of these docking sites causing the protein to be unable to dock its potential target kinase or its potential upstream kinase. This would allow us to test whether either one of these sites was important for this protein's proper functioning.

The above described mutated forms of WDS2 were also intended to be introduced into $w d s 2$ Arabidopsis thaliana plants, in order to see whether they have the ability to rescue $w d s 2$ plants from faster senescence and increased susceptibility to FB1, SA, and salt stress, which they 
have previously demonstrated. The images presented below illustrate the results of the steps taken towards achieving mutation of WDS2 and cloning of the mutant forms of WDS2 into pVKH18::GFPN plasmid (see Appendix 3 for map).

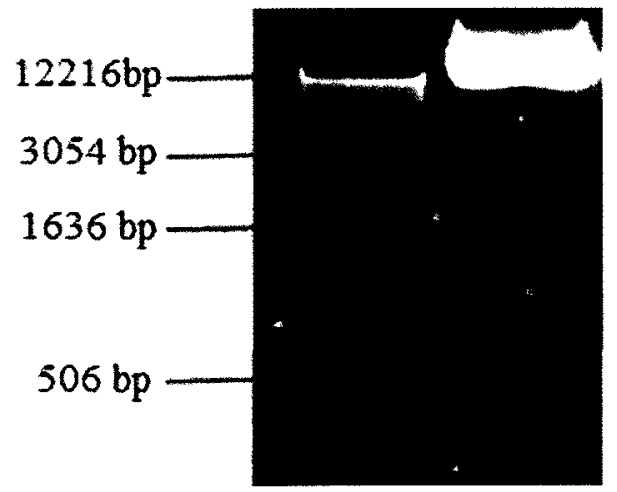

Figure 3.49: pVKH18::GFPN -WDS2 construct, which was used as template in OE-PCR

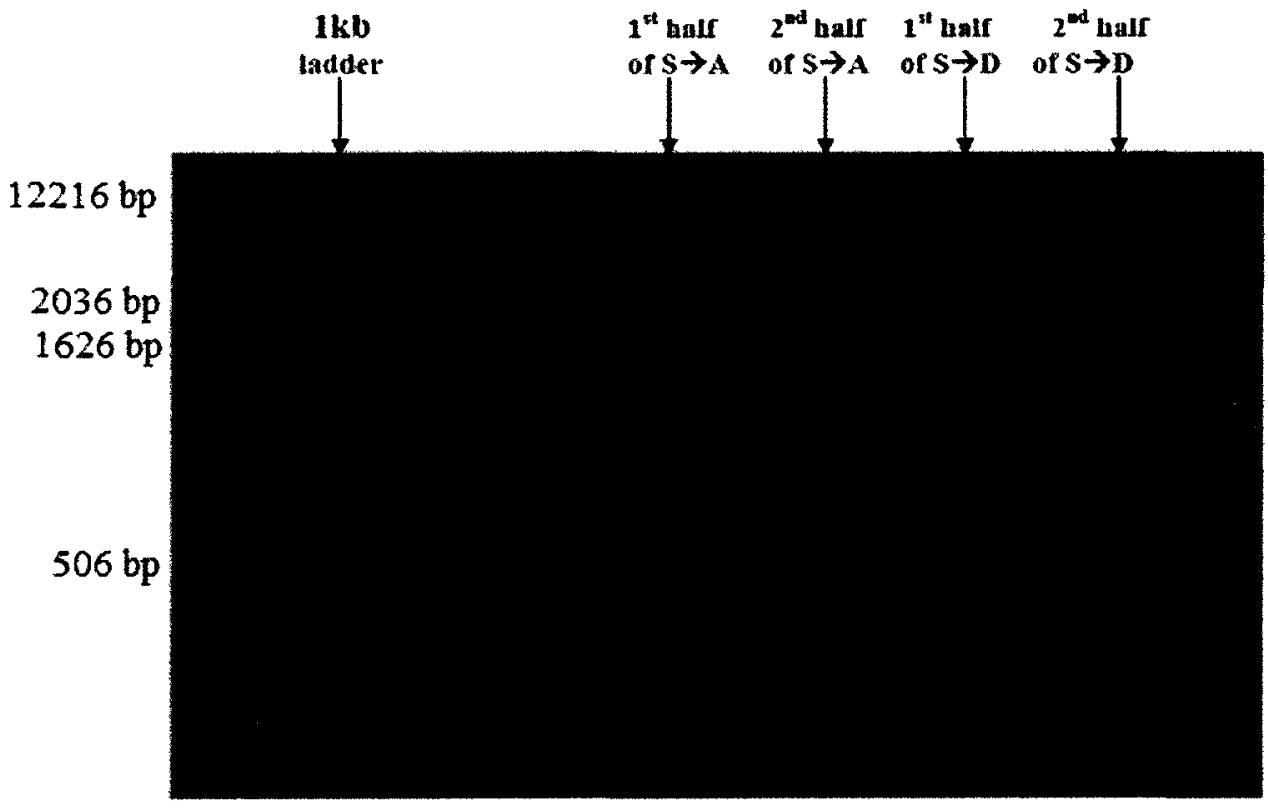

a)

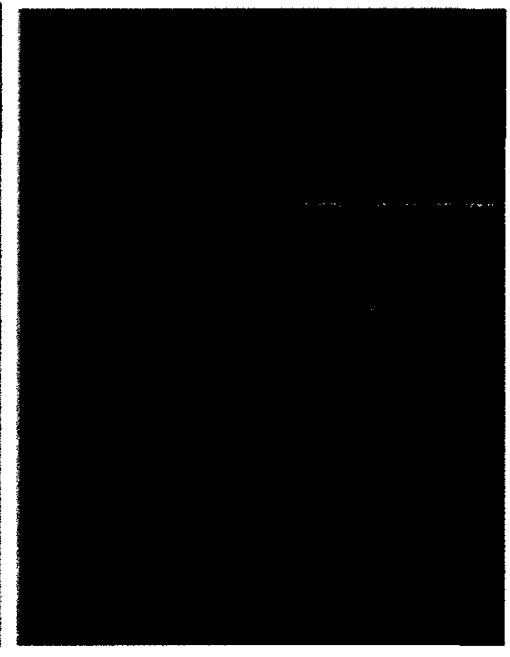

b)

Figure 3.50: a). Site-directed mutagenesis of WDS2. WDS2 was targeted for a serine (S) to alanine (A) and serine (S) to aspartic acid (D) mutation at position 511 that is encoded at the nucleotide level by internal, mutagenic primers. Red arrow points to first half of mutated strands $(1533 \mathrm{~kb})$, while blue arrow points to second half of mutated strands $(237 \mathrm{bp}) \mathrm{b}$ ). Full length WDS2 produced with the half reaction illustrated in a). as templates, and primers that flank the two ends of the gene and contain SalI and BamHI restriction endonuclease cut sites. Bands within red box contain a serine (S) to alanine (A) mutantion, while bands within the blue box contain a serine (S) to aspartic acid (D) mutation. 


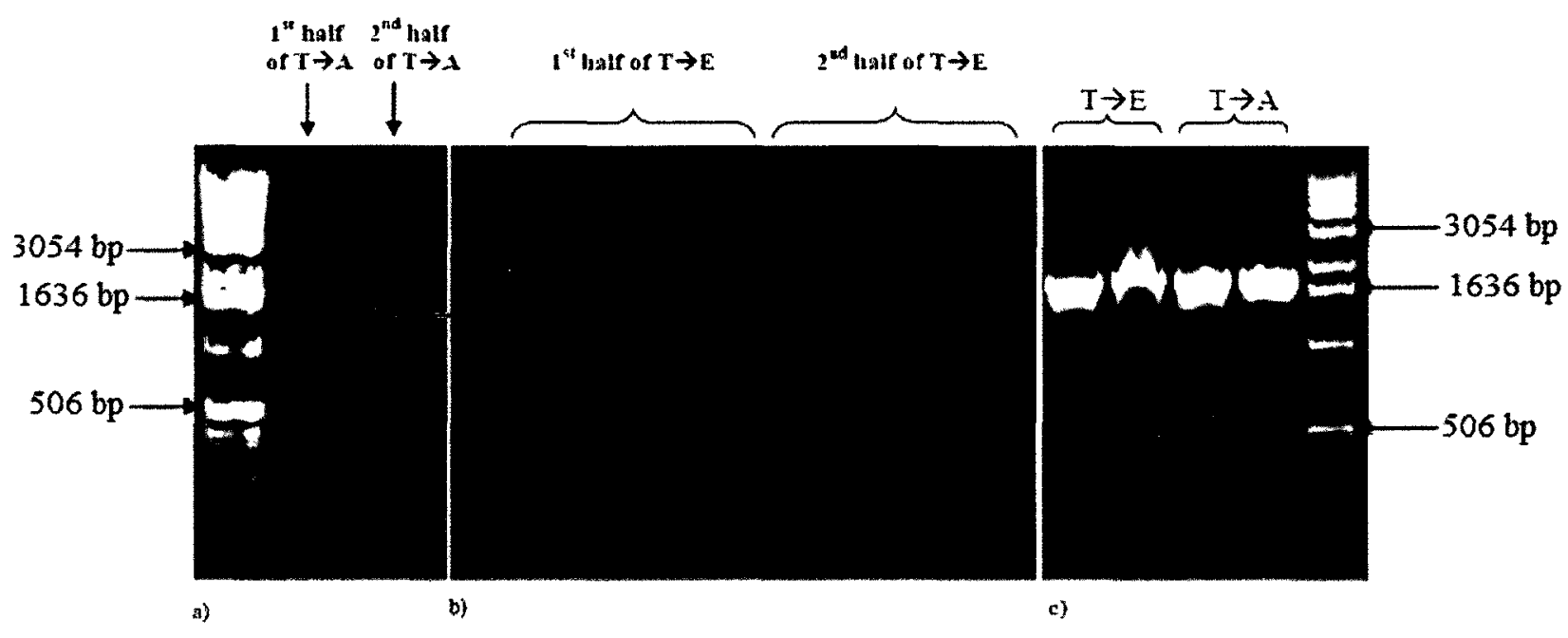

Figure 3.51: Site-directed mutagenesis of WDS2. WDS2 was targeted for a threonine (T) to alanine (A) and threonine (T) to glutamic acid (E) mutation at position 435 that is encoded at the nucleotide level by internal, mutagenic primers. a). illustrates the two half reactions of $\mathrm{T} \rightarrow \mathrm{A}$ mutation; b). illustrates the two half reactions of $\mathrm{T} \rightarrow \mathrm{E}$ mutation. Red arrows point to sequences that are $1305 \mathrm{bp}$ is length, while the blue ones point to sequences that are $465 \mathrm{bp}$ long. c). Full length WDS2 produced with the half reactions (illustrated in a). and b).) as templates, and primers containing SalI and BamHI restriction endonuclease cut sites.

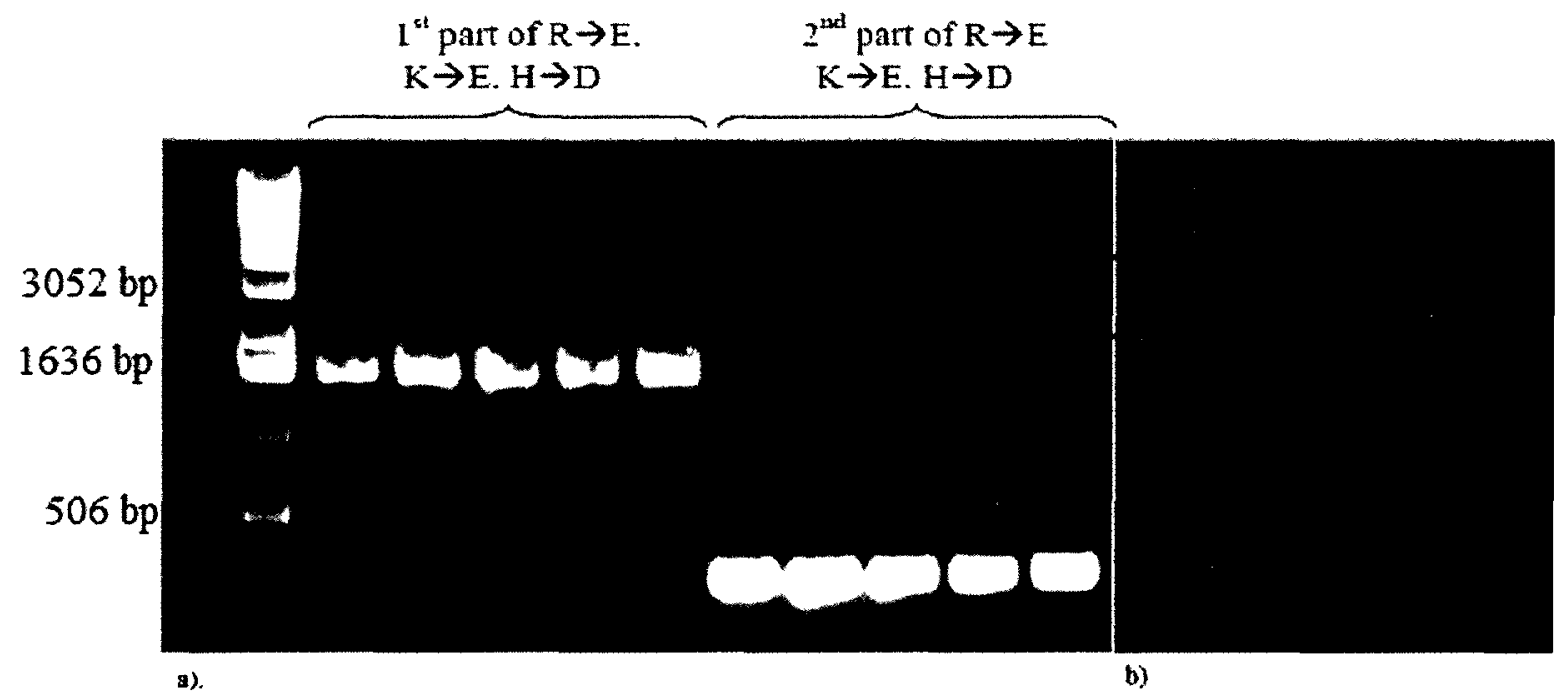

Figure 3.52: Site-directed mutagenesis of WDS2. WDS2 was targeted for an arginine (R) to glutamic acid (E), lysine (K) to glutamic acid (E), and histidine (H) to aspartic acid (D) mutation at positions 518, 522 and 530, respectively, that is encoded at the nucleotide level by internal, mutagenic primers. a). The two DNA sequences that were generated during the first round of PCR. Red arrow points to the sequences that are $1548 \mathrm{bp}$ in length, while the blue arrow points to the sequences that are 222 bp long. b). Full length WDS2 produced with the half reactions (illustrated in a).) as templates, and primers that flank the two ends of the gene and contain SalI and BamHI restriction endonuclease cut sites. Total length of overlap extended DNA is $1770 \mathrm{bp}$. 


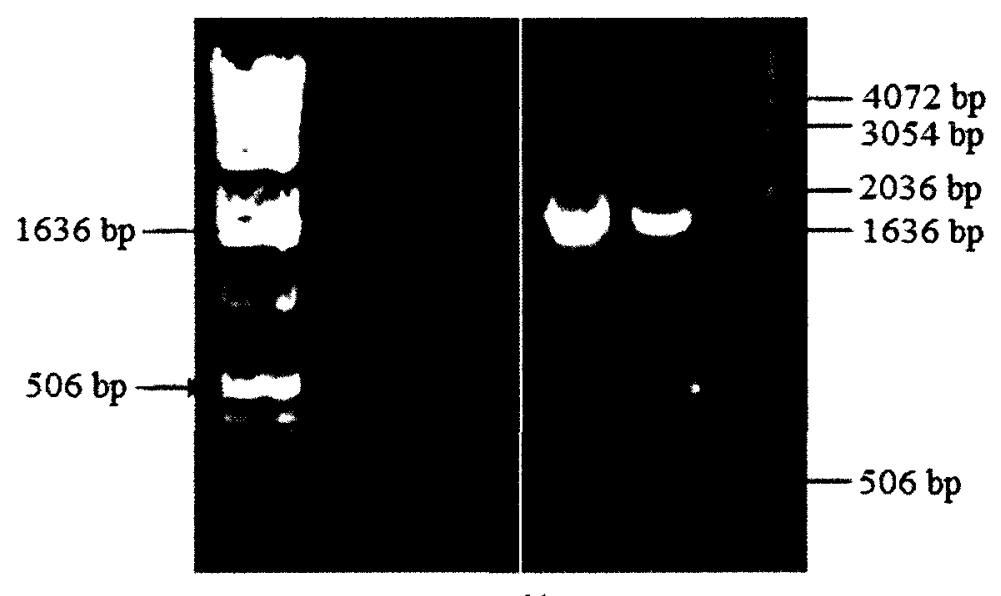

a).

b).

Figure 3.53: Site-directed mutagenesis of WDS2. WDS2 was targeted for a histidine (H) to aspartic acid (D) and lysine (K) to glutamic acid (E) mutation at position 284 and 287, respectively, that is encoded at the nucleotide level by internal, mutagenic primers. a). The two DNA sequences produced during the first round of PCR. The first strand generated was $840 \mathrm{bp}$ (red arrow) and the second was $930 \mathrm{bp}$ (blue arrow) in length b). Full length WDS2 produced with the DNA strands illustrated in a). as templates, and primers that flank the two ends of the gene and contain SalI and BamHI restriction endonuclease cut sites.

Following site directed mutagenesis the PCR products were digested with the restriction enzymes SalI and BamHI (not shown). In order to generate free pVKH18::GFPN, pVKH18::GFPN-WDS2 constructs were also digested (Figure 3.54). The following figure illustrates restriction enzyme digestion of the pVKH18::GFPN-WDS2 constructs prepared by AlShammari (2009).

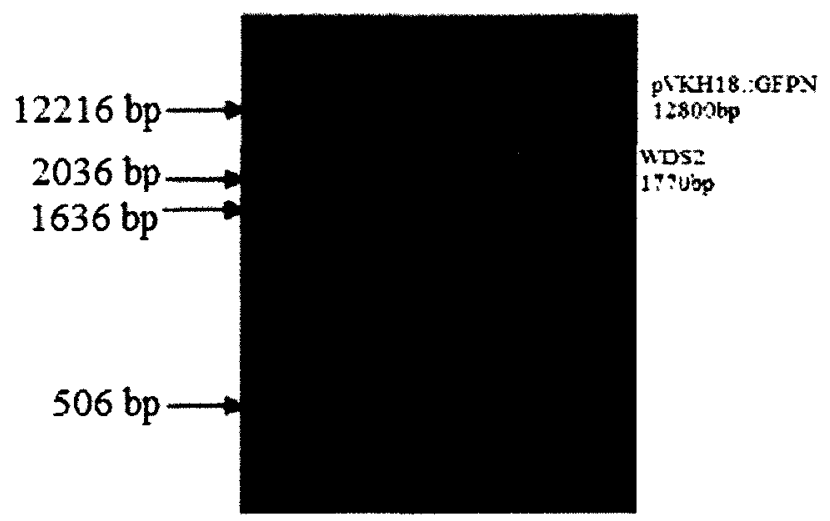

Figure 3.54: Restriction enzyme digestion of pVKH18::GFPN-WDS2 construct with Sall and BamHI 
After the mutated WDS2 sequences were ligated into pVHK18::GFPN plasmids, bacterial transformation was performed. With the exception of the gene containing the serine to alanine mutation at position 511 , none of the cloning attempts were successful. This could have been due to the lack of long enough nucleotide overhangs outside the primers' restriction endonuclease cut sites, which could have resulted in diminished endonuclease docking capacity. Successful cloning of S511 $\rightarrow$ A mutant was confirmed by colony PCR and restriction enzyme digestion of the extracted constructs.

In order to maximize cloning efficiency I have decided to ligate the mutated genes into TOPO vectors. After successful insertion into TOPO, the mutant genes were excised and ligated into pVHK18::GFPN. After ligation the constructs were used to transform Mach1 ${ }^{\mathrm{TM}}$ T1 PhageResistant $\left(\mathrm{T} 1^{\mathrm{R}}\right)$ E.coli competent cells. Successful transformation was verified using colony PCR (Figure 3.55). In order to further confirm that cloning was successful the constructs will be extracted after amplification within Mach1 ${ }^{\mathrm{TM}} \mathrm{T} 1$ Phage-Resistant $\left(\mathrm{T} 1^{\mathrm{R}}\right)$ E.coli competent cells and subjected to cleavage by SalI and BamHI.
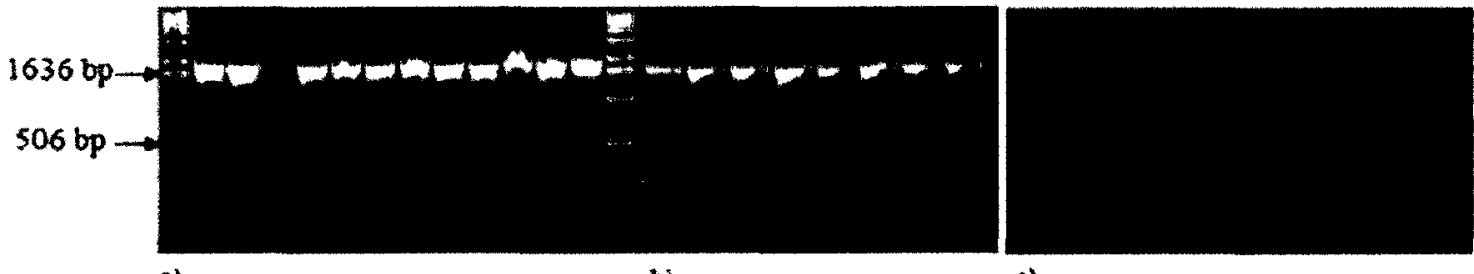

a)

b)

c).

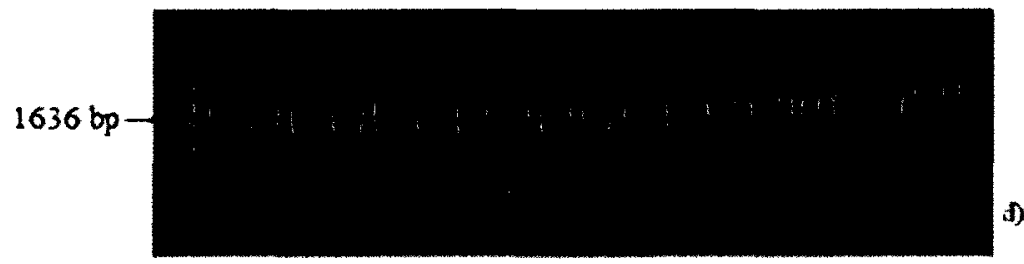

Figure 3.55 Colww pro.

a). 5 to $\mathrm{D}$ mutation at position

511. b) I to A mitution a:

postion $43 \leq \mathrm{ct}$. I to $\mathrm{E}$

matation ponition $\$ 35 \mathrm{~d}) H$

i)

to $D$ ad Kto $E$ motuion at

position 281 and $\geq 57$.

respectnely e). $R$ to $\mathrm{E} . \mathrm{K}: 0 \mathrm{H}$

ard ll to $D$ mitaling at

movition $\$ 18>22$ and $\$ 30$

respectiveity

note different

lanes represent

1636 bo

$506 \mathrm{bp}$

-) 


\subsection{Preparation of pLRCWHEAT2-gevAgdv-WDS2 construct}

In order to create transgenic Triticum aestivum plants, wild type WDS2 was successfully ligated into pLRCWHEAT2-gevAgdv vector (see Appendix 5 for map). This vector contained a ccdB lethal gene, which was bordered by $\mathrm{XbaI}$ and PstI restriction endonuclease cleavage sites. The lethal gene was excised using the latter restriction endonucleases (Figure 3.56a). WDS2 was amplified using primers that were designed to contain XbaI and PstI recognition sites. After digestion, the plasmid and the insert were ligated and inserted into E.coli DH5 $\alpha$ chemically competent cells. Successful transformation was confirmed by colony PCR (Figure 3.56b).

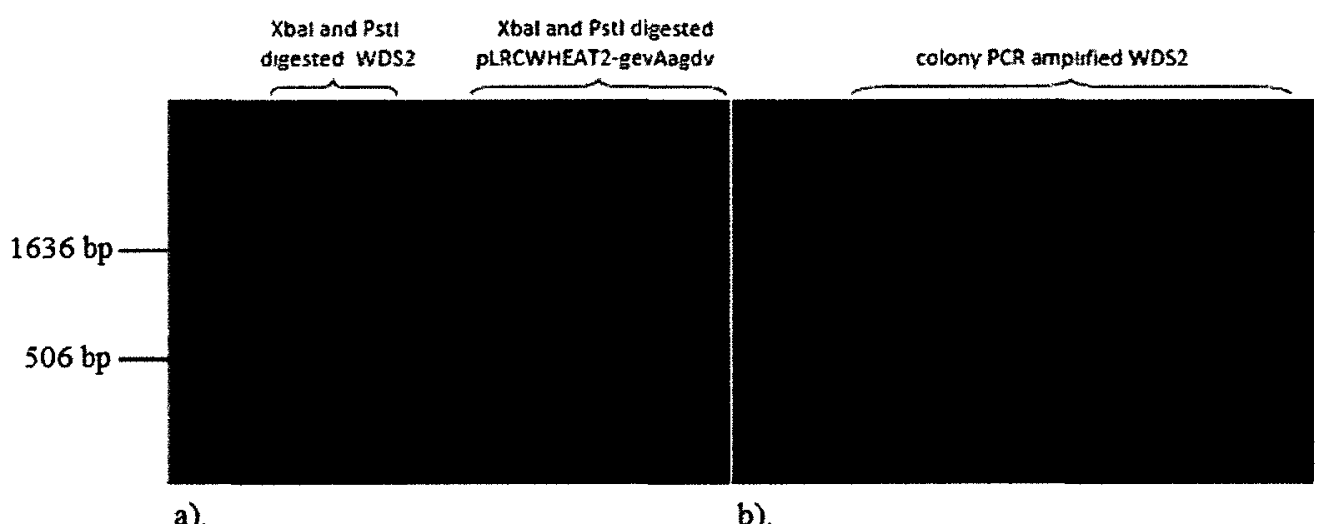

Figure 3.56: a).Restriction endonuclease digestion of WDS2 and pLRCWHEAT2-gevAgdv with $\mathrm{XbaI}$ and PstI. Red arrow points to vector (7642bp) without ccdB, while the blue arrow points to the excised ccdB gene $(681 \mathrm{bp})$. b). Colony PCR for confirmation of successful transformation of competent cells. Primers used were the same as the ones used for WDS2 amplification.

Following confirmation the pLRCWHEAT2-gevAgdv-WDS2 constructs were sent to our collaborators at Lethbridge Research Center, Agriculture and Agri-Food Canada, where transgenic work will be carried out.

\subsection{Construct preparation for pull-down assay}

To determine what proteins WDS2 may physically interact with, I planned to perform pull-down assay. To do this WDS2 was ligated into the $\mathrm{N}$-terminal polyhistidine tag-containing vector, pET-14b (4671 bp) (see Appendix 4 for map). The construct was then inserted into 
NovaBlue competent cells for amplification. The constructs (Figure 3.57) were then extracted and transformation of BL21(DE3)pLysS competent cells, a special protein expression strain of E.coli that provides expression control with $\mathrm{T} 7$ promoter-driven vectors such as $\mathrm{pET}-14 \mathrm{~B}$, was attempted. Unfortunately, this step failed and time did not permit further attempts.

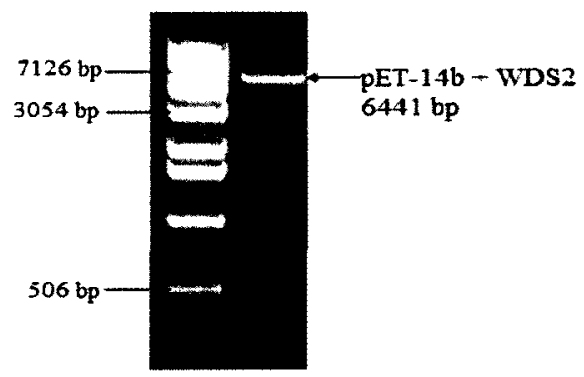

Figure 3.57: pET-14b-WDS2 construct extracted from NovaBlue cells.

\subsection{Cloning of WDS3}

In order to generate Arabidopsis thaliana plants that over-express WDS3, the gene was inserted into pVKH18::GFPN vector. The constructs were then used to transforms E.coli DH5 $\alpha$ chemically competent cells (Figure 3.58).

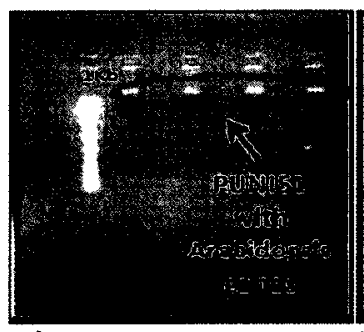

a)

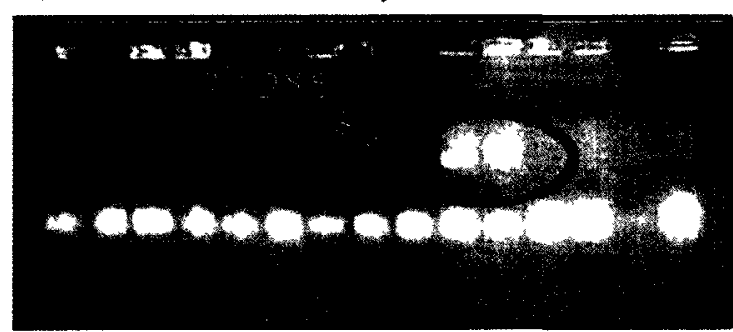

e).

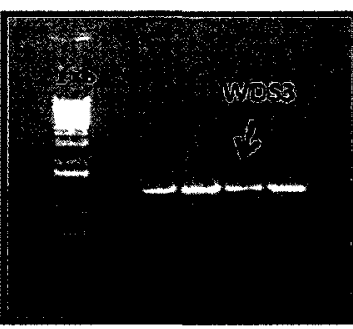

b).

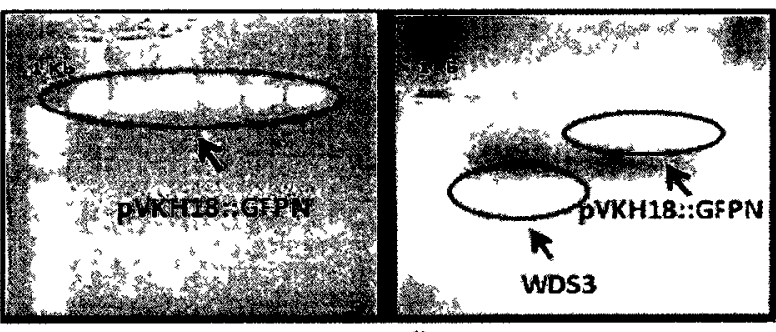

c). d).

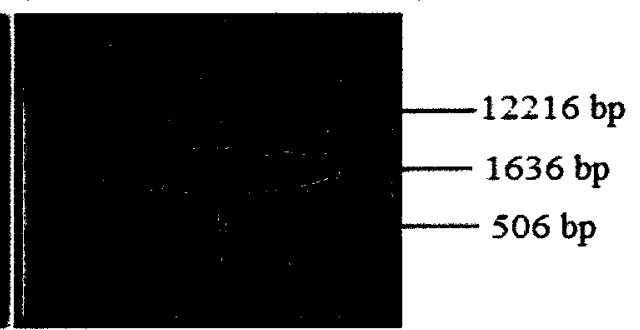

f).

Figure 3.58: Ligation of WDS3 into pVKH18::GFPN; a). cDNA library within pUNI51 plasmids. b). PCR amplified WDS3 (1536 bp); c). undigested pVKH18::GFPN; d). WDS3 and pVKH18::GFPN double digested with SalI and BamHI; e). Transformation check using colony PCR; f). Restriction enzyme digestion of extracted constructs. 


\section{Appendix 2 : ScanSite Database Analysis of Arabidopsis WDS protein}

\section{WDS1}

\begin{tabular}{|c|c|c|c|c|}
\hline \multicolumn{5}{|c|}{ Kinase binding site group (Kin bind) } \\
\hline \multicolumn{3}{|c|}{ Erk D-domain } & \multicolumn{2}{|c|}{ Gere Carra : } \\
\hline Site & $\underline{\text { Score }}$ & Percentile & Sequence & $\underline{\mathrm{SA}}$ \\
\hline L363 & $\underline{0.4661}$ & $0.021 \%$ & RIPKVVDLAVTPDGE & 0.253 \\
\hline \multicolumn{3}{|c|}{ Erk D-domain } & \multicolumn{2}{|l|}{ Gene Carrol } \\
\hline Site & $\underline{\text { Score }}$ & $\underline{\text { Percentile }}$ & Sequence & $\underline{\text { SA }}$ \\
\hline L107 & $\underline{0.5538}$ & $0.121 \%$ & LKRGDVSLALNVLRK & 0.262 \\
\hline \multicolumn{3}{|c|}{ Erk D-domain } & \multicolumn{2}{|l|}{ Gere Card } \\
\hline Site & $\underline{\text { Score }}$ & $\underline{\text { Percentile }}$ & Sequence & $\underline{\mathrm{SA}}$ \\
\hline V365 & $\underline{0.4916}$ & $0.038 \%$ & $\underline{\text { PKVVDLAVTPDGESM }}$ & 0.528 \\
\hline
\end{tabular}

WDS2

\begin{tabular}{|c|c|c|c|c|}
\hline \multicolumn{5}{|c|}{ Tyrosine kinase group (Y_kin) } \\
\hline \multicolumn{3}{|c|}{ Itk Kinase } & \multicolumn{2}{|c|}{ (Gerne Caut } \\
\hline$\underline{\text { Site }}$ & $\underline{\text { Score }}$ & $\underline{\text { Percentile }}$ & Sequence & $\underline{\mathrm{SA}}$ \\
\hline Y514 & $\underline{0.4491}$ & $0.965 \%$ & GSEDSQVYIWHRSTG & 0.463 \\
\hline \multicolumn{5}{|c|}{ Sre homology 2 group (SH2) } \\
\hline \multicolumn{3}{|c|}{ PLCg C-terminal SH2 } & \multicolumn{2}{|l|}{ Gerae Carrel } \\
\hline$\underline{\text { Site }}$ & $\underline{\text { Score }}$ & $\underline{\text { Percentile }}$ & $\underline{\text { Sequence }}$ & $\underline{\mathrm{SA}}$ \\
\hline Y457 & $\underline{0.4170}$ & $0.384 \%$ & $\underline{\text { SLSNDNKYILVNLLN }}$ & 0.515 \\
\hline \multicolumn{5}{|c|}{ Basophilic serine/threonine kinase group (Baso_ST_kin) } \\
\hline \multicolumn{3}{|c|}{ PKC zeta } & \multirow[t]{2}{*}{ Gere Care } & A \\
\hline Site & $\underline{\text { Score }}$ & Percentile & & $\underline{\mathrm{SA}}$ \\
\hline S494 & $\underline{0.5388}$ & $0.935 \%$ & RSRFIIRSCFGGYKQ & 0.194 \\
\hline \multicolumn{3}{|c|}{ AMP_Kinase } & \multicolumn{2}{|l|}{ Greme Card } \\
\hline$\underline{\text { Site }}$ & $\underline{\text { Score }}$ & $\underline{\text { Percentile }}$ & $\underline{\text { Sequence }}$ & $\underline{\mathrm{SA}}$ \\
\hline S185 & $\underline{0.6049}$ & $0.587 \%$ & $\underline{\text { SSLISPSSFISHTTS }}$ & 0.518 \\
\hline \multicolumn{5}{|c|}{ DNA damage kinase group (DNA_dam_kin) } \\
\hline \multicolumn{3}{|c|}{ DNA PK } & \multicolumn{2}{|c|}{ 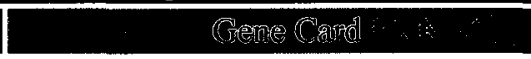 } \\
\hline$\underline{\text { Site }}$ & $\underline{\text { Score }}$ & $\underline{\text { Percentile }}$ & Sequence & $\underline{\mathrm{SA}}$ \\
\hline T435 & $\underline{0.4982}$ & $0.507 \%$ & SLFDREATVERLIEE & 1.457 \\
\hline \multicolumn{3}{|c|}{ DNA PK } & \multicolumn{2}{|l|}{ Gienge Carited } \\
\hline$\underline{\text { Site }}$ & $\underline{\text { Score }}$ & $\underline{\text { Percentile }}$ & Sequence & $\underline{\mathrm{SA}}$ \\
\hline S511 & $\underline{0.5165}$ & $0.689 \%$ & IASGSEDSQVYIWHR & 1.789 \\
\hline \multicolumn{5}{|c|}{ Acidophilic serine/threonine kinase group (Acid_ST_kin) } \\
\hline \multicolumn{3}{|c|}{ Casein Kinase 1} & \multicolumn{2}{|l|}{ ceme Corre } \\
\hline Site & $\underline{\text { Score }}$ & Percentile & Sequence & $\underline{\mathrm{SA}}$ \\
\hline T555 & $\underline{0.4251}$ & $0.689 \%$ & ASASDDGTIRIWGLD & 0.526 \\
\hline \multicolumn{3}{|c|}{ Casein Kinase 1} & \multirow{2}{*}{\multicolumn{2}{|c|}{ Gene Cand }} \\
\hline Site & $\underline{\text { Score }}$ & $\underline{\text { Percentile }}$ & & $\underline{\mathrm{SA}}$ \\
\hline
\end{tabular}




\begin{tabular}{|c|c|c|c|c|}
\hline S95 & $\underline{0.4348}$ & $0.871 \%$ & LEEESGISLHNSTIK & 0.399 \\
\hline \multicolumn{5}{|c|}{ Proline-dependent serine/threonine kinase group (Pro_ST_kin) } \\
\hline \multicolumn{3}{|c|}{ Erk1 Kinase } & \multicolumn{2}{|c|}{ 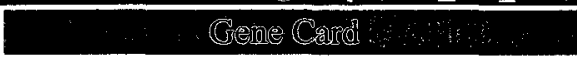 } \\
\hline$\underline{\text { Site }}$ & $\underline{\text { Score }}$ & Percentile & Sequence & $\underline{\mathrm{SA}}$ \\
\hline S182 & $\underline{0.4631}$ & $0.223 \%$ & ELASSLISPSSFISH & 0.493 \\
\hline \multicolumn{3}{|c|}{ Cdk5 Kinase } & \multicolumn{2}{|l|}{ Gene Carrol } \\
\hline Site & $\underline{\text { Score }}$ & Percentile & Sequence & $\underline{\mathrm{SA}}$ \\
\hline T193 & $\underline{0.4696}$ & $0.609 \%$ & FISHTTSTPGKESVN & 1.957 \\
\hline \multicolumn{3}{|c|}{ Cdc2 Kinase } & \multicolumn{2}{|l|}{ Geine Carred } \\
\hline Site & $\underline{\text { Score }}$ & Percentile & Sequence & $\underline{\mathrm{SA}}$ \\
\hline T193 & $\underline{0.5358}$ & $0.902 \%$ & FISHTTSTPGKESVN & 1.957 \\
\hline \multicolumn{5}{|c|}{ Kinase binding site group (Kin_bind) } \\
\hline \multicolumn{3}{|c|}{ PDK1 Binding } & \multicolumn{2}{|c|}{ Gene Card : } \\
\hline Site & $\underline{\text { Score }}$ & Percentile & Sequence & $\underline{\mathrm{SA}}$ \\
\hline S283 & $\underline{0.6144}$ & $0.855 \%$ & EVWFLQFSHNGKYLA & 1.036 \\
\hline \multicolumn{3}{|c|}{ Erk D-domain } & \multicolumn{2}{|l|}{ Gene Carrod: } \\
\hline Site & $\underline{\text { Score }}$ & $\underline{\text { Percentile }}$ & Sequence & $\underline{\mathrm{SA}}$ \\
\hline V525 & $\underline{0.6380}$ & $0.471 \%$ & RSTGKLIVELPGHAG & 0.217 \\
\hline
\end{tabular}

WDS3

\begin{tabular}{|c|c|c|c|c|}
\hline \multicolumn{5}{|c|}{ Tyrosine kinase group (Y_kin) } \\
\hline \multicolumn{3}{|c|}{ Lck Kinase } & \multicolumn{2}{|c|}{ Gene Card: } \\
\hline Site & $\underline{\text { Score }}$ & $\underline{\text { Percentile }}$ & $\underline{\text { Sequence }}$ & $\underline{\mathrm{SA}}$ \\
\hline Y77 & $\underline{0.4022}$ & $0.115 \%$ & RNKLEDLYEQIVLEM & 1.040 \\
\hline \multicolumn{5}{|c|}{ Src homology 3 group (SH3) } \\
\hline \multicolumn{3}{|c|}{ Itk SH3 } & \multicolumn{2}{|c|}{ (Gene (Cond: } \\
\hline Site & $\underline{\text { Score }}$ & Percentile & Sequence & $\underline{\mathrm{SA}}$ \\
\hline P387 & $\underline{0.5216}$ & $0.061 \%$ & DCLQTFKPPPPLRGT & 2.269 \\
\hline \multicolumn{3}{|c|}{ Intersectin SH3A } & \multicolumn{2}{|c|}{ Geras Cand } \\
\hline$\underline{\text { Site }}$ & $\underline{\text { Score }}$ & $\underline{\text { Percentile }}$ & $\underline{\text { Sequence }}$ & $\underline{\mathrm{SA}}$ \\
\hline P390 & $\underline{0.5232}$ & $0.098 \%$ & QTFKPPPPLRGTDAS & 1.354 \\
\hline \multicolumn{3}{|c|}{ Cbl-Associated protein C-SH3 } & \multicolumn{2}{|l|}{ 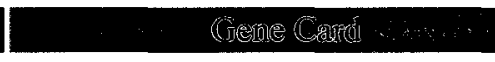 } \\
\hline Site & $\underline{\text { Score }}$ & $\underline{\text { Percentile }}$ & $\underline{\text { Sequence }}$ & $\underline{\mathrm{SA}}$ \\
\hline P390 & $\underline{0.6209}$ & $0.186 \%$ & QTFKPPPPLRGTDAS & 1.354 \\
\hline \multicolumn{3}{|c|}{ p85 SH3 mode2 } & \multicolumn{2}{|l|}{ 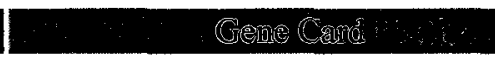 } \\
\hline Site & $\underline{\text { Score }}$ & $\underline{\text { Percentile }}$ & Sequence & $\underline{\mathrm{SA}}$ \\
\hline P390 & $\underline{0.4523}$ & $0.041 \%$ & QTFKPPPPLRGTDAS & 1.354 \\
\hline
\end{tabular}

WDS4

\begin{tabular}{|c|c|c|c|c|}
\hline \multicolumn{5}{|c|}{ Src homology 2 group (SH2) } \\
\hline \multicolumn{3}{|c|}{ PLCg N-terminal SH2 } & \multicolumn{2}{|l|}{ Gere (Cagd } \\
\hline Site & $\underline{\text { Score }}$ & $\underline{\text { Percentile }}$ & Sequence & $\underline{\mathrm{SA}}$ \\
\hline Y94 & $\underline{0.4018}$ & $0.843 \%$ & PGIADDFYLNLLDWG & 0.590 \\
\hline
\end{tabular}




\begin{tabular}{|c|c|c|c|c|}
\hline Site & $\underline{\text { Score }}$ & Percentile & Sequence & $\underline{\mathrm{SA}}$ \\
\hline Y94 & $\underline{0.4484}$ & $0.281 \%$ & PGIADDFYLNLLDWG & 0.590 \\
\hline \multicolumn{5}{|c|}{ Basophilic serine/threonine kinase group (Baso_ST_kin) } \\
\hline \multicolumn{3}{|c|}{ PKC delta } & \multicolumn{2}{|c|}{ Grene Card: } \\
\hline Site & $\underline{\text { Score }}$ & Percentile & $\underline{\text { Sequence }}$ & $\underline{\mathrm{SA}}$ \\
\hline S397 & $\underline{0.4092}$ & $0.245 \%$ & KTTKKAASKKYTDPF & 1.964 \\
\hline \multicolumn{3}{|c|}{ PKC alpha/beta/gamma } & \multicolumn{2}{|l|}{ Gene Caral: } \\
\hline$\underline{\text { Site }}$ & Score & $\underline{\text { Percentile }}$ & Sequence & $\underline{\mathrm{SA}}$ \\
\hline S397 & $\underline{0.4342}$ & $0.422 \%$ & KTTKKAASKKYTDPF & 1.964 \\
\hline \multicolumn{3}{|c|}{ PKC delta } & \multicolumn{2}{|c|}{ Gere Carta } \\
\hline Site & Score & $\underline{\text { Percentile }}$ & $\underline{\text { Sequence }}$ & $\underline{\mathrm{SA}}$ \\
\hline S281 & $\underline{0.4606}$ & $0.995 \%$ & AWCPFQASLLATGGG & 0.369 \\
\hline \multicolumn{3}{|c|}{ PKC mu } & \multicolumn{2}{|c|}{ Gene Card: } \\
\hline Site & $\underline{\text { Score }}$ & Percentile & $\underline{\text { Sequence }}$ & $\underline{\mathrm{SA}}$ \\
\hline S356 & $\underline{0.4797}$ & $0.744 \%$ & AELNGHTSRVLFMAQ & 0.723 \\
\hline \multicolumn{3}{|c|}{ Calmodulin dependent Kinase 2} & \multicolumn{2}{|l|}{ Gerae Carral: } \\
\hline Site & $\underline{\text { Score }}$ & Percentile & $\underline{\text { Sequence }}$ & $\underline{\mathrm{SA}}$ \\
\hline $\mathrm{T} 338$ & $\underline{0.5176}$ & $0.888 \%$ & GFTQNQLTLWKYPSM & 0.819 \\
\hline \multicolumn{3}{|c|}{ Akt Kinase } & \multicolumn{2}{|l|}{ Gerae (Card? } \\
\hline$\underline{\text { Site }}$ & $\underline{\text { Score }}$ & $\underline{\text { Percentile }}$ & Sequence & $\underline{\mathrm{SA}}$ \\
\hline S182 & $\underline{0.5921}$ & $0.938 \%$ & GHESRVGSLAWNNHI & 0.198 \\
\hline \multicolumn{3}{|c|}{ AMP_Kinase } & \multicolumn{2}{|c|}{ Gerce Card } \\
\hline$\underline{\text { Site }}$ & $\underline{\text { Score }}$ & $\underline{\text { Percentile }}$ & Sequence & $\underline{\mathrm{SA}}$ \\
\hline S344 & $\underline{0.6163}$ & $0.716 \%$ & LTLWKYPSMVKMAEL & 1.093 \\
\hline \multicolumn{5}{|c|}{ DNA damage kinase group (DNA_dam_kin) } \\
\hline \multicolumn{3}{|c|}{ DNA PK } & \multicolumn{2}{|c|}{ Gerne Comed } \\
\hline Site & $\underline{\text { Score }}$ & $\underline{\text { Percentile }}$ & Sequence & $\underline{\mathrm{SA}}$ \\
\hline T143 & $\underline{0.4890}$ & $0.432 \%$ & PVTSINWTQDGLDLA & 1.662 \\
\hline \multicolumn{3}{|c|}{ ATM Kinase } & \multicolumn{2}{|l|}{ Gere Cand } \\
\hline$\underline{\text { Site }}$ & $\underline{\text { Score }}$ & $\underline{\text { Percentile }}$ & $\underline{\text { Sequence }}$ & $\underline{\mathrm{SA}}$ \\
\hline T143 & $\underline{0.5225}$ & $0.793 \%$ & PVTSINWTQDGLDLA & 1.662 \\
\hline \multicolumn{5}{|c|}{ Acidophilic serine/threonine kinase group (Acid_ST_kin) } \\
\hline \multicolumn{3}{|c|}{ Casein Kinase 1} & \multicolumn{2}{|l|}{ Geme (Cand: } \\
\hline Site & $\underline{\text { Score }}$ & $\underline{\text { Percentile }}$ & Sequence & $\underline{\mathrm{SA}}$ \\
\hline S25 & $\underline{0.4375}$ & $0.938 \%$ & VDEVTSASRKAYMTQ & 1.645 \\
\hline \multicolumn{3}{|c|}{ Casein Kinase 2} & \multicolumn{2}{|l|}{ Geme Carro } \\
\hline$\underline{\text { Site }}$ & $\underline{\text { Score }}$ & $\underline{\text { Percentile }}$ & Sequence & $\underline{\mathrm{SA}}$ \\
\hline T129 & $\underline{0.4967}$ & $0.818 \%$ & GSTYKLVTIDEEEGP & 0.410 \\
\hline \multicolumn{5}{|c|}{ Kinase binding site group (Kin_bind) } \\
\hline & Erk1 Bi & ading & Geme Crand: & \\
\hline Site & $\underline{\text { Score }}$ & $\underline{\text { Percentile }}$ & Sequence & $\underline{\mathrm{SA}}$ \\
\hline P343 & $\underline{0.6008}$ & $0.586 \%$ & QLTLWKYPSMVKMAE & 1.093 \\
\hline
\end{tabular}


WDS5

\begin{tabular}{|c|c|c|c|c|}
\hline \multicolumn{5}{|c|}{ Phosphoserine/threonine binding group (pST_bind) } \\
\hline \multicolumn{3}{|c|}{ 14-3-3 Mode 1} & \multicolumn{2}{|c|}{ Gieme Caird } \\
\hline$\underline{\text { Site }}$ & $\underline{\text { Score }}$ & Percentile & $\underline{\text { Sequence }}$ & $\underline{\mathrm{SA}}$ \\
\hline $\mathrm{S} 135$ & $\underline{0.4663}$ & $0.897 \%$ & VWDCRSHSVEPVQII & 1.113 \\
\hline \multicolumn{5}{|c|}{ Lipid binding group (Lip_bind) } \\
\hline \multicolumn{3}{|c|}{ PIP3-binding PH } & \multicolumn{2}{|c|}{ Gene Carad : } \\
\hline$\underline{\text { Site }}$ & $\underline{\text { Score }}$ & Percentile & Sequence & $\underline{\mathrm{SA}}$ \\
\hline F230 & $\underline{0.7205}$ & $0.641 \%$ & KGHISKSFKTDCCLT & 2.563 \\
\hline \multicolumn{3}{|c|}{ PIP3-binding PH } & \multicolumn{2}{|c|}{ Gere Carat an: } \\
\hline Site & $\underline{\text { Score }}$ & $\underline{\text { Percentile }}$ & Sequence & $\underline{\mathrm{SA}}$ \\
\hline W297 & $\underline{0.7261}$ & $0.700 \%$ & VDGTIRVWKK* & 2.888 \\
\hline
\end{tabular}

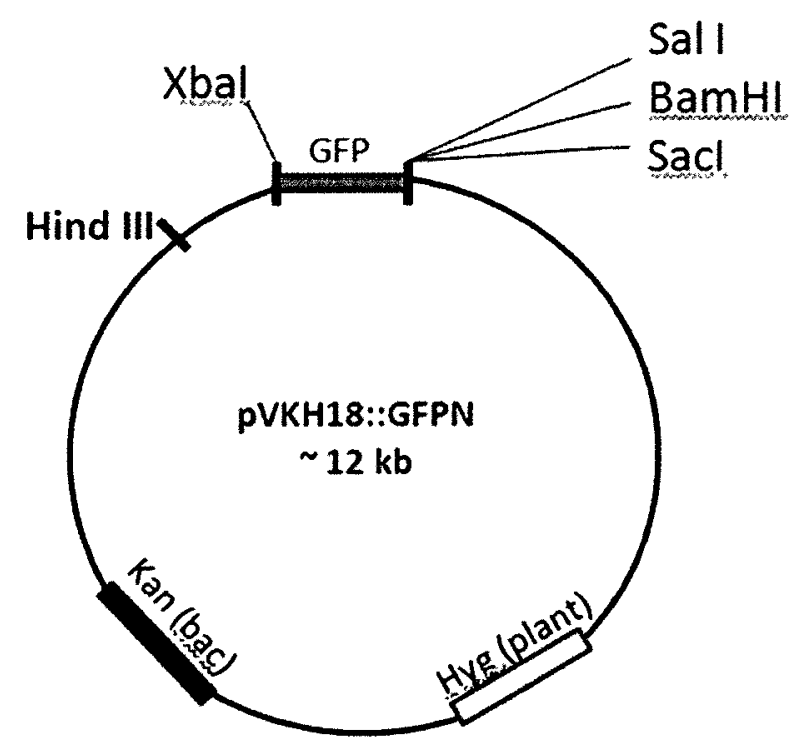

Appendix 3: pVKH18::GFPN vector map 


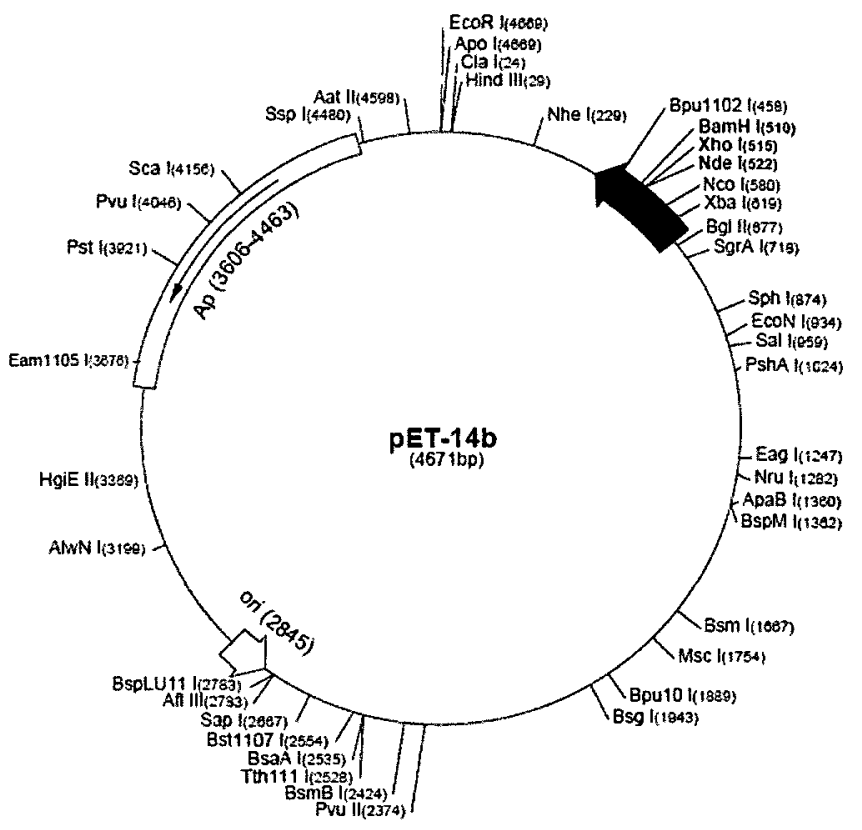

Appendix 4: pET-14b vector map

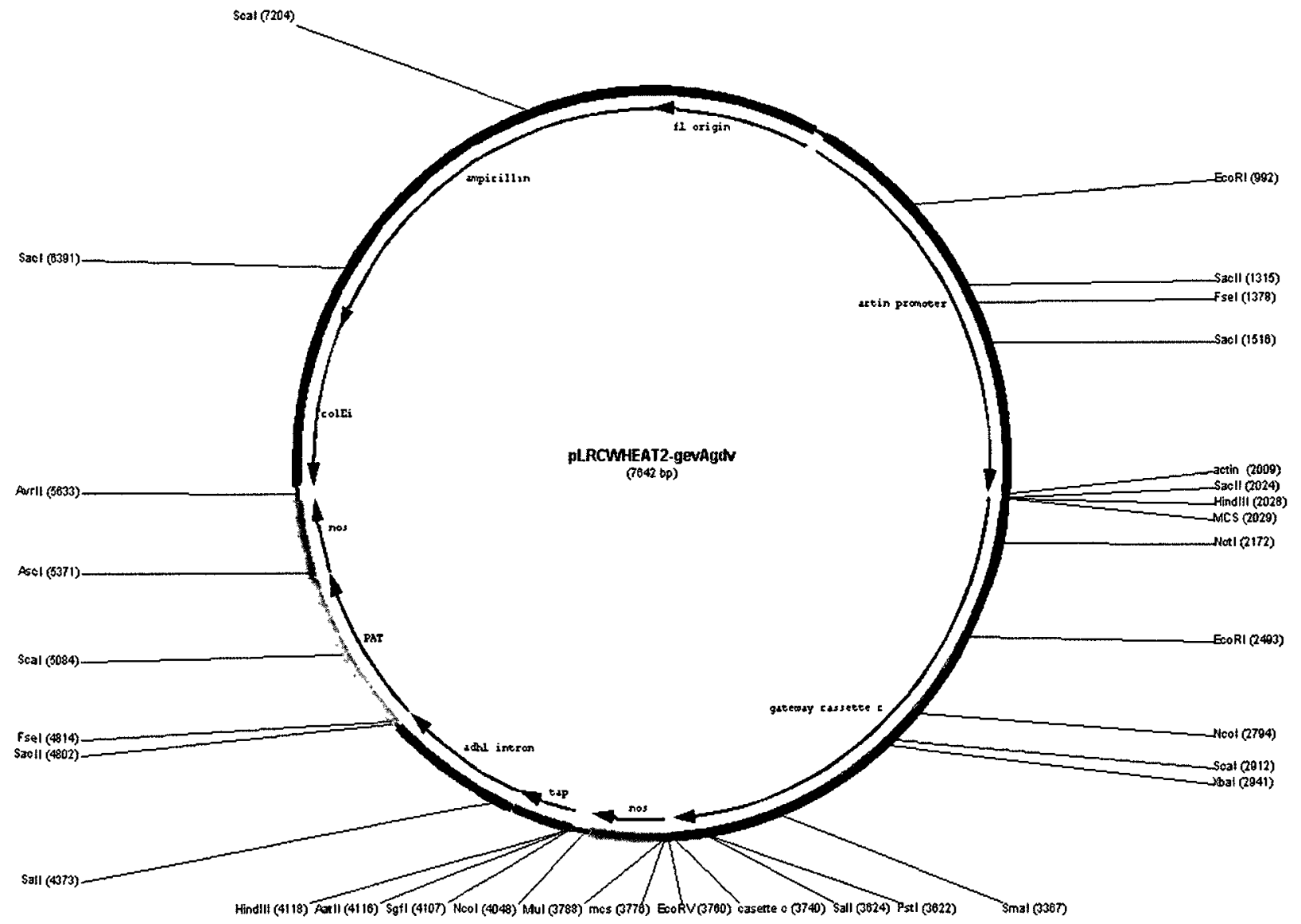

Appendix 5: pLRCWHEAT2-gevAgdv vector map 


\section{References}

Affenzeller, M. J., A. Darehshouri, A. Andosch, C. Lutz, and U. Lutz-Meindl. 2009. Salt stress induced cell death in the unicellular green alga micrasterias denticulata. J Exp Bot 60(939):954.

Al-Olayan, E. M., G. T. Williams, and H. Hurd. 2002. Apoptosis in the malaria protozoan, plasmodium berghei: A possible mechanism for limiting intensity of infection in the mosquito. Int J Parasit 32:1133-43.

Al-Shammari A. 2009. Molecular genetic analysis of will die slowly 2(WDS2) gene in Arbidopsis thaliana. . Ottawa, Ontario: Carleton University.

Amaral JD, Xavier JM, Steer CJ, Rodrigues CM. 2010. The role of p53 in apoptosis. Discov Med 9(45):145-52.

Ameisen JC. 2005. Selective "death programs" or pleiotropic"life programs"? looking for programmed cell death in the light of evolution. J Soc Biol 199(3):175-89.

Ameisen JC. 2004. Looking for death at the core of life in the light of evolution. Cell Death Differ 11(1):4-10.

Ameisen JC. 2002. On the origin, evolution, and nature of programmed cell death: A timeline of four billion years.. Cell Death Differ 9(4):367-93.

Arnoult, D., I. Tatischeff, J. Estaquier, M. Girard, F. Sureau, J. P. Tissier, A. Grodet, M. Dellinger, F. Traincard, A. Kahn, et al. 2001. On the evolutionary conservation of the cell death pathway: Mitochondrial release of an apoptosis-inducing factor during Dictyostelium discoideum cell death. Mol Biol Cell 12:3016-30.

Asai T, Tena G, Plotnikova J, Willmann MR, Chiu WL, Gomez-Gomez L, Boller T, Ausubel FM, Sheen J. 2002. MAP kinase signalling cascade in Arabidopsis innate immunity. Nature 415:977-983

Bassler BL LR. 2006. Bacterially speaking. Cell 125(2):237-46.

Baster, Pawel., Ledwon, Agnieszka., Gliwicka, Marta., Trojanowska, Aneta., Gaj, Malgorzata D.,. 2009. Arabidopsis tanmei/emb2757 embryo mutant is defective for in vitro plant morphogenesis. Plant Cell Tiss Organ Cult 99(3):305-12.

Bera, A., S. Singh, R. Nagaraj, and T. Vaidya. 2003. Induction of autophagic cell death in leishmania donovani by antimicrobial peptides. Mol Biochem Parasit 127:23-35.

Berman-Frank, I., K. D. Bidle, L. Haramaty, and P. G. Falkowski. 2004. The demise of the marine cyanobacterium, trichodesmium spp., via an autocatalyzed cell death pathway. Limnol Oceanogr (49):997-1005. 
Bidle, K. D., and P. G. Falkowski. 2004. Cell death in planktonic, photosynthetic microorganisms. Nat Rev Microbiol 2:643-55.

Bidle, K. D., L. Haramaty, J. B. E. Ramos, and P. Falkowski. 2007. Viral activation and recruitment of metacaspases in the unicellular coccolithophore,emiliania huxleyi. Proc Natl Acad Sci USA 104:6049-64.

Bonneau L, Ge Y, Drury GE, Gallois P. 2008. What happened to plant caspases?. J Exp Bot 59(3):491-9.

Borgne A, Versteege I, Mahé M, Studeny A, Léonce S, Naime I, Rodriguez M, Hickman JA, Meijer L, Golsteyn RM. 2006. Analysis of cycline B1 and CDK activity during apoptosis induced by camptothecin treatment. Oncogene 25(56):7361-72.

Bozhkov PV, Filonova LH, Suarez MF, Helmersson A, Smertenko AP, Zhivotovsky B, von Arnold S. 2004. VEIDase is a principal caspase-like activity involved in plant programmed cell death and essential for embryonic pattern formation. Cell Death Differ 11(2):175-82.

Bracha K, Lavy M, Yalovsky S. 2002. The arabidopsis AtSTE24 is a CAAX protease with broad substrate specificity. J Biol Chem 277(33):29856-64.

Branzei D FM. 2008. Regulation of DNA repair throughout the cell cycle. Nat Rev Mol Cell Biol 9(4):297-308.

Bratton SB SG. 2010. Regulation of the apaf-1-caspase-9 apoptosome. J Cell Sci 123(19):3209 14.

Bruce Alberts \& Dennis Bray \& Karen Hopkin \& Alexander Johnson \& Julian Lewis \& Martin Raff \& Keith Roberts \& Peter Walter. 2006. Essential cell biology. 2nd ed. Garland Science.

Cacas JL. 2010. Devil inside: Does plant programmed cell death involve the endomembrane system?. Plant Cell Environ 33(9):1453-73.

Cagnol S CJ. 2010. ERK and cell death: Mechanisms of ERK-induced cell deathapoptosis, autophagy and senescence. FEBS J 277(1):2-21.

Campbell N.A and J.B. Reece. 2002. Biology. 6th ed. Pearson Benjamin Cummings.

Cervia, D., G. Di Giuseppe, C. Ristori, D. Martini, G. Gambellini, P. Bagnoli, and F. Dini. 2009. The secondary metabolite euplotin $\mathrm{C}$ induces apoptosis-like death in the marine ciliated protist euplotes vannus. J Euk Microbiol 56:263-9.

Chang HC RG. 1997. 14-3-3 epsilon positively regulates ras-mediated signaling in drosophila. Genes Dev 11(9):1132-9. 
Chose, O., C. O. Sarde, D. Gerbod, E. Viscogliosi, and A. Roseto. 2003. Programmed cell death in parasitic protozoans that lack mitochondria. Trends Parasit 19:559-64.

Christensen, S. T., J. Chemnitz, E. M. Straarup, K. Kristiansen, D. N. Wheatley, and L. Rasmussen. 1998. Staurosporine-induced cell death in tetrahymena thermophila has mixed characteristics of both apoptotic and autophagic degeneration. .. Cell Biol Int 22:591-8.

Chung, C. C., S. P. Hwang, and J. Chang. 2008 . Nitric oxide as a signaling factor to upregulate the death-specific protein in a marine diatom, skeletonema costatum, during blockage of electron flow in photosynthesis. Appl Envir Microbiol 74:6521-7.

Danon A, Rotari VI, Gordon A, Mailhac N, Gallois P. 2004. Ultraviolet-C overexposure induces programmed cell death in arabidopsis, which is mediated by caspase like activities and which can be suppressed by caspase inhibitors, $\mathrm{p} 53$ and defender against apoptotic death. J Biol Chem 279(1):779-87.

Darehshouri, A., M. Affenzeller, and U. Lutz-Meindl. 2008. Cell death upon $\mathrm{H}_{2} \mathrm{O}_{2}$ induction in the unicellular green alga micrasterias. Plant Biol 10:732-45.

Das, M., S. B. Mukherjee, and C. Shaha. 2001. Hydrogen peroxide induces apoptosis-like death in leishmania donovanipromastigotes. J Cell Sci 114:2461-9.

De Veylder L, Beeckman T, Inzé D. 2007. The ins and outs of the plant cell cycle. Nat Rev Mol Cell Biol 8(8):655-65.

Devarenne TP, Ekengren SK, Pedley KF, Martin GB. 2006. Adi3 is a Pdk1-interacting AGC kinase that negatively regulates plant cell death. EMBO J 25(1):255-65.

Devarenne TP MG. 2007. Manipulation of plant programmed cell death pathways during plant-pathogen interactions. Plant Signal Behav 2(3):188-9.

Duckett CS. 2005. IAP proteins: Sticking it to smac. Biochem J 385:1-2.

Duronio V. 2008. The life of a cell: Apoptosis regulation by the PI3K/PKB pathway. Biochem J 415(3):333-44.

Engelberg-Kulka H, Amitai S, Kolodkin-Gal I, Hazan R. 2006.

Bacterial programmed cell death and multicellular behavior in bacteria. PLoS Genet 2(10):135.

Enright AJ, Iliopoulos I, Kyrpides NC, Ouzounis CA. 1999. Protein interaction maps for complete genomes based on gene fusion events. Nature 402(6757):86-90

Fadeel B, Ottosson A, Pervaiz S. 2008. Big wheel keeps on turning: Apoptosome regulation and its role in chemoresistance. Cell Death Differ 15(3):443-52. 
Ferreon JC, Martinez-Yamout MA, Dyson HJ, Wright PE. 2009. Structural basis for subversion of cellular control mechanisms by the adenoviral E1A oncoprotein. Proc Natl Acad Sci U S A 106(32):13260-5.

Franklin-Tong VE GC. 2008. A role for actin in regulating apoptosis/programmed cell death: Evidence spanning yeast, plants and animals. Biochem J 413(3):389-404

Fukuda H. 2004. Signals that control plant vascular cell differentiation. Nat Rev Mol Cell Biol 5(5):379-91.

Gerlitz G, Darhin E, Giorgio G, Franco B, Reiner O. 2005. Novel functional features of the lis $\mathrm{H}$ domain: Role in protein dimerization, half-life and cellular localization.. Cell Cycle 4(11):1632-40.

Golsteyn RM. 2005. Cdk1 and Cdk2 complexes (cyclin dependent kinases) in apoptosis: A role beyond the cell cycle. Cancer Lett 217(2):129-38.

Gourlay, C. W., W. Du, and K. R. Ayscough. 2006. Apoptosis in yeast-mechanisms and benefits to a unicellular organism. Mol Microbiol 62:1515-21.

Gray J, editor. 2004. Programmed cell death in plants. 1st ed. Blackwell Publishing. 287 p.

Hauptmann P, Riel C, Kunz-Schughart LA, Fröhlich KU, Madeo F, Lehle L. 2006. Defects in N glycosylation induce apoptosis in yeast. Mol Microbiol 59(3):765-78.

Hazan, R., B. Sat, and H. Engelberg-Kulka. 2004. Escherichia coli mazEF-mediated cell death is triggered by various stressful conditions. J Bacteriol 186:3663-9.

Henriksson ML, Trollér U, Hallberg B. 2000. 14-3-3 proteins are required for the inhibition of ras by exoenzyme S. Biochem J 349:697-701.

Kerrigan JJ, Xie Q, Ames RS, Lu Q. 2011. Production of protein complexes via coexpression. Protein Expr Purif 75(1):1-14.

Kim MH, Cooper DR, Oleksy A, Devedjiev Y, Derewenda U, Reiner O, Otlewski J, Derewenda ZS. 2004. The structure of the N-terminal domain of the product of the lissencephaly gene Lis 1 and its functional implications.. Structure 12(6):987-98.

Kressler D, Roser D, Pertschy B, Hurt E. Source. 2008.

The AAA ATPase Rix 7 powers progression of ribosome biogenesis by stripping Nsa1 from pre 60S particles. J Cell Biol 181(6):935-44.

Kroemer G, Galluzzi L, Vandenabeele P, Abrams J, Alnemri ES, Baehrecke EH, Blagosklonny MV, El-Deiry WS, Golstein P, Green DR, Hengartner M, Knight RA, Kumar S,Lipton SA, Malorni W, Nuñez G, Peter ME, Tschopp J, Yuan J, Piacentini M, Zhivotovsky B, Melino G and Nomenclature Committee on Cell Death 2009. 2009. Classification of cell 
death: Recommendations of the nomenclature committee on cell death 2009. Cell Death Differ 16(1):3-11.

Leadsham JE, Miller K, Ayscough KR, Colombo S, Martegani E, Sudbery P, Gourlay CW. 2009. Whi2p links nutritional sensing to actin-dependent ras-cAMP PKA regulation and apoptosis in yeast. J Cell Sci 122(5):706-15.

Light $Y$, Paterson H, Marais R. 2002. 14-3-3 antagonizes ras-mediated raf-1 recruitment to the plasma membrane to maintain signaling fidelity. Mol Cell Biol 22(14):4984-96.

Lim PO, Kim HJ, Nam HG. 2007. Leaf senescence. Annu Rev Plant Biol 58:115-36.

Ling Pan, Maki Kawai, Li-Hua Yu, Kyung-Min Kim, Aiko Hirata, Masaaki Umeda and Hirofumi Uchimiya. 2001. The arabidopsis thaliana ethylene-responsive element binding protein (AtEBP) can function as a dominant suppressor of bax-induced cell death of yeast. FEBS Letters 508(3):375-8.

Madeo, F., E. Frohlich, and K. U. Frohlich. 1997. . A yeast mutant showing diagnostic markers of early and late apoptosis. J Cell Biol 139(729):734.

Mariante, R. M., R. G. Vancini, and M. Benchimol. 2006. Cell death in trichomonads: New insights. Histoch Cell Biol 125:545-56.

Martin SJ. 2010. Cell biology. opening the cellular poison cabinet. Science 330(6009):1330-1

Mateja A, Cierpicki T, Paduch M, Derewenda ZS, Otlewski J. 2006.

The dimerization mechanism of LISI and its implication for proteins containing the LisH motif.. J Mol Biol 357(2):621-31.

Mellor J. 2006. It takes a PHD to read the histone code. Cell 126(1):22-4.

Mendoza, L., E. Orozco, M. A. Rodriguez, G. Garcia-Rivera, T. Sanchez, E. Garcia, and P. Gariglio. 2003. Ehp53, an entamoeba histolytica protein, ancestor of the mammalian tumour suppressor p53. Microbiology-SGM 149:885-93.

Meslin, B., C. Barnadas, V. Boni, C. Latour, F. De Monbrison, K. Kaiser, and S. Picot. 2007. Features of apoptosis in plasmodium falciparum erythrocytic stage through a putative role of PfMCA1 metacaspase-like protein. J Infect Dis 195:1852-9.

Moharikar, S., J. S. D'Souza, A. B. Kulkarni, and B. J. Rao. 2006. Apoptotic-like cell death pathway is induced in unicellular chlorophytechlamydomonas reinhardtii (chlorophyceae) cells following UV irradiation: Detection and functional analyses. J Phycol 42:423-33.

Montsant, A., A. E. Allen, S. Coesel, A. De Martino, A. Falciatore, M. Mangogna, M. Siaut, M. Heijde, K. Jabbari, U. Maheswari, et al. 2007. . Identification and comparative genomic analysis 
of signaling and regulatory components in the diatom thalassiosira pseudonana. J Phycol 43:585-604.

Morrison DK. 2009. The 14-3-3 proteins: Integrators of diverse signaling cues that impact cell fate and cancer development. Trends Cell Biol 19(1):16-23.

Moujalled D, Weston R, Anderton H, Ninnis R, Goel P, Coley A, Huang DC, Wu L, Strasser A, Puthalakath H. 2011. Cyclic-AMP

dependent protein kinase A regulates apoptosis by stabilizing the BH3-only protein bim. EMBO Rep 12(1):77-83.

Mullen TD, Jenkins RW, Clarke CJ, Bielawski J, Hannun YA, Obeid LM. 2011. Ceramide synthase-dependent ceramide generation and programmed cell death: Involvement of salvage pathways in regulating post mitochondrial events. J Biol Chem 289(18):15929-42.

Murik, O., and A. Kaplan. 2009. Paradoxically, prior acquisition of antioxidant activity enhances oxidative stress-induced cell death. Env Microbiol 11:2301-9.

Murphy, K., Travers, P. \& M.Walport. 2008. Janeway's immunobiology. . 7th ed. New York \& London: Garland Science.

Myers K, Gagou ME, Zuazua-Villar P, Rodriguez R, Meuth M. 2009. ATR and Chk1 supresses a caspase -3 dependent apoptotic response following DNA replication stress. PLoS Genet 5(1).

Nagano, M.; Ihara-Ohori, Y.; Imai, H.; Inada, N.; Fujimoto, M.; Tsutsumi, N.; Uchimiya, H.; Kawai-Yamada, M. 2009. Functional association of cell death suppressor, Arabidopsis Bax Inhibitor-1, with fatty acid 2-hydroxylation through cytochrome b5. Plant J. 58, 122-134.

Nariya, H., and M. Inouye. 2008. MazF, an mRNA interferase, mediates programmed cell death during multicellular myxococcusdevelopment. Cell 132:55-66.

Nasirudeen, A. M., K. S. Tan, M. Singh, and E. H. Yap. 2001. Programmed cell death in a human intestinal parasite, blastocystis hominis. Parasitology 123:235-46.

Nedelcu AM, Driscoll WW, Durand PM, Herron MD, Rashidi A. 2011. On the paradigm of altruistic suicide in the unicellular world. Evolution 65(1):3-20

Nedelcu AM. 2006. Evidence for p53-like-mediated stress responses in green algae. FEBS Lett 580:3013-7.

Nooden L, editor. 2004. Plant cell death processes. 1st ed. Elsevier Academic Press. 392 p.

Ogawa T., Pan L, Kawai-Yamada M., Yu L., Saburo Yamamura, Tomotsugu

Koyama, Sakihito Kitajima, Masaru Ohme-Takagi, Fumihiko Sato, and Hirofumi Uchimiya. 2005. Functional analysis of arabidopsis ethylene-responsive element binding protein conferring 
resistance to bax and abiotic stress-induced plant cell death. Plant Physiol 138(3):1436-45.

Parcellier A, Tintignac LA, Zhuravleva E, Hemmings BA. 2008. PKB and the mitochondria: AKTing on apoptosis.. Cell Signal 20(1):21-30.

Raetz CR WC. 2002. Lipopolysaccharide endotoxins. Annu Rev Biochem 71:635-700.

Ramsdale M. 2008. Programmed cell death in pathogenic fungi. Biochim Biophys Acta 1783(7):1369-80.

Reape TJ MP. 2010. Apoptotic-like regulation of programmed cell death in plants. Apoptosis 15(3):249-56.

Reape TJ MP. 2008. Apoptotic-like programmed cell death in plants. New Phytol 180(1):13-26.

Regev-Yochay, G., K. Trzcinski, C. M. Thompson, M. Lipsitch, and R. Malley. 2007. SpxB is a suicide gene of streptococcus pneumoniae and confers a selective advantage in an in vivo competitive colonization model. J Bacteriol 189:6532-9.

Ren D, Tu HC, Kim H, Wang GX, Bean GR, Takeuchi O, Jeffers JR, Zambetti GP, Hsieh JJ, Cheng EH. 2010. BID, BIM, and PUMA are essential for activation of the BAX- and BAK dependent cell death program.Science 330(6009):1390-3.

Rice, K. C., E. E. Mann, J. L. Endres, E. C. Weiss, J. E. Cassat, M. S. Smeltzer, and K. W. Bayles. 2007. The cidA murein hydrolase regulator contributes to DNA release and biofilm development in staphylococcus aureus. Proc Natl Acad Sci USA 104:8113-8.

Ridgley, E. L., Z. H. Xiong, and L. Ruben. 1999. Reactive oxygen species activate a Ca ${ }^{2+}$ dependent cell death pathway in the unicellular organismtrypanosoma brucei brucei. Bioch $\mathrm{J}$ 340:33-40.

Ross, C., L. Santiago-Vazquez, and V. Paul. 2006. Toxin release in response to oxidative stress and programmed cell death in the cyanobacteriummicrocystis aeruginosa. Aquat Toxicol 78:66-73.

Roy SS, Madesh M, Davies E, Antonsson B, Danial N, Hajnóczky G. 2009.

$\mathrm{Bad}$ targets the permeability transition pore independent of bax or bak to switch between $\mathrm{Ca} 2+$ dependent cell survival and death. Mol Cell 33(3):377-88.

Salvesen GS RS. 2009. Structure of the Fas/FADD complex: A conditional death domain complex mediating signaling by receptor clustering. Cell Cycle 8(17):2723-7.

Segovia, M., L. Haramaty, J. A. Berges, and P. G. Falkowski. 2003. Cell death in the unicellular chlorophyte dunaliella tertiolecta. A hypothesis on the evolution of apoptosis in higher plants and metazoans. Plant Phys 132:99-105. 
Serralbo O, Pérez-Pérez JM, Heidstra R, Scheres B. 2006. Non-cell-autonomous rescue of anaphase-promoting complex function revealed by mosaic analysis of HOBBIT, an Arabidopsis CDC27 homolog.. Proc Natl Acad Sci U S A 103(35):13250.

Sha J, Ghosh MK, Zhang K, Harter M.L.2010. E1A interacts with two opposing transcriptional pathways to induce quiescent cells into S phase. J Virol 84(8):4050-9.

She QB, Chen N, Dong Z. 200. ERKs and p38 kinase phosphorylate p53 protein at serine 15 in response to UV radiation. J Biol Chem 275(27):20444-9.

Søgaard-Andersen L YZ. 2008. Programmed cell death: Role for MazF and MrpC in myxococcus multicellular development. Curr Biol 18:337-9.

Taiz LaZ, E. 2006. Plant physiology. 4th ed. Sunderland, Massachusetts: Sinauer Associates Inc.

Taylor RC, Cullen SP, Martin SJ. 2008. Apoptosis: Controlled demolition at the cellular level. Nat Rev Mol Cell Biol 9(3):231-41.

Tse, A.N., Carvajal, R. \& G.K. Schwartz. 2007. Targeting checkpoint kinase 1 in cancer T. Clinical Cancer Research 13(7):1955-60.

Umeda M, Nishitani H, Nishimoto T. 2003. A novel nuclear protein, Twal, and muskelin comprise a complex with RanBPM. Gene 16(303):47-54.

Vermeulen, K., Berneman, Z. N. and Van Bockstaele, D. R. 2003. Cell cycle and apoptosis. Cell Prolif 36(3):165-75.

Villalba, J. D., C. Gomez, O. Medel, V. Sanchez, J. C. Carrero, M. Shibayama, and D. G. P. Ishiwara. 2007. Programmed cell death inentamoeba histolyticainduced by the aminoglycoside G418. Microbiol -Sgm 153:3852-63.

Voet, D. \& J., Voet. 2004. Biochemistry 3rd ed. Hoboken, NJ: John Wiley \& Sons Inc.

Watanabe N LE. 2008. BAX inhibitor-1 modulates endoplasmic reticulum stress-mediated programmed cell death in arabidopsis. J Biol Chem 283(6):3200.

Watanabe N LE. 2009. Bax inhibitor-1, a conserved cell death suppressor, is a key molecular switch downstream from a variety of biotic and abiotic stress signals in plants. Int J Mol Sci 10(7):3149-67.

Watanabe N LE. 2008. Arabidopsis bax inhibitor-1: A rheostat for ER stress-induced programmed cell death. Plant Signal Behav 3(8):564. 
Watanabe N. Lam E. 2006. Arabidopsis bax inhibitor-1 functions as an attenuator of biotic and abiotic types of cell death. Plant J 45(6):884-94.

We1 X, Song L, Jiang L, Wang G, Luo X, Zhang B, Xiao X. 2010. Overexpression of MIP2, a novel WD repeat protein, promotes proliferation of $\mathrm{H} 9 \mathrm{c} 2$ cells. Biochem Biophys Res Commun 393(4):860.

Welburn, S. C., C Dale, D. Ellis, R. Beecroft, and T. W Pearson. 1996. Apoptosis in procyclic Trypanosome brucet rhodestense in vitro. Cell Death Diff 3:229-36.

Wennerberg K, Rossman KL, Der CJ. 2005. The ras superfamily at a glance. J Cell Sc1 118(5):843-6.

Xiao-Ming Yin and Zheng Dong, editor 2009. Essentials of apoptosis A guide for basic and Clinical research. 2nd ed. Human Press. 707 p.

Xiong X. 2007. The role of will die slowly 1 (WDS1) gene in the development and defense response of arabidopsis thaliana. Ottawa, Ontanio: Carleton University.

Xu C, Xu W, Palmer AE, Reed JC. 2008. BI-1 regulates endoplasmic reticulum Ca2+ Homeostasis downstream of bcl-2 family proteins.. J Biol Chem 283(17):11477-84.

Yamagıshı K, Nagata N, Yee KM, Braybrook SA, Pelletıer J, Fujıka S, Yoshida S, Fischer RL, Goldberg RB,Harada JJ. 2005. TANMEI/EMB2757 encodes a WD repeat protein required for embryo development in arabidopsis.. Plant Physiol 139(1):163-73.

Yukı Ichinose. 2009. Study of flagella-mediated interactions between plants and pseudomonas syringae. Journal of general plant pathology 75(6):452-4.

Zeng L, Zhang Q, Li S, Plotnikov AN, Walsh MJ, Zhou MM. 2010 Mechanism and regulation of acetylated histone binding by the tandem PHD finger of DPF3b. Nature 7303(258):62.

Zhang L, Zambon AC, Vranıan K, Pothula K, Conklın BR, Insel PA. 2008. Gene expression signatures and cAMP/protein kinase A (PKA)-programmed mitochondrial-dependent apoptosis. Comparative analysis of wild-type and cAMP-deathless S49 lymphoma cells. J Biol Chem 283(7):4304-13.

Zuppinı, A., C. Andreoli, and B. Baldan. 2007. Heat stress: An inducer of programmed cell death in chlorella saccharophila. . Plant Cell Physiol 48:1000-9. 